Portland State University

PDXScholar

$1-1-1984$

\title{
Enhancing impact assessment with extrapolative fiction
}

Ruth-Ellen Miller

Portland State University

Follow this and additional works at: https://pdxscholar.library.pdx.edu/open_access_etds Let us know how access to this document benefits you.

Recommended Citation

Miller, Ruth-Ellen, "Enhancing impact assessment with extrapolative fiction" (1984). Dissertations and Theses. Paper 816.

https://doi.org/10.15760/etd.816

This Dissertation is brought to you for free and open access. It has been accepted for inclusion in Dissertations and Theses by an authorized administrator of PDXScholar. Please contact us if we can make this document more accessible: pdxscholar@pdx.edu. 


\title{
ENHANCING IMPACT ASSESSMENT WITH \\ EXTRAPOLATIVE FICTION
}

\author{
by \\ RUTH-ELLEN MILLER
}

A dissertation submitted in partial fulfillment of the requirements for the degree of

\section{DOCTOR OF PHILOSOPHY \\ in \\ SYSTEMS SCIENCE}

\author{
Portland State University \\ c. 1984 Ruth-Ellen Miller
}


TO THE OFFICE OF GRADUATE STUDIES AND RESEARCH:

The members of the Committee approve the dissertation of Ruth-Ellen Miller presented January,13, 1984.

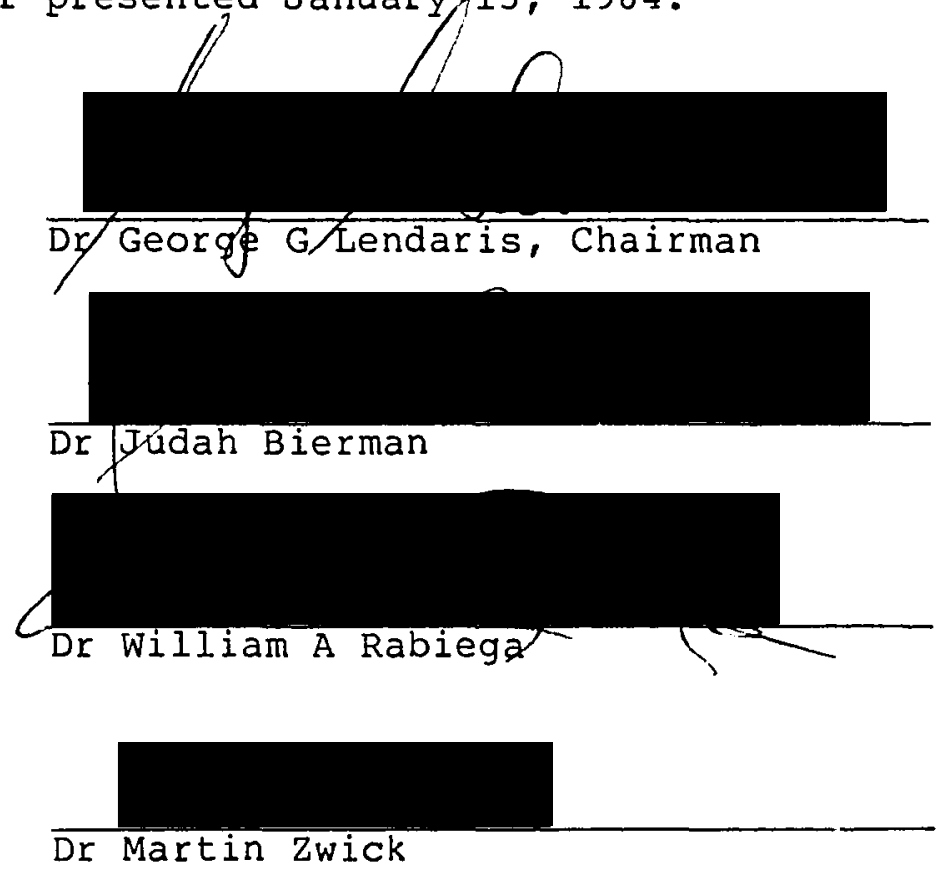

APPROVED :

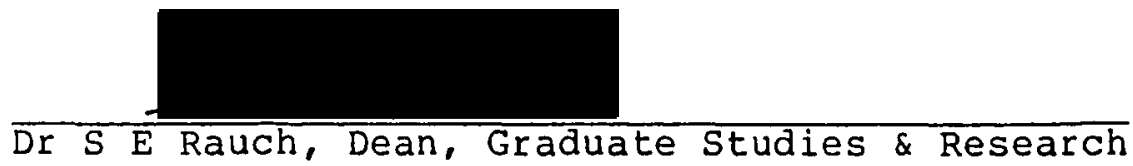


(C) 1984

RUTH-ELLEN MILLER

All Rights Reserved 


\section{ACKNOWLEDGEMENTS}

Over the years that I have been working on this dissertation, I have received far more than the usual share of time, effort, and understanding from all of my committee members--for which I am truly grateful. Together and individually, they have guided and advised me through the various stages of the process with remarkable patience and fortitude, and deserve considerable credit for the results.

Beyond that, special thanks must go to my chairmar, Dr. George Lendaris for taking this project on at a difficult time and shepherding it through the necessary steps to completion.

Additional thanks go to Joseph Coates, who consented to take on the role of "outside reader" and provided very thoughtful and helpful comments on the draft. I hope I have done them justice in this final version.

For supplying me with their own working notes and for taking the time to "talk methodology" with me, Ellen Heckler and Patricia Warrick deserve special thanks, as do Steve Rogers, Bill Rabiega, Nora Lehnhoff, and (again) Ellen Heckler for granting me free access to their libraries, and Arlene Landry for going beyond the call of friendship in coding IA reports. 
Thanks also go to Susan Page for her careful reading of early drafts, and to Sally Lopez for her assistance with this final one.

And, finally, most gratefully, I acknowledge the love, patience, and unwavering support granted me by my colleagues and co-workers, my good friend Michela, and by those very special people in my life: Jack, Dawn, and Aurora.

Thank you all, very much. 
TABLE OF CONTENTS

PAGE

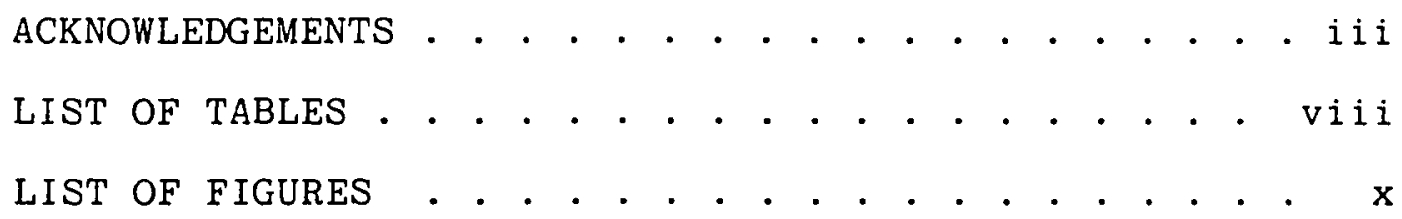

CHAPTER

I INTRODUCTION AND OVERVIEW . . . . . . . . . 1

Context For The Research . . . . . . 4

Approach and Overview . . . . . . . 9

I I THE EMERGING FIELD OF IMPACT ASSESSMENT. • . 21

Forms and Functions of Impact Assessment 22

Environmental Impact Assessment

Technology Assessment

A Generalized Definition of Impact

Assessment . . . . . . . . . . 36

Objectives for Impact Assessment

The Results of Impact Assessment

Concerns and Criticisms

The Call for Alternative Approaches

III EXTRAPOLATIVE FICTION . . . . . . . . . 51

Futuristic Fiction as a Tool for the

Policy Sciences... . . . . . 52

Futuristic Fiction and Scenarios

Forms of Futuristic Fiction

Extrapolative Fiction and Impact

Assessment . . . . . . . . . 60

Producing Extrapolative Fiction . . . . 62

The Editors

Fans as Critics

The Authors 
Alternative Verbal Models . . . . . 70

Transportation Stories

Research and Development Stories

Nuclear Power Stories

Societal Forecasts

IV COMPARATIVE ANALYSES OF IMPACT ASSESSMENT

AND EXTRAPOLATIVE FICTION . . . . . . 100

Statistical Content Analysis . . . . 101

Methodology

Results

Thematic Analysis . . . . . . . . . 116

Approach

Results

Comparisons of Specific Impacts

Described . . . . . . . . . . . 149

Transportation Systems

Nuclear Power Plants

$V$ INCLUDING EXTRAPOLATIVE FICTION IN IMPACT

ASSESSMENT • . . . . . . . . . . . . . 177

A Synthesized Approach . . . . . . . . 177

Collecting Information

Developing Models

Communicating the Results

Including Extrapolative Fiction

Appending EF Stories to IA Reports:

Alternative Formats . . . . . . 187

Stories as Scenarios in the Report Anthologies

Quotes and References

Extrapolative Fiction in the Research

Process . . . . . . . . . . . . 194

Including a Fiction-oriented Team Member

VI ILLUSTRATIVE CASE STUDIES . . . . . . . . . 201

An Anthology Describing Life-Extending Technologies . . . . . . . . . 201

vi 
The Futures Group Study

An Extrapolative Fiction Anthology

The Guayule Rubber Studies . . . . . 224

The University of Arizona Assessment

Developing An Alternative Model

VII CONCLUSIONS AND IMPLICATIONS . . . . . . 249

Summary of Results . . . . . . . . 249

Discussion . . . . . . . . . . . 253

Implications and Limitations of the

Research . . . . . . . . . . 264

REFERENCES . . . . . . . . . . . . . . . . . . . 267

APPENDICES

A Topical Bibliography of Extrapolative

Fiction . . . . . . . . . . . 279

B An Alternative Report Format for Assessing 284 the Impacts of Commercializing Guayule 


\section{LIST OF TABLES}

TABLE

PAGE

I SOME EXAMPLES OF ENVIRONMENTAL IMPACT STATEMENTS . . . . . . . . . . . . . . . . 28

I I SOME EXAMPLES OF TECHNOLOGY ASSESSMENTS . . . 34

II I RECOMMENDED STRATEGIES FOR TA AND EIS . . . . 37

IV OBJECTIVES FOR IMPACT ASSESSMENT . . . . . . 40

$\mathrm{V}$ SOME COMMENTS UN IA REPORTS . . . . . . . . . 42

VI EXAMPLES OF EXTRAPOLATIVE FIC'TION . . . . . 75

VII WORKS SELECTED FOR THE STATISTICAL CONTENT ANALYSIS--IMPACT ASSESSMENT REPORTS . . . . 103

VIII WORKS SELECTED FOR THE STATISTICAL CONTENT ANALYSIS--EXTRAPOLATIVE FICTION STORIES . . 104

IX IMPACT CATEGORIES USED FOR THE CONTENT ANALYSIS . . . . . . . . . . . . . . . . . 106

$\mathrm{X}$ DIFFERENCES BETWEEN CODERS ON A SAMPLE TEXT 108

XI INFORMATION USED IN $t$-TESTS, ILLUSTRATIVE . . . . . . . . . . . . . . . . 109

XII SIGNIFICANCE OF DIFFERENCES BETWEEN MEANS 112

XIII DIFFERENCES BETWEEN AGGREGATED CATEGORIES 113

XIV IMPACT CATEGORIES DESCRIBED BY ALL OR NO EF STORIES AND IA REPORTS . . . . . . . . . 115

XV EF STORIES SELECTED FOR THEMATIC ANALYSIS $\cdot 117$

XVI THEMES SYNTHESIZED FROM EF STORIES--1940-80 122

XVII TRANSPORTATION TECHNOLOGIES ASSESSED IN THE

SRI REPORT . . . . . . . . . . . . . . . 153

XVIII COMPARISON OF IMPACTS DESCRIBED--AUTOMATED ROADWAYS . . . . . . . . . . . . . . . . 156

XIX CONTENTS OF THE SEABORG REPORT . . . . . . . 162

XX IMPACTS DESCRIBED IN THE SEABORG REPORT • . 164 


\begin{tabular}{|c|c|c|}
\hline XXI & CLASSIFICATION OF POSTULATED ACCIDENTS . & 166 \\
\hline XX I I & 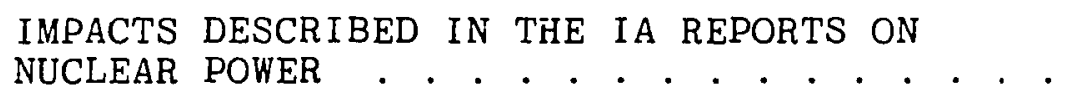 & 170 \\
\hline $\mathrm{XX} I \mathrm{I} I$ & 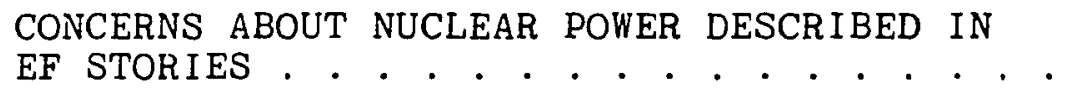 & \\
\hline$X X I V$ & 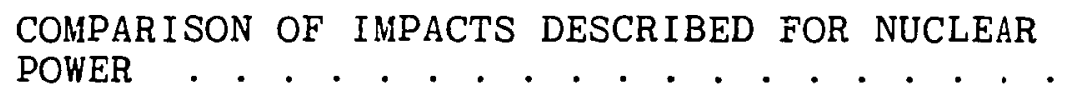 & \\
\hline $\mathrm{XXV}$ & $\begin{array}{l}\text { POSSIBLE OUTLINE FOR AN IA REPORT THAT } \\
\text { INCLUDES EF STORIES } \\
\cdot\end{array}$ & \\
\hline$X X V I$ & $\begin{array}{l}\text { TIME-BASED TABLE OF CONTENTS FOR AN ANTHOLOGY } \\
\text { ON LIFE-EXTENDING TECHNOLOGIES } \cdot \cdot \cdot \cdot \cdot \cdot \cdot \cdot \cdot \cdot\end{array}$ & \\
\hline XXVI I & SUMMARY OF ECONOMIC AND DEMOGRAPHIC IMPACTS & 206 \\
\hline XXV I I I & 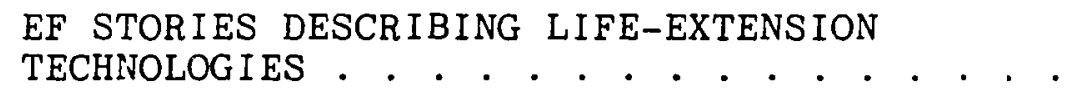 & 213 \\
\hline $\mathrm{XXIX}$ & KEY ACTORS INTERVIEWED FOR THE GUAYULE STUDY & 234 \\
\hline $\mathrm{XXX}$ & QUESTIONS USED FOR THE GUAYULE INTERVIEWS & 236 \\
\hline $\mathrm{XXXI}$ & $\begin{array}{l}\text { ONE OUTLINE CONSIDERED FOR THE GUAYULE STUDY } \\
\text { STORY } \\
\end{array}$ & \\
\hline
\end{tabular}




\section{LIST OF FIGURES}

FIGURE

PAGE

1. The genres and subgenres within the larger body of futuristic fiction, including extrapolative fiction... . . . . . . . . . 7

2. The research approach used for this dissertation 10

3. Alternative configurations for integrating extrapolative fiction into the impact assessment process... . . . . . . . . . . . . 16

4. Content analysis procedure, in which the contents of message $A$ are compared to those of message $B$ to see differences in the sources . . 101

5. Molitor's issues-tracking model, used to determine the effectiveness of EF stories in identifying emergent issues . . . . . . . . . . 121

6. Articles dealing with nuclear power plant safety 1940-1980................ . 132

7. Articles dealing with Blackouts, 1940-1980 . . 134

8. Articles dealing with Public worker strikes . . 136

9. The pattern of modelforms in a synthesized approach, with its emphasis on mental and verbal models... . . . . . . . . . . . 182

10. Divergence map framework for placing $E F$ stories in time... . . . . . . . . . . . . . . . . . 191

11. Format for the SRI report, incorporating anecdotal images as sidebars . . . . . . . 199 
AN ABSTRACT OF THE DISSERTATION OF Ruth-Ellen Miller for the Doctor of Philosophy in Systems Science presented January $13,1984$.

Title: Enhancing Impact Assessment with Extrapolative Fiction.

APPROVED BY MEMBERS OF THE DISSERTATION COMMITTEE:

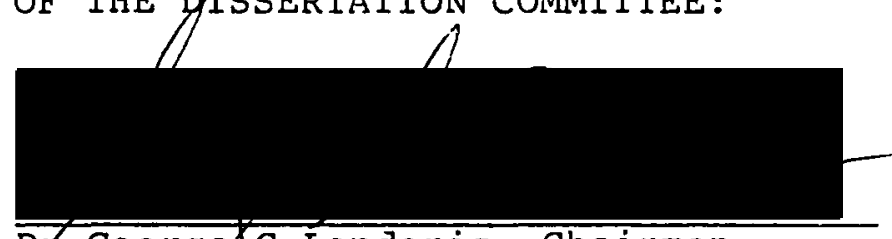

Df Georgof Lendaris, Chairman
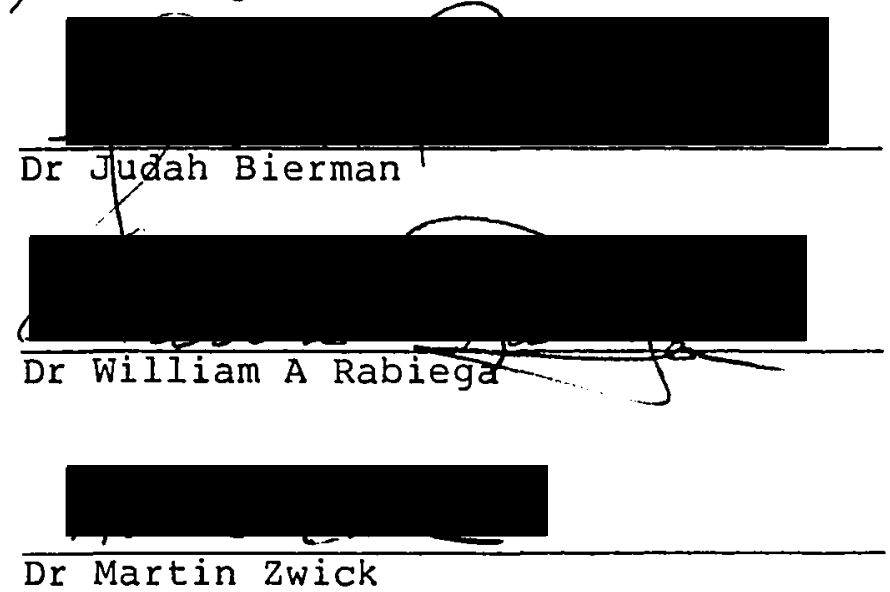

This dissertation proposes the use of fiction as models to enhance the process of impact assessment (IA) and to improve the quality of IA reports. It demonstrates that works of extrapolative fiction (EF), a subset of 
science fiction, raise issues and clarify concerns not currently included in the IA process, suggesting the potential for improving the relevance of IA results for decisionmakers. The dissertation also demonstrates that EF stories can enhance the presentation of IA results, making those results more readable.

Through literature review and content analysis, the current IA process is shown to lead to results lacking in specific content areas (e.g., effects on emotional well-being and community cohesiveness) necessary for their utility to decisionmakers. The body of literature here called extrapolative fiction is then shown to include many content areas missing in existing assessments.

Two alternatives for an IA process that could incorporate extrapolative fiction are presented and discussed by means of examples. The first includes existing EF stories as a part of or an appendage to an IA report. The example is a preliminary combining of published EF stories with an IA report concerning life-extending technologies. The second includes the use of existing EF stories in the assessment process through inclusion of an EF-oriented reader on the IA team. The example is a case description of an IA process regarding the commercialization of guayule as a source of natural rubber, a process in which the author incorporated EF methods.

Several other results emerged from this research: 
(a) an initial statement of objectives for a unified field of impact assessment (recently emerging as an amalgamation of technology assessment, environmental impact statements and social impact assessment); (b) a working definition for an emerging subgenre of science fiction here called extrapolative fiction; (c) a topical bibliography of some hundred EF stories. These results extend the current understanding of the field of impact assessment and the emerging genre of extrapolative fiction and should be useful to both the impact assessment and science fiction criticism communities. 


\section{CHAPTER I}

\section{INTRODUCTION AND OVERVIEW}

In 1979, having spent six years studying, practicing and teaching impact assessment, this author was searching for a new approach--one which included human concerns, as well as political ones, in the assessment process. In that frame of mind, I attended a writer's workshop directed by the noted science fiction author and scholar, Ursula $K$. LeGuin. Interestingly, many of the methods used for and insights gained in that workshop were quite similar to the methods used and results achieved in my own field. An exploration of the similarities and differences between these two activities seemed both interesting and useful, and was undertaken in the fall of that year. The research described in this dissertation builds on that exploration, as an attempt to extend and enhance the field of impact assessment by incorporating the processes and concerns of fiction into the assessment process.

As with all such efforts, this research has built on the work of many others in the fields on which it draws. A number of works contributed substantially to the direction of the research. Porter et al.'s Guide to Technology Assessment and Impact Analysis (1980) formally integrated technology assessment, environmental impact assessment, and social impact assessment, and acknowledged the intuitive and 
creative aspects of social forecasting. Similarly, I. F. Clarke (1979) presented an historical framework linking futuristic fiction with impact assessment and other futures studies. In addition, the work of 0 . W. Markley at SRI International and the University of Houston on the use of mental images in social forecasting (1980), of Harold Linstone at Portland State University's Future Research Institute on the use of personal and organizational perspectives in assessing impacts of technologies (1981, 1983), and of Gus Root (1976) and John Warfield (1975) on alternatives to dynamic models in the systems research process also contributed substantially to the orientation and approach taken in this research.

Four writers in the field of science fiction criticism contributed to the development of the proposals presented here. Two of them are science fiction writers of the highest order--Ursula LeGuin and Robert Heinlein--and two are well-known and respected critics of the genre. LeGuin's collection of essays entitled The Language of the Night (1979) pointed out the relationship between an author's mental images and the verbal models--stories--that depend on them. Heinlein's essays $(1969,1980)$ on the requirements for writing speculative fiction illustrated the strong connection between the research necessary for effective speculative fiction and that necessary for forecasting. Darko Suvin's Metamorphoses of Science Fidtion (1979) provided a framework for discriminating between the 
subgenres that was used in identifying the characteristics of stories or novels that might be appropriate to this discussion. Finally, Patricia Warrick's analysis of stories and novels describing robots and computers (1980) covered that topical area and offered a systems-theoretical framework for selecting works that might be appropriate to the IA process.

The research described here has also been encouraged by the increasing number of practitioners and educators in systems and policy science who have considered science fiction as a possible contributor to impact assessment and related disciplines in those fields. A number of their suggestions have been published in the policy sciences literature (e.g., Heckler, 1968; Greenberg and Warrick, 1974; Rabiega, 1979; and Porter et al., 1980), some of which are discussed in detail in Chapter III. Others have presented their recommendations at professional society meetings. For example, the keynote address for the 1983 meeting of the International Association for Impact Assessment, entitled "Science Fiction and Technology Assessment: A Possible Interdisciplinary Correlation?" (Michaelis, 1983), called for an analysis such as this dissertation describes as a means for improving the quality of technology assessments. In addition, the organizers of the International Forecasting Symposium accepted a paper entitled "Forecasts from the Individual Perspective: Speculative Fiction" (Miller, 1983) for presentation at the 
1983 session. Also, the agenda for the 1984 meeting of the Society for General Systems Research includes a session on impact assessment as an application of general systems theory and methodology, and the American Society for Cybernetics has scheduled a session on science fiction for the 1984 meeting, both of which will draw on and contribute to the research whose current results are presented here.

CONTEXT FOR THE RESEARCH

In the late 1960s, members of the U.S. Congress became concerned that they lacked necessary information to make effective decisions. They were aware that in an increasingly complex world, present actions may have long-term and unexpected impacts, impacts that could far outweigh any immediate benefits. So, over a period of several years they conceived and passed the National Environmental Protection Act (92nd U.S. Congress, 1970) and the Technology Assessment Act (94th U.S. Congress, 1972). These acts established of the Council on Environmental Quality (CEQ) in the Executive Branch and the office of Technology Assessment (OTA) in the Legislature, setting both content and process objectives for the new agencies, and authorizing them to draw on the resources of the National Science Foundation, college and university research centers, and consulting firms to accomplish those objectives.

Through the 1970s many impact assessment (IA) reports were prepared and, in the review process, many criticisms 
were leveled against those assessments. Observers have criticized the process as relying too heavily on quantitative, technical disciplines and methods (e.g., Armstrong and Harman, 1978; Arnstein and Christakis, 1975) • Reviewers have criticized the reports as lacking in quality-of-life and social impacts, clarity, and readability (e.g., Bendix, 1980; Peele, 1980; Porter et al., 1980). Such criticisms of a process and body of works intended to inform decisionmakers of the possible outcome of their decisions demand to be addressed.

During the same years that impact assessment was emerging, a number of policy scientists were suggesting that one field, with some apparent similarities in content, might be appropriately used to enhance the instruction and practice of the policy sciences. Called futuristic fiction, this particular form of short story or novel is usually published in the science fiction journals and anthologies. It deals with human responses to "what if?" questions posed by authors or editors and is typically placed in far-distant times and places.

I.F. Clarke explains the policy scientists' suggestion in his history of futuristic literature (1979), when he describes how impact assessment and futuristic fiction evolved from the same tradition. According to Clarke, futuristic literature has been a part of American literature for over a hundred years, but in the 1960s and 1970s was maturing and reaching a larger audience--in the varied forms 
of technological and social forecasts, impact assessments, systems analyses, and science fiction. Clarke, along with other historians of the genre (e.g., Suvin, 1979), describes how, at the same time that Congress was institutionalizing impact assessment, an increasing number of science fiction writers seem to have outgrown the gadgets and battles of early "space opera" stories and to have begun extrapolating current cultural and technological trends into the future. The novels and short stories produced by these writers examine the possible consequences of present actions through the perceptions and experiences of story characters who live with those consequences.

Stories or novels of this type, dealing with near-term futures (i.e., fifty years or less) and located on this planet, make up a special, hitherto unrecognized subgenre of the larger genre of science fiction. I have called this subset extrapolative fiction (EF) in this dissertation to distinguish these works from other forms of futuristic fiction (e.g., fantasy, utopias). Figure 1 illustrates the relationship between extrapolative fiction and other types of stories that might be published in the same journals.

There are a number of apparent similarities between extrapolative fiction and IA reports. They both deal with the near future, looking at the immediate to fifty-year timeframe. They both assume that values and day-to-day behaviors remain relatively constant and so present few, if any, significant cultural changes. Most importantly, 


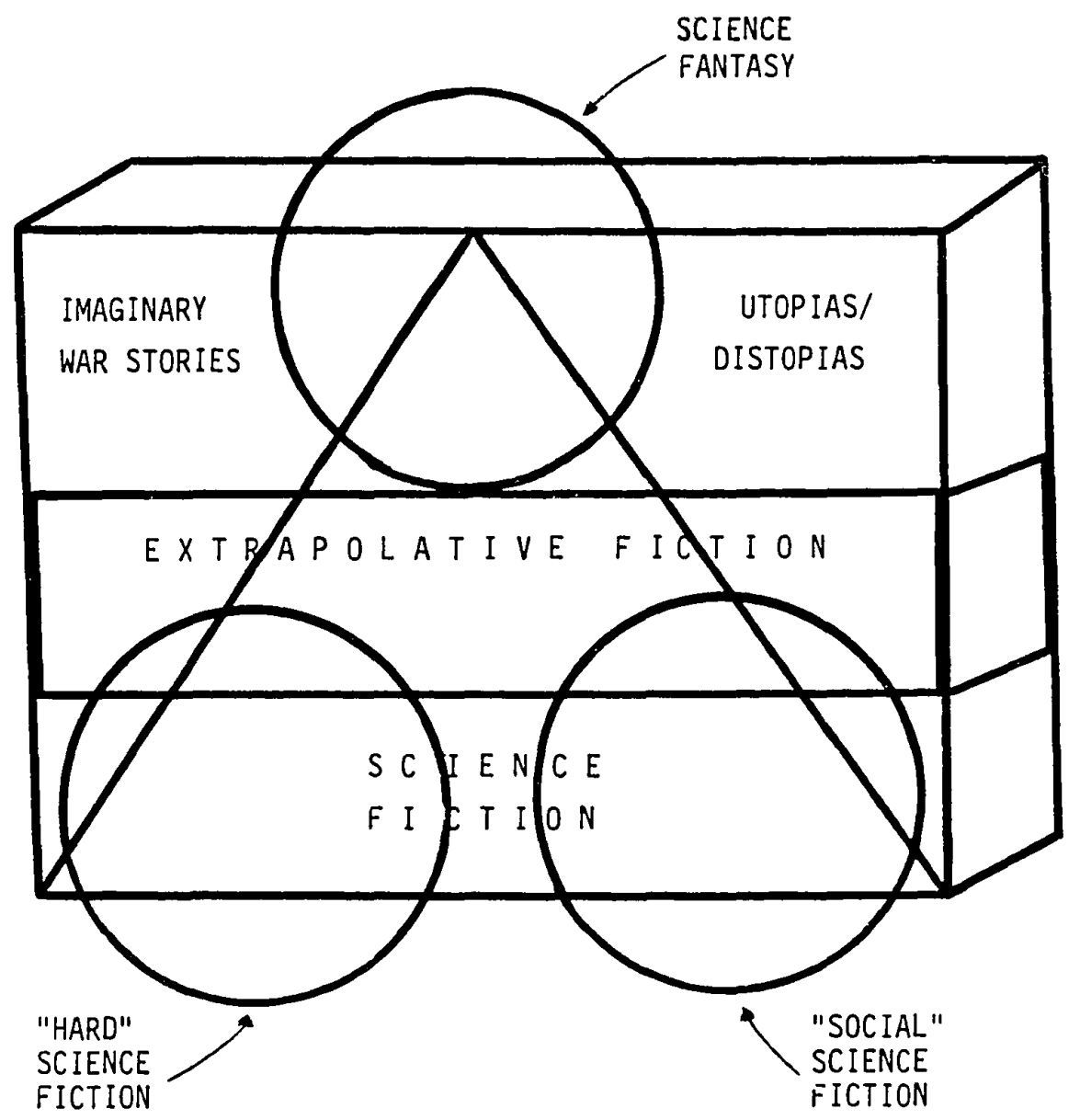

Figure 1. Extrapolative fiction in relation to other forms of futuristic

fiction. 
however, they both identify and examine the possible consequences of innovations being considered in the society in which they are written.

There are a number of differences between extrapolative fiction and impact assessment, as well. While IA reports use tables, graphs, and quantitative descriptors to present the results of large changes on a societal level, EF stories use symbols, images, and metaphors to present individual consequences in qualitative terms. While IA reports use what Linstone (1983) has called a "technoscientific" perspective to address large-sca?e, statistically measurable effects, EF stories use what he has called a "personal" perspective, focusing on the individual's response to the innovation. In Elkins' terms (1979), these stories provide "dramatic" models of human actions and responses to change, while the reports provide "rational" models of the system's behavior.

These differences suggest that extrapolative fiction may provide an alternative set of techniques for reaching the objectives for impact assessment. They suggest that the use of extrapolative fiction in the IA process would emphasize the qualitative presentation techniques and the insights gained from a focus on individual and community concerns and would therefore enhance the IA field's effectiveness as an aid to decisionmakers. 


\section{APPROACH AND OVERVIEW}

The intent of the research described in this dissertation is to determine whether extrapolative fiction can enhance the process and results of impact assessment. Specifically, the research seeks to show whether EF stories and novels (1) raise issues and clarify concerns that are not now included in the IA process, (2) provide presentations of IA results that are more readily understood and acted upon by decisionmakers, and (3) can be effectively integrated into the process and products of impact assessment.

To answer these questions, a series of literature reviews and analyses was undertaken and a set of examples was formulated illustrating proposed alternative methods for achieving a synthesis (see Figure 2). (1) The IA literature was reviewed, and a catalogue of objectives and criticisms of IA reports was synthesized. (2) The science fiction literature was reviewed, leading to the identification of a list of works that, focusing on near-future on-Earth settings to explore the consequences of current actions, inight be considered analogous to IA reports--works of fiction called here extrapolative fiction. (3) A statistical content analysis of selected EF stories and IA reports yielded objective measures of the similarities and differences between them. (4) A thematic analysis of EF stories related the themes and concerns presented in each to the content objectives for impact assessment. (5) A 


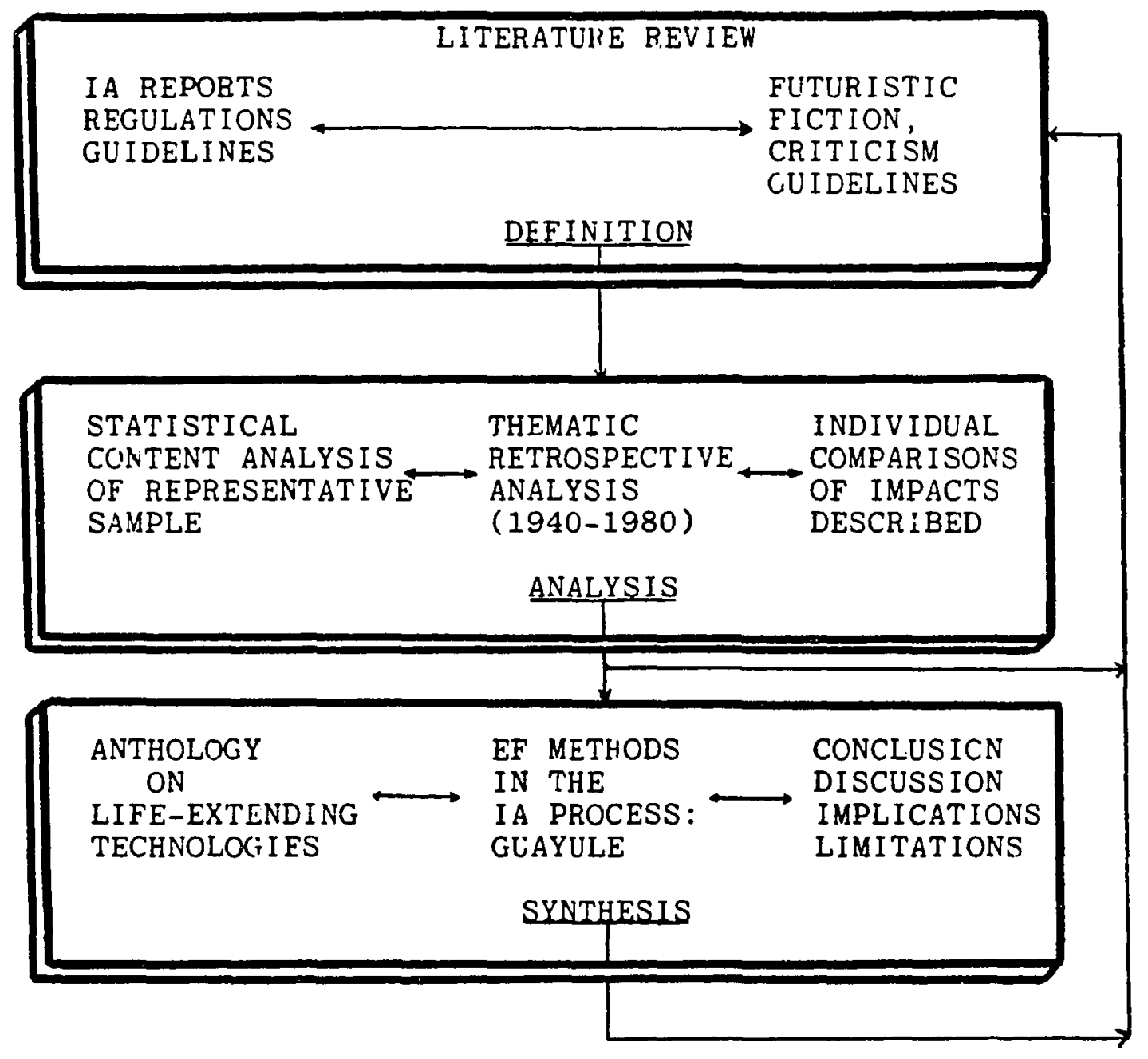

Figure 2. The research approach used for this dissertation. 
comparison of EF stories and IA reports describing the impacts of nuclear power plants provided a detailed singlecase analysis of the specific similarities and differences. (6) Examples were developed to demonstrate the practical potential of including extrapolative fiction in the IA process and led to a set of guidelines for practitioners. (7) A discussion of the results explains some of the differences in content and provides some basis for understanding the criticisms published concerning the readability of IA reports. Finally, the implications of implementing the recommendations of the dissertation are discussed.

In the first literature review I examined the published methodological guidelines for and criticisms of IA reports. Journals, reports of symposia, and methodological guidebooks were examined. The results of this phase include: (1) a clearly defined set of objectives for a unified field of impact assessment, as it has evolved since the original legislation; and (2) an analysis of the content and process criticisms of impact assessment, within the framework of that set of objectives.

The next phase of research required a review of the science fiction journals, reviews, anthologies, handbooks, and bibliographies to select works with a potential for meeting some of the objectives for impact assessment. Such stories should deal with the timeframe of impact assessment (usually five to fifty years), should be placed on this 
planet and in the context of our industrialized culture, and should have no extraterrestrial involvement. The results of this search led me to create a topical bibliography of some hundred near-future stories and novels written between 1940 and 1980 , and to identify a separate subgenre composed of these works, which I have called here extrapolative fiction. Using these results, I undertook a content analysis of a sample of eleven IA reports and ten comparable EF stories to determine the degree to which they met the content objectives for impact assessment. The statistical analysis required counting statements describing impacts in both the EF stories and comparable IA reports. A group of coders identified and counted impact descriptors by categories put forth in the IA guidelines synthesized from the first Iiterature review. Because of the relatively small size of the sample, a series of $\underline{t}$-tests were applied to the coders' data to establish the significance level of the differences between the mean numbers of statements in each impact category for each set of works. Out of that analysis it became clear that while neither the IA reports nor the EF stories fully met the content objectives for impact assessment, together (and with some overlap) they nearly covered the full set of impact categories. Specifically, in over half the categories, there was no significant difference between the samples. The IA reports had significantly more statements describing the aggregated physical, technological, and economic environments, while the EF stories analyzed showed 
significantly higher means in certain (qualitatively rather than quantitatively defined) categories in the technoeconomic and social environments, as well as quality-of-life factors, and described impacts in a wider range of categories than the IA reports did. Also, there were a significantly greater number of statements describing general impacts (that is, statements like "air quality will not be affected," or "little effect on plant life is expected") in the IA reports compared to almost no such statements in the EF stories, suggesting a substantial difference in level of focus.

An analysis of the themes and concerns described in EF stories set prior to 1980 demonstrates the degree to which those concerns reflect the emergent concerns of the culture as expressed later, in other media, and provides a basis for comparing them against the content objectives of impact assessment. Using a matrix framework derived from the IA literature (Martino, 1965; Miller et al., 1972), I analyzed over a dozen EF stories and novels to identify the social, technological, economic, environmental and political concerns expressed at three levels. These levels were (1) philosophy and ideals (values and ethics factors), (2) setting (sociocultural factors), and (3) the character's experience (quality-of-life factors). Descriptors from a given story in the cells of this matrix were indicators of the degree to which that work met the content objectives for IA. For most cases, each cell contained at least one 
descriptor. The number of themes and concerns dealt with in professional and popular periodicals after a story's publication was used as the measure of that story's effectiveness in identifying emergent issues. For the stories dealing with innovations not yet implemented, many of the concerns raised in the stories were reflected in the literature by 1980. For the stories dealing with nuclear power plants, all of the issues raised in the stories were discussed in the Iiterature.

A comparison of the impacts described by EF stories on nuclear power and transportation systems to IA reports about such systems shows the degree to which IA reports differ from EF stories in the scale and types of impacts described. The EF stories analysed included three on the operation of nuclear power plants (Heinlein, 1940; Piper, 1951; Edwards, 1953) and four on transportation systems (Heinlein, 1942; Herbert, 1956; Clarke, 1957; Ellsion, 1968). The nuclear power assessments studied include the report to President Kennedy which was the basis for his decision to support privately-owned nuclear power plants (Seaborg, 1962), and the environmental impact statement for the Three Mile Island plant (Nuclear Regulatory Commission, 1976). The transportation assessments were completed for the Department of Transportation by SRI International (1978) and Peat, Marwick, Mitchell, and Company in response to a request from that agency for technology assessments of current and energing transportation technologies. The analysis showed 
that EF stories described impacts relating to the causes and effects of accidents, the effects of stress and unionization on personnel, the effects of capital-intensive systems on policymakers, the displacement of related technologies, the location of population centers in relation to the technology, and shifts in power in related bureaucratic structures. The IA reports on nuclear power discussed the expected radiation exposure associated with accidents, the economic benefits and cost overruns associated with plant construction, the effects of such plants on the coal and transportation industries, and the utility of nuclear technologies to military and space programs. The IA reports on transportation described high-density traffic corridors, energy use, cost of construction, operation and maintenance, and aesthetic improvement in downtown cores.

These combined results suggest that integrating extrapolative fiction into the IA process is an obvious next step. Two basic alternatives were developed to be tested: (1) the use of already published works to augment a completed IA report, exemplifying and illustrating the conclusions; and (2) the use of extrapolative fiction early on in the IA process by including a person with fictive skills on an IA team to help shape research questions and concerns (See Figure 4). I developed examples for each of these alternatives as a way to demonstrate their feasibility and to provide a basis for evaluating the problems and potentials for implementing them. Based on the experience 


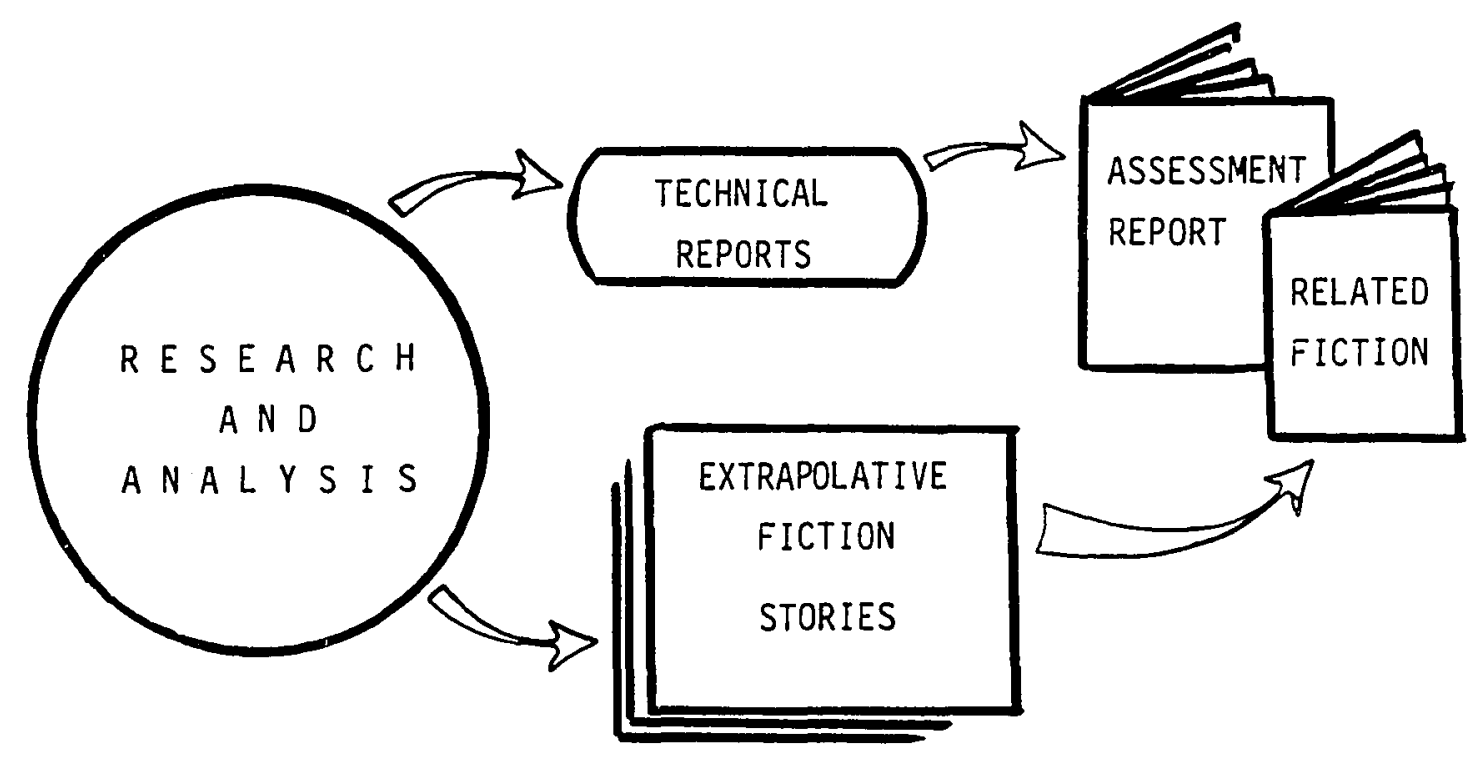

3a. EF stories are used to augment a complete report.

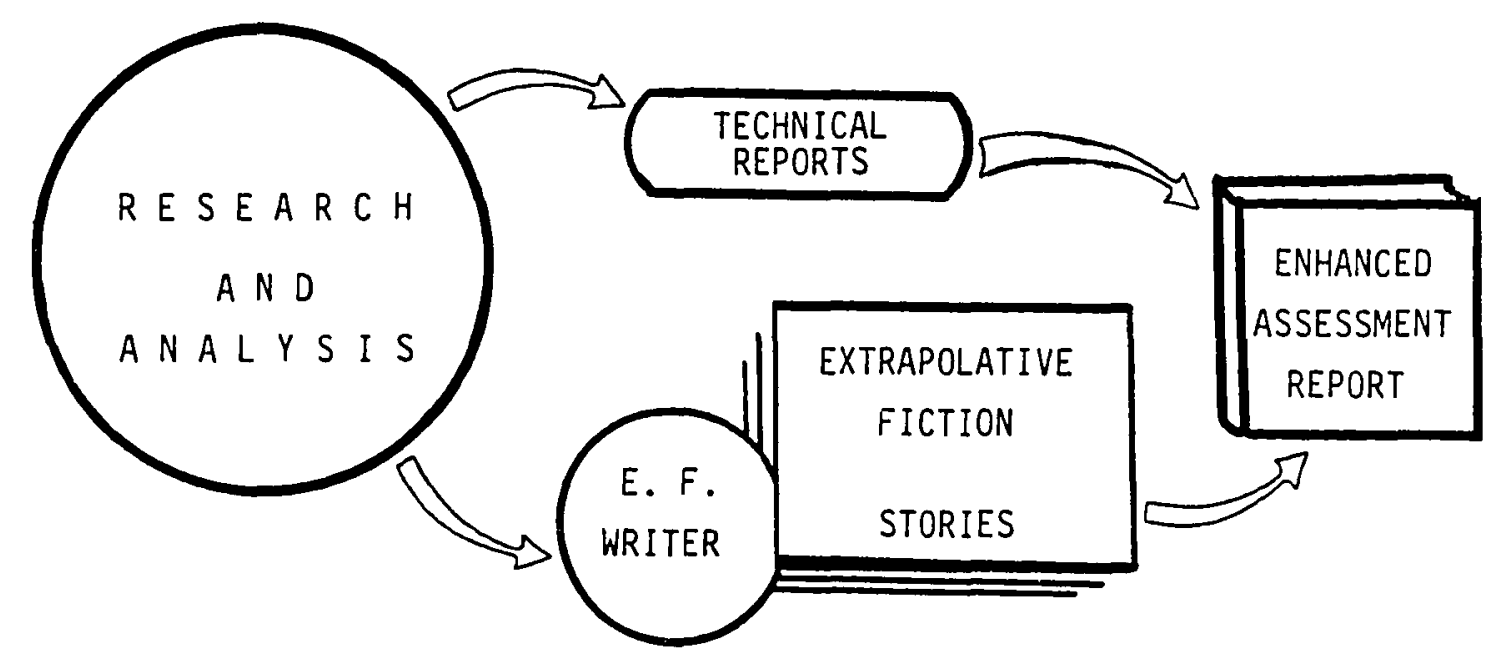

3b. A fiction-oriented person is included on the IA team.

Figure 3. Alternative configurations for integrating extrapolative fiction into the impact assessment process. 
of developing the alternatives, I prepared some guidelines for IA practitioners.

The first example for integrating extrapolative fiction and impact assessment appends a collection of published short stories and excerpts from novels to an IA report on Iife-extending technologies. Focusing on the experience of Iife extension, these works of fiction complement the assessment at several levels and exemplify and extend the issues and concerns raised in the IA report. Where the report provides the statistical, demographic, policy and ethical factors associated with these technologies, the stories illustrate the conflicts involved in the experience of living with extended lifespans. Where the IA report describes the general demographics of a population with an increasingly large proportion of senior citizens, the collection of stories helps the reader feel the hopes and fears of characters living in such a culture. By illustrating such contrasts and similarities, this example demonstrates the way that published EF stories can provide individual and quality-of-life impacts and provide imagistic models of the innovation-in-context, enhancing the utility of a traditional IA report.

The second alternative for integrating impact assessment and extrapolative fiction requires including EF stories or methods in the IA process. The example developed here describes including a person with an orientation toward fiction as part of an IA team, introducing EF methods in the 
team's process. Personal experience in that role provides the basis for this example. As a member of a team studying transportation alternatives some years ago, I was one of several who insisted on the use of anecdotal material and imagination in developing the scenarios. The result was a set of scenarios that included anecdotal vignettes and fanciful illustrations alongside the text, describing the lives of people who might live in those scenarios (SRI, 1977). I contributed to that process through team discussions and suggestions for images and anecdotal material.

In 1979-80, an assessment of the commercialization of guayule (as an alternative source of natural rubber) again permitted a fiction orientation. The guayule study had a smaller team, so, in addition to contributing to the team's process, the results of my interviews and analyses were included as separate contributions to the report (Linstone et al., 1980). The story that emerged served to synthesize the study results and provided many of the insights that were documented in the final report (Linstone et al., 1981). Together, the research results documented in this dissertation provide a basis for assessing the potential usefulness of extrapolative fiction as part of impact assessment. The analyses--comparing the issues raised and impacts described by EF stories and IA reports--show that the fiction can point out important and otherwise overlooked considerations to assessors. The first alternative for 
integrating the fiction and the assessments--collecting a supplemental set of EF stories--shows the complementary nature of the two forms and provides a way to illustrate the range of experiential concerns raised by some technologies. The second alternative--including a person with skills in s esearching and writing works of fiction on an assessment team--has been utilized with some success on at least two funded studies (described in this dissertation), and leads to substantially different insights and reports, suggesting considerable potential usefulness for that approach.

A number of guidelines, caveats, and suggestions for further research come out of this study of extrapoaative fiction and impact assessment. First, assessors need to be clear about the differences in form and content between traditional, estranged science fiction and the emerging new form of extrapolative fiction. They can make use of aficionados of this genre as starting points and decide early on whether it is appropriate to include someone who has some experience with the fictive mode on the team. They should recognize that writing EF stories is, in itself, a useful device for synthesizing complex information, even though a story may not be appropriate in the final report of results of the synthesis. Finally, using the bibliography developed here (See Appendix A) as a starting point, future assessors should continue to search for EF stories, exploring possible uses and misuses of fictional tools in the IA process as they gain experience. 
Should the recommendations of this dissertation be implemented, the implications for the evolution of impact assessment are substantial. The enhanced process may lead to "model" reports that are published to reach a mass market and lead to a new level of citizen involvement in the IA process. These enhanced reports may, in turn, lead to the development of new, humanities-based methodologies. In addition, the writing of EF stories as part of the IA process may affect the quality and form of the currently unrecognized subgenre of extrapolative fiction, perhaps evolving to form a wholly separate genre, of fictional nearfuture forecasts and speculations. 
CHAPTER II

THE EMERGING FIELD OF IMPACT ASSESSMENT

Having been legislated into existence in the early 1970s, the various forms of impact assessment have just begun to become established among the policy sciences. As with any new branch of research, much of the early work in this area was plagued with methodological and substantive difficulties that caused a number of observers to wonder whether the effort was in fact worthwhile. Toward the end of the decade, however, the processes had been sufficiently standardized and large enough databases had been established to permit a fairly consistent quality of product. As a result, practitioners and observers are now able to critically assess the utility and relevance of the IA process and its results, and to offer some possible improvements to the field as a whole.

This chapter defines the field of impact assessment in an historical context and reviews some of the criticisms which have been leveled against it. A set of objectives for a generalized IA process are derived from the literature and a sample set of IA reports are critiqued in light of these objectives. 
FORMS AND FUNCTIONS OF IMPACT ASSESSMENT

As the pace of industrial development increases and the interrelationships between people, their institutions, their technologies, and their physical environment become more complex, traditional assumptions concerning the effects of actions falter. Decision-makers can no longer afford to assume that individual actions resulting in local good will also contribute to the general good. For example, a power plant intended to supply needed electricity to a city in one state can result in acid rains and coal-smoke haze that affect several other states, or the town in which the power plant is placed may experience a "boom-and-bust" period, destroying the social fabric of the community. How impacts are identified and then mitigated or enhanced has become an increasingly important concern for society as a whole. The rise of the environmental movement in the early 1970s and the associated rise in political activism are measures of that concern. Activists have increased the pressure on lawmakers and regulators to prevent negative environmental consequences. Federal and state decisionmakers are faced with the increasingly difficult task of ensuring that their choices do in fact result from the consideration and mitigation or enhancement of all relevant impacts.

In the late 1960s, decisionmakers began to hope that, using the tools of systems science and technological forecasting, they could truly comprehend--perhaps even 
manage--the consequences of their actions. In an age when the democratic decisionmaking process seemed doomed to failure, elected leaders finally felt that they could make truly informed decisions. As a result, in the 1970s, laws were passed and agencies established to provide legislators and elected officials with appropriate information. Various forms of impact assessment were defined, starting with the environ-mental impact statement (92nd U.S. Congress, 1970). Later forms included technology assessment ( 94 th U.S. Congress, 1972), social impact assessment (Wolf, 1980), and program or area-wide assessment (U.S. Department of Highways, 1980). Each of these forms had its own guidelines, regulations and methodology, and each addressed a different aspect of (or level of concern regarding) the future consequences of present actions.

Environmental Impact Assessment

The need to consider the implications of change--for both society and its environment--became institutionalized in this country with the passage of the U.S. National Environmental Policy Act of 1969 (NEPA) (92nd U.S. Congress, 1970). Emerging out of a decade of heated debate over the potential harm caused by pollution of air and waterways, this act aimed to "encourage productive and enjoyable harmony between man and his environment" (92nd U.S. Congress, 1970: Sec.101 (a)). Specifically, NEPA required that federal agencies and their contractors include an environmental impact statement "in every recommendation or 
report on proposals for legislation and other major Federal actions significantly affecting the quality of the human environment" (Sec. $102(2)(c))$. This statement was to detail the impacts of the action, unavoidable adverse effects, possible alternatives, short-term vs. long-term effects, and "irreversible and irretrievable" resource commitments associated with the action (Sec. $102(2)(c)(v)$ ).

Further, NEPA established the Council on Environmental Quality (CEQ) to set guidelines and (later) regulations for agencies and organizations to follow in preparing impact statements. The Council was also to review such statements and make policy recommendations to the president (92nd U.S. Congress, 1970: Title II). CEQ regulations describe the NEPA process as intended to "help public officials make decisions" by providing them with the information they need to understand the "environmental consequences" of their decisions and to act in ways that "protect, restore, and enhance the environment" (CEQ, 1980: Sec 1500.1 (c)). The regulations further define the environmental impact statement (EIS) as "an action-forcing device to insure that the policies and goals defined in the Act are infused into the ongoing programs and actions of the Federal Government" (CEQ, 1980: 1500.1 (a)). They specify more clearly the definition of the term "human environment" as used in NEPA, to be "the natural and physical environment and the relationship of people with that environment" (CEQ, 1980: $1508.14)$. 
$C E Q$ regulations state four main objectives for the EIS :

1. provide full and fair discussion of significant environmental impacts

2. inform decisionmakers and the public of reasonable alternatives

3. be concise, clear, and to the point

4. be supported by evidence (1502.1)

Further, when the assessment process discloses that "economic or social and natural or physical environmental effects are interrelated," the EIS must include all of these effects in a discussion analyzing their significance at several levels "such as society as a whole (human, nationa1), the affected region, the affected interests, and the locality" (CEQ, 1980: 1502.16). The CEQ regulations at once established the content of environmental impact statements and set the tone for others to follow.

Following the federal example, a number of state governments (thirty as of the summer of 1980) enacted similar legislation. There is some variation in language and review process across them, but the intent of all is the same. In most states, therefore, projects using state or federal funds or making use of a state- or federally-funded service (e.g., waterways maintained by the Army Corps of Engineers) are subject to the preparation and public review of a statement describing the full range of environmental impacts likely to result from the project's implementation. As a consequence, virtually every major program (e.g., research 
in recombinant DNA), development (e.g., the commercialization of guayule), or construction project (e.g., dams, roads, major buildings) proposed in this country must be assessed and reviewed for its potential impacts on the local, human environment.

Together, federal and state regulations establish the legal necessity for an IA process focusing on the effects of a specific project or program on the natural (or physical), social, and economic environment in which it will be placed. They indicate the form of document needed and provide extensive instructions for reviewing the contents. However, although the regulations define the need for, the intent, and the use of impact assessment, they proovide few guidelines for the process of researching, analyzing, and preparing IA reports. Since this process is a new one, such guidelines have been sorely needed.

Thomas Dickert and Jens Jorgensen provide one of the earliest attempts to meet this need for procedural guideIines in their article, "Content and Organization of Environmental Impact Statements" (in Dickert and Domeny, 1974). Unlike the framers of NEPA and the CEQ regulations who were concerned with the IA report, Dickert and Jorgensen consider impact assessment primarily as a process and so give assessors an initial set of guidelines for that process. They define impact assessment as consisting of three functions: 
1. identification of impacts;

2. prediction of the state of society and the environment at some future time (along with effects likely to be felt at that time);

3. evaluation of the costs and benefits associated with those impacts and effects (in Dickert and Domeny, 1974).

Dickert and Jorgensen are particularly concerned with establishing the scale of impacts, which they describe as "one of the most important functions in assessment" (1974: 32), and which is dependent on reliable forecasts for utility. They suggest that, although regulations and reviewers tend to focus on the contents and format of the final EIS report, for the assessor, performing the assessment in a methodologically sound manner is as important as the content of the report. This view is supported by the criticisms leveled against completed EISs by reviewers and other practitioners (e.g., Bendix, 1980; Porter et al., 1980). Together, they will be discussed in detail in a later section of this chapter.

Table I illustrates some of the types of EISs that have been submitted in the last decade or so. The statements illustrated are representative of four main types of project that are subject to the NEPA review process, and hence to the preparation of an EIS. They describe the impacts of a federal policy, a regional or areawide project, a local project, and modifications on an existing project. The first example in Table I describes the expected impacts of a federal policy. The policy was enacted on the 
TABLE I

SOME EXAMPLES OF ENVIRONMENTAL IMPACT STATEMENTS TITLE SOURCE

\section{FEDERAL POLICY EIS}

NIH Guidelines for Research

National Institutes of Health, U. Involving Recombinant DNA S. Department of Health, Education, Molecules and Welfare, DHEW (NIH) 1489 and 1490, Washington, D. C., 1977.

REGIONAL OR AREAWIDE EIS

Proposed Increase in Acreage to be Offered for $0 i 1$ and Gas Leasing on the Outer Continental Shelf

Bureau of Land Management, U. S. Department of the Interior, DES 74190, Washington, D. C., 1974

\section{LOCAL PROJECT EIS}

Environmental Assessment, Rossman Processing Station, Portland, Oregon

U. S. 59 in Stevens County, Minnesota
Solid Waste Division, Metropolitan Service District, Portland, Oregon, 1976.

\section{MODIFICATIONS EIS}

Federal Highway Administration and State of Minnesota Department of Highways, EIS-MN-74-0180-F. St. Paul, Minnesota, 1974. 
demand of public interest groups and members of the research community to establish guidelines for experimentation with recombinant DNA molecules (National Institute of Health, 1977). The statement describes the costs involved in enforcing the regulations, their effects on laboratory personnel, the likely secondary impacts resulting from their enactment and enforcement, the probable impact of experiments conducted according to the suggested guidelines, and the likelihood of spreading agents resulting from those experiments. The draft report was issued according to CEQ regulations and was reviewed by scientists, practitioners, and public servants, whose comments are included in the final report.

The second example may be called a "regional" EIS. This report describes the effects of a project across a large but fairly well-defined region--in this case the continental shelf of the United States (Bureau of Land Management, 1974). The format, typical of many controversial IA reports, consists of a number of reports from experts describing in great detail the impacts of the project--a coastal oil and gas leasing program--on the coastal zone as defined by those experts' fields of expertise. It includes descriptions of the effects of extracting oil and natural gas from offshore wells on $f$ ish and aquatic wildlife, local coastal fishing industries, on the economics and demographics of local urban areas, and on 
the use and development of alternative energy sources (i.e., coal).

The third EIS listed describes a new project, intended by its sponsor to reduce one type of load on the environment --landfilling--by creating an electricity-generating incinerator (Portland Metropolitan Service District, 1976). This report is of medium length, something less than 200 pages, and offers minimal-level analysis of the impacts such a plant would have on air, water, noise, traffic, land use, wildlife, and local aesthetics. It also describes the economic costs and potential benefits to result from reduced landfilling in the local area.

Finally, the fourth example describes the modification of an existing structure, the creation of a short by-pass around a city, using some existing roadway and building some new (Federal Highway Administration, 1974). This report is typical of the "pro forma" reports that tend to emerge from projects that it is assumed everybody wants. It is brief, highly qualitative, and assumes--hence finds and reports--no negative impacts.* Since the by-pass includes a bridge, the report describes its potential impacts on the river, the water quality, the floodplain to be crossed, and local wildlife. The report assumes that increased commercial

\footnotetext{
* It has been suggested by Dickert and Domeny (1974) and Porter et al. (1980) that by far the largest number of EIS reports are of this type and that political acceptance of a project prior to its assessment is a common--and dangerous--hindrance to an effective IA process since it discourages careful research and analysis.
} 
development along the by-pass will have positive effects on the economy of the region.

\section{Technology Assessment}

Technology assessments are like environmental impact assessments in being concerned with the full range of impacts. However, while environmental impact staternents focus on the effects in a specific community or locale of introducing a project or program, technology assessments focus on the effeects of introducing a new technique or product into the societyy as a whole. This difference in focus stems, in part, from the difference in the audience receiving the report (TAs are prepared for members of Congress, for the most part, as opposed to executive branch regulators for EISs) and in the structure of the agency established by the legislation.

Congressman Emilio Daddario coined the term Technology Assessment when, in the same year that NEPA was passed, the House Committee on Science and Astronautics considered his bill to establish a federal office of Technology Assessment (OTA). In October, 1972, President Nixon signed the Technology Assessment Act, according to which OTA is governed by a board made up of members from both the House and the Senate and serves as a research arm for Congress. The office is charged with providing Congressional committee chairmen the information they need to determine whether the long-term effects of a technological innovation--defined as production 
method or line of products--or new federal program (e.g., strategic stockpiles) would be favorable or adverse for the nation as a whole (94th U.S. Congress, 1972).

The Technology Assessment Act defines technology assessment as a means for enabling Congress "to gain a legislative capability for policy determination in applied science and technology and for anticipatory decisions involving technological matters" (94th U.S. Congress, 1972). With this act, the legislative branch joined the executive (with its environmental impact assessment) in requiring policy decisions to be made based on an understanding of the potential social and environmental consequences of the policy or innovation under consideration.

In technology assessment, the effects of using the technology rather than the technology itself are examined. Emphasis is placed on the "explicit consideration of societal costs and benefits" ( 94 th U.S. Congress, 1972). Seeking to enrich the decisionmaking process, technology assessment aims "to identify affected parties and anticipated impacts in as broad and long range a fashion as is possible" (Hetman, 1973:44). This includes individuals and social groups, the ecosystem, the economy, other technologies, and politics (Hetman, 1973). Technology assessment has been described as an "early warning system," providing decisionmakers with a glimpse of what could happen before it actually does happen (Carpenter, R., 1972). As such, it gives legislators some basis on which to develop long-term 
or nation-wide policies regarding new technologies or technology-related innovations.

In order to more fully understand the nature of technology assessment and to point out the ways in which it differs from and is similar to environmental impact assessment, it is useful to consider some examples. Table II lists a few reports as examples of Technology Assessment. Together, they represent the three main approaches to technology assessment.

The first of the reports listed in Table II, concerning the impacts of residential use of photovoltaic systems (Krupka, 1979), more closely resembles an environmental impact assessment than a technology assessment. In the kinds of impacts it explores (e.g., use of resources and fabrication residues) and in its lack of policy analysis, this report offers little assistance to legislators considering policy options regarding the implementation of solar photovoltaic energy systems on a nationwide basis. It does, however, provide some very useful information to the individual considering implementing such a system in a residence. Based on a "model" residence in Phoenix, Arizona, using silicon cells to generate about ten kilowatts (peak) electricity, the report identifies major uses of resources, operating residues, and decommissioning residuals. It suggests major environmental impacts when fabrication and transportation of cells are considered. Cost estimates are developed using a computer model, and 
TABLE II

SOME EXAMPLES OF TECHNOLOGY ASSESSMENTS

TITLE SOURCE

\section{QUANIITAT IVE DESCRIPIIVE IA}

Decentralized Solar Photovoltaic Systems

Krupka, M.C., report to the U. S. Department of Energy Office of Technology Impacts, prepared under contract: Los Alamos Scientific Laboratories, Los Alanos, New Mexico 1979.

HOW-TO IA

Office of Technology Assessment

An Assessment of Information Systems Capabilities Required OTA-M-40, December, 1976 to Support U. S. Materials Policy Decisions

NEW POTENTIALS TA

The Implications of Electronic Funds Transfer
Ernst, M. V. et al., report to the National Science Foundation, Research Applied to National Needs Program, Arthur D. Little, Inc., 1975. 
zoning and building codes, along with interaction with utilities are described as social impacts.

The second report, by contrast, is almost purely a policy document (Office of Technology Assessment, 1976). Developed by OTA on request from Congress as part of a larger study, this assessment of information system capability describes the options available to Congressmen for dealing with the information related to policy decisions concerning maintaining materials stockpiles. The report is intended to provide Congress with information concerning policy options. It describes existing information systems and their inadequacies, based on interviews. It offers three alternative approaches and seven institutional mechanisms for implementing the. Qualitative analysis of impacts deal with governmental, economic, social, legal, and international policy concerns. Policy issues are analysed, and three alternative approaches and seven institutional mechanisms are described, with their related governmental, social, legal and international policy concerns. The emphasis of this $\mathrm{TA}$ is on how such systems may be implemented rather than on what may happen if they are.

The third report (Ernst, 1975) studies the potential new applications of computer technology in the banking community, describing the possible uses (e.g., automated teller machines) without identifying or analyzing their effects. Conducted by a professional management consulting firm, this study emphasizes the potential uses of the new 
technologies in the banking community, including automated teller machines, automated clearinghouses, check safe keeping, and direct inter-corporate transactions. The report has been hailed as one of the most readable yet least verifiable assessments published (see Linstone et al., $1980)$.

The three assessments presented in Table II provide examples of three different approaches. The first exemplifies the highly quantitative descriptive report. The second is a typical "how-to" report. The third provides an exploration of new potentials. Each report, then, deals with one part of the technology assessment process as defined under the 1972 Congressional act.

\section{A GENERALIZED DEFINITION FOR IMPACT ASSESSMENT}

The above discussion suggests that there is a great deal of congruence between the goals and processes of technology assessment and environmental impact assessment. The two were formalized with a common intention: to encourage measures protecting the society and its environment, and to provide an information base for decisionmakers. Similar methodologies and philosophies--many drawn from the practices of technological forecasting and policy analysis-underlie the two forms' processes.

This similarity is made obvious in Table III. Here, several recommended strategies for performing impact assessments are compared: three from the EIS guidelines and 
TABLE II I

RECOMMENDED STRATEGIES FOR TA AND EIS

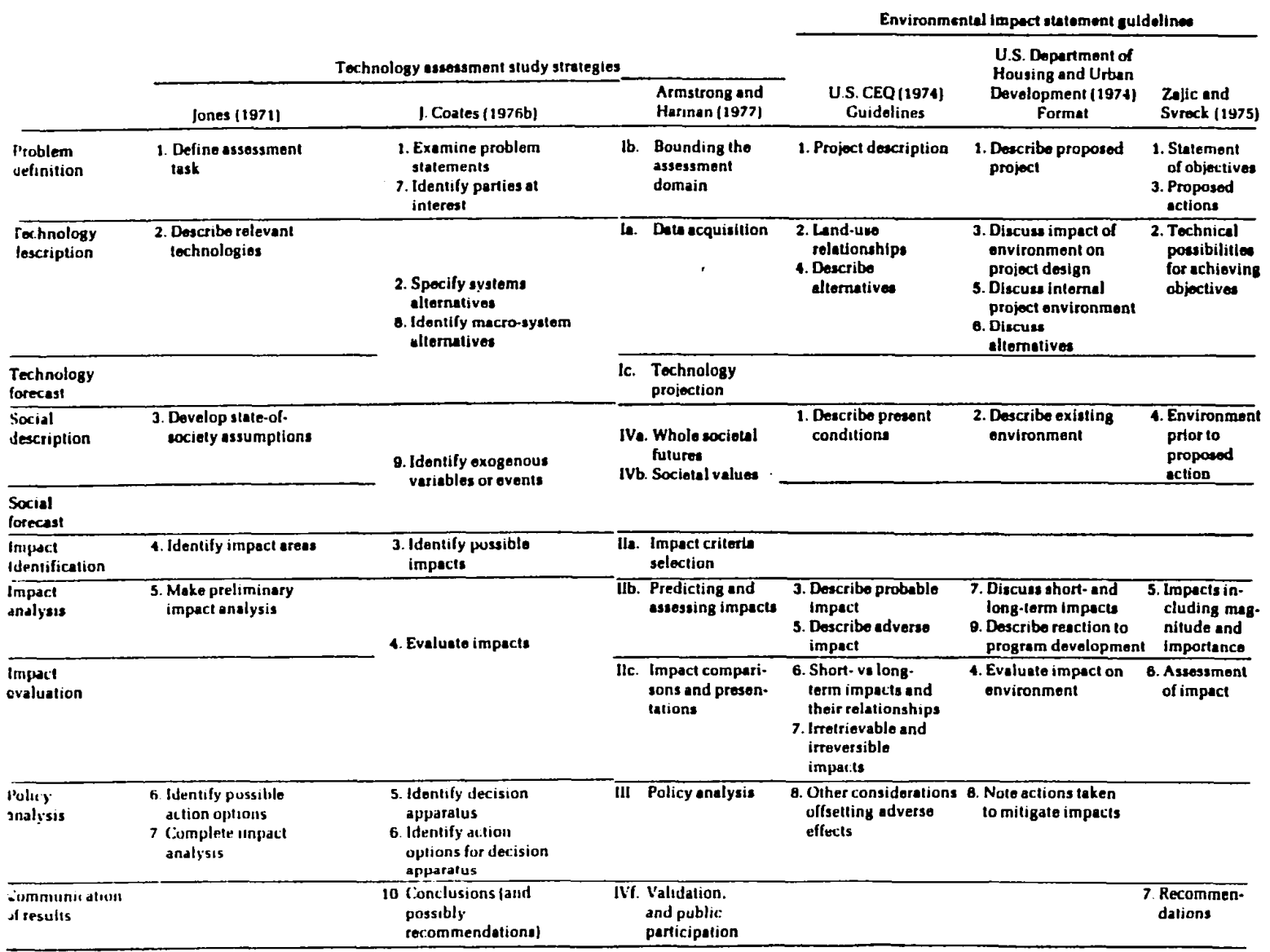

SOURCE: Porter et al., A Guidebook for Technology Assessment and 
regulations, and four from the TA literature. The similarities in process between these several approaches have led Porter and his colleagues to combine them and to describe a more generalized form (Porter et al., 1980). The strategy recommended by Porter and his colleagues (column I)--problem definition, technology description, technology forecast, etc.--incorporates the essential elements of the other six strategies and guidelines. The Porter team's strategy is a flexible structure that permits the inclusion of elements from the other strategies as appropriate to a given assessment. Further it meets the criteria which they suggest in their guidelines for a combined TA/EIA process:

It must accurately describe the state of the art of the relevant technology and forecast the changes that the technology is likely to undergo. It should also describe the relevant features of the society, its values, and ways of managing the technology, and should anticipate how these factors might limit and shape the context in which the technology must function in the future. It must identify areas of the social and physical environments that are likely to be impacted by the technology and analyze the character and extent of significant impacts. Policy options. . must also be identified. Finally, since no TA/EIA can be effective unless its results are communicated to the user, it should be presented in a clear, logical, and effective manner. (Porter et al., 1980: 5)

Objectives for Impact Assessment

The criteria for TA/EIA put forth by Porter et al. (1980) do not fully cover social impact assessment (as defined by C. P. Wolf, 1980) and program or area impact assessment (currently seen as a special case of EIS or TA, depending on who the client is (see Hornick and Enk, 1980)). 
To include these forms of impact assessment it is necessary to make a few additions to Porter et al.'s contribution.

Table IV lists Content and Process Objectives for environmental impact assessment, technology assessment, area-wide or programmatic assessment, and social impact assessment, combined. These objectives are synthesized from the guidelines and regulations for each of these IA forms and are presented here as a framework to permit further analysis and discussion of the IA process as a whole, along with its results.

The content objectives presented in Table IV illustrate impact assessment's orientation to the broadscale impacts of an innovation. They are clearly tied to the decision-making process and the user's need to be fully informed. The process objectives are, similarly, oriented to making the IA results useful to the decisionmaker. The objectives in both categories are specific enough to permit analysis and evaluation of existing IA reports and establish the degree to which such reports meet these objectives.

\section{Concerns and Criticisms}

The first decade of impact assessment has produced over fifty thousand environmental impact statements--prepared to meet National Environmental Protection Act requirements and equivalent state regulations (Hornick and Enk, 1980)-and a hundred or so technology assessments (based on reports from OTA, the National Science Foundation, and the National Technical Information Service), including some two dozen 
TABLE IV

UBJECTIVES FOR IMPACT ASSESSMENT

\begin{tabular}{|c|c|}
\hline Objectives & Source \\
\hline \multicolumn{2}{|l|}{ CONTENT OBJECTIVES } \\
\hline $\begin{array}{l}\text { Provide full and fair discussion of significant } \\
\text { impacts on } \\
\text {-the natural or physical enviroment } \\
\text {-individuals and groups in society } \\
\text {-the economy } \\
\text {-related technologies } \\
\text {-politics }\end{array}$ & $\begin{array}{l}\text { Arrstein and Chistaikis, 1975; Porter et al,, 1980; } \\
\text { Nitional Enviromental Protection Act (NEPA) }\end{array}$ \\
\hline Analyze the extent and character of impacts & NEPA \\
\hline $\begin{array}{l}\text { Inform the public and decisionmakers of reasonable } \\
\text { alternatives }\end{array}$ & Technology Assessment Act, NEPA \\
\hline $\begin{array}{l}\text { Anticipate changes in the physical and social } \\
\text { enviroment-longterm, indirect, or unanticipated }\end{array}$ & NEPA; Hetman, 1973 \\
\hline $\begin{array}{l}\text { Focus on the effects rather than the technology } \\
\text { or project under study }\end{array}$ & Hetman \\
\hline $\begin{array}{l}\text { Consider explicitly the costs and benefits to } \\
\text { society }\end{array}$ & Hetman \\
\hline $\begin{array}{l}\text { Relate forecasting and evaluation activities } \\
\text { closely to identified impacts }\end{array}$ & Porter et al. \\
\hline $\begin{array}{l}\text { Describe society's values and ways of managing } \\
\text { PROCESS OBJECTIVES }\end{array}$ & Porter et al. \\
\hline $\begin{array}{l}\text { Ensure congruence between predicted and actual } \\
\text { results }\end{array}$ & NEPA \\
\hline $\begin{array}{l}\text { Ensure adequate evidence so that study results } \\
\text { are credible }\end{array}$ & NEPA \\
\hline Laintain a neutral and objective position & Congressional Research Service \\
\hline $\begin{array}{l}\text { Present results in a clear, concise, and } \\
\text { meaningful statement }\end{array}$ & Porter et al. ; NEPA \\
\hline $\begin{array}{l}\text { Release statement at an appropriate time to } \\
\text { assist the decisionmaking process }\end{array}$ & Porter et al.; Council on Enviromental Quality, 1980 \\
\hline $\begin{array}{l}\text { Improve the methodology by carefully designing } \\
\text { and documenting the process }\end{array}$ & Hetman; Porter et al. \\
\hline
\end{tabular}


from the Office of Technology Assessment and another thirtyodd supported by the National Science Foundation.

The IA reports listed in Tables I and II (pp. 28 and 34) are examples selected on the basis of recommendations from other professionals in the field as typical of assessments of their type. Table V summarizes the comments on these reports as they have either (for EIS's) been included in the final draft based on public review of the review draft, or (for TA's) been printed in the methods Iiterature.

These comments fall into four main categories: those calling for more analysis, those calling for more documentation of results, and those requesting additional descriptions of impacts or alternatives. Several of the reports reviewed were cited for assuming, rather than analysing, either initial data or the impacts themselves. Lack of documentation was cited in several reports--for assumptions, data, effects, and analysis. Inadequate discussion of impacts, effects, or "evolutionary consequences", was cited in most of the reports reviewed. In addition, a few were noted as lacking in alternative policy options or means for implementation.

These and other reviews of IA results have raised serious questions about the validity and utility of the impact assessment process and its products. Reviewers have criticized the reports as lacking in important and essential information. Practitioners have suggested that lacks in 
TABLE V

SOME COMMENTS ON IA REPORTS

\section{Environmental Impact Statements}

Research Guidelines for Recombirant DNA (NIH, 1977)

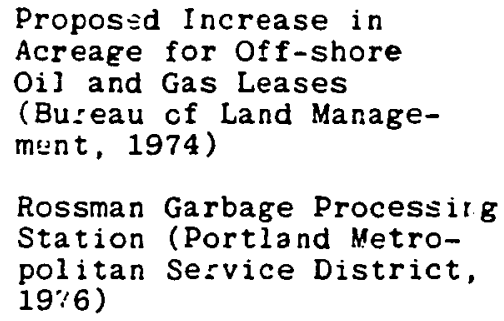

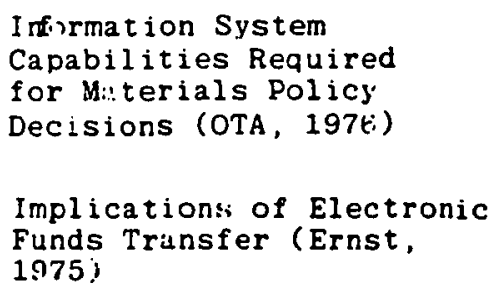

Decentralized Solar Fhotovoltaic Systenis (Krupka, 1979)

Comments on EISs frum the Final Drafts. Comments on TAs from Porter et al., 1980; A:mstrong and Harman, 1981; Linstone, 19181.

- no summary of issues, impactsi

- little attention paid to sccial impacts

- good use of appendix for explane.tions tied to discussions of sane

- no policy optiors discuss

- expert judgement plays heavily

- useful sumary

- little attertion jaid to nonfederal institutions

- strong focus: on orgarizations involved
- inadequate participation by the cubiic

- insufficient discussion of porsitle evolutionary consequences of accidents

- need more discussion of implementation

- insufficient s;ecuiation on deliberate misusage

- need documentation for assertion of lack of harmful effects

- excessive use of technical language.

- inudequate support dccmentation for certain figures

- excess:ve focus on highly cletailed discussior of sftcific impacts

- air quality from monitoring stations assum:d to be representative for site

- no "mo:ring baseline" for dufining physical impacts

- no assessment of the hazari of waste residues

- no quantitative analysis

- no atterition to socias or insitutional effects

- little atcention paid to alternatives

- careful consideratior. of corstruction ccncerns

- inadequate discussion of ecoramic effects

Technology Assessments

- conclusicns regarding impacts not closely

- little or no quantitative data, analysis

- bised on existing, nor emerging technology

- good use of sce.jarjos to illustrate impacts 
information are the result of inadequacies of assessment methodology. These concerns, pointing to underlying problems in the assessment process, are discussed below.

Sociocultural Factors. Major criticisms of the content of impact assessments emphasize their ineffectiveness in dealing with socio-cultural factors. Porter and his colleagues (1980) report a "tendency for most TAs and EIAs to neglect social descrip-tion, social forecasting, the analysis of social and political impacts, and policy analysis" ( $p$. 153); the examples described earlier illustrate these lacks. Porter et al. also note a lack of "historical perspective" (quoting Lynn White, Jr., p. 153), which may be illustrated by the assessments describing offshore leasing programs (Bureau of Land Management, 1977) and an urban incinerator (Portland Metropolitan Service District, 1976), both of which treated the projects as if they were being implemented in an historical vacuum. Anthropologist Bodley expresses the concern that future needs are "characteristically identified on the basis of current cultural conditions and past trends" with little consideration for the dynamics of culture change (Bodley, 1976: 218). As a result, for instance, it is assumed that oil will continue to be consumed and garbage produced at current rates (or will increase at current rates).

Length of Reports. Other content concerns emphasize the unnecessarily lengthy reports. Dickert and Jorgensen raise the issues of "padding" and "a strong natural tendency 
for public agencies . . to present their project in the most favorable perspective", as factors that reduce the usefulness of the EIS to the decisionmaker, as well as the credibility of the impact assessment process $(1974: 37$ ). It is not unusual, for example, for a report to have negative impacts buried in a list of seemingly unimportant details while positive impacts are displayed prominently in an executive summary. In the early days of impact assessment, when a study might be as long as fourteen volumes, this technique has been particularly effective.

Lack of Synthesis. Selena Bendix (1980) states that the training of the assessment's team members in single disciplines lead them to prepare sections of the report individually, each section detailing the concerns of a team member's discipline. In such cases, says Bendix, the authors have typically

written something appropriate for a professional journal, but . . have become unintelligible to the members of the community activist group, . . . the city council members . . . who would like to have an informed opinion and be able to answer the questions of their constitutents, and the decisionmakers who have to decide whether to approve.. . (Bendix, 1980: 19)

The resulting whole lacks a synthetic statement of the relevant issues and options, as well.

Process Concerns. A number of process concerns have been expressed, as well. Bodley comments on a "tendency to deemphasize the cultural implications" of an innovation and the effects of specialization on the research. "Problems," he notes "are seen in isolation... [hence] their 
aggregate consequences and implications may be overlooked" (1976: 219). Thus, for example, the study of solar photovoltaics--a step to individual energy self-sufficiency --does not include descriptions of other steps in that direction and so does not address the cultural shift to self-sufficiency which solar photovoltaics may help to create.

Revised Guidelines. In their 1980 regulations for EIS's, the Council on Environmental Quality has taken note of these criticisms. CEQ regulations include specific instructions for "reducing paper-work" and "reducing delay" in the research and review process (1980: 1500.4). CEQ has implied a number of specific criticisms of the IA process through their use of such phrases as "reducing the length of" and "preparing analytical rather than encyclopedic" impact statements, as well as "following a clear format", "reducing emphasis on background material" and "emphasizing interagency cooperation . . rather than adversary comments," (1500.1 - 5). These regulations, if enforced, may significantly reduce the amount of effort required by the decisionmaker to understand the assessment, but they address only some of the concerns expressed in the literature.

Underlying Problem Areas. Other areas of concern include a lack of social forecasting, insufficient identification of impacts, inadequate models of social and 
cultural change, treatment of problems in isolation, wordiness, and lack of timeliness. According to Joseph Coates, then director of NSF's Technology Assessment Program*, these concerns result, in large part, from five basic process problem areas. These are (1) interdisciplinary team research, (2) identification of impacts and (3) their evaluation, (4) drawing conclusions and making recommendations, and (5) the writing, presentation, and communication of results (Arnstein and Christakis, 1975). Of these, Coates states, problems in interdisciplinary team research are fundamental, as differences in language and thought patterns associated with the different disciplines tend to lead to a breakdown in communication and a lack of unity in reports. This problem usually becomes apparent in the type of report described by Bendix, above.

Coates' other problems have been the basis for much of the critical literature on impact assessment. Current methods for identification and evaluation of impacts are inadequate for the nonquantifiable social forecasts and resultant impacts. Problems of interdisciplinarity combine with this lack of adequate forecasts to prevent the team from developing the clear image of the study's results necessary to draw conclusions and make recommendations, or to present either effectively.

* Coates later became Director of the office of Technology Assessment and currently owns a consulting firm specializing in technology and other forms of impact assessment. 
Methodological Concerns. Porter and his colleagues document a number of specific methodological criticisms from practitioners. These include:

1. arbitrary weightings of cost-benefit variables

2. averaging out of costs and benefits per capita

3. quantitative treatment of subjective probability ratings which permit them to "take on a life of their own"

4. a "lack of conceptual advance in development of methods [as opposed to imcremental improvements in techniques]" (Porter, et al, 1980: 462-464)

of the problem areas most frequently mentioned in IA critiques, identification and evaluation of impacts--and the societal forecast on which these activities depend--have been said to be the heart of the impact assessment process (Porter et al., 1980). As was illustrated in Table III, ( $p$. 38) these activities, though present in all of the published guidelines, take on different forms in each. Identification and evaluation are, in Porter's terms, "the least developed components of the assessment process" (1980: 58). Another writer suggests that they proceed "without any standardized method and with serious analytical deficiencies" (Peele, $1980: 6)$.

Participants in Arnstein and Christakis' workshop also identified these concerns, stating that while there are numerous methods for the analysis of quantifiable impacts such as those on resources, demographics, and economics, there are none that permit the quantitative measurement of significant social impacts such as institutional shifts 
(Arnstein and Christakis, 1975). Many impact assessments, therefore, have neglected social impacts entirely. Others have limited discussion to those economic and demographic impacts for which there exist both baseline data and a substantial body of theory and methodology. Still others have substituted "generalities and disclaimers" for credible forecasts and impact analyses (Dickert and Domeny, 1974: 135). According to C. P. Wolf, the effect has been that As matters now stand, even if responsible agencies and officials know they should take account of social impacts, they are far from confident about how this might be done and what to do with the results (Wolf, 1980: 32)

The problems associated with identification and evaluation of social and other qualitative impacts, therefore, are crucial to the utility of the IA report. They are compounded by and contribute to: problems of interdisciplinarity, a lack of historical perspective and knowledge of cultural change processes, and an encyclopedic rather than analytical approach to presenting results.

The Call for Alternative Approaches

Taken together, such criticisms reflect fundamental lacks in impact assessment as currently practiced. They suggest that the hope and dream that led to the establishment of impact assessment as a legally required activity have come far short of being met. Recognizing this, new reports and guidelines are calling for a new approach (see Porter et al., 1980; Linstone, 1983)--one which enables decisionmakers to develop an intuitive understanding of the 
innovation-in-context so that its impacts are easily grasped.

These new reports assert that the traditions of the disciplines and backgrounds of the investigators have led to assessments with a limited perspective. They state that the typical "techno-scientific" perspective in which impact assessments are conducted (Linstone, 1983) sees situations only as problems to be solved; offers only quantitative analysis as the tool-set to solve those problems; ignores the individual in the interest of statistical averages; and pretends that investigators can be totally objective about whatever they study. The result, these reports state (and the above review of the critical literature supports), is an assessment that is presented in quantitative terms, with numerous generalizations and abstractions, and without a clear presentation of the consequences of alternative actions.

These reports call for a new, enlarged perspective that considers individuals and values as well as artifacts in the IA process, that recognizes that much information of value to impact assessment is nonquantifiable, and that permits-even encourages--subjectivity in the investigator, the decisionmaker, and the people being investigated in developing IA results. The reports suggest that assessment is "as much art as science" (Porter et al., 1980) and offer the possibility of drawing on other disciplines as a source of material and methodology for the assessment process. One 
such discipline is literature, and in particular, the form of literature that describes hopes, fears, and possibilities for the future. 
CHAPTER I I I

EXTRAPOLATIVE FICTION

Over the late 1960s and the 1970s, while impact assessment was emerging as an institutionalized activity, fiction about the future was becoming a major literary form in our society. One historian of the field, I. F. Clarke (1979), points out that such fiction--which he calls futuristic fiction--has been a literature based in and expressing the hopes and fears of society for many years. Drawing on the "most recent inventions and social changes" as its source, Clarke states, such fiction has typically reflected its authors' perceptions of the relationship between science and society at the time of writing (Clarke, 1979). Alongside the technical-academic reports of professional futurists, he goes on to state, futuristic fiction has emerged in a variety of forms, including utopias, dystopias, "imaginary war" stories, science fantasy, and realistic science (sometimes referred to as 'hard' science) fiction.

This chapter reviews suggestions that futuristic fiction may be considered a potential tool for the policy sciences in general and examines an emergent form, called here 'extrapolative' fiction, as a possible analog and tool for the special field of impact assessment. 
FUTURISTIC FICTION AS A TOOL FOR THE POLICY SCIENCES

A number of policy science educators and practitioners have recommended futuristic fiction as a useful tool for studying and practicing the policy sciences. Through the 1970s, many new classes, texts, and anthologies were created, using carefully selected stories to demonstrate possible relationships within disciplines. For example, political scientist M. H. Greenberg, in collaboration with anthologist Patricia Warrick, produced an anthology of short stories exemplifying the principles of political science and illustrating some possible developments in political systems (1973). The Sierra Club commissioned anthologist Terry Carr to put together a collection--made up of stories published in earlier anthologies--about "problems of our immediate future". They hoped that such works might, in the same way that the early space travel stories encouraged readers to become actively involved in astronautics, motivate "people to devote their working 1 ives to solving environmental problems" (Carr, 1980). Some years earlier, the Council of Planning Librarians published William Rabiega's bibliography "Environmental Fiction for Pedagogical Purposes" as an aid for instructors in urban planning programs (Rabiega, 1974). Both Greenberg and Rabiega are explicit about their reasons for using this form of literature in the classroom. According to Rabiega,

First, the literature contains expressions of those future conditions which are most feared or desired by 
the elements of the population the authors have given voice to in their prose. Thus, they set some loose parameters on the types of policies those who can affect the future through their current administration might consider. Second, they represent entertaining portrayals of possible futures against which current environmental information and trends may be compared to teach about these contemporary situations (Rabiega, 1974: 4).

For these reasons he specifically recommends the use of such fiction in "future studies" or "man and environment" courses as an introduction to these topical areas within the more traditional disciplines. His bibliography is a tool to make such use more effective.

Greenberg also considers the fictional portrayal of developing trends as an important contribution to classroom study, along with the presentation of alternatives. Most importantly, however, he finds that "the student who encounters political theory only in a textbook tends to see it as already determined, fixed, and static," when the political process and the theory describing it are constantly changing and dynamic (Greenberg, 1973: 23). He suggests three ways in which this "emerging fictional mode" assists the student to understand political. theory. A story

(1) translates the abstractions.. . into particular situations and individuals that are representative of these concepts. . .

(2) can sharpen the [student's] awareness of technology's impact on . . . systems . . .

(3) [develops] flexibility in considering alternatives -. Greenberg, 1973: 27).

Carr and Rabiega have shown that these characteristics are also found in stories describing the concepts of and 
developments in ecological, social, and cultural systems. Effectively, then, futuristic fiction is an alternative mode for presenting and understanding the complexities of and alternatives for our culture.

Similarly, a number of policy analysts and IA practitioners have suggested that such stories might be useful to the policy sciences, and to impact assessment. SRI International's Ellen Heckler suggests that the genre is a "valuable source for policy research analysts" (Heckler, 1968: 16). Based on her analysis of some hundred novels and short stories, Heckler concludes that the writers have "been able to visualize technological trends, and to an even more accurate degree, they have been able to visualize social and cultural trends" in such a way that their works may be considered appropriate resources for policymakers and reearchers to use when considering the implications of present actions (Heckler, 1968: 18). She quotes an early issue of The Futurist, stating that the writer in this genre is valuable not because he predicts the automobile, but he may foresee the parking problem; not because he foresaw radio, but because he might have anticipated the soap opera. "Not the action but the reaction." (Futurist, 1967: 32; quoted in Heckler, 1968)

The potential value of such stories to policy science has been considered by others, as well. Anthony $R$. Michaelis, addressing the 1983 Annual Meeting of the International Association for Impact Assessment, suggested a possible "interdisciplinary correlation" between science fiction and technology assessment. He concluded that: 
in a certain number of cases. . a definite correlation exists between technology assessment and science fiction namely when the author of a fictional tale has thought through the full implications of his imagination. (Michaelis, 1983: 9)

He concluded with a request for "continuation of the experiment [ I have] here begun, as it may help the methodology of technology assessment" (1983).

During discussion following Michaelis' presentation, Joseph Coates indicated that his group had found using a fictional autobiography to describe the experience of using an emerging technology to greatly enhanced the utility of one of their reports.* Other participants were also intrigued with the possibilities, but were clearly at a loss as to what kinds of fiction to use or how to use it.

\section{Futuristic Fiction And Scenarios}

The question that must be answered before such uncertainty can be resolved is: what is it about futuristic fiction that causes these educators and practitioners to suggest that it may be useful to the policy sciences?

A step toward answering that question is taken by Porter et al. when they describe the potential use of 1984 as "a booklength scenario" (1980:153). A number of practitioners have used scenarios in impact assessment and other futures research activities (e.g., SRI, 1977; Krupka, 1974). Several sets of guidelines have suggested using scenarios to

*The report itself is proprietary and is not available for review. 
present such forecasts and enhancing the IA process (e.g., Armstrong and Harman, 1980; Mitchell et al., 1975).

These references suggest that the use of descriptive images of the state of society at some point in the future is an accepted practice in impact assessment. Moreover, such descriptions are recognized to be less analytical and quantitative in their development and presentation. Porter and his colleagues, summarizing the writers quoted above, state that "common sense, insight, and intuition are still the author's best guides" to developing and describing possible scenarios for the future (1980: 153). They go on to quote Ascher's (1978) description of the scenario as a "blend of insightful forecasting with storytelling" (1980: 151), suggesting a close link between scenario development and fiction.

There are four main characteristics linking futuristic fiction with scenarios. These include: the subject matter of futuristic stories, the language used to write them, the orientation or perspective the author takes in writing a story or novel, and the use of technically accurate detail to ground the story in known reality. These four characteristics also distinguish the fictional account from the technical or academic report in which the scenario is embedded.

Subject Matter. The first of these characteristics relates to fiction's subject matter. The subjects of futuristic fiction are of ten very similar to that of 
contracted policy studies. As speculations about the social and technological potentials associated with emerging innovations, policy studies and futuristic fiction have much in common. Rabiega, Heckler, Michaelis, and the others cited above have reviewed stories describing urban problems, educational systems, modes of transportation, and political processes. Based on those results, they emphasize commonality of subject matter when they propose the use of this form of fiction for instruction in and the practice of the policy sciences.

Language. Another characteristic mentioned by several of the policy scientists who have suggested futuristic fiction as a useful tool is fiction's ability to capture and hold the reader's interest, while conveying understandings of complex interrelationships. This characteristic is a function of the form of language used in fiction, what Embler has called the highly imagistic and subjective "language of the arts" (1966). In contrast, scenarios, impact assessments and other futures research reports are typically written in Embler's "language of reports," using objective, precise terminology and focusing on abstractions. The use of symbols, metaphors, and images in fiction lend a sense of concreteness to the material and shift the reader from the consideration of abstractions to the experience of a possible reality. Since the reader is experiencing that possibility, his or her attention is held. And since the interrelationships between the elements of the setting and 
the characters are presented through the use of commonly held images of concrete reality--rather than the abstractions, graphs, or tables found in technical reports and academic studies--they may be understood more readily by a reader not trained in interpreting such graphs and tables. Perspective. The third characteristic of futuristic fiction also distinguishes such tales from policy reports, by shifting the reader's perspective. Policy scientists are confined to, in Linstone's (1983) terms, the "technoscientific"--objective, problem-oriented, rational and analytical--perspective. The writers of fiction, on the other hand, use intuition and imagination from what Linstone calls the "personal" perspective. They describe individual human concerns--the feelings, changes in lifestyles, actions expected or required, etc.-- about and responses to innovations and their effects. This difference in perspective combines with the difference in language to provide for the reader a personal, concrete, and intuitive experience (hence understanding) of the innovation being described.*

Accurate Detail. Finally, the educators and practitioners who recommend the use of futuristic fiction in the policy sciences have suggested one other important characteristic of such fiction. This fourth quality is the use of technically accurate detail to enhance both the sense

*Charles Elkins (1976) calls this a "dramatic" model of future possibilities, as opposed to the "rational" models developed by policy scientists and futurists. 
and the possibility of reality in the story (Heinlein, 1965; Heckler, 1968; Warrick, 1980). Many authors of futuristic fiction draw on their own backgrounds and training in the sciences to develop explanations and useful gadgets for the situations they create in their stories. These explanations and gadgets add richness to the story while enhancing the reader's understanding of the story's focus--the impacts of the innovation being described.

\section{Forms of Futuristic Fiction}

Together, these characteristics explain the interest expressed by policy science educators and practitioners in using futuristic fiction in the study and practice of the policy sciences. They provide some guidelines for selecting fiction that may be useful to the policy sciences in general. They do not, however, address the question of which stories or novels may be useful to which fields within the discipline, or the more practical question of how to use them.

There are a number of forms of futuristic fiction that deal with times and places so far removed from present reality as to greatly reduce their utility to the study or practice of a given field. For example, the many "space operas" (e.g., Smith's Lensman series and Lucas' Star Wars) provide vivid opportunities for the imagination but may contribute little to the reader's understanding of how to deal with immediate issues. More realistic speculation, placed in far distant times and places (e.g., LeGuin's The 
Dispossessed (1969), or Asimov's Foundation Trilogy (1951, 1952, 1953)), may contribute to the reader's understanding of systems and processes, but do not typically describe immediately available policy options.

Clarke (1979), Suvin (1979), and others have divided futuristic fiction into the fields of utopias (including both positive and negative utopias), "hard", realistic, or speculative science fiction (which deal with the potentials associated with known scientific principles or emerging technological developments), fantasy (works placed outside of known physical or psychological constraints which may or may not depend on scientific or technological advances), and imaginary war stories (which extend current strategies, technologies, and tactics by introducing new ones or bringing up old ones to consider the possible outcomes of imagined battles). Clearly, selection criteria must be established if futuristic fiction is to be used effectively in specific policy applications.

\section{EXTRAPOLATIVE FICTION AND IMPACT ASSESSMENT}

The consideration of futuristic fiction as a useful tool for the policy sciences in general suggests that, for specific fields within the larger discipline, there may be specific forms of futuristic fiction that meet those fields' specific requirements. If a subset of this fiction were to be useful in meeting the special needs and requirements of impact assessment, such fiction should be limited to a 
timeframe and location equivalent to those of impact assessment. That is, it should deal with the next fifty years in a clearly defined locale on this planet. Moreover, fiction, to be useful to impact assessment, would have to be similar in scope of concern regarding the impacts of the innovation being described. Then, such fiction should be supported by sufficient accurate technical detail to be credible to the informed reader who is involved in the IA process.

Within the larger body of hard science, or speculative, fiction, there has been emerging over recent decades a group of works that explore the near-future consequences of current actions. These stories and novels look at political and social as well as technological innovations, and present scenario-like images of what is likely to occur in the next few years. Rather than create far-distant alternatives that might provide clearer perspectives on what is now, as most of the works published in science fiction journals currently do, these works extrapolate current developments into a cultural context that is changed only by those developments.

The favorite themes of this fiction, according to one critic, "involve the impact of developments or revelations derived from the human or the physical sciences upon the people who must live with those revelations or developments" (Rose, 1969: 5). Using the techniques and forms of one subset of futuristic fiction--realistic science fiction--as their medium, the authors extrapolate from issues and 
developments emerging now to systems and structures that might be in place some years hence.

Clearly, the authors who accomplish these tasks are more than skilled storytellers. One major author emphasizes the need for an "adequate knowledge of the real world, past and present," combined with "a thorough understanding of the nature and significance of the scientific method" to develop such scenarios (Heinlein, 1969: 26). Only thus, he states, can the author be in a position to logically extrapolate current developments and create a realistic context for them.

Those works that deal with the near-term future consequences of emerging issues and technologies I have called here "extrapolative" fiction (EF) as it deals with timeframes, locations, and problems that are comparable to those dealt with in the impact assessment process.

\section{PRODUCING EXTRAPOLATIVE FICTION}

The process of producing Extrapolative Fiction is highly individual and creative, yet relies on the long tradition and the analytic techniques of futuristic fiction. EF writers use a variety of models and engage in primary and secondary research to develop their stories and novels. A number of guidebooks have been published, (e.g., Block, 1969; Elrick, 1979; Bova, 1983) and other writers, critics, and editors often have strong views on how a story should be written to be both plausible and entertaining. Most of 
these apply to near-future extrapolative fiction as well as other forms of futuristic fiction.

The Editors

Perhaps the most significant of these other actors in the field of futuristic fiction are the editors, for unless they choose to publish a work, neither the fans nor the critics will comment on it. Over the last four decades a few editors have had a powerful effect on the development of futuristic fiction, through their work with writers and choice of works for publication. To a large extent, these men have shaped the genre, and more, have opened up new possibilities for authors and readers alike.

In 1938, John W. Campbell, Jr. became editor of the magazine Astounding Stories. Unlike editors of other pulp magazines at the time, Campbell refused to cater to his young audience's naivete. He insisted on a quality of logical and scientific coherence, or "reasonableness." $\mathrm{He}$ changed the name to Astounding Science Fiction and required that his writers describe plausible extrapolations of known scientific phenomena. This requirement ushered in a new phase of development in science fiction literature and reestablished futuristic fiction in this country. Under Campbell, technologies were the dominant theme in the story, and new, technically trained writers were fostered. Among others, these included Robert Heinlein, Isaac Asimov, L. Sprague DeCamp, A. E. van Vogt, and Theodore Sturgeon. Together they produced a body of work that inspired Ossip $K$. 
Flechtheim, coiner of the term "futurologist," to say that such fiction "may yield insights that are more revealing than the voluminous writings of learned system-builders" (quoted in Clarke, 1979: 273).

As an editor, Campbell insisted on stories with real people--e.g., housewives, crewmen, businessmen--instead of the cardboard caricatures of symbolic personalities which were the previous norm. One of his authors, Theodore Sturgeon, points out that what was required was

a story built around human beings, with a human problem and a human solution, which would not have happened at all without its scientific content (Platt, 1980: 64).

Campbell looked for stories and novels in which the use of a technology presented a problem to be solved, and which explored possible solutions in the context of a changing society. For this reason, one of his authors, Isaac Asimov, has said that "if Gernsback [the founder of Astounding] is the father of science fiction, Campbell is the father of social science fiction" (Asimov, 1972: 16). Campbell used his magazine to set the tone and, through it, provided his audience with consistently entertaining and rationally plausible stories about possible futures.

Over the years, Campbell changed the title and format of the magazine, as the new form of fiction grew and evolved. By 1960 , he said that the content of the fiction was analogous to science facts and called the magazine Analog, The Magazine of Science Fact and Fiction. He defined an analog as "a system which behaves in a manner similar to some other 
and less manipulable system so that it is easier and more convenient to study" (Campbell, 1960: v), and declared that the term was representative of the kinds of stories that he chose to print. Using the letters-to-the-editor column as a forum, he involved his readers in the change and selection process. Partly due to this participative style, by the mid-1960s Analog was, for most, the baseline standard for good science fiction.

With Campbell's heavy emphasis on science and technical accuracy, the stories he published often described changes in society that many people felt might be right around the corner. They often dealt with subjects like the problems and potentials of nuclear power, or nuclear war, or the effects of automation (in the form of robots). While this made his magazine particularly timely for those following the development and implications of new technologies, Campbell's journal was coming too close to a reality that many people were not comfortable with. Moreover, many of the stories tended to assume the current socioeconomic structure as a constant and history as repeating itself in clearly definable and recognizable cycles. As a result, editor Campbell was not providing room for the reader to hope or for the imagination to explore, and, more importantly, was not reaching some of the potential audience--those who were concerned with longterm social or ideological, rather than shortrange scientific or technological problems. 
Horace L. Gold, recognizing the need for science fiction with a more social orientation, began publishing Galaxy Science Fiction in 1950. He built on Campbell's efforts but emphasized possible social structures and political alternatives. Under editor Gold, writers such as Robert Sheckley, Cyril Kornbluth, Frederik Poh1, and Damon Knight began to develop an additional set of standards, outside of Analog's mainstream. In stories describing shifts in corporate power (e.g., Pohl and Kornbluth's Gladiator-at-Law (1955)) or the new forms of society to be formed in space colonies, they required accuracy in institutional and cultural as well as technological extrapolation. Gold's Galaxy provided the opportunity for exploring very different socioeconomic systems, either as extrapolations from the system of the time or as carefully constructed alternatives.

As a result, Galaxy encouraged the growth of social science fiction. New possibilities were opened up and many new writers entered the field at this point. Works such as Tiptree's "The Women Men Never See" (1968) explored gender relations in our culture by placing them against the context of extraterrestrial visitations. Other women writers created whole new cultures exploring the social implications of parapsychological developments (e.g., Bradley's "Darkover" series and McCaffery's "Dragonriders" series). The "New Wave" writers began to appear, including Michael Moorcock with his "Cornelius" series, Harlan Ellison with 
his "A Boy and His Dog" (a post-World War III story--1968)

and "Repent, Harlequin! Said the Ticktockman" (1969), and Thomas Disch with his "334" stories (1978). These new works, combined avant garde writing styles with biting social commentary and extended the genre still further.

By encouraging and publishing specific authors and styles, editors such as Campbell and Gold played a major part in defining the genre as a whole. Their editorial requirements and expectations motivated the writers to expand and enhance their knowledge and skills. Particularly for authors who "trained" under Campbell and Gold, these skills included the use of the scientific method in researching and structuring their works, the extrapolation of current social and technological trends, and the creation of plausible, coherent settings--or scenarios--in which human characters experience alternatives to present-day reality.

\section{Fans as Critics}

Then there are the fans. As noted by Elrick (1979), during World War II, one hundred fifty copies per month of Astounding were purchased by scientists at Oak Ridge National Laboratories within three days of publication. A few years later, in 1948 , a survey of one thousand readers found the majority to be male, between seventeen and twentyseven years of age. In 1961, Elrick states, a similar survey found that 85 percent of readers were only or oldest children who built their lives around "fanzines"--the 
newsletters prepared by and circulated among fans. By 1974, however, the average fan had matured. He was slightly over 26 ; 81 percent were college-educated males, and some 29 percent held advanced degrees.

Such "savvy fans", having read or viewed a piece of science fiction, conduct

an autopsy that's virtually a vivisection. God help any author or script writer who makes a technical mistake 'because they're on you like a pack of wolves' [quoting editor Ben Bova]... They demand accuracy--or at least a gestalt-like consistency--in supportive details . . . They regard the so-called space-opera' with scorn. . . Readers rightfully expect their pet authors to provide penetratingly fresh visions of $l$ ife presented via a wedding of the scientific and the aesthetic. (Elrick, 1979: 14)

This attention to detail means that, in order to convince an editor that one is publishable (i.e., acceptable to the fans) or to continue to sell, a writer must know and provide a plausible explanation for both the technological and social developments around which the story is built.

One long-established author, describing the process of writing fiction in this context, says that

speculative fiction is the most difficult of all prose forms. Not only does it require greater knowledge to do it well, greater imagination to make it rational and consistent. . But also, [the writer of l a speculative novel, to be entertaining, must. . . create the scene and the culture and make it come alive. . ( Heinlein, 1969: 35)

Heinlein distinguishes between the style expected of early authors writing for younger audiences and that demanded of a writer addressing a sophisticated adult audience:

it is not enough to say 'With a blast the spaceship took off for Mars.' Oh, it may do for comic books 
and for pulp magazines aimed at 10-year-olds, but not for serious literature; the writer must fill in this strange scene clearly enough to create empathy. . . he must do it without slowing up the story . . . he must get his gadgets in . . without getting them in the way of his human characters and their human problems--yet get them in he must, else the story takes place in a literary vacuum and suffocates at once! . . It still gives me headaches with each new story I write. (Heinlein, 1969: 36-37)

Clearly, special demands are placed on the authors of this genre--by the editors and by the readers--with accuracy, consistency, and a good idea being as important as a pleasant and entertaining style.

\section{The Authors}

The authors of extrapolative or other futuristic fiction create plausible and coherent environments based on more-or-less formal, logical "formulae" for social change. These contexts take the form of the setting for the story (which could be described as a scenario, or forecasting model, of the society) in which the responses and perceptions of the characters reveal something about the innovation, the particular context that the author has created, and the author's own experienced reality.

The authors of science--and especially extrapolative-fiction, therefore, tend to be scientists and engineers* whose interests go beyond the development of a technology to the implications of its application. As John Campbell pointed out, his publication was

* Most of the early EF writers have degrees in the physical sciences or engineering. More recent writers may have their degrees in one of the social sciences, instead. 
one of the few places in the modern world where a scientist is permitted to publish his speculations on what might be done with present scientific knowledge. (Campbell, 1960: vi)

This scientific awareness, together with the "intensiveness with which the writers are required to develop logical detail" by both their editors and their readers (Heckler, 1968), and a heavy emphasis on cognitive Iogic (Suvin, 1979), make the work of science fiction--and particularly near-future-oriented extrapolative fiction--highly plausible, and hence of interest to the impact assessment process.

\section{ALTERNATIVE VERBAL MODELS}

One framework for model use in research and analysis is illustrated in Figure 3 (Root, 1976). According to this framework, the investigator uses different model forms for different phases in the research and analysis process. In impact assessment, as illustrated by the figure, considerable attention is paid to the structural and dynamic models available for analysing systems. In both impact assessment and extrapolative fiction, the process of writing the report or story involves mental and verbal models almost entirely.

For fiction, the writer develops an idea and a set of images. He or she may write out a few descriptive notes or paragraphs and outline the plot. Then, if necessary, the writer may go to experts or related publications for supporting information. Such analysis and research contribute to the author's mental model and to the verbal model being created. As the writer proceeds, the story or 
novel that results may seem to take on a life of its own, extending the author's mental model as he or she sees the verbal model on paper.

Describing this process, Isaac Asimov, one of the bestknown and most prolific science fiction (and science fact) writers, says

When I am writing, I am fascinated by what emerges, for all of it is more or less unexpected . . . I am an interested spectator (in Olander and Greenberg, 1977: 203-204).

Clearly, the verbal models and mental models are working together to extend each other.

As an example, in an early work within this genre, written before the successful maintenance of the first atomic Pile at the west stands of the University of Chicago and updated in 1946, Robert Heinlein considered the impacts of the nuclear power plant (Heinlein, 1940; 1946). One of his characters tries to comprehend the nature of "the pile." As part of his process, the character asks a local merchant if he is not afraid to live so close to the nuclear power plant.

The tavernkeeper's eyebrows shot up. "Afraid of the pile? But it is my friend!"

"Makes you money, eh?"

"Oh, I do not mean that." He leaned toward them confidentially. "Five years ago I come here to make some money quickly for my family before my cancer of the stomach, it kills me. At the clinic, with the wonderful new radiants you gentlemen make with the aid of the Big Bomb, I am cured--I live again. No, I am not afraid of the pile; it is my good friend." "Suppose it blows up?"

"When the good Lord needs me, he will take me." He crossed himself quickly. (Heinlein, 1946: 43) 
In this fashion, Heinlein uses his own technical knowledge of the nature and potentials of nuclear reactors (consistent with the state-of-the-art in 1940-46), shifts his perspective to that of his characters, and permits his reader to "have a feeling for" the nature of the technology in question--both its destructive and healing potential.

A similar process, focusing on organizational developments, occurs in a recent story--specifically with reference to the possibilities of space industrialization. Author Charles Sheffield looks at emerging bureaucratic roadblocks through the eyes of two starstruck young men applying for a license to develop a new rocket propellant in the year 2005 (Sheffield, 1981). They are disillusioned by a sympathetic bureaucrat:

\footnotetext{
"I've been around this office for thirty-five years--as long as we've had the evaluation procedure. When I first started here, I read all the applications. . I'd take each application, and I'd study it for a day, maybe two days. For something like a propellant, I'd dig out the relevant patents, and the engineering handbook. Maybe do a few calculations, see if things seemed to be in the right ballpark. And you'd get an answer, yes or no. It took a week, sometimes two weeks, from start to finish."

"But we've waited over four months," said Len. see?"

"Right." A rueful smile. "That's progress, yer

Delso looked around his office, at the ranks of file cabinets, the computer terminal, and the elaborate multi-channel telephone. "I had none of this in the old days. Look at what we have to do now. Rocket propellant, see, first thing I have to do is look up the Industrial Codes. . . . That tells me which Government departments must be involved in the evaluation procedure, where they are, and so on."

"Hell, if we'd known that we could have contacted them before we sent in the forms," said Len. "We could have saved you a lot of time here."

"Not the approved method." Henry Delso poured tea into three chipped cups and pushed the tray forward.
} 
"Help yourselves to milk and sugar."

He picked up a cup. "I can tell you the complete list if you want it, but it wouldn't help you. The law says they have to be contacted from here, whether you talk to them or not. Let's look at just a few of them. Environmental Protection Agency, naturally-you have to get their approval, because you'll be releasing some substances into the air. It might affect the environment when you do the bench tests. Center for Air Quality, same thing applies to them. Food and Drug Administration"--he looked at them over the top of his thick glasses--"didn't think of them, did you?" You'll be working with new compounds, they'll want samples to test for the effects on humans, plants and animals. . . Then there's Defense, they have to be involved on anything that might have defense implications. Then, let's see, the office of Safety are on the list--with a new material test, they have to be sure there's no danger to workers who'll be involved."

"But we're the only two people who'll be involved!" Gary's eyes were bulging. "We don't want their stupid protection."

"Ah, but it's for your own good--you don't have a say in it. Where was I?" Delso leaned back, checking off his fingers.

"Health Department, naturally--they duplicate some . . but they have they're own checking system and that has to be followed."

Len Martello's scarred mouth was more twisted than usual. "I just can't believe it. You mean we have to get approval from all those groups... that we can't do any more testing until that's finished?"

"That's right." Delso handed him a cup. "All those groups--and we're just getting started. Equal Opportunity, there's a dilly for you. They have to be sure that your company will have a positive action program for minorities."

"But there's only the two of us in it!"

"Makes no difference, laws are laws. Then there's the Women's Civil Commission. They'll have to be satisfied that there's no sex discrimination in the operation--that's not considered the same thing as the minority question. Mustn't forget the Department of . . (Sheffield, 1981: 36-38).

And so forth. In this fashion, through the use of images and the creation of an experience, the reader is given a clear idea of where current trends may be leading in terms 
of bureaucratic process and the potential barriers being placed for new technologies emerging from small shops. As further examples of the effectiveness of EF stories in accomplishing this, the following paragraphs summarize several stories written between 1940 and 1970 and descriling innovations to take place prior to 1980 (See Table VI).

Transportation Stories

Possible developments in transportation technologies are common themes in science--and extrapolative--fiction. Typically, these stories focus on space transport devices, but a number of authors have explored the potential effects of earth-bound transports. The stories in this group are early works whose storyline is driven by a new transportation technology.

"Historical Note", by Murray Leinster (1951), presents a lightly farcical account of "what would happen if" a Russian scientist discovered a principle permitting clean, individual air-transport devices. The discovery is immediately declared a State Secret until the following May Day parade, when a battalion floats over Red Square in the devices. After that, although the principle technically still remains a secret, it becomes very difficult to keep the devices themselves inside the country. Soon, independent "garage shop" inventors up and down the West side of the Iron Curtain are turning them out--each new shop producing them for slightly less than the last, until, finally, the transporters are mass produced and sold on both sides of the 
TABLE VI

EXAMPLES OF EXTRAPOLATIVE FICTION

\section{TRANSPORTATION}

"Historical Note" Murray Leinster (1951)

"The Roads Must Roll" Robert Heinlein (1946)

Under Pressure Frank Herbert (1957)

$$
\mathrm{R} \& \mathrm{D}
$$

"The Mercenaries"

H. Beam Piper (1950)

"What Thin Partitions" Clifton \& Apostolides (1953)
NUCLEAR POWER

"Blowups Happen"

Robert Heinlein

$(1940,1946)$

"The Day of the Moron"

H. Beam Piper (1951)

"Counterspy"

K. Edwards (1953)

\begin{tabular}{|c|c|}
\hline \multicolumn{2}{|c|}{ SOCIETAL FORECASTS } \\
\hline OPEN SYSTEM & CLOSED SYSTEM \\
\hline$\frac{\text { Alongside Night }}{\text { J. Schulman (1979) }}$ & $\begin{array}{l}\text { The Sheep Look Up } \\
\text { John Brunner (1972) }\end{array}$ \\
\hline $\begin{array}{l}\text { Equality in the Year } \\
2000 \\
\text { M. Reynolds (1979) }\end{array}$ & $\underbrace{\text { Stand on Zanzibar }}_{\text {John Brunner }(1968)}$ \\
\hline $\begin{array}{l}\text { Commune, } 2000 \text { A.D } \\
\text { M. Reynolds }(1974)\end{array}$ & \\
\hline
\end{tabular}


Atlantic (and in Japan) for considerably less than the cost of a bicycle. In a very short time, land use patterns have been substantially altered, and national boundaries have all but disappeared. In the end, the scientist who made the discovery is wooed to the U.S., where he is kept in an isolation only differing from that he experienced in the U.S.S.R. in its comparative luxury--and in the absence of his favorite red cabbage soup.

The story explores the relationship between nationalism and controlled access. An omnidirectional, virtually undetectable transporter removes the control and invalidates the concept of border. In the story it

(1) makes it impossible to keep a standing (floating?) army

(2) renders border guards and customs officials useless

(3) eliminates mountains, rivers, and walls as barriers

(4) opens up whole new areas of wilderness, frontier and security sites to the general public

(5) makes rural and suburban, island, or wilderness homes reasonable for commuters.

Clearly, implementing the concept has the ultimate effect of completely changing the shape of the whole culture.

In developing this storyline, the author has assumed several behaviors as characteristics of human nature:

(1) soldiers will get out of duty if they can

(2) people will help them do so--especially if there's something interesting in it for them

(3) if it is produced once, someone else will figure it out again, cheaper

(4) if there's a market people will fill it 
(5) people don't need borders, only heads of state and their generals do.

The process Leinster describes whereby the fliers move from unique and expensive toys to the mainstay of a redefined cultural pattern is dependent on these assumptions. Interestingly, it parallels that of television in the fifties, stereos in the sixties, calculators in the seventies, and (apparently) microcomputers in the eighties. In all of these cases, a technology was introduced with an apparently limited usefulness and market, that for several reasons became incredibly popular, used for a significantly broader range of activities than expected, and led to the creation of a whole new subculture within the larger society while affecting numerous unforeseen aspects of everyone else's life.

Robert Heinlein's "The Roads Must Roll" (1946) is another story describing the new cultural patterns emerging from new transportation modes. Here, using a power source from an earlier story in his timeline ("Let There Be Light" (1940), describing photoelectric panels), Heinlein draws on the conveyor belt/"slidewalk" concept to create great bands of multiple spead "roads" that are the main distributors of people and goods throughout the country. Strip Cities, such as Diego-Reno and Chicago-St.Louis, form along these roadways, and people combine rural, urban, and industrial Iifestyles as they move at speads up to one hundred miles per hour between home and work, work and play, or one home and another. 
In this novella, Heinlein has created an image of a roaring mass of moving people and buildings that the reader can hear and feel, has introduced some of those who must Iive with that, and presented some of the major issues that must surround such a technology. Using the "out-of-towner" device for explanations, providing considerable foreshadowing for the story's action, and relying heavily on his own military experience and engineering training for the necessary realistic detail, Heinlein carries us through an engineer's strike that badly cripples the automated roadway. The technology is explained as the out-of-tovner encounters it. The political-technological infrastructure is an extension of the current Army Corps of Engineers, with an undercoat of Annapolis to provide the "esprit de corps" necessary to avoid future such incidents. The general social system is an expansion of our current freewayoriented commuter and trucker society, including "strip cities" (e.g., Diego-Reno, St.Louis-Chicago, San FranciscoLos Angeles), and chain restaurants.

Under Pressure by Frank Herbert (1956) is a novel describing the use of nuclear mini-submarines as undersea tugboats. It assumes that the United States' oil reserves are depleted and the military must mine the sea-bed off Eastern Bloc shores to maintain the needed supply. To accomplish this, the Navy has designed a special four-man nuclear submarine that can dodge enemy patrols crossing the Atlantic and can tow back a bag--a 
subsurface barge--full of oil. The problem which determines the storyline is that the last several subs have not succeeded, and the Navy leadership wants to know why. They suspect psychological problems, so a specialist in psychology and electronics is assigned to a sub crew with equipment that allows him to monitor the captain's emotional state.

The plot of the novel follows the psychiatrist's attempts to be effective in his position while the sub completes its assignment. Secrecy, of course, is absolutely essential to the success of the research--and of the mission (whose failure means certain death for the four men in the sub)--and maintaining secrecy is a primary source of tension for the story. The psychiatrist must keep his identity and research secret, the agent on board must be discovered even as he keeps his own identity a secret, the whereabouts of the vessel must be kept a secret from Eastern Bloc vessels, and the Navy's involvement in both the mission and the research must remain secret--even from the protagonist's wife.

A secondary source of tension lies in the fact that the sub is nuclear-powered and must travel through radioactive waters, making the crew's environment doubly hostile, and ensuring that any mistake means certain death--either immediately (under the ocean) or lingeringly (on land) from overexposure. Under these circumstances, strained relationships crack. The Captain's function is to keep the crew 
working together and, though the psychiatrist's job is to find out how the Captain does so, he himself cracks and ends up in a catatonic state, only to cone out of it as the sub approaches home base. He has learned much, however, and will ensure that some changes are made in the system to allow other captains to succeed as well.

\section{Research and Development Stories}

The period immediately following World War II saw the formation of many new independent and corporateowned "thinktanks." Research and development was seen as the basis for and backbone of industrial, hence economic progress. Seeing this, writers of the period began to explore the possible directions and effects of this new development. The following stories focus on research and development methods and structures in the context of our changing society. "The Mercenaries," by H. Beam Piper, (1950) provided a new idea in science fiction that has become a common idea for extrapolative fiction: looking at the politics of the research and development process instead of at the search for a solution. Rather than focusing on the crises that determine whether a solution can be found, Piper uses this story to look at who is doing the seeking and what their roles are and what relationships exist among themselves and with those governments or corporations who have hired them. 
The story takes place in the late 1960s or early 1970s. The main character is the leader of a team of independent contract researchers which includes basic and applied scientists--men and women of several nationalities, including his wife--who have been hired to "launch the first spaceship to reach the moon and build a fortress . . ." (1950: 63). The plot involves two main themes: (1, traditional) the identification of a spy; and ( 2 , innovative) the maintenance of the team's independent status, untouchable by any nation's laws except as agreed upon in their contract. As the story proceeds, it becomes clear that in order to $r$ aintain the group's independence and integrity, the leader must convince one of its members to acknowledge selling information from the team and to take the appropriate action to undo the effects of those sales. The whole team becomes involved, in various ways. Working with the local security personnel (who told them about the leak in the first place), they find out what form the information is going out in and begin to pass on "wrong" information. Paired interactions and smallgroups within the team increase the pressure on the culprit until, finally, he commits suicide in a way which permits the rest of the team to present it as a natural death to the press and as an execution to the concerned security personnel and their contractors. 
The identification of the channel by which the information has been leaked of the station remains to be solved, however, and the teamleader finally discovers the weak link in security--one which is totally invisible to the security personnel observing from within their system. In spite of detailed, even nude searches of all personnel entering or leaving the station, one car--the commanding officer's--enters and leaves without question. The leader points this out to the security personnel who apprehend the chauffeur. Now, saddened, though relieved, the team resumes work with their independence and integrity assured, and with a teamleader who wishes psychology were not as essential as his beloved physics to the effective accomplishment of his work.

"What Thin Partitions", by Clifton and Apostolides (1953), provides an interesting account of the protifris and possibilities associated with developing a product that has been observed to work but is lacking the theoretical basis to explain how it works or to effectively replicate it. The authors use the story to develop a caricature of the corporate research and development process, from the initial accidental discovery through the selling of the idea to the bitter realization that simply too little is known about the process to replicate it in a manufacturing setting.

The personnel officer of a manufacturing corporation has an idea based on observations of an employee's child 
and attempts to implement it in the corporation. Working with the Research and Develongert department and the chief executive officer, he attempts to recreate the observed situation so that others can develop a production process for it. A meeting with representatives of the Department of Defense ensures that there will be a market for the product, but, unfortunately, while he is negotiating the arrangements, the original behavior is elimimatrci and the process is no longer replicable.

Nuclear Power Stories

One of the exciting possibilities projected for the post-Hiroshima world was the "peaceful use of the atom;" specifically, the use of controlled nuclear reactions as a source of industrial heat and electrical power. Several EF writers saw the potentials for good and, at the same time, wondered about the potential problems associated with this new power source. Based on the theoretical understandings of the process then being published, these writers explored both sides of the question in some of the bestknown stories of the period. Stories by three writers are summarized in this section.

"Blowups Happen", written by Robert A. Heinlein in 1940 and updated in 1946, is one of the earliest EF stories. His presentation of the technology is limited by what was known at the time, but his presentation of the human problems associated withoperating ruclear power plants has been shown (by the experiences at Three Mile Island and of the 
Washington Public Power Supply System, among others) to be relatively accurate.

The story opens in the control room of an atomic power plant located in the Arizona desert. An engineer-operator has just been relieved of duty for behavior suggesting that he "had at last broken under the strain of tending the most dangerous machine in the world" (Heinlein, 1946: 6). The psychologist and the $\leftarrow$ Gineer he has asked to have relieved are to meet with the general superintendant. On the way, they are greeted by the secretary, a former engineer who "had suffered a blanking out of the ability to handle mathematical operations" (Heinlein, 1940: 9) and had been rehabilitated for office work.

Once in the office, the psychologist reports his obervations. In response, the general superintendent suggests that the engineer take a vacation, then take the psychometrical examinations or be transferred to another department. The engineer, however, points out that the strain of the job is compounded by the strain of being under observation all the time. The superintendent agrees, and decides that it's time to bring in the leading specialist in situational psychosis to help him find a solution to the problem of keeping his engineers from going crazy.

The engineer who has been relieved and his buddy decide that, as long as the engineer will be engaged in research, he should work on a problem they both are intrigued with: developing an "atomic fuel for inter- 
planetary flight" (Heinlein, 1946: 12). They proceed to set up a series of experiments to test the possible combinations of isotopes.

When the top man in situational psycums arrives, he is given a history of the plant and an outline of the problem, including the mathematics predicting a "dampening" effect in the plant's design that is predicted to prevent a full explosion should the fuel ever reach critical mass. They agree that although not enough is known about either human or subatomic interactions to make valid predictions, such predictions are necessary if people are to function, so the psychologist agrees to stay on and observe the situation for a few days.

Wandering around the plant, the psychologist happens into the two engineers' lab and causes a foul-up in their preparations which, amazingly, leads to the desired results--they have found a compound that might: work as a fuel. After several days of observing, listening, and reviewing files, however, the psychologist must report to the superintendent that "short of shutting down the ?wik there is no solution to the problem--none whatsoever!" (Heinlein, 1940: 20). At that point a Naval officer arrives--another mathematician. He, too, is particularly concerned that the plant should be shut down, based on his recalculations of the predictive mathematics the two had discussed earlier. According to his results, an explosion would not be dampenil, an: wi: is:stead lead to incompre- 
hensible damage. He insists that the plant be disassembled, immediately.

The three discuss the fact that since thirteen percent of the nation's power--that portion supporting much of the heavy industry in the country--is provided by the plant, it cannot be shut down, or if it were--given a profit-making board--it would not be for long. The psychologist redirects some of the officer's anger about the situation away from the superintendent by pointing out that

$$
\begin{aligned}
& \text { but with a political and economi cit, ion. - . . } \\
& \text { [Superintendent] King doesn't own that bomb out } \\
& \text { there; he's only the custodian. If he dumps it } \\
& \text { against the wishes of the legal owners, they'll } \\
& \text { simply oust him and put in someone more amenable. } \\
& \text { (Heinlein, 1946: 26) }
\end{aligned}
$$

The only possibility is to convince the Board of Directors that it is in their best interest to shut the plant down. When the superintendent and the psychologist try--and fail-to do so, however, the Board's response to llwir attempt is to accept the superintendent's (untendered) resignation, on the grounds that he has bad attitude.

At this point the two engineers announce their new fuel. They have succeeded in isolating a series of isotopes that can lift a rocket free of earth's gravititionili full. This revelation learis to a new plan: to set the power plant on a satellite and sell the isotopes generated by it (including the new fuel). The Board members object, again, seeing no reason w!y they should invest further in an already Iucrative venture. The psychologist only persuades 
them by threatening to destroy their reputations if they don't move the plant, and offering them full credit if they do.

This major crisis having passed, there is still the actual implementation of the plan. Fnough fuel must be produced by the plant to lift its mass into orbit, and facilities must be built to maintain it and its operators in orbit. Then, just as the tension reaches an intolerable level and an operator goes berserk, knocking out his observer, the word comes through. The superintmicent, in the control room to deal with the berserker, can finally "dump" the fuel into its storagt "ontainers, rendering it harmless until it is reassembled out in space. "The Day of the Moron", by H. Beam Piper (1951) was a classic in this group, and was the cover story for the September, 1951 issue of Astounding. This novella was written when the United States government was installing some of the first nuclear power plants and the "atoms for peace" movement was emerging. Like Heinlein's, the strry deals with the personnel problems in building and operating such a plant and, again, presents the technology as it was understood at the time of his writing, although with an insider's awd'en.ss of the potential dangers.

The opening lines are:

There were still, in 1968, a few people who were afraid of the nuclear power plant. Oldsters, in whom the term "atomic energy" produced semantic relations associated with Hiroshima. Those who saw, in the towering steam-column above it, a tempting target for enemy--which still meant Soviet--bombers and gnujled 
missiles. Some of the F.B.I. people who realized how futile even the most elaborate security measures were against a resourceful and suicidally determined saboteur. And a minority of engineers and nuclear physicists who remained unpersuaded that accidental blowups at nuclear-reaction plants were impossible (Piper, 1953: 13).

The next paragraph refers to "several nasty, meticulously unpublicized near-catastrophes" (Piper, 1953: 13).

In the opening description, the protagonist, an independent contracting engineer who specializes in cybernetic control mechanisms, is describur is "reviewing the eight different ways" a breeder reactor could go critical and "wondering if there might not be solve unsuspected ninth way" (Piper, 1951: 14). His primary concern is about "the ubiquitous lame-brain with a dangerous mechanism" (Piper, 1951: 14). To prevent this, he has hired a psychologist to function as a "dimwit detector" so that no one who does not think first can be placed in a critical position and cause the reactor to reach critical mass. The tests the psychologist will use are expected to lead to the dismissal of three or four workers out of a ti-nlil of about thirty. The union, however, is not about to run the risk of having any of their senior people declared mentally unfit to work on a nuclear power plant. Their violent reaction to the testing leads to the first confrontation. In defense of what has been called his "obstssion" about fools, the engineer points out that a worker "can go on for years, doing routine work heler supervision . . then, someday, he does something on his own lame-brained initiative, and when 
he does . . wholesale catastrophe" (Piper, 1951: 16). He bolsters his argument with the introduction of another thread in the story--the role the reactor plays in its environment. The engineer points out that when energy systems and communities were pretty well self-contained, people could do little damage, but that the scale and interconnectedness of the system, combined with the immense power of the reactor, makes a moment of foolishness extremely dangerous and the current situation ripe for disaster.

The psychometric tiest.s are given, over protests from the union leaders, and the work goes on. Equipment is being built and the reactor is being prepared to take it. One of the reactor cells (still graphite blocks, but containing breeder-fuel plutonium) is not emptied properly in the process, hut ariopriate corrective action is ordered before continuing with the installation.

When the psychometric test results come in, the two people to be fired are the union leaders--the ones who have objected most strongly to the testing. All work stops as the union leaders scream persifcution. The engineer arranges to bring in his own company technicians to install the equipment while the cell is still empty, then is called to a negotiation meeting with union and government executives in New York. As he leaves, he is informed that the union workers have countermanded his (I) ders and are reloading the 
reactor cell they were emptying so that his own people won't be able to work on it during the strike.

At the meeting, the engineer is, once again, required to defend his position regarding workers who don't think about the consequences of what they're doing. At the point in the conversation when the negotiator is asking what the engineer imagines might happen if someone did something stupid with the reactor, there is a sudden blast of light to the north. The plant blows up.

New York state is blasted with radiation and is completely without electrical power because "some moron-some untested and undetected moron--made the wrong kind of mistake" (Piper, 1951: 29), and reloaded an incompletely emptied cell in the reactor, bringing it to critical mass and destroying the centralized power source in a highly interconnected grid. The meeting is adjourned. As they work their way down the long, dark staircase and out into the darkened streets, the engineer considers the fate of a city "that had put all of its eggs in one basket, and left the basket in the path of any blundering foot" (1951: 34). K. Edwards" "Counterspy" (1953) also deals with the problems surrouncing atomic piles, though in this case the pile is only secondarily a power generator: its primary purpose is for weapons research. The security precautions are similar to those described in the other stories, however. The site is removed from other habitation. The perimeter is fenced and guarded. Only those with clearances 
city "that had put all of its eggs in one basket, and left the basket in the path of any blundering foot" (1951: 34).

$$
\text { K. Edwards' "Counterspy" (1953) also deals with the }
$$

problems surrounding atomic piles, though in this case the pile is only secondarily a power generator: its primary purpose is for weapons research. The security precautions are similar to those described in the other stories, however. The site is removed from other habitation. The perimeter is fenced and guarded. Only those with clearances may enter the plant area. Security personnel monitor most personal as well as professional activities in the plant area.

There are two main questions dealt with in this story: (1) what are the mechanisms and the consequences of sabotage? and (2) is there such a thing as "enough" security where nuclear plants are concerned? Clearly, there is a high degree of similarity between this and the two stories already discusses. The primary difference between them is one of focus. The first two are concerned with the consequences and prevention of accidental blowups, while this one deals with the prevention of intentional blowups and the consequences of the actions necessary to that prevention.

This story, written in 1953, takes place a very few years later--sometime in the late 1950s. (The characters, in their mid- to late thirties, are World War II veterans who went through college on their G.I. benefits.) Because it 
was written later than the other two, the technological descriptions are more sophisticated. Rather than graphite bricks, stainless steel slugs contain the uranium. Steam turbines, rather than direct conversion, generate the electricity, while the water cools the reactor coolant-liquid sodium. Pencil dosimeters, rather than clock times, are used to measure exposure. Finally, several levels of failsafe mechanisms minimize the potential for the kinds of problems dealt with in the other stories. But still, weak points exist, and again, human frailty is the one unpredictable determinant.

The story opens with a team of technicians practicing the discharge process, using a "dummy" slug to develop their skill with the specialized tools and techniques. As the plot unfolds, the protagonist--a physicist--is informed that there is a traitor in their midst, someone who has managed several minor accidents and is trying to destroy the reactor. The physicist is told that he is expected to help identify the man responsible, and, if possible, stop him from succeeding. The question of who the traitor might be colors his thoughts and experiences for the rest of the story, as he interacts with his team-mates in a variety of social and work settings (interestingly, none including women).

Not surprisingly, relationships become strained, and the feeling of pressure mounts up until the protagonist finds himself locked in the reactor room with the signaling 
device broken and the slugs (real, this time) about to be discharged. Someone is determined to prevent him from discovering who the traitor is, and is willing to kill him to do so. Even as he makes himself heard and is rescued, who that person might be dominates the physicist's thoughts, and when he observes himself going through the habitual motions of washing the radioactive dust of $f$ his hands and removing the protective covers from his shoes, the means for answering the question comes to him. His assailant did not stop to clean up, and therefore has left an invisible trail of radioactive particles behind him in the hallways. He grabs a geiger counter and some of the everpresent (except when you need them most) security guards to identify and take into custody the former friend and co-worker who nearly became a murderer in his attempt to destroy the plant. However, how the assailant was going to do so remains to be discovered. Finding it provides a secondary theme for the story, as the protagonist and the security personnel work through the alternatives. After lengthy discussions of what might and won't work, they finally hit on the one that will. They find a few tools near the heat exchanger, a small bomb in the gridwork of pipes containing liquid sodium and immersed in the water bath which simultaneously cools the coolant and turns into high-pressure steam to run the generators. A few broken pipes here would, very simply and elegantly, destroy the reactor and probably cause the whole plant to blow up. So the physicist and security chief 
retire to figure out how to secure that weak spot, and wonder what others there might be.

These stories each describe a (when they were written) not-yet-existent technology--nuclear power reactors--from the point of view of the people who must work with them on a day-to-day basis. In doing so, they provide insights into the problems and emergent issues associated with the technology that are likely to arise from human actions, interactions, and responses.

\section{Societal Forecasts}

Another type of story that may be considered here is the "whole body projection," in which the author attempts to portray life in a society that is extrapolated as a whole from his own. In many ways, this form is most like the scenarios currently being used in impact assessments and other policy research documents. Over the late 1960 s and 1970s, during the period of expansion for futuristic fiction as a whole, a number of novels of this type were published,* examples of which are listed in Table VI (p. 73). They are typically full-length novels, tracing one character's coming-to-terms-with the nature of that society. Moreover, they generally conform to one of two of Warrick's (1980) classes: those based on what she terms an "open" system model, and those based on her "closed" system model.

\footnotetext{
*Until that time, the market for futuristic fiction was limited to short stories. It took increased public interest to persuade publishers to buy novels.
} 
between ordering it and its arrival his appetite seemed to be eroded by apathy. He put on a record he had bought and sat down to watch the play of colour on the screen which matched the music; it had hardly begun before he was on his feet again... [S]omeone had persuaded him to get a polyforming kit. He opened its box and cosidered starting a copy of Rodin's Kiss, but halted his hand in mid-movement and let the 1 id fall shut again. . . .

He was suddenly appalled. These days, a great many people never left their homes at night except for some specific purpose, when they could call a cab to the door and expose themselves for no longer than it took to cross the sidewalk. It wasn't inevitably dangerous to wander the night streets of the city--the hundreds of thousands who did still do so were proof enough of that. In a country of four hundred millions there were two or three muckers per day, yet some people acted as though they couldn't get past the next corner without being attacked. There were rollings, robberies and rumbles; there were even riots.

The habit had settled on Donald's mind unnoticed, like gradually thickening fog. He had stopped going out after six or seven in the evening for the mere sake of not being at home. . . And [when he did] the cab that came to fetch them was driven by a man or a woman secure behind armoured glass, its doors could only be opened from the dashboard, and affixed to the neat little nozzle of the air conditioning system was a certificate stating that sleepy-gas cylinders had been approaved by the City Licensing authority. For all its smoothness and fuel-cell silence, it was like a tank, and encouraged the feeling that one was venturing on to a battlefield. (Brunner, 1968: 128129)

Later, another character states the case at a larger level

of focus:

Why do you think you get such a generous trade-in allowance when you switch from next year's model of some gadget to the year after nexts's? Because some of the parts are going to be put right back into the new sets, and what can't be cannabalised will be sold as precious--I repeat precious--scrap.

The biggest single building project in this country right now is costing a hundred million buckadingdongs. What do you think it is? You're wrong. It's a jail.

Friends, you don't have to go to India or Africa to find people existing on the borderline of poverty. You are. Our resources are stretched to the point where reclaiming a gallon of water so someone can 
drink it a second time costs eleven times more than it did in 1960. TV you can live without, a phone you can live without, but water? Uh-huh! We don't starve to death but if you want a diet that's fit to match your unprecedented tallness and muscularity you pay . . like nine or ten times [as much as your grandfather] depending on how you take your vitamins and other supplements. (Brunner, 1968: 353)

This diatribe concludes:

Did you ever wonder how a doctor feels, faced with a disease he can't cure, which he knows is so contagious he's liable to catch it off the patients he can't help? That's me at this minute.

There seems only one thing to do, and that's get drunk. (Brunner, 1968: 435)

And, in this dying world, there are plenty of ways to alter consciousness, some of which, it seems, are the causes of the very violence they are taken to avoid. There is no way out of a closed system.

In contrast, the "open" system stories in this group are those which are based on the possibility of a solution to current social and environmental ills. Schulman's Alongside Night, (1979), with its "agorist revolutionary cadre" ousting the existing corporate-political power structure epidomizes this group. In this novel, people who believe in a free market structure (hence "agora") build an underground economy replete with underground marketplaces. This set-up means that, when the existing structure finally gives way under the force of hyperinflation, a new structure is ready to take its place, in an information-based transformation of the politico-economic structure. By including the possibility of new ideas, and of new energy to 
implement those ideas, Schulman rejects the "closed" system hypothesis of Brunner and other similar writers.

Another "open" system writer is Mack Reynolds, who has written a series of books taking place in A.D. 2000. In each of these, he explores the texture of life in the society he has projected.* Equality in the Year 2000 (1979) (modeled after Bellamy's Equality (1893), a classic of the 19 th century) provides a view of life from the perspective of a university professor's family. Commune, 2000 A.D. (1974) contrasts that life with the lives of those "on the dole"--who are not called for jobs.

In Commune, the main character is an anthropologist with a Ph.D. who must complete another degree to be given a position. He is asked to research the communes that surround the towering cities as a possible topic for his thesis. The request is seconded by the head of the National Data Banks...

He began to see some of the reasons why George Dollar was anxious to get more material on the communes into his data banks. Why, whole new ways of life were developing in them. . .

"I'm in rebellion because I can't get a job. I'm ashamed to take my Universal Guaranteed Income. But here you are saying that this whole commune wouldn't do their share, even if requested [on job muster day ]."

"You're doing your share... . You're trying to work. So are all the artists in New Woodstock. It's just that the human race has gatten to the point where practically no work is necessary to produce plenty.". . (Reynolds, 1974:60-61)

*Reynolds' interest is econometrics, which provides the basis for most of his work. 
So less than ten per cent of the people work, and the rest are free to live the Iife they choose. There is a flaw in this utopia, however: if a citizen chooses not to take a job in production or administration when called for it, he or she loses all citizen's rights, including the Guaranteed Income.

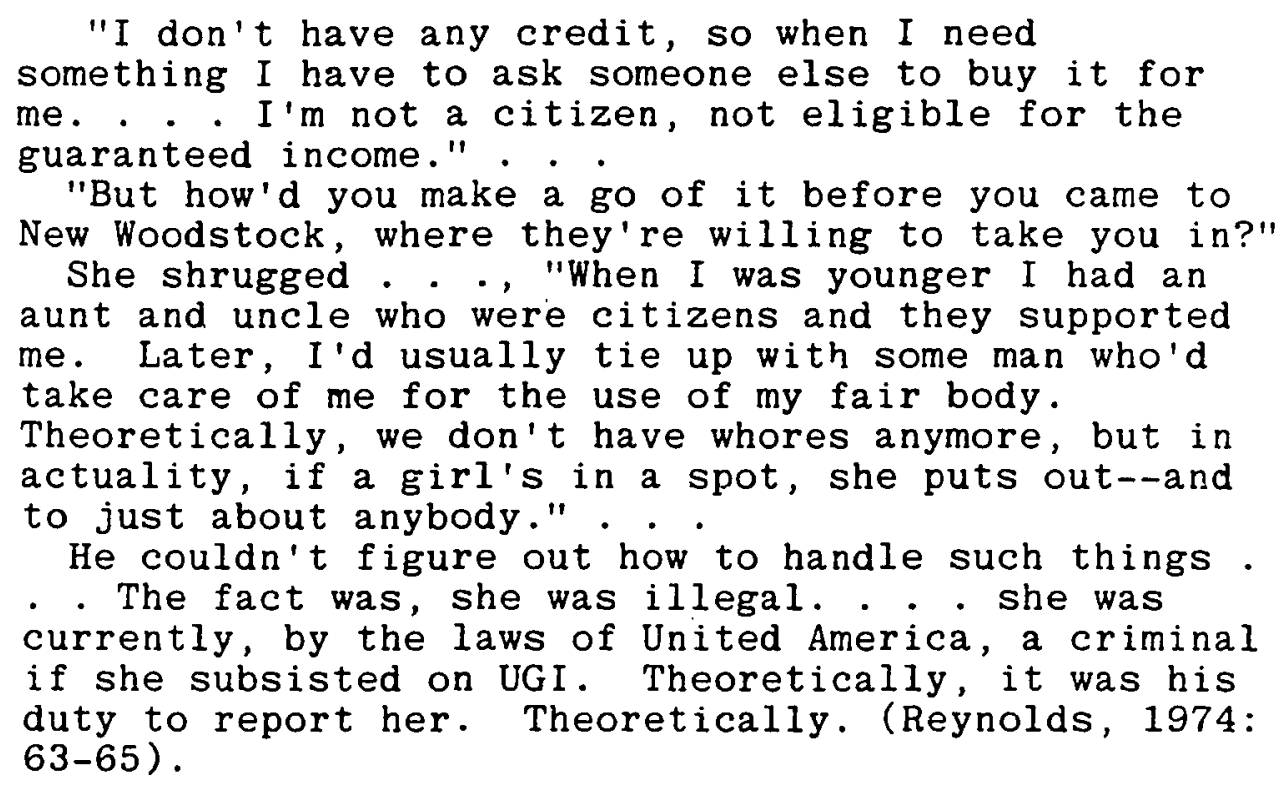

In this fashion, Reynolds clearly shows the potential social

and personal consequences of current socioeconomic trends,

illustrates the systems law that apparent solutions

usually bring on new problems of their own, and offers a new

form of solution--the mutual support of the communes.

Such fiction draws on personal feelings and experiences

to present insights about the technical, economic, and

institutional aspects of our culture. As the authors create

an experience for the reader which parallels their own

personal, imagined experience, they produce a work of

fiction. As their own experience is founded in technical 
understanding and rational extrapolations of emerging technological, economic, and institutional possibilities, EF writers produce a work that may be useful to those whose role it is to make decisions about those possibilities. As they describe such experiences in a story, these writers create a work of extrapolative fiction which is at once entertaining and informative, capturing the reader's attention, engaging the imagination, and providing an alternative image of future possibilities for the reader to consider. These alternative models, then, have the potential for communicating to decisionmakers insights that may not be communicated through the traditional verbal models in impact assessment: the technical report or academic study. By focusing on the individual human being's experience of an innovation and using the language of the arts to examine the near-future effects of innovations within a clearly defined locality, extrapolative fiction appears to have some potential as a useful tool for ameliorating some of the criticisms of impact assessment described above. 
CHAPTER IV

\section{COMPARATIVE ANALYSES OF IMPACT ASSESSMENT \\ AND EXTRAPOLATIVE FICTION}

A comparison of EF stories with IA reports addresses the question of whether extrapolative fiction can enhance impact assessment by identifying those content areas in which IA reports are lacking and those which EF stories may include. In this chapter, three analyses are described, comparing EF stories and IA reports in increasing detail. The first of these analyses compares the mean numbers of statements that describe impacts by category in a representative sample of EF stories and IA reports, with a $\underline{t}$-test establishing the significance of the differences found between the two samples. The second analysis examines a set of EF stories published between 1940 and 1975 (describing a number of innovations to take place prior to 1980) and traces the themes and concerns described in those stories through the journals to test those stories' effectiveness in identifying emerging policy issues issues. The third analysis compares three EF stories focusing on nuclear power plant technologies to historically significant IA reports on the same subject, demonstrating the degree to which the extrapolative fiction complements the impact assessment in the types of impacts described. Together, the three analyses demonstrate the degree to which extrapolative 
fiction and impact assessment overlap and differ in their descriptions of impacts of innovations.

\section{STATISTICAL CONTENT ANALYSIS}

A statistical content analysis of a representative sample of works in extrapolative fiction and impact assessment is one way to test the degree of similarity and difference between the two. Such comparison provides a quantitative test of the hypothesis that EF stories raise issues and clarify concerns that are not now included in the impact assessment process.

\section{Methodology}

The methods used here to analyse EF stories and IA reports conform to the standard content analysis procedure illustrated in Figure 4, where messages from two sources are compared to identify differences between the two sources.

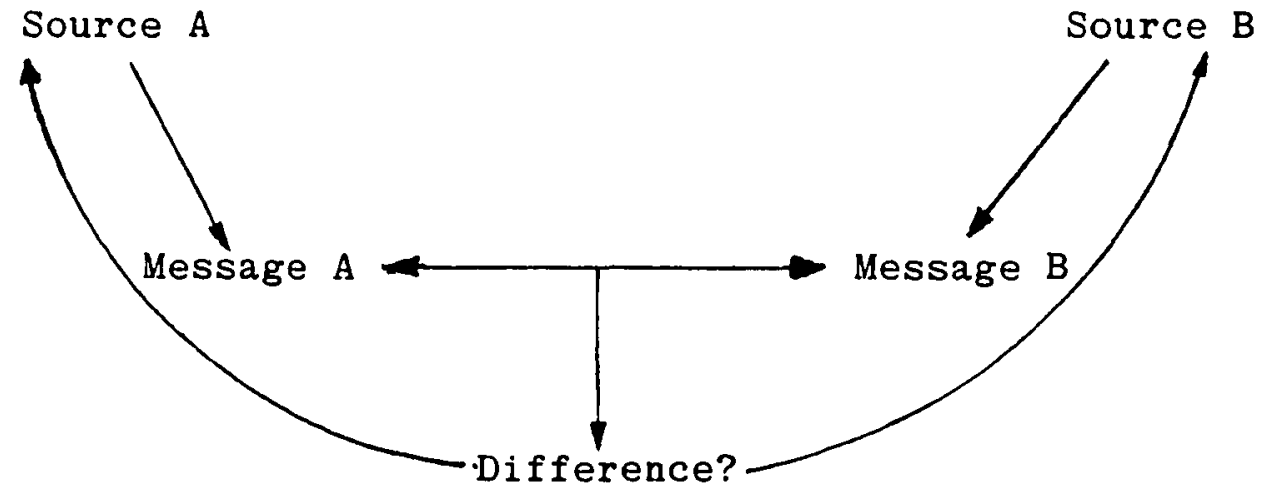

Figure 4. Content Analysis Procedure, in which the contents of message $A$ are compared to the contents in message B to learn about the sources. (SOURCE: Holsti, 1964) 
In this analysis, EF stories and IA reports were analyzed to identify statements describing impacts of the innovations under study. For the purposes of this research, statements were defined as sentences, phrases, a line of cells on a table, lines or bars on a graph, or descriptions of behaviors that depend on impacts not explicitly described in the text. The statements were tallied and categorized according to impact area described and the mean number of statements in each category was compared for the two forms. A t-test, establishing the statistical significance of the difference between the sets of means, was used to identify the areas of similarity, difference, or complementarity between the works of fiction and the IA reports.

Samples for this analysis were selected on the basis of recommendations in the literature (Greenberg and Warrick, 1973; Porter et al., 1980; Linstone, 1981) and from practitioners in both fields (Rabiega, 1979; Heckler, 1981;

Lehnhoff, 1982) as being exemplary works of their type. As listed in Tables VII and VIII, eleven IA reports and ten EF stories were analysed in this task. Of the reports, six are technology assessments and five are environmental impact assessments. Of the fiction works studied, seven are short stories and three are short novels; all deal with specific innovations in the context of a society whose elements and relationships have been extrapolated from the present. The topics covered by both groups of works include programmatic, regional, local, and conceptual innovations. All of them 
TABLE VII

\section{WORKS SELECTED FOR THE STATISTICAL ANALYSIS:}

\section{IA REPORTS}

\begin{tabular}{|c|c|c|c|}
\hline AUTHOR & TITLE & BIBLIOGRAPHICAL DATA & PREMISE \\
\hline Foster, $K$. et al. & $\begin{array}{l}\text { A Technology } \\
\text { Assessment of } \\
\text { Guayule Rubber } \\
\text { Commercialization }\end{array}$ & $\begin{array}{l}\text { University of Arizona Office } \\
\text { of Arid Lands Studies, report } \\
\text { to N.S.F. "PRA 78-11632, Tucson } \\
\text { Arizona, May, 1980, pp } 149-183\end{array}$ & $\begin{array}{l}\text { production of rubber from } \\
\text { the guayule plant is com- } \\
\text { mercially feasible in the } \\
\text { southwestern U.S. }\end{array}$ \\
\hline Krupka, M.C. & $\begin{array}{l}\text { Technology } \\
\text { Assessment of Solar } \\
\text { Energy: Solar } \\
\text { Photovoltaic Energy } \\
\text { Systems }\end{array}$ & $\begin{array}{l}\text { Los Alamos National Laboratories } \\
\text { report to DOE HLA } 7866-T A S E \text {, } \\
\text { Los Alamos, New Mexico, } 1979 \\
\text { pp. } 16-40 \text {. }\end{array}$ & $\begin{array}{l}\text { widespread use of photo- } \\
\text { voltaic devices for } \\
\text { decentralized generation } \\
\text { of electricity }\end{array}$ \\
\hline Gordon, T.J. et al. & $\begin{array}{l}\text { A Study of Life- } \\
\text { Extending } \\
\text { Technologies }\end{array}$ & $\begin{array}{l}\text { The Futures Group reoprt to N.S.F. } \\
\text { *NSF-CIO34, Glastonbury, Conn., } \\
\text { also published by Pergamon Press, } \\
\text { Elmsford, N.Y., 1979, pp. 119-230. }\end{array}$ & $\begin{array}{l}\text { technologies are in use and } \\
\text { being developed which will } \\
\text { extend the lifespan of the } \\
\text { current population } 25-50 \text { yrs }\end{array}$ \\
\hline Burt, L. et al. & $\begin{array}{l}\text { Light Rail Transit: } \\
\text { the Eanfield }\end{array}$ & $\begin{array}{l}\text { Portland State University } \\
\text { Systems Science Ph.D. Program } \\
\text { Portland, Oregon, May, I979, } \\
\text { pp. A-3-IV-6 }\end{array}$ & $\begin{array}{l}\text { building a light rail system } \\
\text { between downtown core and } \\
\text { outlying suburbs concentrates } \\
\text { population }\end{array}$ \\
\hline Kaufman, E.L. \& & $\begin{array}{l}\text { Environmental } \\
\text { Analysis of } \\
\text { Fenton Hill } \\
\text { Hot Dry Rock } \\
\text { Geothermal Test } \\
\text { Site }\end{array}$ & $\begin{array}{l}\text { Los Alamos National Laboratory } \\
\text { report to DOE HA-7830-HDR, } \\
\text { Los Alamos, New Mexico, May, } \\
\text { 1979, pp. } 40-54\end{array}$ & $\begin{array}{l}\text { closed-loop cycling of cold } \\
\text { water through hot magma layer } \\
\text { produces electricity and } \\
\text { cascaded heat }\end{array}$ \\
\hline $\begin{array}{l}\text { Bonneville Power } \\
\text { Administration }\end{array}$ & $\begin{array}{l}\text { Environmental } \\
\text { Assessment: } \\
\text { Proposed BPA Region- } \\
\text { wide Weatherization } \\
\text { Program }\end{array}$ & $\begin{array}{l}\text { Bonneville Power Administration } \\
\text { Division of Energy Conservation } \\
\text { Portland, Oregon, April, } 1981\end{array}$ & $\begin{array}{l}\text { negative effects on health } \\
\text { from sealing/insulating } \\
\text { buildings may outweigh gains } \\
\text { from energy savings }\end{array}$ \\
\hline U.S. Forest Service & $\begin{array}{l}\text { Methods of Managing } \\
\text { Competition: A } \\
\text { Programatic Environ- } \\
\text { mental Impact Statement }\end{array}$ & $\begin{array}{l}\text { U.S.D.A. Forest Service, Region } \\
\text { May, } 1981 \\
\text { nt }\end{array}$ & $\begin{array}{l}\text { comparison of several ways } \\
\text { to reduce vegetation that } \\
\text { competes with forest growth }\end{array}$ \\
\hline $\begin{array}{l}\text { Land Mangement } \\
\text { Service }\end{array}$ & $\begin{array}{l}\text { Draft Environmental } \\
\text { Impact Statement: } \\
\text { Veterans Adminis- } \\
\text { tration Medical } \\
\text { Center }\end{array}$ & $\begin{array}{l}\text { Veterans Administration office of } \\
\text { Construction, Washington, } 0 . C \text {. } \\
\text { May, } 1979 \text {, pp. } 2-1--2-86\end{array}$ & $\begin{array}{l}\text { construction of a } 600 \text {-bed } \\
\text { hospital in a low-income } \\
\text { neighborhood }\end{array}$ \\
\hline Northern Energy & $\begin{array}{l}\text { Environmental } \\
\text { Impact Statement: } \\
\text { The Spring Creek } \\
\text { Project }\end{array}$ & $\begin{array}{l}\text { VTN Environmental Consultants } \\
\text { Oregon, 1979, Pp. IV-1 -- IV-6I }\end{array}$ & $\begin{array}{l}\text { a strip mine is placed near } \\
\text { the state line between } \\
\text { Montana and Wyoming }\end{array}$ \\
\hline $\begin{array}{l}\text { Office of } \\
\text { Appropriate } \\
\text { Technology }\end{array}$ & $\begin{array}{l}\text { Genetic Technology: } \\
\text { A New Frontier }\end{array}$ & $\begin{array}{l}\text { Hestriew Press, Boulder, Colorado } \\
\text { 1982, pp. } 242-254\end{array}$ & $\begin{array}{l}\text { patenting living organisms } \\
\text { has effects on research and } \\
\text { commercialization of rDNA }\end{array}$ \\
\hline Landis, R.C. & $\begin{array}{l}\text { A Technology } \\
\text { Assessment Method- } \\
\text { ology: Mariculture } \\
\text { (sea farming) }\end{array}$ & $\begin{array}{l}\text { The MITRE Corporation, report to } \\
\text { the Office of Science and Tech- } \\
\text { nology, PB 202778-05, Hashington, } \\
\text { D.C. June, 1971, pp. 70-95, 108- } \\
\text { I13 }\end{array}$ & $\begin{array}{l}\text { intensive seafarming could } \\
\text { alter third world's diet } \\
\text { and hence their economy }\end{array}$ \\
\hline
\end{tabular}


TABLE VIII

WORKS SELECTED FOR THE STATISTICAL ANALYSIS:

EF STORIES

\begin{tabular}{|c|c|c|c|}
\hline $\begin{array}{l}\text { Vinicoff, E. \& } \\
\text { M. Martin }\end{array}$ & Malthus' Last Laugh & 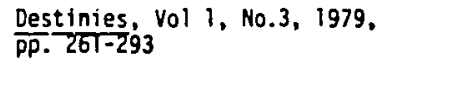 & $\begin{array}{l}\text { population growth and poor } \\
\text { harvests lead to a new solu- } \\
\text { tion }\end{array}$ \\
\hline Raphael, R. & Code Three & $\begin{array}{l}\text { New York, Berkeley Medallion, } \\
\text { 1967, pp5-57 }\end{array}$ & $\begin{array}{l}\text { continental thruways permit } \\
\text { groundspeeds to } 600 \mathrm{mph} \text { and } \\
\text { require special police }\end{array}$ \\
\hline Disch, T. & $\begin{array}{l}\text { Emancipation: A } \\
\text { Romance of limes to } \\
\text { Come }\end{array}$ & $\begin{array}{l}\text { in P. Sargent, Bio-Futures, New } \\
\text { York, Vintage, Tg76, pp. } 57-86\end{array}$ & $\begin{array}{l}\text { a marriage is saved when a } \\
\text { husband is given a test tube } \\
\text { baby to nurse }\end{array}$ \\
\hline Pournelle, J. & Power to the People & $\begin{array}{l}\text { in High Justice, New rk, Pocket } \\
\text { Books, TgT, pp. } 40-60\end{array}$ & $\begin{array}{l}\text { a nuclear-reactor-based } \\
\text { agro-industrial complex is } \\
\text { sited in the Namib desert }\end{array}$ \\
\hline Felice, $C$. & $\begin{array}{l}\text { No One Said } \\
\text { Forever }\end{array}$ & $\begin{array}{l}\text { in v. Kidd Milennial Women, New } \\
\text { York, Dell, T978, pp. } 5=20\end{array}$ & $\begin{array}{l}\text { a woman's career path breaks } \\
\text { up her family }\end{array}$ \\
\hline Heinlein, R. & Blow-Ups Happen & $\begin{array}{l}\text { in Expanding Untverse, New York, } \\
\text { Ace, } 1980,00.35-90\end{array}$ & $\begin{array}{l}\text { engineers at a nuclear power } \\
\text { plant behave stragnely under } \\
\text { the pressure }\end{array}$ \\
\hline Herbert, $F$. & Under Pressure & New York, 8allantine Bookes, 1978. & $\begin{array}{l}\text { oil shortage and war lead to } \\
\text { U.S. submarines pumping oil } \\
\text { off Soviet territory }\end{array}$ \\
\hline Asimov, I. & Evidence & $\begin{array}{l}\text { in I, Robot, New York, Doubleday, } \\
\text { ig46. }\end{array}$ & an andraid is elected mayor \\
\hline Dervic, $C$. & $\begin{array}{l}\text { Adrift on the Policy } \\
\text { Level }\end{array}$ & $\begin{array}{l}\text { in M.H. Greenberg and P. Warrick } \\
\text { Political Science Fiction, } \\
\text { Englewood Chiffs, New Jersey, } \\
\text { Prentice-Hall, } 1974, \text { pp.111-i27 }\end{array}$ & $\begin{array}{l}\text { a needed scientific advance } \\
\text { must be sold to each level } \\
\text { of decisionmaker before it } \\
\text { can be implemented }\end{array}$ \\
\hline Heinlein, R. & I Will Fear No Evil & New York, Berkeley Books, 1970 & $\begin{array}{l}\text { the C.E.0. of a giant } \\
\text { corporation has his brain } \\
\text { transplanted into a young } \\
\text { body }\end{array}$ \\
\hline
\end{tabular}


deal with a fifty-year-or-less time frame and directly extrapolate current sociotechnical parameters. Although the reports tended to considerably greater length than the fiction works, the sections describing potential impacts were generally comparable in length.

Table IX lists the impact descriptor categories used for the analysis. Derived from a combination of federal guidelines (Department of Agriculture, 1976) and suggestions from practitioners in the field (cf, Arnstein and Christakis, 1975; Enk et al., 1978; Porter et al., 1980), these categories represent general impact areas within which a variety of specific statements might be made. For example, category A.2, "Earth," includes any statement describing land use, soil availability and quality, radiation levels in the area, or presence of mineral resources. Category E.2, "Population," includes ang statements describing the innovation's effect on the size, age, mobility, or demographic structure of the population under study. Counting the statements in each of these sixty-one categories for each of the twenty-one works analyzed required the efforts of several people. Two coders were used, with the author spot-checking to ensure consistency between coders. Statements were counted if they were direct statements ("two hundred jobs will be created"), implied statements ("they avoided the radioactive areas along the roadway"), or were tabular data (typically a line across the columns in a matrix was counted as one statement). Among 
TABLE IX

IMPACT DESCRIPTORS F'UK STÄTISTICAL CONTENT ANALYSIS

IMPACT CATEGORY

A. PhYSical ENVIRONMENT

1. General

2. Earth--soil, radiation, etc,

3. Water-quality, temperature, etc

4. Atmosphere--air quality, climate

5. Geological Processes--floods, etc

B. BIOLOGICAL ENVIRONMENT
1. General
2. Flora
3. Fauna
4. Microorgani suls
5. Disease
6. rood chains

C. TECHNO-ECONOMIC ENVIRONHENT

1. Structures--design, use

2. Production systews--mining, etc

3. Utility networks--power sources

4. Transportation systems

5. Waste Disposal systems

6. Communication systens

7. Distribution systems

8. Employinent patter

9. Labor availability

10. Revenues

11. Capital availability

12. Market/property value shifts

13. Research and Development

14. Resource Supplies

15. Alternative market structures

16. Technological processes

17. General economy
IMPACT CATEGORY

D. SOCIAL EFFECTS

1. General

2. Population--density, mobility, etc.

3. Gender/race relations

4. Community growth

5. Institutional Shifts

6. Decisionmaking Processes

7. Relationship between change process/env

8. Power structures

9. Role of mass media

10. Health care

11. Social Services

12. Community cohesion

13. Leisure, recreation services

E. QUALITY-OF-LIFE FACTORS

1. General

2. Aesthetics

3. Food--quality, availability

4. Shelter--quality, availability

5. Clothing--quality, availability

6. Security

7. Physical well-being

8. Emotional well-being

9. Stability/Change balance

10. Companionship, love fanily

11. Job opportunities, satisfaction

12. Education opportunities, quality

13. Leisure/recreation opportunities

14. Personal riobility

15. Social mobility

15. Social mobility

16. Personal growth opportunities

17. Privacy

18. Freedom

19. Philosophical rootedness--faith, values

20. Cultural, historical, archaeological res. 
the IA reports analyzed, no graphs or maps were used to describe impacts.

Differences of opinion occasionally arose between coders as to whether sets of statements did in fact describe impacts of the innovation. In one study a large number of statements describing the general effects of radon were ascribed to the specific project under study (this was later corrected). For the most part, however, the differences between coders were of the type and frequency illustrated in Table $X$. Where differences were considered significant, the author met with the coders to come to an agreement. (In the case of the radon statements, the general statements were dropped from the count and the revised figures became the basis for calculations.)

In order to test for significant difference, it was first necessary to establish means for each impact category. Means were also figured for the major categories: Physical Environment, Biological Environment, Techno-economic Environment, Social Effects, and Quality-of-Life Factors. Then, means were calculated for each sample as a whole, to provide a comparison of the relative number of descriptive statements, given comparable lengths (in number of words).

These means and information in the form illustrated in Table XI are necessary to perform the standard $t$-test for means of independent samples. A standard one-tailed $t$-test was used to determine the significance of the differences between the means of the two samples: that is, whether it 
TABLE X

SAMPLE OF CODER RESULTS IN THE STATISTICAL ANALYSIS

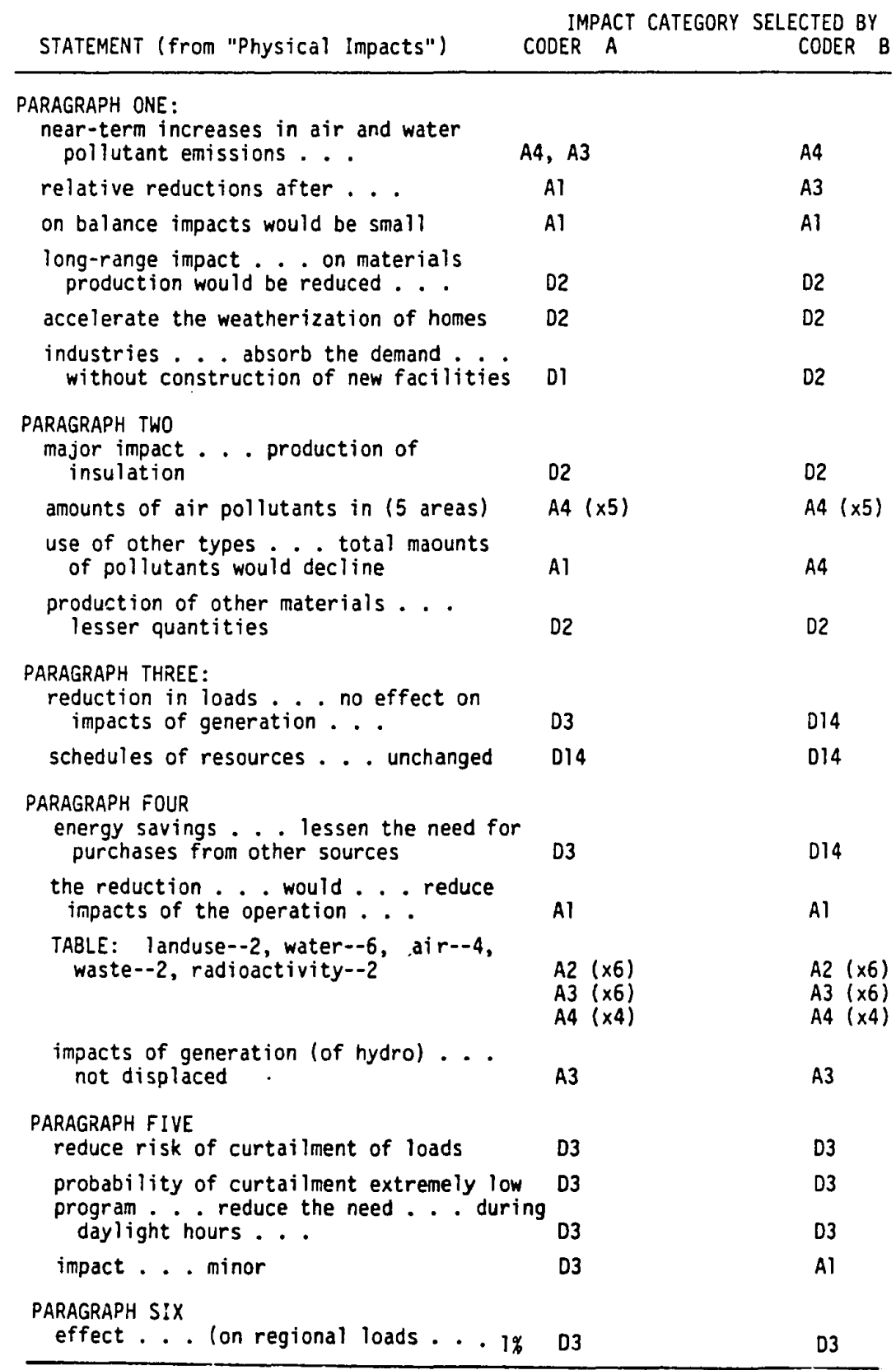


TABLE XI

INFORMATION USED IN $\underline{\mathrm{t}}$ TESTS (ILLUSTRATIVE)

\begin{tabular}{lcc} 
& EF Stories & IA Reports \\
\hline $\begin{array}{l}\text { Number in Sample } \\
(N)\end{array}$ & 10 & 11 \\
$\begin{array}{l}\text { Number of Statements } \\
(X)\end{array}$ & 1330 & 3657 \\
$\begin{array}{l}\text { Mean of Statements } \\
(X)\end{array}$ & 133 & 332.4 \\
$\quad X$ & 235222 & 1508393 \\
degrees of freedom $(N+N-2)=19$ &
\end{tabular}

would be possible to reject the hypothesis that IA reports will have consistently higher means than EF stories. Ferguson (1966) states that for such a directional test, in order to reject the null hypothesis (that the difference results from chance--i.e., that the difference between the means is less than or equal to zero) and accept that Sample A (in this case, the IA reports) have significantly higher means (of statements), a positive value of $\underline{t}$ corresponding to five percent (or less) probability is necessary. Ferguson also states that an equivalent negative value of $t$ is necessary to accept the hypothesis that Sample B (EF stories) have a significantly higher mean (number of statements in any given category). To test these hypotheses, sixty-one values of $\underline{t}$ were calculated, including values for each impact category, for each aggregated, major category, and for the two samples as a whole.

To find $\underline{t}$, the difference between the means is divided by the square root of a sum of squares of deviation about 
the means (that is, the standard error) in the formula

$$
t=\frac{\bar{x}_{1}-\bar{x}_{2}}{\sqrt{\frac{s^{1}}{\bar{N}_{1}}+s^{2}}}
$$

where

$$
s^{2}=\frac{x_{1}^{2}-\frac{\left(x_{1}\right)^{2}}{N_{1}}+x_{2}^{2}-\frac{\left(x_{2}\right)^{2}}{N_{2}}}{N_{1}+N_{2}-2}
$$

This formula, applied to each of the impact categories, yields a number that indicates the statistical probability that the two samples will have those means. Referring to a standard t-test table (Ferguson, 1966) it is possible to determine at what significance level the difference between them lies.

For this one-tailed, directional test, with nineteen degrees of freedom $(11+10-2)$, the results for IA reports are significant at the .05 level where $\underline{t}$ is greater than 1.729, the .025 level where $\underline{t}$ is greater than 2.093 , the .01 level where $\underline{t}$ is greater than 2.63 , and at the .005 level where $\underline{t}$ is greater than 2.861. The results for EF stories would be significant if the same values of $t$ were negative (i.e, t less than -2.093 would be significant at the .025 level, etc.) (Ferguson, 1966).

After these calculations and comparisons, I reviewed the impact categories to identify any that were completely missed by either the IA reports or the EF stories, and any that might be covered by all works in either sample. 
$\underline{\text { Results }}$

A number of interesting results emerge from this analysis. In over half of the categories tested (51\%) there was no significant difference between the means of the two samples. In over one quarter of the categories (fourteen, or 26\%) EF stories had mean numbers of statements equal to or greater than those of the IA reports, of which one third had values of $t$ indicating a significant difference.

Table XII lists the categories in which the EF stories tested had significantly greater mean numbers of statements describing impacts. These were: (C.6) communication systems, (C.16) technological processes, (D.9) media role, (E.5) clothing, (E.8) emotional wellbeing, and (E.10) companionship, love, and family. The first two of these (C.6 and C.16) are in the major category of techno-economic environment, and describe the qualitative relationships within that environment--namely the types of communication systems used and the types of and changes in technological processes over the period being investigated. The category (D.9) describes the role of the media regarding changes in the social environment. The last three (E.5, E.8, and E.10) describe quality-of-life factors: the types and quality of clothing worn (an indicator of the degree to which physical needs are met), the degree to which emotions are affected or supported as a result of the innovation, and the presence, absence, or role of intimate companionship, love, and family resulting from changes in the human environment. 
TABLE XII

SIGNIFICANCE OF DIFFERENCES

\begin{tabular}{llll} 
IMPACT CATEGORY & $\bar{X}$ & & IA \\
\hline
\end{tabular}

IA REPORTS HAVE SIGNIFICANTLY GREATER MEANS

A.1. Physical, general

A.2. Earth/land/soil

A.3. Water

A.4. Air/Climate

$\begin{array}{rr}3 & -- \\ 26 & 3\end{array}$

221

1.82

3.42

151

1.95

2.78

.05

B.3. Fauna

10.4

1.87

C.3. Utilities/power source

82

2.0

C.9. Labor availability

C. 10. Revenues

$\begin{array}{lll}71 & 1.8\end{array}$

C.12. Market values shifts

2.222

2.07

.01

D.1. Social Effects, general

11

2.56

.05

E.7. Physical well-being

E.20 Cultural resources

2

1.77

1.83

.05

166

2

.025

.05

EF STORIES HAVE GREATER MEANS

C.6. Communication systems

C.16 Technological processes

47

$-.54$

$-.97$

D.8. Power structures

D.9. Media role

$\begin{array}{lll}3 & 7 & -1.31\end{array}$

$--1$

$-2.929$

.025

E.5. Clothing

$\begin{array}{cc}-- & 3 \\ 1 & 6\end{array}$

$-4.62$

E.8. Emotional well-being

$\begin{array}{rr}1 & 6 \\ .1 & 5\end{array}$

$-2.0$

$-2.275$

.05

E.15. Social mobility

$-3.02$

.05 
Table XII also lists the categories in which the IA reports showed significantly higher means. Four out of the twelve listed describe the physical environment, three the biological environment, four the techno-economic environment, two quality-of-life factors, and one describes social effects ("general"). These twelve categories represent less than a quarter (23\%) of the total number of impact categories in this list, indicating that the first hypothesis (that IA reports will have consistently higher mean numbers of statements describing impacts than will EF stories) should be rejected for three quarters of the impact categories suggested in the IA guidelines and regulations.

TABLE XIII

DIFFERENCES BETWEEN AGGREGATED CATEGORIES

\begin{tabular}{|c|c|c|c|c|c|c|c|}
\hline & CATEGCRY & STO & RIES & $1 R$ & ETORTS & $\mathrm{t}$ & SIG. \\
\hline A & Physical Environment & 50 & (5) & 70 & $(77)$ & 380 & .005 \\
\hline B & Biological Environment & 15 & $(1.5)$ & 291 & $(27)$ & 3.68 & .005 \\
\hline $\mathrm{C}$ & Techno-Ecenomic Env & 462 & $(46.2)$ & 134 & $(130)$ & 2.49 & .025 \\
\hline li & Social Environment & 298 & $(29.8)$ & 495 & $(45)$ & 1.326 & none \\
\hline & Quality of Life & 505 & $(50.5)$ & 667 & $(61)$ & .901 & none \\
\hline & TAL & 330 & & $: 657$ & & 2.37 & .025 \\
\hline
\end{tabular}


At another level of analysis, as shown in Table XIV, the IA reports as a sample showed a significantly greater number of statements describing impacts than the EF sample at the .025 level $(t=2.286)$, as well as in the major categories of Physical, Biological, and Techno-economic Environment (at levels of $.01, .01$ and .025 respectively). There was no significant difference between EF stories and IA reports in the aggregated categories of Sociocultural effects and Quality-of-life factors.* These results suggest that the hypothesis should be modified to say that, in general, IA reports contain a higher mean number of statements describing impacts than EF stories, and that those impacts are most frequently described in the areas of the physical, biological, and techno-economic environments.

A third set of results emerges from a comparison of the categories in which all of the EF stories or IA reports describe impacts. Table XIII lists those and shows that while all of the EF stories tested describe impacts in eight of the fifty-three categories (15\%), no categories of impacts are described by all IA reports, indicating that a major difference between the two samples lies in the fraction of works describing impacts in each category. Only impacts on Employment (category D.8) were described by ten

*This result appears to derive from the high number of statements which the IA reports showed in the "General" categories for Social Effects (D.1) and Quality-of-Life Factors (E.I), compared to no statements in those categories for the EF stories. 
TABLE XIV. IMPACT CATEGORIES DESCRIBED BY

ALL OR NO IA REPORTS AND EF STORIES

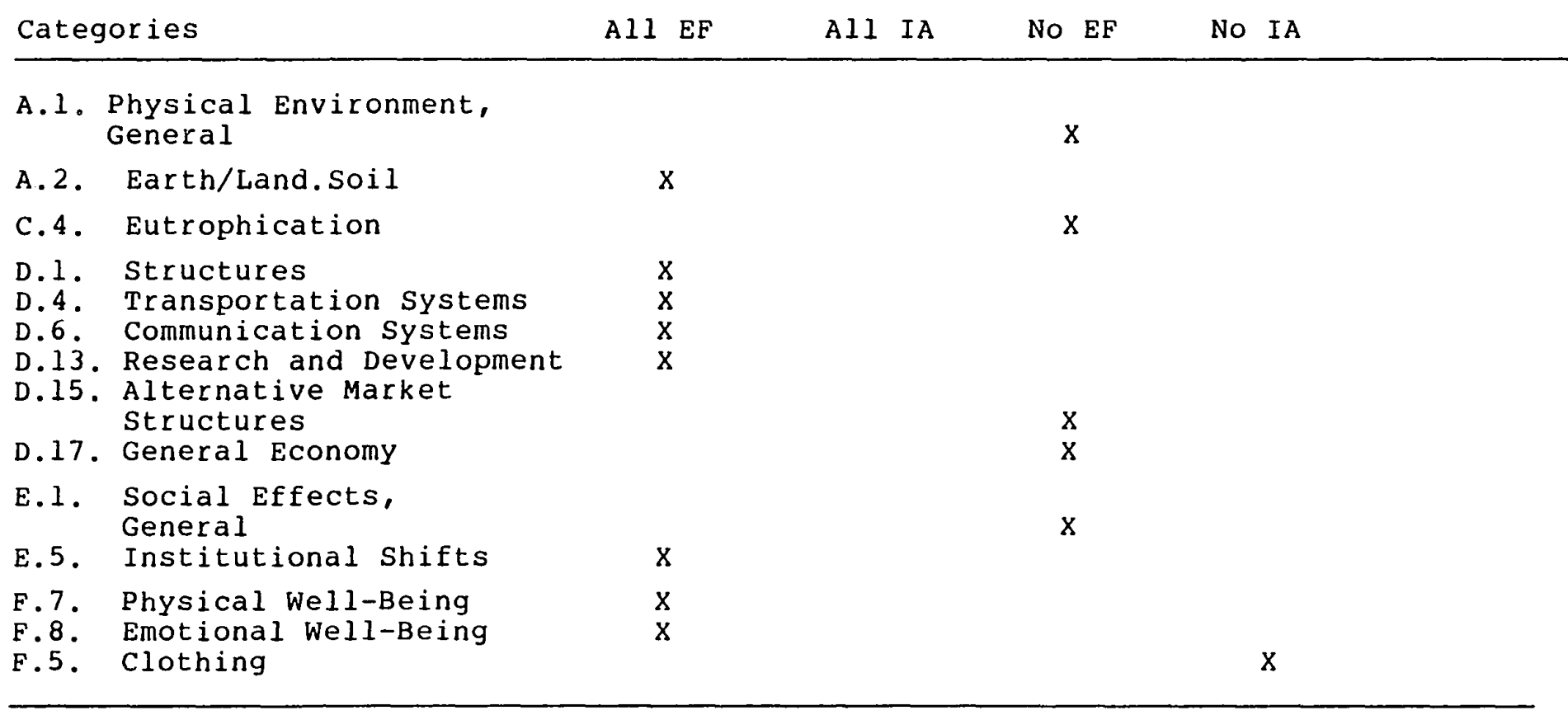


of the eleven IA reports and those on Earth (A.2), Water (A.3), Market Value (D.12) were dealt with in nine of them.

So, while the IA reports studied showed a significantly higher mean number of statements describing the Physical, Biological, and Techno-Economic environments than the EF stories, EF stories showed significantly higher means in certain categories in the Techno-economic environment, social effects and quality-of-life factors, and consistently described a wider range of impacts than the IA reports.

\section{THEMATIC ANALYSIS}

A thematic analysis of extrapolative fiction (EF) stories, with its qualitative methodology, at once complements the statistical analysis described in the preceding section and permits the examination of extrapolative fiction at a higher level of generality. Rather than counting the number of statements, the method used here identifies underlying themes in the work. The degree to which these themes conform to the content objectives for scenarios in impact assessment was taken as a measure of the potential utility of extrapolative fiction in the IA process. The degree to which these themes are dealt with as issues in news, opinion-forming, and political analysis literature over the years subsequent to the story's publication was taken as a measure of EF's potential relevance to decisionmakers concerned with public response to an innovation. Together, then, these measures provide substantive support 
for this thesis, helping to answer the question of whether the inclusion of EF stories can improve the IA process and IA results.

This section presents the description and analysis of a set of EF stories published between 1940 and 1975 that deal with innovations to occur during the last forty years, through 1980. A number of innovations dominated these stories: exploration of the oceans and journeys to the moon were common; so were atomic/nuclear power plants and alternative transportation modes and systems. Many of these stories are concerned with the social and personal effects of political and institutional shifts in the culture, based on the techniques of extrapolation, speculation, and interpretation (see Chapter Three). Moreover, tradition indicates that often such fictional interpretations reflect concerns held by the larger public. This dissertation, however, must answer a specific question: are these stories useful to IA practitioners? This section, looking at the historical record, asks a variation on that question: would reading these stories have been useful to someone trying to decide between alternative sets of actions at the time of their writing?

\section{Approach}

In order to answer the last question, a retrospective analysis was designed. A set of EF stories written since 1940 and dealing with the years through 1980 was selected, as 1 isted in Table XV. These stories were published in a 
TABLE XV

EF STORIES SELECTED FOR THE

THEMATIC ANALYSIS

\begin{tabular}{|c|c|c|}
\hline TITLE & AUTHOR & SOURCE \\
\hline Blowups Happen & Robert A. Heinlein & $\begin{array}{l}\text { Astounding Stories, } 1940 \\
\text { Conklin, The Year's Best SF } \\
\text { The Past Through Tomorrow, } 1967 \\
\text { Expanding Universe, T980 }\end{array}$ \\
\hline The Roads Must Roll & Robert A. Heinlein & $\begin{array}{l}\text { Astounding Stories, } 1940 \\
\text { The Man who Sold The Moon, } 1950 \\
\text { The Past Through Tomorrow, } 1967\end{array}$ \\
\hline Inher itance & Arthur C. Clarke & $\begin{array}{l}\text { Astounding Stories, September, } \\
1948 \text {, Vol. XLII } \#, \text { p. } 145 \mathrm{ff} \text {. }\end{array}$ \\
\hline Unite and Conques & Theodore Sturgeon & $\begin{array}{l}\text { Astounding, Stories, October, } 1948 \\
\text { vol XLII \#2, pp63-99 }\end{array}$ \\
\hline The Mercenaries & H. Beam Piper & $\begin{array}{l}\text { Astounding Scince Fiction, March, } \\
1950 \text {, Vol XLV } 11 \text {, pp. } 57-77\end{array}$ \\
\hline Quixote and the Windmill & Poul Anderson & $\begin{array}{l}\text { Astolnding Science Fiction, } \\
\text { November, 1950, Vol XLVI } \approx 3 \text {, pp. } \\
95-102\end{array}$ \\
\hline Historical Note & Murray Leinster & $\begin{array}{l}\text { Astounding Science Fiction, } \\
\text { September, 1951, Vol XLVII, "2 } \\
\text { pp. } 45 \mathrm{ff} \text {. }\end{array}$ \\
\hline The Day of the Moron & H. Beam Piper & $\begin{array}{l}\text { Astounding Science Fiction, } \\
\text { September, 1951, voi xLV!!!, *1, } \\
\text { pp7-34 }\end{array}$ \\
\hline What Thin Patitions & M. Clifton and A. Apostolides & $\begin{array}{l}\text { Astounding Science Fiction, } \\
\text { September, 1993, Vol. LII "I } \\
\text { pp. } 9 \mathrm{ff}\end{array}$ \\
\hline Counterspy & K. Edwards & $\begin{array}{l}\text { Astounding Science Fction, } \\
\text { December, } 1953 \text {, Vol LII, } 4 \\
\text { PP. } 122-139\end{array}$ \\
\hline $\begin{array}{l}\text { Under Pressure } \\
\text { Toriginality The } \\
\text { Oragon in the Sea) }\end{array}$ & Frank Herbert & Ballantine Books, New York, 1926 \\
\hline The Deep Range & Arthur $\tau$. Clarke & Ballantine Books, New York, 1957 \\
\hline A Different Purpose & Kim Burnett & $\begin{array}{l}\text { The Best of rantasy and Science } \\
\text { Fiction Ninth Series, T958 }\end{array}$ \\
\hline Brain Twister & Mark Phillips & Pyramid Books, New York, 1960 \\
\hline
\end{tabular}


variety of places--predominantly in Campbell's Astounding-by a number of authors, many of whom were wel1-known. They were selected on the basis of recommendations from aficionados and from scanning a complete collection of Astounding and Galaxy which covered the period in question. The stories were read and analyzed according to a set of parameters developed on the basis of suggestions for preparing scenarios and societal forecasts from IA practitioners and futurists (e.g., Martino, 1972; Mitchell, 1975; Armstrong and Harman, 1978; Porter et al., 1980). These areas include the Social, Technological, Economic, Environmental, and Political sectors of the culture. The forecasting parameters were cross-compared with the levels of focus generally found in fiction--the character's experience, the social and physical setting, and the philosophical ideas or moral issues that underlie the action in the story. These headings also conform to the content requirements established in the legislation for IA: the character's experience as quality-of-life factors, the setting as sociotechnical environment factors, and the philosophy/ideas level as values/ethics factors.

As each work was read the resultant matrix cells were filled with statements describing issues or themes that emerged from the story. This placement required a thorough understanding of the sectors and levels used, and involved a number of qualitative judgements. In order to improve the reliability of the results, the matrices were put away and 
reviewed some months later to identify inconsistencies and oversights. A few corrections and additions were made in this second pass and are reflected in the current matrices. On completion of the individual analyses, a collective matrix was prepared. (Table XVI, described in the Results Section, below, shows this matrix.) The individual story matrices were synthesized to identify issues and themes which appeared in greater than half of the works studied. This phase also identified clusters of innovations or foci for the stories analysed, as recurrent themes were listed. The stories analyzed fell into three main groups according to the type of innovation considered--atomic power, transportation, and research and development--and one "grab-bag" group of unrelated topics..

A model for tracking the general literature on a subject, developed by Graham T. T. Molitor to identify emerging issues, was used to determine whether the themes developed in an EF story have, in fact, reached a level of national concern. As Figure 5 illustrates, within Molitor's framework, if the theme is dealt with in professional journals, but has not yet reached his "instantaneous coverage" stage with TV, radio, and newspapers reporting on the issue as it develops, then it has not yet emerged as an issue of national concern. If, on the other hand, articles describing the theme are to be found in papers such as The New York Times, then the theme is an emergent issue. If such coverage was present at the time the story was being 


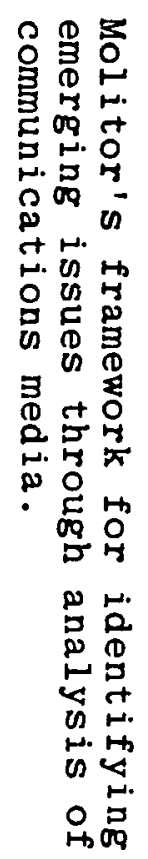

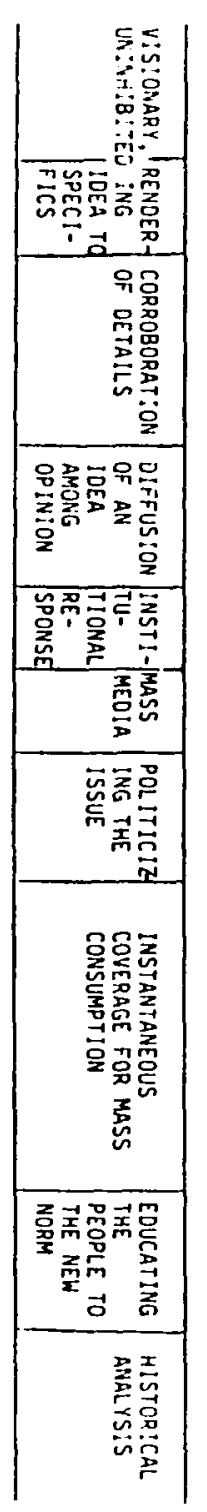

-ARTISIIC, POETIC HORKS ........... -SCIENCE FICTION

- TRINGE MEDIA, UMOERGROUND PRESS

-UNPUBL ISHED NOTES AND SPEECHES MONOGRAPHS. TREATISES

Scientific techical, professional jourmals... - HIGHLY SPECIALIZED, NARROH-VIEMPOINI PUBL ICATIONS STATISTICAL DOCLHEETS (SOCIAL INDICATORS. STA-

TISTICAL SERVICES)

-ABSIRACIING SERYICES, JOURMALS

-DATASEARCH COMPOSIIES ........... - EGGHEAD JOURNALS (e.g., SCIENCE, SCIENTIFIC AMERI-

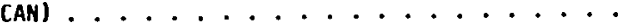
- INSIOER "DOPESHEETS" (e.g., PRODUCT SAFETY LETTER) -POPULAR INTELLECTUAL MAGAZINES (e.g., haRPERS) . - METHORK COMUNICATIONS (BULLLETINS, NEWSLETJERS) - JOURMALS FOR the CaUSE (e.g., CONSUMER REPORTS) -GENERAL INTEREST PUBLICATIONS (e.g.. TIME, NEWSHEEK - CONOENSATION OF GENERAL LIITERAIURE (e.g., REAOER'S

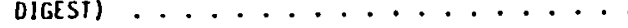
-POLL DATA, PUBLIC OPINION, Behavioral aNd VOTER

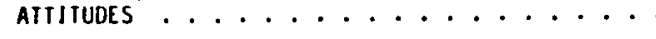
--Legislative/gOVERMmEntal SERVICES, REPORTS . . -BOOKS

-FICIION -- MOVELS PROVIDE SOCIAL ANALYSES OF

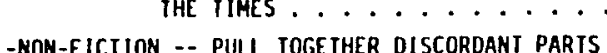
PULL TOGEIHER DISCORDANT PARTS
INTO CASILY UNOERSTOOD HHOLE MEHSPAPERS (HEW YORK TIMES \& MASHINGTON POST EARLY. SOUTHERN RURAL PAPERS LATE COMMENIATORS) . . . . RADIO \& TELEVISION INETWORKS COMHENT EARLIER THAN

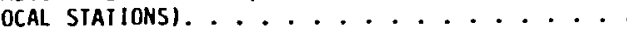

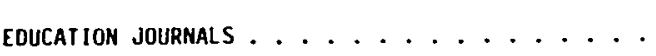

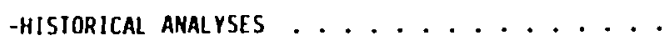

-TRADIIIONAL DOC TORAL IHESES ........

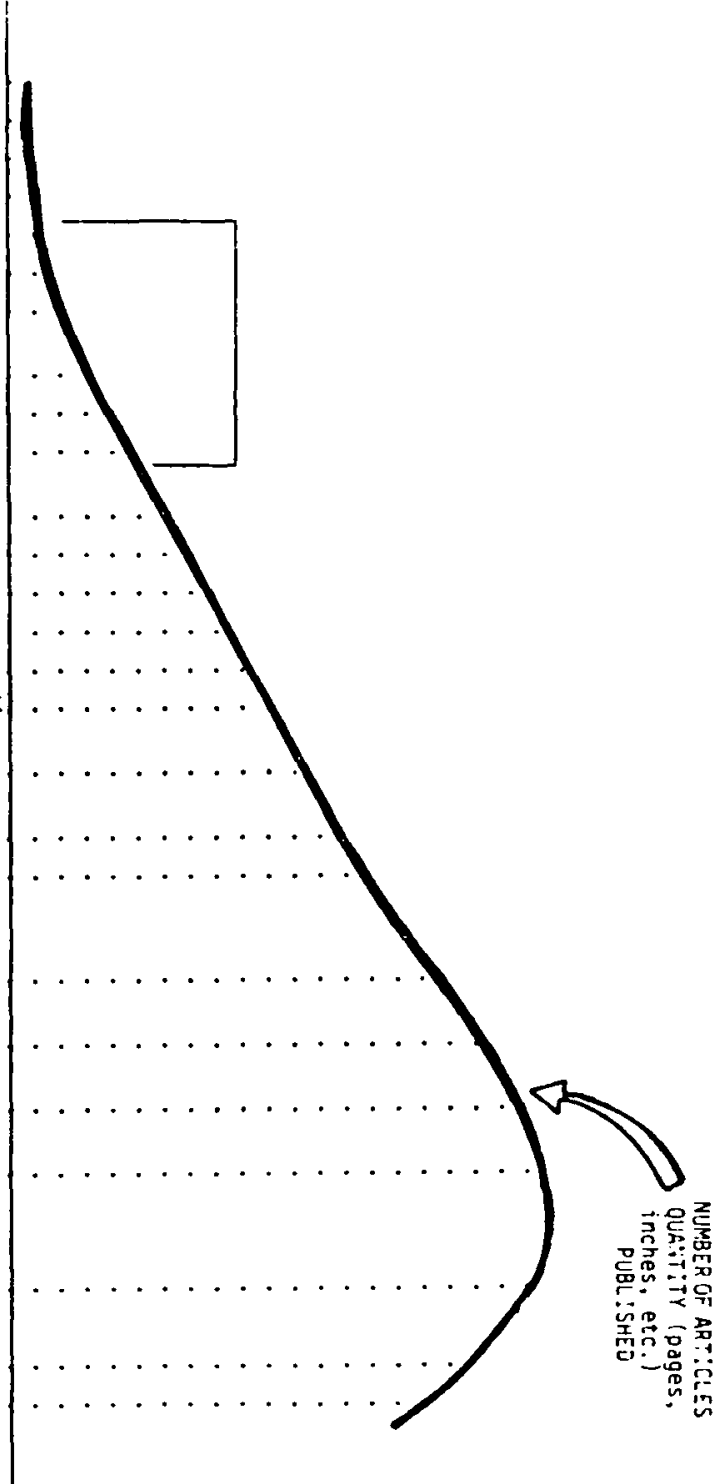


written, then, rather than presenting an emergent issue, the author was presenting an already established national concern (Molitor, 1972).*

Results

In the stories analyzed for this phase of the research, writers explored the potential benefits and problems associated with technological and institutional innovations against a common background of stable social and political values that their readers could identify with. As a result of this common background, a number of themes and issues appear in all (or a majority) of the stories analyzed. These are presented in Table XVI, and are discussed below.

Character. At Level III, personal experience, the one common factor in all of the stories analyzed is technological: the personal automobile as a dominant form of transportation. Clearly, the writers did not expect Americans or other members of Western society to give up the "American Dream Machine" within the stories' time frames. Interestingly enough, in spite of a sixfold increase in fuel prices and massive efforts by various governments over the intervening years to make mass transit glamorous and available, industrial society's love affair with the automobile shows every sign of continuing well into the

* Parallel indicators exist at the local level. For example, letters to the editor or phone calls in to "talk" shows may indicate the possibility of an emerging issue, while front page coverage in the local newspaper, or bulletins on the evening news shows are indicative of an issue's establishment as a major local concern. 
TABLE XVI

THEMES SYNTHESIZED FROM EF STORIES, 1940-1980

(* indicates presence in all)

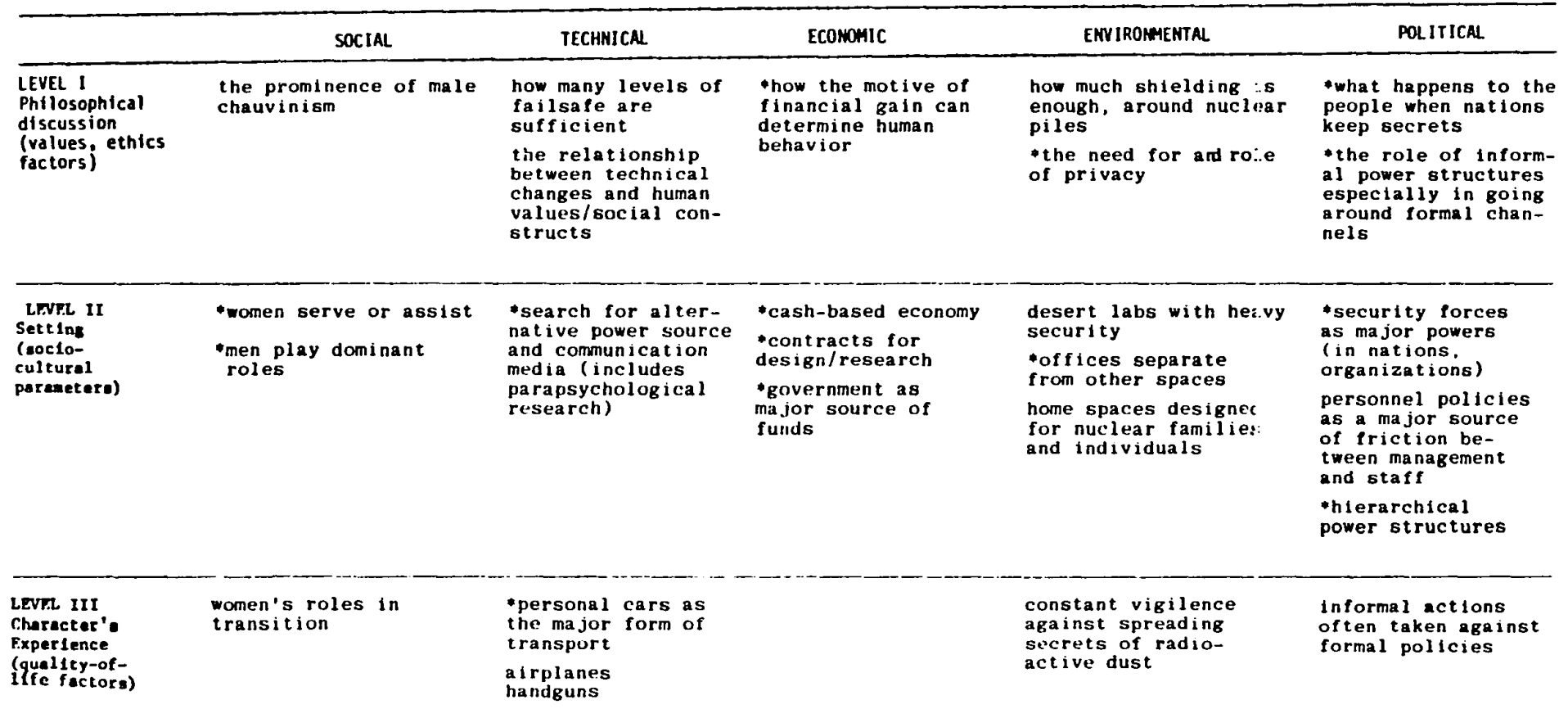


1980s. As a primary indicator, the number of new Americanmade cars sold in 1981 reached 6,206,296 (Automotive News, 1982) and nearly 125 million automobiles were registered in the United States that year (U.S. Department of Transportation, 1982).

Setting. At the system parameters level, Level II, the authors described the setting for their stories; seven factors are common to all the stories studied. A consistent theme in the social sector is that, with notable exceptions, women act to serve or assist men who play dominant roles. Many stories have a uniquely gifted, talented, or trained female protagonist who is placed in contrast to other women. A few include women as sexual objects. For the most part, however, women enter the stories as secretaries, nurses, housewives, or in other supporting roles (in keeping with the attitudes and expectations of the years in which the stories were written). Since the early 1970 s many projects have been undertaken to change this state of affairs. However, a recent issue of Scientific American confirms that, in 1980 , these were still the roles that the majority of women fill in this country (Scientific American, 1982).* The common parameter in the technological sector is a continued search for alternate power sources and communications media--even including parapsychological research for techniques in both areas. This kind of drive for technological progress is an underlying theme in nearly all futures-oriented fiction of the period, but is particularly 
evident in the near-future speculations studied here. It is also evident in the culture as a whole--both in the period the story was written and today. As an indicator of the pace of technological innovation in this country today, over sixty thousand patents were issued in 1980 (U.S. Department of Commerce, 1982).

Two themes dominate the economic sector descriptions. One is the continued use of cash as a medium of exchange (as opposed to barter or some sophisticated computerized accounting system). The assumption on which this theme is based is validated by the large number of bills in circulation today. The other theme is an assumption that the federal government is a major source of contract funds, both for research and for products. Even in the early stories, whose writers had seen the government playing such a role for less than a decade, this parameter remains fixed in their projections. As of 1980, the government was in fact the major purchaser of products in a large number of industries. Moreover, government supported research through the National Science Foundation, the Institutes of Health and Mental Health, and various other agencies and departments totalled close to $\$ 30$ billion in grants and

*Although nearly all of the stories studied included women as characters, none included clear reference to specific racial minority groups (except the 1940 version of Heinlein's "Blow-Ups Happen", in which the tavenkeeper is clearly a Southern Black, but in the 1946 version--quoted in Chapter Three, above--is identified simply as an immigrant). The analysis described in this chapter, therefore, is restricted to the stories' handling of women, rather than minorities in general. 
contracts in 1981 (U.S. Office of Management and Budget, 1980). This comprises some sixty per cent of the total, with private funding of research at a level of approximately $\$ 20$ billion in the same year (Norman, 1981).

Two factors are consistent in the system parameter descriptions of the built environment: specifically, in the descriptions of structures and land use patterns. Office space is described as separated from other work and living spaces--either as part of a building's design, or more than once, by a plywood partition added where no previous division existed. Home spaces are designed for individuals and nuclear families; no extended families or group homes or dormitories are included in these stories. In those that go into any detail, eating spaces are separate from other living and working spaces except for occasional meals brought in during meetings or rush work periods. Again, present experience conforms, for the most part, to these descriptions.

In the political sector at this level, two main factors emerge across the stories studied. All describe hierarchical--typically pyramidal--power structures in whatever type of organization they deal with. At the same time, however, every author points out that the real power lies in the informal power structure, typically dominated by whatever security force is employed by the organization. Frequently, the conflict resolved through the course of the story involves a confrontation with security personnel. The 
degree to which these parameters still hold true is not as easily documented as it was for those parameters described above. Yet the management training literature--particularly those in Molitor's "Books" category--has recently included a number of guidelines for and references to the importance of networking and identifying a mentor (a senior manager to support one's efforts and sponsor one's advancement) in an organization if one wants to function effectively in that organization (e.g., Wilson, 1981).

Philosophy. At Level I--values, ethics, and ideas-the writers whose stories were analyzed have in common four main concerns. In the Economic sector, they all discuss ways in which human actions are driven or determined by the possibility of financial gain. Regarding the physical environment, all of the stories deal, either directly or indirectly, with the need for, role of, and means for acquiring privacy in society. The political question of secrecy and how national or corporate security regulations affect individuals is another consistent concern. Finally, the contrast between the formal power structure and the informal channels that are used by people who want to get things done is another concern that shows up consistently through the stories studied.

The Underlying Scenario. The factors common to the EF stories analyzed are all elements of the authors' own experience. Their presence in the EF stories of this period suggests that, as a group, the authors expected the cultural 
context to stay pretty much the same between 1940 and 1980 . A contextual scenario based on these elements would look something like the following:

The continued search for alternative power sources and communications media is driven by government funds. A male-dominated cadre of professionals, motivated by the ideal of wealth to reach the top of the power pyramid, works in offices separated from their female assistants and support staff. Driving to individual homes in personal cars, they greet wives or girlfriends, who provide emotional relief and support, as well as links into the informal power structure. These links are doubly important as they not only permit the men to get things done, but they often make it possible to circumvent the security personnel who hold considerable control over who has access to what in the system. Privacy is taken for granted, except where secrets affecting the nation are concerned, where security forces have full authority to pry or take control over one's life.

This basic scenario underlies--describes the cultural context for--all of the stories studied.*

The innovations--nuclear power plants, transportation technologies, etc.--in all of these stories, then, are placed in a cultural context that is rather narrowly extrapolated, but a context that is open to question. The questions asked in selected stories--and the issues associated with them--are discussed in some detail in the next few pages. The issues are then compared to Molitor's phases in development (see Figure 15, p. 123) in order to determine whether they have, in fact, emerged as national concerns since the stories were written.

*Interestingly, though most stories are set near the writer's current home, the nation as a concept is not present in all of the stories studied. Frequently, the cultural background is assumed to be the whole world. 
Nuclear Power Stories. Three stories in the group selected for this analysis focused on nuclear power plants as an innovation with fictionally interesting consequences. These three are: "The Day of the Moron" by H. Beam Piper (1951), "Counterspy" by K. Edwards (1953), and "Blowups Happen" by Robert A Heinlein (1940, 1946). Summarized in Chapter Three, these stories have been analyzed according to the matrix format described above and the themes and concerns expressed in them are discussed in detail, below. Each of them deals with the human actions and responses associated with operating nuclear reactors, and each of them illustrates a number of issues that have arisen in the decades following their publication.

In reading "Blowups Happen" (Heinlein, 1940, 1946), for example, it is important to realize that Heinlein wrote it long before the first nuclear power plant was designed. In fact, the 1940 version of the story preceded the first "Pile" (in Chicago) by two years. The size and quantity requirements of a power plant based on a pile similar to the one described by Heinlein are, therefore, way out of line with current practice. Nevertheless, the stress of operating a not-fully-understood, potentially highly destructive, operated-by-hindsight machine is still very real. So are the mistakes that occur under such stressful conditions. "Dismantling the safety interlocks" and using the wrong wrench--as described in Heinlein's story--are both highly reminiscent of the problems that led to the Three 
Mile Island disaster as described in the Nuclear Regulatory Commission's analysis (Nuclear Regulatory Commission, 1979-see also pp 175-185).

All of these stories have dealt with several themes as important regarding the nuclear power industry in the 1950s and 1960s. Most of these themes were not being considered in other forms of media at the time the story was published but have, since then, either become institutionalized in this country (through the passage of legislation) or have passed Molitor's "critical point" as emerging issues of national concern. The themes described by these stories include:

(from "The Day of the Moron", (1951))

1. the relative danger of nuclear power plants and the need for safeguards

2. the vulnerability of a centralized power grid and the consequences of an accident within it

3. the necessity for heavy security around nuclear reactors

4. the potential problems of unionized labor in critical work areas

5. male chauvinism and resultant difficulties for female professionals

6. the requirements for a different kind of training to deal with nuclear power plants, given the damage potentially resulting from human error.

(from "Counterspy" (1953))

1. the near-impossibility of absolute security

2. the strain placed on those who are responsible for maintaining the security of the plant; and, indirectly 
3. the total absence of women from the technical and operational staff of the plants.

(from "Blowups Happen" (1940, 1946))

1. the relative danger of nuclear power plants and the inadequate understanding we have of what harm they might do

2. the special personal and training requirements for reactor operators

3. the expanding need for electricity in this country

4. the possibility of orbiting power stations

5. the relative powerlessness of the President, or any Chief Executive to countermand policy in a bureaucracy

6. the socially irresponsible and blinding effects of profits on decisionmaking.

The following paragraphs trace the evolution of these themes in terms of Molitor's phases. They describe the number of articles published in a variety of journals corresponding to the phases in Molitor's framework, or indicate the degree to which the issue has been accepted and insitutionalized in this country.

Figure 6 shows the number of articles dealing with the safety of nuclear power plants between 1940 and 1980 . As demonstrated in that figure, few people in 1951 thought that any real safety problem existed, and concern about nuclear power as actually much less safe than the Atomic Energy Commission had presented it was expressed only occasionally in the journals until the late 1960's and early 1970s. Accidents, safety, and longterm or side effects of radiation exposure became an issue in the professional journals in 1960. It reappeared with the Idaho accidents in 1962 and 


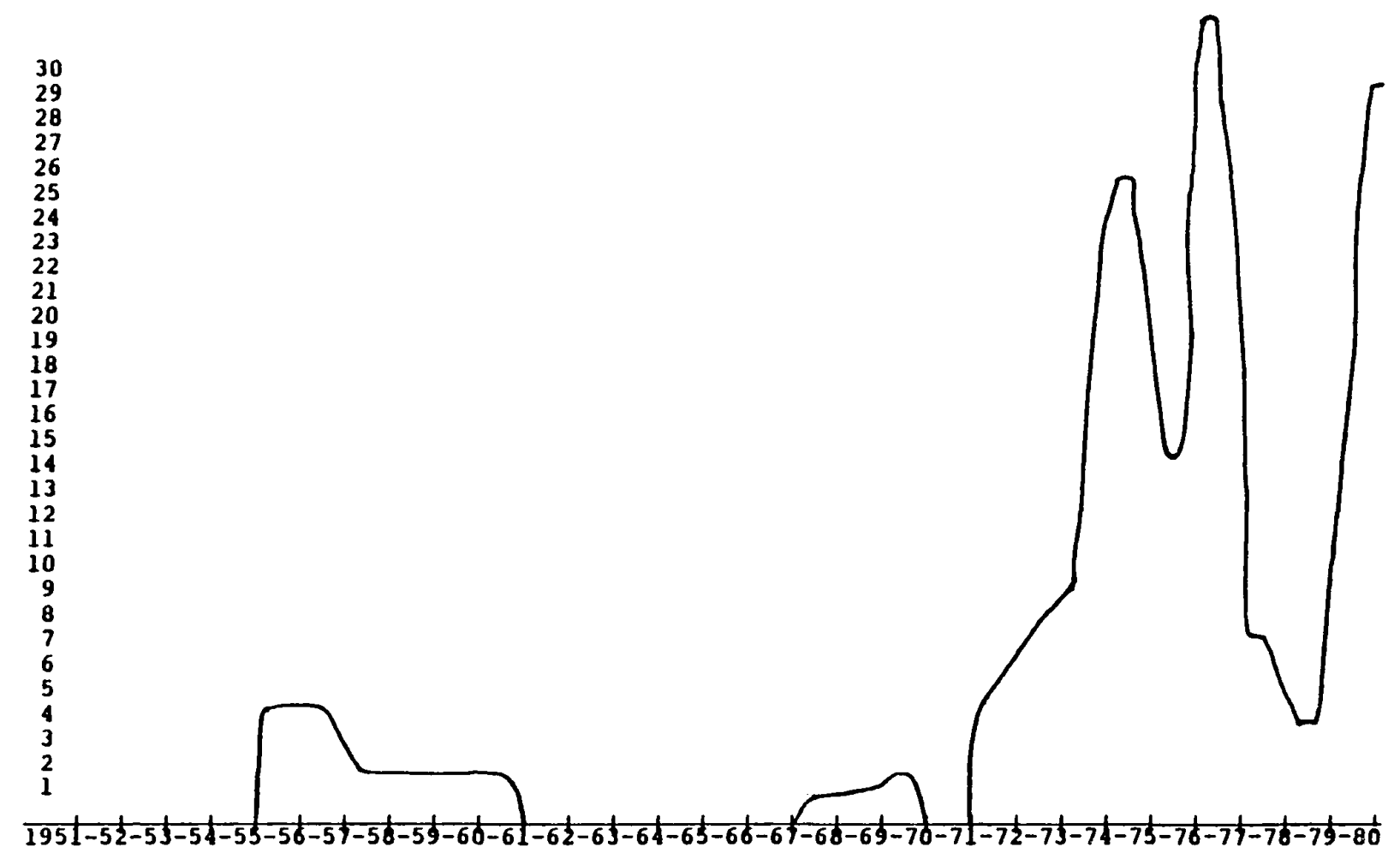

Figure 6. Number of articles dealin with Nuclear Power Plant Safety. (SOURCE: Reader's Guide to Periodical

Literature) 
1965. By 1973, this concern provided material for basic science classes at the undergraduate level (Rulon, 1973; U.S. Atomic Energy Commission, 1973). Interest waned, however, and few publications were concerned about accidents again until 1979, when the Three Mile Island incident once more placed the issue of nuclear accidents in Molitor's General Interest journals and in the public eye.

Figure 7 shows that media interest in electrical power blackouts erupted in 1965 when the Northeast coast (including New York City) experienced its great blackout, just three years before the year in which Piper set his story. As Piper observed, a centralized grid proved too vulnerable, and as in Piper's story, elevators were stopped, people were injured and killed, and stores were looted. The mass media covered the blackout extensively and novels were written based on the event, making the potential for blackouts also an issue of national concern--according to Molitor's schema--through the latter 1960 s and into the early 1970s (where no such concern had been previously indexed in the periodical literature). In the aftermath, historical analyses identified the "stupid mistake" that caused the blackout and many dollars were spent in installing cross-connections to other sources so that such a situation could not be repeated--either in New York or anywhere else in the country.

The unionizing of professionals and government employees was an emerging issue when Piper was writing 


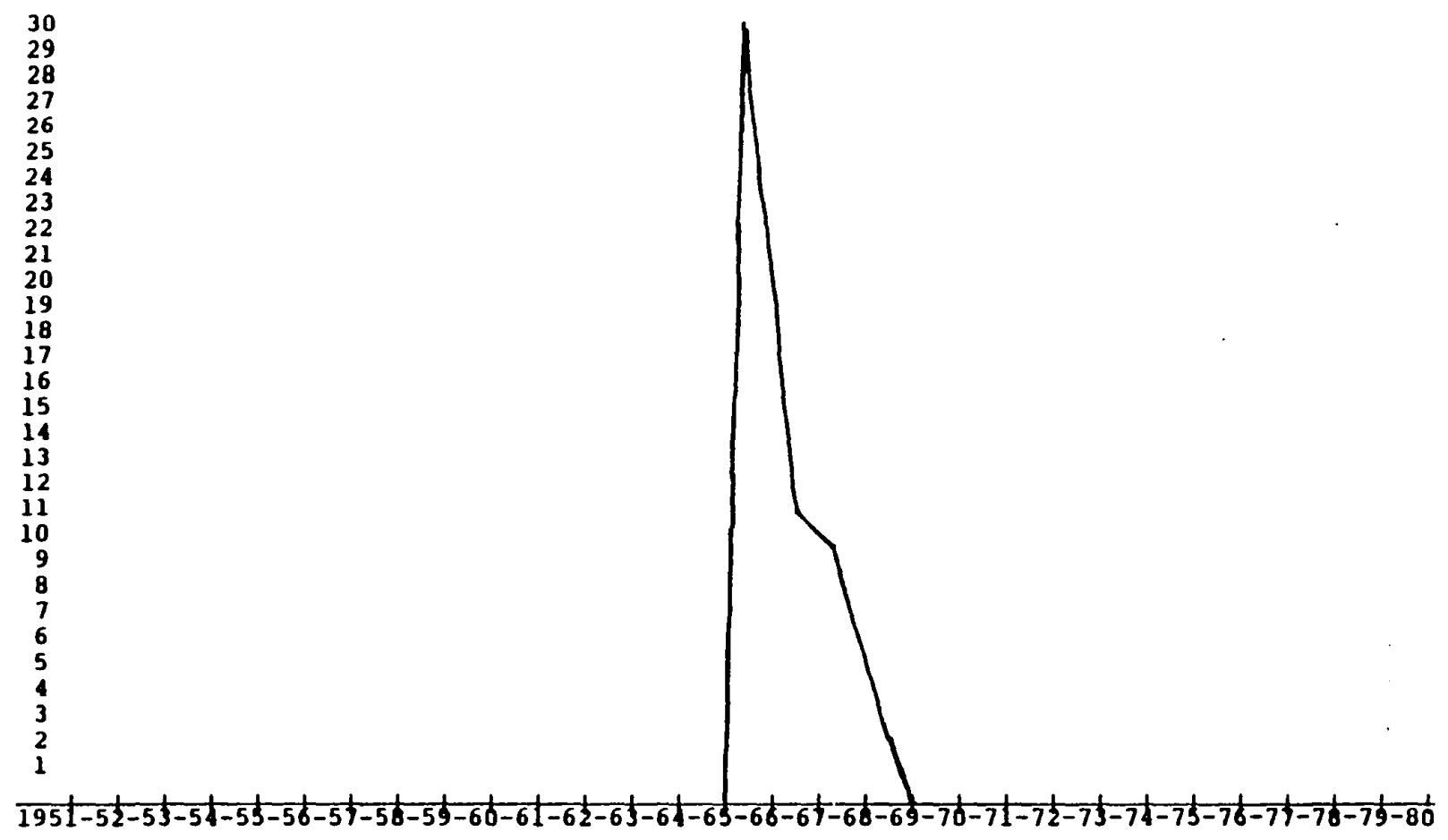

Figure 7. Number of articles dealing with electrical power blackouts. (SOURCE: Reader's Guide to Periodical Literature)

$\stackrel{\omega}{\omega}$ 
"Moron" and became a national issue in the mid-1950s, when instantaneous coverage of teachers and policemen in several cities forming unions and going on strike to demand higher wages and better working conditions became the norm, as shown in Figure 8. Prior to that time, most people had assumed that workers in critical positions--whose absence could have significant negative results in the community beyond their employers--were neither legally nor morally eligible for unions and the capacity for strike that went along with them. Molitor's Narrow-viewpoint publications (e.g., The New Republic) and Popular Intellectual magazines (e.g., Harper's) considered the possibility of the unionization of professionals and its implications in between events. Some shred of concern remains in these publications the 1980s, but workers in a wider and wider range of professions are forming unions and considering strikes. As an indicator, in 1982, all of California's state university system was organized into a teachers' union. Moreover, paralleling the "Moron" -storyline a strike by workers at Portland General Electric's Trojan nuclear power plant delayed bringing that plant back on line after repairs in 1979. mass media covered the blackout extensively and novels were written based on the event, making the potential for blackouts also an issue of national concern--according to Molitor's schema--through the latter 1960s and on into the early 1970s (where no such concern had been previously indexed in the periodical literature). In the aftermath, 


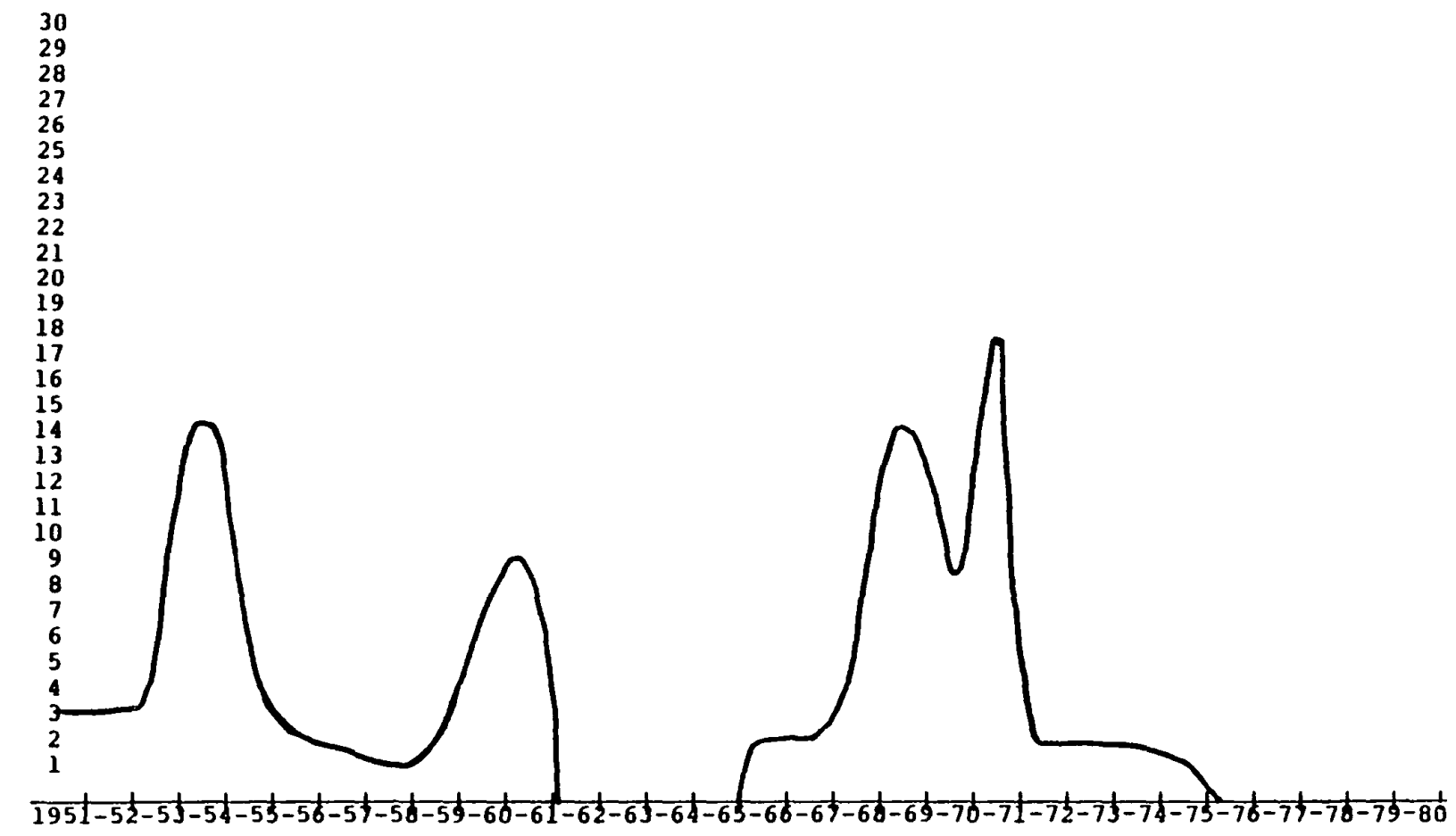

Figure 8. Number of articles dealing with public worker strikes and unions. (SOURCE: Reader's Guide to Periodical Literature) 
historical analyses identified the "stupid mistake" that caused the blackout and many dollars were spent installing cross-connections to prevent another.

Then, the concern that there was "still a little of what used to be called male sex-chauvinism" (Piper, 1951) became a national concern in 1970 with the mass media coverage of the formation of women's "consciousness-raising groups" all over the country and the National Organization for Women (NOW), with three thousand members, publishing its Women's Bill of Rights (NOW, 1970). In that year, women receiving $\mathrm{Ph} . \mathrm{D} . \mathrm{s}$ made up $13.4 \%$ of the total (compared to less than $10 \%$ in 1950), though women made up less than $10 \%$ of the faculty in psychology and less than $6 \%$ of the faculty at research institutions (Giele, 1978). Since that time, the number of books, articles, and academic theses on the subject has continued to increase, with thirteen bibliographies (of more than fifty books and articles in each) published on "women--employment" between 1970 and 1979 (Ballou, P.K., 1980), compared to twenty articles on the same subject in 1951-1953 (cf. The Reader's Guide).

The possibility that the United Siains night not be able to keep up with demand for electrical power with current practices was made a popular issue by the "swords into plowshares" campaign associated with the formation of the Atomic Energy Commission in the early 1950s. The assumptions underlying this concern were not questioned outside of the "fringe" environmentalist journals until the 
oil crisis of $1973-74$ spawned research into the possibilities of conservation. At that point, government reports and non-fiction syntheses were published which laid out the specific growth factors affecting demand and the resource levels limiting the supply (cf. The Ford Foundation's study Energy For the Future, and the Department of Energy's "Monthly Energy Review"). Based on these publications, shifts in demand for power were covered instantaneously by the media into the 1980 s.

While Heinlein considered the possibility of orbiting power stations in "Blowups Happen," orbiting satellites with microwave transmitters beaming power to earth-based receivers was not presented to the Congressional Subcommittee on Space and Astronomics until 1975 (U.S. House of Representatives, 1975). Such power stations are fundamental to Gerard O'Neil's space colonization strategy, which reached the point of nonfiction synthesis in 1977 (Heppenheimer, 1977) and newspaper coverage in 1981-82 (The Oregonian, $1981 ; 1982$ )

The Nuclear Regulatory Commission's report on Three Mile Island (1979) and the President's Commission's Report on the same incident (1979) point out the need for a different kind of training for reactor operators than for traditional power plant engineers and are based on just the kinds of concerns and problems described here in Heinlein's story (discussed in greater detail in the following section). However, the issue has not yet reached Molitor's 
Diffusion stage and so is not yet assured of becoming an issue of national interest and concern.

Philosopher/historian James Ogilvie explained the blocks on a President's actions in 1980, in an article entitled "The Death of the Presidency" (Ogilvie, 1981) in one of Molitor's Egghead journals, but, although there is some discussion of the lack of power of a Chief Executive Officer in bureaucracies among management theorists (e.g., Jay, 1969; Wilson, 1981), the concept has not yet reached the rnass media.

The need for corporate social responsibility emerged in the aftermath of the environmentalist movement. This emergence is characterized by Ralph Nader's nonfiction synthesis published in 1973 (Nader, 1973), which year corresponded with Congressional action (96th U.S. Congress, 1973), closing the issue for a time by institutionalizing it.

The possibility of terrorist attack was one of the stated reasons for not selling nuclear power plant technologies to third world countries in the 1960 s and was one of the arguments against building new plants presented during the 1970s. The issue reached Molitor's politicizing stage in Oregon with the Pebble Springs decision in 1979 (Oregon Siting Council, 1979).

Although many of the stories of the period in question include nuclear power as part of the context for the story, the three discussed here deal specifically with the problems 
and potentials of this particular power technology. As the preceding tables, graphs, and discussion have indicated, most of the issues they raise have, in fact, received attention over subsequent years from both the media and the government. Some have passed the peak and are no longer issues to be considered for action, but have been legislated or regulated and are part of the institutional setting in our society. Among these issues are equal employment opportunity for women, corporate social responsibility, unionization of professionals and public employees, development of alternative energy sources, and decentralization of electrical power grids. Others have yet to pass the critical point beyond which Molitor has found their emergence as issues to be assured. This latter group of issues includes: the specialized training and support needs of nuclear plant operators, the relative lack of power of a chief executive officer in a bureaucracy, and the high levels of stress experienced by those responsible for the safety and security of nuclear plants.

Research and Development Stories. Several themes were developed in the stories focusing on innovations in research and development, including some which have already been discussed. The stories analysed in this group include: Piper's "The Mercenaries" (1950) and "What Thin Partitions" (1953) by Clifton and Apostolides. The themes and concerns developed in these stories include: 
(from "The Mercenaries")

1. the power of security forces and the indignities of their searches, especially "strip" searches

2. the potential for women to work as equals on a research team

3. the contrast between the expectations held for women within the team and those held for them outside of it

4. the importance of maintaining independence in order to be effective as researchers (both for the team and for the individuals--especially women--within it)

5. the effects of intercorporate or international secrecy and competition on research and development

6. the emergence of essentially sovereign entities other than nation-states--particularly businesses.

(from "What Thin Partitions")

1. the problems working mothers have and the potential effects on the children when childcare is not available

2. the benefits to the corporation of readily available daycare

3. the subordinate, supporting roles of women in the corporation

4. the role of computer research corporations in the research and development process

5. the role of government--especially the military--in supporting research and promoting new technologies

6. the necessity of informal power structures to get things done.

In the area of security, the indignity of searches, particularly strip searches, reached Parade Magazine in 1981 with a lengthy article and several follow-up stories on the technique and its misuse/abuse by police and customs officials in our country. According to Molitor's schema, 
such publication means that this issue is past the critical point and is on its way to becoming a national concern.

The contrast between the rare situation of women working as equals and the more normal situation of subordinate roles for women has also been discussed above. As presented in Piper's story, however, this concern illustrates a need to maintain a sense of independence, and is related to the two longterm trends toward increasing independence and individuality in this country. To a large extent this story may be said to be an extrapolation of the theme of scientists' (and scientifically inclined writers'?) need for room to create and explore without the interference of ignorant officials. "The Mercenaries" explores possible consequences and implications of scientists--for example, Norbert Weiner--"refusing to tell the government anything" but what they specifically contract to tell them (Platt, 1980)

The problem of daycare, and the benefits to employers and corporations of making such facilities available to their employees are old and difficult themes. In the 1970s, however, a number of hospitals installed daycare centers for the children of employees. Cities funded daycare information and referral centers for concerned parents, and by the 1980s, some companies began to franchise daycare centers, while others offered daycare as one of the benefits employees could choose from. Smaller companies have found the costs of maintaining such facilities--especially for 
insurance--too high to be feasible for them. These companies are looking at the alternatives contracting out the service to a nearby facility (Strain, 1983).

Computer Research, Inc. is the name of the research firm the authors describe in "Partitions". It is the equivalent of numerous small firms now scattered throughout the country--for example, Columbia Research, Inc. in the Portland, Oregon, area. At the time they were writing about this fictional firm, however, the RAND (Research ANd Development) Corporation was newly founded, Stanford Research Institute (now SRI International) had not yet broken off from the University, and computers were roomsized calculators. Yet World War II, and then Korea, had taught the United States military to rely on mathematicians and other scientists to convert their raw data (e.g., observations of enemy activities) into meaningful information (e.g., patterns from which policy decisions might be made). The scientists, in their turn, found they enjoyed tackling "real world" problems and, throughout the 1950s and 1960s, were forming a variety of organizations that might enable them to do so on a per-contract basis. By 1980, RAND and SRI had become the model contract research organizations for several countries, and most metropolitan areas with universities or a population over half a million had a smaller version or two.

Together, the stories discussed in this section raise some interesting issues regarding research and development 
in this country. Both of them continue the concern about the role of women that was expressed in the nuclear power stories--taking that issue a little further by pointing out the problems of childcare and professional independence when a married woman continues to work outside the home. The stories also point out the ubiquitous role of the federal government as the major sponsor of research and purchaser of the results, as well as the effects of intercorporation or intergovernment competition on the individuals who must live with it.

Transportation Stories. Innovations in transportation technologies are present in nearly all speculative stories. In extrapolative fiction, the trick is to develop alternatives that might be implemented within a fairly short timespan (remembering that it takes about thirty years for a highway to be built). The other trick is to consider not only the immediate effects of the transportation technology, but also the secondary, tertiary, and seemingly unrelated effects (e.g., the effect of the automobile on American social and sexual mores).

The stories published between 1940 and 1975 and focusing on transportation innovations to occur before the 1980s are, then, particularly constrained. They include: "Historical Note" by Murray Leinster (1951), Robert Heinlein's "The Roads Must Roll" (1946), and the novel Under Pressure by Frank Herbert (1956). 
The lightly farcical "Historical Note" illustrates these constraints. Written in 1951, when the Cold War was beginning to be institutionalized in this country, and before the Berlin Wall was built, in many ways, the story describes the various behaviors that led to the building of the Wall--even as it shows how the Wall could be rendered useless. The process Leinster describes whereby the fliers move from being military tools to unique and expensive toys to the mainstay of a redefined cultural pattern parallels that of a number of similar innovations. Among these are: television in the fifties, stereos in the sixties, calculators in the seventies, and (apparently) microcomputers in the eighties. In all of these cases, a technology that was introduced with an apparently Iimited usefulness and market, became, for a number of reasons, incredibly popular. Each was used for a substantially broader range of activities than expected, and led to the creation of a whole new subculture within the larger society around those uses. Meanwhile, each technology affected numerous unforeseen aspects of everyone else's life, in much the same way as Leinster has illustrated.

Herbert wrote Under Pressure (1956) in the early years of the Cold War, when limited nuclear war still seemed possible and ongoing hostilities between East and West seemed inevitable. With this story, he extrapolated thencurrent political and environmental trends and used a number of not-yet-existent technologies to create the setting for 
this examination of human actions and responses under overwhelmingly stressful conditions.

These stories present a number of themes that have emerged as issues in this country since the stories' publication. These issues include:

(from "Historical Note")

1. new technologies assumed and developed by the military

2. the tendency of governments to adopt new technologies without considering the full range of consequences

3. the degree to which our lives and social systems are determined by our transportation technologies

4. scientists as a national resource, to be protected from other nations

5. the role of the free market in establishing an innovation.

(from "The Roads Must Roll")

1. development of strip cities along transportation corridors

2. service requirements for complex transportation systems and the subculture growing around it

3. unionization of critical or public service personnel

4. supporting roles of women in a men's lives

5. the stress associated with too much power and responsibility

6. the need for careful testing and monitoring of key personnel.

(from Under Pressure)

1. the relative powerlessness of a junior officer in the military--and of his wife 
2. the need for formal power structures in the larger society and for informal ones in small working groups

3. the need for some spiritual base under stressful conditions

4. the high level of stress associated with working under water and around radioactives

5. the effects of secrecy on individuals and their relationships

6. the power of security forces.

Most of these themes have been discussed above, in the analyses of the other groups of works. Two remain to be considered: the transportation subculture of "Roads," and the relative powerlessness of junior officers in the military hierarchy. The theme central to "Roads" is the highly structured service system needed to maintain a complex transportation system and the tendency for a subculture to form around that system. Perhaps the most obvious example of this phenomenon in this country today is the "trucker" culture that has grown up on the Interstate freeway system. These drivers and their service providers now handle a substantial portion of the goods hauled between cities in the United States. Like Heinlein's Road Crews, they have their own dress code, jargon, communication and maintenance technologies, and social structures. What's more, as is the case with Heinlein's crew, only those who have been brought up in the culture are really a part of it. The result is a striking parallel between life on freeway strip cities and on Heinlein's Road Cities. The theme of a junior officer's relative powerlessness is so fundamental to 
the military organization as to make it unlikely to emerge as an issue in our society in the near future, given the maintenance of the military tradition.

The three stories presented here deal with three very different forms of transportation: air, land, and submarine. They also focus on very different levels of concern: the global effects of individual transporters, the social structures evolving around fixed-surface transport-ation systems, and the adaptation of individuals to a highpressure, manmade, enclosed environment. All three stories raise issues concerning the relationship between designed transportation systems and social systems. All of them present hierarchical organizational structures and show how informal structures evolve within them. Finally, all portray women as supportive of men (who are the actors in these stories) and as putting up with the consequences of men's actions.

In each of the sets of stories studied, the idea-gem being presented was the answer to a "what if. . . ?" question. In the nuclear power stories, the authors explored the possible consequences of installing and operating nuclear power plants. In the transportation stories, they explored alternative systems and the possible effects their alternat-ives might have on the culture. In the research and development stories, they examined the process of research in a changing organizational context. Many of the themes these authors have developed have emerged 
as issues in the popular literature in the years following their publication. Some stories have been almost predictive. In this analysis, all of the stories examined have been shown to have provided insights into characteristics of specific innovations and their consequences that would be relevant to decisionmakers concerned with popular responses to those innovations.

\section{COMPARISON OF SPECIFIC IMPACTS DESCRIBED}

The next level of detail in these analyses is an individual comparison of EF stories and IA reports that describe one particular technology. This section describes a comparison of the sets of EF stories focusing on transportation innovations and nuclear power plants analysed in the preceding section with historically significant IA reports describing the same technologies. For both the reports and the stories, the individual works were analyzed and the impacts described were listed. Then the two sets of results were compared and discussed.

Transportation Systems

Two type of transportation systems were described by the EF stories summarized in Chapter III. Heinlein's "The Roads Must Roll" (1942; in Heinlein, 1980) focused on highspeed automated conveyer systems, running between major cities. Herbert's Under pressure (1956) focused on smallscale submarines as underwater tugs. Other stories have focused on these themes, as well. Harlan Ellison describes 
the role of conveyer-belt transportation system in an highly mechanized society in "Repent Harlequin! Said the Ticktockman" (1968; in Greenberg and Warrick, 1974). Arthur C. Clarke describes the use of small submarines as "scout-subs" for whale herders in his The Deep Range (1957). These four stories are compared here to TAs of transportation technologies prepared for the federal government in the late 1970 s.

IA Reports: Transportation. A technology assessment of "future intercity transport-ation systems" through A.D. 2025 was prepared for the National Aeronautics and Space Administration and the U.S. Department of Transportation in 1976 by the consulting firm of Peat, Marwick, Mitchell and Co.. This assessment consisted of four volumes, the fourth of which presents background (context) and transportation scenarios and presents the impacts derived from those scenarios. In the assessment four types of transportation systems are described: air systems, including conventional aircraft, SST, airbus, short runway aircraft, short-haul services, and air traffic control; rail/fixed guideway systems, including AMTRAK service (improved or curtailed), improved passenger trains (IPT), and tracked levitated vehicle systems; bus systems, including improved service (cost/speed/comfort) and small vans; automotive systems, including improved fuel efficiency, higher speed service, and electric-powered vehicles. Neither automated conveyer systems nor marine systems were considered in this IA report 
as being of interest to national intercity transportation policies. However, the report did point out that improved speeds, convenience, and efficiency along high-density traffic corridors--such as those created by freeways or passenger trains--would increase traffic in those corridors by about forty per cent (Peat, Marwick and Mitchell, 1976).

About the time that Peat and Co. were completing their report, SRI International began work on "Transportation in America's Future" (1977).* This report includes reference to the "widely accepted" understanding that "improvements in personal mobility lead to greater freedom of choice for living and working arrangements" (pointing out that Lewis Mumford (1958) was one of very few who accepted this postion even in the late 1950s), and suggested a constant commuter travel time of 1.1 hours as the critical boundary on that development (SRI, 1977). The report also points out that high travel costs tend to reduce commuting to the urban core and encourage job-seeking in suburban areas.

The SRI report describes technologies for A.D. 2025 in the areas listed in Table XVII. Included in the innovative urban systems, Accelerated Pedestrian Conveyers are the same general technology as Heinlein and Ellison have described. SRI's conveyer ranges in speed from 4.5 to 9 miles per hour, most often built in elevated and underground structures. The impacts projected for the conveyers they describe are

*Further references to this report and some description of the methodology employed are included in Chapter V, following. 
limited, due to their small scale and limited application:

downtown cores, shopping centers, and airports. These

impacts include:

1. low labor costs for operating them due to automation and continuous process operations

2. possible high maintenance costs

3. low capital costs for small structures, partially offset by co-construction activities

4. reduced land requirements and fuel consumption for transportation in the downtown core

5. increased attraction to the core because of the innovative systems

6. possible longterm effects on urban renewal and new community designs--similar to the elevator's

These impacts provide some indication of the extent to which the SRI team saw the technology advancing in the next fifty years.

The SRI study also describes submarines, largescale, for carrying bulk liquid or slurry cargo. The report suggests that such subs would be designed to offload at midocean and offshore mining, manufacturing, and energy stations, due to the difficulties of surface loading. Larger submarines are expected in SRI's "success" future (with rapid technological and economic growth), and mediumsized ones are expected in less affluent circumstances.

EF Stories: Automated Roadways. In comparing Heinlein's "Roads" to IA reports, two major points are worth noting. First, the kinds of problems associated with heavy commuter traffic (e.g., strip cities, rush hour peak loads) are, in fact, major problems of concern to transportation 
TABLE XVII

TRANSPORTATION TECHNOLOGIES DESCRIBED IN THE SRI REPORT*

SYSTEM

TYPE

\begin{tabular}{|c|c|}
\hline$\overline{\mathrm{AIR}}$ & $\begin{array}{l}\text { VTOL/STOL aircraft, all-cargo } \\
\text { aircraft, and improvements in } \\
\text { design, materials and production, } \\
\text { avionics, airtraffic control, and } \\
\text { airports; }\end{array}$ \\
\hline SHIPPING & $\begin{array}{l}\text { submarines (bulk carriers), bulk } \\
\text { cargo vessels, barges, small supply } \\
\text { craft, tugs, air cushion vehicles, } \\
\text { hydrofoils, and changes in power } \\
\text { plants, navigation systems, } \\
\text { construction materials, and ports; }\end{array}$ \\
\hline PIPELINES AND TUNNELS & $\begin{array}{l}\text { undersea, slurry, and recycling } \\
\text { pipelines, and tunnel construction } \\
\text { methods; }\end{array}$ \\
\hline RAILROADS & $\begin{array}{l}\text { tracks, control systems, yards, } \\
\text { cars and loading, new systems } \\
\text { (e.g., levitated), and motive power } \\
\text { (electrical, deisel, nuclear); }\end{array}$ \\
\hline AUTOMOBILES & $\begin{array}{l}\text { speeds, power plants, emissions, } \\
\text { and parking; }\end{array}$ \\
\hline $\begin{array}{l}\text { INNOVATIVE URBAN } \\
\text { SYSTEMS }\end{array}$ & $\begin{array}{l}\text { urban rail, commuter rail, } \\
\text { automated guideway transit, charter } \\
\text { buses, auto rentals; }\end{array}$ \\
\hline PARATRANSIT & $\begin{array}{l}\text { limousines, taxis, } \\
\text { jitneys, pooling and cooperatives, } \\
\text { and hitchiking; }\end{array}$ \\
\hline
\end{tabular}

* Stanford Research Institute:(1977) 
and landuse planne rs today, even though, as the SRI report pointed out (SRI, 1978), few people saw the potential as late as the 1950s. This concern is expressed in the Peat and Co. study in their description of "High Density Travel Corridors," specifically including Chicago-St. Louis, Portland-Seattle, and Boston-Washington (1976). Several analyses of highway design and EISs for highway improvements have raised these issues, as well (e.g., Federal Highway Administration, 1974). Both of the assessments agree with Heinlein that a highly successful "work in the city--live in the country" economy, with extensive available energy is at once necessary to maintain such corridors and is encouraged by them.

The second major consideration is the fact that, while the SRI study limits their assessment to the type of "slidewalks" used in airports today, and the Peat and Co. study ignores them completely, Heinlein is talking about massive, highspeed belts. Heinlein's "Roads" are far more like freeways than "slidewalks", offering gradated speeds from twenty to one hundred miles per hour, and including restaurants and other services on the belts. This difference in scale suggests that a comparison to the impacts (already felt)* of freeways may be in some respects more appropriate than to the impacts of APCs. However, a major point of the story is that the "roads" are vulnerable,

* Such a comparison is made in the Retrospective Thematic Analysis section, pp 113-151. 
and that an operator strike in such a centralized system can cripple large sections of the economy--as well as cause great harm to life and property--necessitating a special, paramilitary, training program for such operators and their managers.

Ellison's automated roadways (1968) are part of a society which is ruled by the clock, and the steady, standardized pace of the roadways ensures that everybody gets to his or her appointed place at precisely the proper moment. In the story, the protagonist dresses up as a clown (Harlequin) and dumps a ton or so of jelly beans on a central intersection, causing the roadways to stop and a large number of people to be considerably delayed. Since the roadways are more like SRIs APCs than Heinlein's "roads", few people are injured, but still, the economy suffers from the ripple effect. In addition to offering some biting commentary on certain social trends, this story, like Heinlein's, points out the relative vulnerability of such a transportation system and the broad impacts a breakdown can have.

IA Reports and EF Stories: Automated Roadways. Table XVIII lists the impacts of automated roadways as described by the Peat and Co. report (1976) the SRI report (1977), Heinlein's "Roads" (1942) and Ellison's "Harlequin" (1968). Both the IA reports and the EF stories studied talked about the relationship between commuter transportation systems and the development of High Density Traffic Corridors. Both 
TABLE XVIII

COMPARISON OF IMPACTS DESCRIBED IN EF STORIES AND IA REPORTS: AUTOMATED ROADWAYS

EF Stories*

IA Reports**

High Density Traffic

Corridors

Energy Usage

"work in the city--

live in the country"

increased use with

increased speed,

efficiency, convenience

system-oriented

merchandizing,

restaurants

crippling effects of strikes by service or

operator crew

disastrous effects

of accidents
High Density Traffic Corridors

Energy Usage

"work in the city--

Iive in the country"

increased use with

increased speed,

efficiency, convenience

comparative labor costs for operation and

maintenance

comparative labor use

for operation and

maintenance

possible increased attraction to downtown core

need for special

training and

"socialization"

role of men as

actors, women as

supportive of men

*Heinlein (1946), Ellison (1968)

**Peat, Marwick, Mitchell, and Co. (1976), SRI (1977) 
talked about the high energy usage associated with moving such masses of people and the need for an economy whose production level could sustain that usage. Both also talked about the increased use of such systems as their speed, efficiency, and convenience increases. The IA reports also discussed the comparative labor usage and costs associated with the APCs and the possible increased attraction for the downtown core, should such systems be placed there.

The EF stories also described the emergence of systemoriented merchants (i.e., chain restaurants) and a systemoriented subculture centered around the service personnel for the system. They described the crippling effect of operator strikes and accidents, and the need for specialized training and "socialization" for operator personnel. In addition they presented men as the main actors in the system, with women serving and supporting them as secretaries, wives, and waitresses.

EF Stories, Small-scale Submarines. Herbert's Under Pressure (1956) has been summarized in Chapter Three and analyzed in the Retrospective Thematic Analysis, above. The possible use of small subs as underwater tugboats towing bags full of liquid or slurry cargo is the major innovation focus of that novel. Navy-owned and operated subs are used to haul bags full of oil from undersea wells for use in military applications. With four-member crews and nuclear power plants, these subs are designed for relatively short trips of four to six weeks, providing quick and silent 
undersea travel when unfettered, and steady hauling power when loaded down.

Arthur Clarke's The Deep Range (1957) focuses on mariculture as a potential solution to world food problems. In the story, whales are herded as a source of protein and oil. They are systematically bred and slaughtered to maximize protein production. In addition, they are protected from marauders such as people on whaling boats, sharks, and orcas. In order to effectively meet the needs of the herds, the "whaleboys" ride in one- and two-man subs that are loaded with highly sophisticated communications and navigation equipment as well as the various "tools of the trade" (i.e., tranquilizer harpoons, electrified harpoons, remote control manipulators, etc.).

In these stories, the impacts described for this transportation mode are limited to those experienced by the crews of the subs, their immediate families and their superiors. These include:

1. high pressure on and corresponding stress for operators and crew

2. high correlation with development of undersea resource-based technologies (e.g., in mining, food production)

3. development of special technologies to support the submarines' and crews' needs

4. close relationship with the military

5. redefined conception of oceans by operators

6. special training, psychological preparation for operators

7. use limited to professional operators and crew 
8. long, of ten unexpected absences from home for operators and crew

9. overlap with space technologies

10. development of system-oriented subcultures

11. modification of bureaucratic structures to support the technology.

These impacts overlap considerably with those of the transportation stories; one author is present in both groups and the writers were in communication with each other periodically over the years during which the stories were written. Yet the impacts described for both forms clearly are related to the technologies which they derive from, suggesting the possibility that there are some constants in human responses to system innovations.

IA Reports: Small Subs. Of the two IA reports on transportation systems, only one mentioned submarine transport and that was limited to large cargo subs (SRI, 1978). No discussion of the impacts of such a transportation mode was included in the report. Further, in a technology assessment of mariculture (Mitre, 1973), no mention was made of such vehicles in overseeing or managing the crops. Therefore, no comparison can be made with IA reports on this subject.

Nuclear Power Plants

The stories analyzed in this section were written in the years when nuclear power plant technology was in its infancy. They describe the plants from the point of view of individuals working in them and as a result, offer a unique, 
individual perspective on the problems and potentials of the technology. The IA reports analyzed here were selected as models of the state-of-the-art for the IA process, and because of the important role they played in the decisionmaking process regarding the implementation of nuclear power plant technologies in this country.

Impacts in IA Reports. Many of the Iongest and bestknown environmental impact statements produced in this country are the results of assessments of nuclear power plants. This section describes a critical environmental assessment and an early (pre-TA legislation) technology assessment, listing the impacts described in them. These two reports were chosen on the grounds that they were, in fact, the critical assessments leading to the current national policy with regard to nuclear power, and that they represent the most complete examples of the state-of-the-art following the period in which the EF stories analyzed were written, thus typifying the results likely to be achieved with any other assessments.

The Seaborg Report. The 1962 decision to implement the commercialization of nuclear power was made pursuant to legislative guidelines set in amendments to the Atomic Energy Act, on the basis of a report from the AEC to President Kennedy (Seaborg, 1962). The President had requested the report from the Director of the Atomic Energy Commission to describe the potential for commercializing 
nuclear power. Specifically, he asked the chairman of that commission to

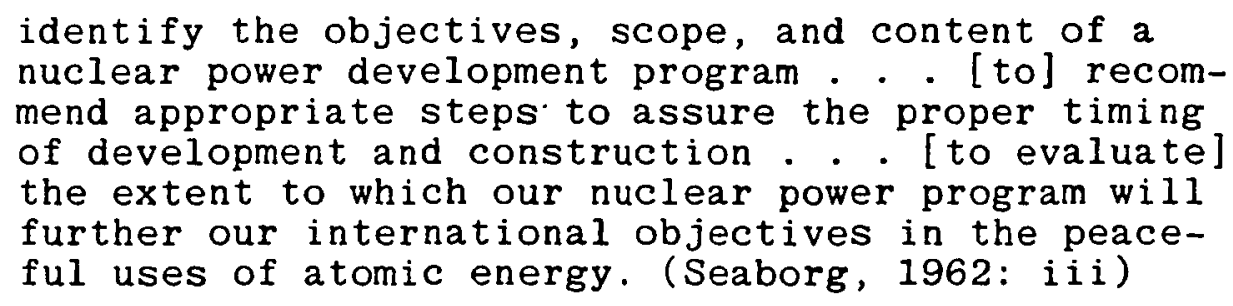

In addition, the president called for "realistic forecasts

of the future of economically competitive nuclear power in this country" (Seaborg, 1962: iii).

The chairman of the AEC at that time, Dr. Glenn T. Seaborg, replied eight months later with a sixty-seven page document whose table of contents is listed in Table XIX. In keeping with the tone of the President's request, $\mathrm{Dr}$. Seaborg provided information concerning the current status of electrical power generation and of nuclear power, outIined a set of objectives for the immediate, intermediate, and long-range futures, and briefly described (in less than ten pages) programs in place to deal with construction problems, siting problems, waste handling problems, a number of policy issues concerning the processing and ownership of nuclear materials, and the expected impacts of nuclear power on the coal and transportation industries. The report stated that while there had been some problems in bringing experimental plants on line, nuclear power was clearly costeffective and could bring relatively cheap electricity to those parts of the country where other fuels were becoming increasingly expensive. 
TABLE XIX

THE SEABORG REPORT: TABLE OF CONTENTS

Page

INTRODUCTION . . . . . . . . . . . . . . 1

SUMMARY . . . . . . . . . . . . . . 7

THE NEED FOR NUCLEAR POWER . . . . . . . . 16

Nuclear Energy as a Resource . . . . . . . . . 16

Benefits of Nuclear Electric Power . . . . . . . 23

THE ROLE OF GOVERNMENT. . . . . . . . . . . 27

THE PRESENT SITUATION . . . . . . . . . . . . . 29

REACTOR SYSTEMS . . . . . . . . . . . . 35

Converters . . . . . . . . . . . . . 35

Breeders . . . . . . . . . . . . . . . . 37

Probable Trends . . . . . . . . . . . . . 39

ASSESSMENT OF THE DEGREE OF URGENCY . . . . 42

STATEMENT OF OBJECTIVES . . . . . . . . . . 48

THE FUTURE PROGRAM . . . . . . . . . . . 49

A Program for the Immediate Future . . . . . . . 49

The Intermediate Program: Improved Converters . . 50

Program for the Long-Range Future . . . . . . . 51

A Possible Construction Program . . . . . . . . 51

SUPPORTING TECHMICAL PROGRAMS . . . . : . . 53

General Technology . . . . . . . . . . . . 53

Reactor Safety: Siting Problems . . . . . . . . 54

Waste Mianagement . . . . . . . . . . . . . 54

LEGAL, FINANCIAL AND ADMINISTRATIVE

MATTERS . . . . . . . . . . . . . . 56

Policies Relating to Nuclear Materials . . . . . 56

Ownership of Special Nuclear Materials . . . . . 56

Toll Enrichment . . . . . . . . . . . . . 57

Plutonium Prices . . . . . . . . . . . . 57

Uranium Procurement . . . . . . . . . . . 58

Service Industries . . . . . . . . . . . . . . 59

Licensing and Regulation. . . . . . . . . . . 60

POSSIBLE INDUSTRIAL IMPACTS OF THE

NUCLEAR POWER PROGRAM . . . . . . . . . . 61

The Coal and Transportation Industries . . . . . . 61

APPENDIX . . . . . . . . . . . . . . 65

SOURCE: Seaborg, G.T., "Civilian Nuclear Power, A Report to the President" Atomic Energy Commission, Washington, D.C., 1962. 
In the Introduction to the report, Seaborg pointed out that after building six plants,

sufficient developmental and operational experience has been accumulated to permit a reasonably accurate assessment of future possibilities. Nuclear electric power has been shown to be technically feasible, indeed readily achieved. Power reactors can be reliably and safely operated. However, contrary to eariler optimism, the economic requirements have led to many problems. . . Attempts to optimize the economics by working at the outer fringes of technical experience, together with the difficulties always experienced in a new and rapidly advancing technology, have led to many disappointments and frustrations. . . Many construction projects have experienced delays and financial overruns (Seaborg, 1962: 4).

Nonetheless, Seaborg concludes

Nuclear power is believed to be on the threshold of competitiveness with commercial power for large plants, in areas of the country where fossil fuel costs are high (Seaborg, 1962: 5).

Table XX Iists the impacts of nuclear power plants described in the AEC report. Clearly, the focus of concern is at a much higher level of generality than in an environmental assessment for a single plant (as described below), making this report one of the first technology assessments.* That it was the basis for President Kennedy's decision to support a program for commercializing nuclear power in this country makes this report doubly important for consideration here.

*Even though written before the TA legislation was passed, this is the only published assessment of the technology per se, and was intended to fill the role of a technology assessment--that of informing federal-level decisionmakers concerning the impacts of implementing a nationwide program or policy. 
TABLE XX

SUMMARY OF IMPACTS IN THE SEABORG REPORT*

- . The above projected use of nuclear power would result in . . annual savings . . between $\$ 4$ billion and $\$ 5$ billion...

High cost power areas would no longer exist. . .

- . would add to the health and vigor of our industrial and general economy . . .

The Technical program would assist the space and military programs . .

Our international leadership in the field would be maintained with benefits to our prestige and foreign trade...

- . would not burden the transportations system during national emergencies. . . 
The Three Mile Island Assessment. In 1976, the Nuclear Regulatory Commission (NRC) published the final draft of the Three Mile Island (TMI) environmental impact statement (NRC, 1976). Unlike many of its predecessors (e.g., the report on the Hudson River plant--14 volumes--or the San Onofre plant report--7 volumes), this statement was relatively brief (eleven chapters). Much of the length common in earlier reports was avoided by effective use of references to related analyses. In this way the TMI assessment clearly reflects the growing body of knowledge and expertise about nuclear power plants and their effects. And, in fact, at the time of publication, it was considered a "model" assessment.

Chapter Seven of the TMI IA report deals with the impacts of postulated accidents at the TMI plant. Table XXI describes the classes of accidents from which the accidents whose impacts were analyzed were chosen. Of these classes, impacts for all but Class Nine were analyzed. Regarding Class Nine, the report states:

The postulated occurrences in Class 9 involve sequences of successive failures more severe than those required to be considered in the design bases of protection systems and engineered safety features. Their consequences could be severe. However, the probability of their occurrence is judged so small that their environmental risk is extrernely low. (NRC, 1976: 7-1).

Such a refusal is not unusual in NRC assessments, and is permitted by the Code of Federal Regulations (10 CFR, part 51) in a paragraph that describes "negative declarations" (10 CFR, 51.7). This section requires that the declaration 
TABLE XXI

CLASSIFICATION OF POSTULATED ACCIDENTS IN

THE THREE-MILE ISLAND REPORT*

\begin{tabular}{|c|c|}
\hline Class & AEC Description \\
\hline $\mathbf{I}$ & Trivial Incidents \\
\hline 2 & $\begin{array}{l}\text { Small Releases Outside } \\
\text { Containment }\end{array}$ \\
\hline 3 & Radwaste System Faflure \\
\hline 4 & $\begin{array}{l}\text { Fission Products to Primary } \\
\text { System (BWR) }\end{array}$ \\
\hline 5 & $\begin{array}{l}\text { Fission Products to Primary } \\
\text { and Secondary Systems (PWR) }\end{array}$ \\
\hline 6 & Refueling Accidents \\
\hline 7 & Spent Fuel Handling Accident \\
\hline 8 & $\begin{array}{l}\text { Accident Initlation Events } \\
\text { Considered in Design Basis } \\
\text { Evaluation in the Safety } \\
\text { Analysis Report }\end{array}$ \\
\hline
\end{tabular}

9

Hypothetical Sequences of Failures More Severe Than Class 8 .

\section{Accident's Example(s)}

None

Spili in Sample Hood

Inadvertent Release of Waste Gas Decay Tank

Not applicable

One day Operation with Primary System Leak to Reactor Buflding

Normal Operation with Steam Generator

- Tube Leak and Release from Condenser

Drop of Fuel Assembly or Drop of Heavy object on Fuel Assembly

Drop of Fuel Assembly

Uncompensated Operating Reactivity Changes

Startup Accident

Rod Withdrawal Accident

Moderator Dllution Accident

Cold Water Accident

Loss of Coolant Flow Accident

Stuck-Out, Stuck-In, or Dropped Control Rod Accident

Loss of Electric Load Accident

Steam Line Fallure

Steam Line Leakage

Steam Generator Tube Fallure

Rod Ejection Accident

Loss of Coolant Accident

Waste Gas Tank Rupture

None

*Nuclear Regulatory Commission (1976) 
will state that the Commission has decided not to prepare an environmental impact statement for the particular action and that an environmental impact appraisal setting forth the basis for that determination is available for public inspection (10 CFR 51.7 ).

For this report, then, as for many NRC reports, the commission decided not to describe impacts except for those of accidents less than Class $\mathrm{Nine}$ in intensity, and used their standard paragraph referring the reader to an appraisal that explains the minimal probability that such an accident could occur. As a result, in the Final Draft version of the EIS that includes comments by reviewers and responses by the preparers, the Department of Interior requested an analysis of Class Nine accidents, but the NRC staff disagreed--once again on the grounds that the probability of such an accident was "acceptably low, and that generic discussion of these events are adequate" (NRC, 1976: 11-6). Moreover, as a result of these refusals to perform such an analysis, the TMI assessment does not include descriptions of the impacts of an accident such as those described in the stories describing this technology (i.e.,"Blowups Happen" where overstressed operators made errors adjusting coolant valves and moderators (Heinlein, 1940; 1946), and "Day of the Moron" where inadequately prepared operators started up the reactor with fuel "stuck in" and caused it to reach critical mass (Piper, 1951)) that are analyzed later in this chapter.*

* "Counterspy," where loss of primary coolant flow was presented as a way to destroy a nuclear reactor (Edwards, 1953), would be considered a Class Eight accident. 
The missing analysis is an especially unfortunate lack in light of the fact that the accident that occurred at Three Mile Island in 1979 was the result of a sequence of failures described by Class Nine, whose environmental risk was deemed "acceptably low" in the IA process and so was not planned for (Nuclear Regulatory Commission, 1979; The President's Commission on Three Mile Island, 1979). In that accident, according to later investigations,

The plant experienced a total loss of feedwater, initiated by a loss of condensate flow with an almost simultaneous trip of the main turbine. Reactor coolant system (RCS) temperature and pressure increased. The PORV [pilot-operated relief valve] opened as designed. . . The PORV failed to close when its lower set point was reached. . . This failure of the PORV to close when the pressure decreased, followed by early operator action that throttled the flow from the HPI [high pressure intake] pumps, initiated an abnormal sequence of events that led to this severe accident. (President's Commission on Three Mile Island, 1979: 176)

The report goes on to state that

the absence of this [PORV] signal in the control room added to the confusion of the operators during the TMI-2 accident. . . . The PORV was not classed as a safety-related component . . There have been 11 failures of PWR [pressurized water reactor] PORVs failing in the open position before TMI-2... The NRC has not highlighted PORV problems as an unresolved safety issue . . (President's Commission on Three Mile Island, 1979: 209)

During the "confusion in the control room" the operators made three critical errors, one of which has already been alluded to. According to the NRC investigation of the accident,

At the time of the initiating event, loss of feedwater, both of the auxiliary feedwater trains were valved out of service... 
Subsequently the high pressure injection system was intermittently operated...

Tripping of reactor coolant pumps during the course of the transient, to protect against pump damage due to pump vibration, led to fuel damage...

(Nuclear Regulatory Commission, 1979)

Clearly the events at Three Mile Island are precisely of the type described in the nuclear power plant stories, as well as of the Class deemed too unlikely to be included in an IA report.

Table XXII lists the impacts described by these critical, state-of-the-art IA reports. In the area of accidents, the table shows that the TMI assessment described radiation exposures for surrounding populations for four types of accidents. No impacts on personnel were described for the plant's normal operation. Economic impacts included expected annual savings for the nation as a whole from implementing the technology, cost overruns resulting from trying to build the latest (not necessarily proven) designs, and the expectation that discrepencies in the cost of electricity in different areas of the country would be reduced as high-cost areas were provided nuclear power. Impacts on related technologies included assistance for space and military programs, reduced strain on existing transportation systems during national emergencies, and an expectation of no significant effect on coal technologies from the introduction of nuclear fuels (because of expected increases in demand for electricity). Impacts on related corporate or governmental structures and organizations were not described. 


\section{TABLE XXI I}

IMPACTS DESCRIBED IN THE IA REPORTS ON NUCLEAR POWER PLANTS

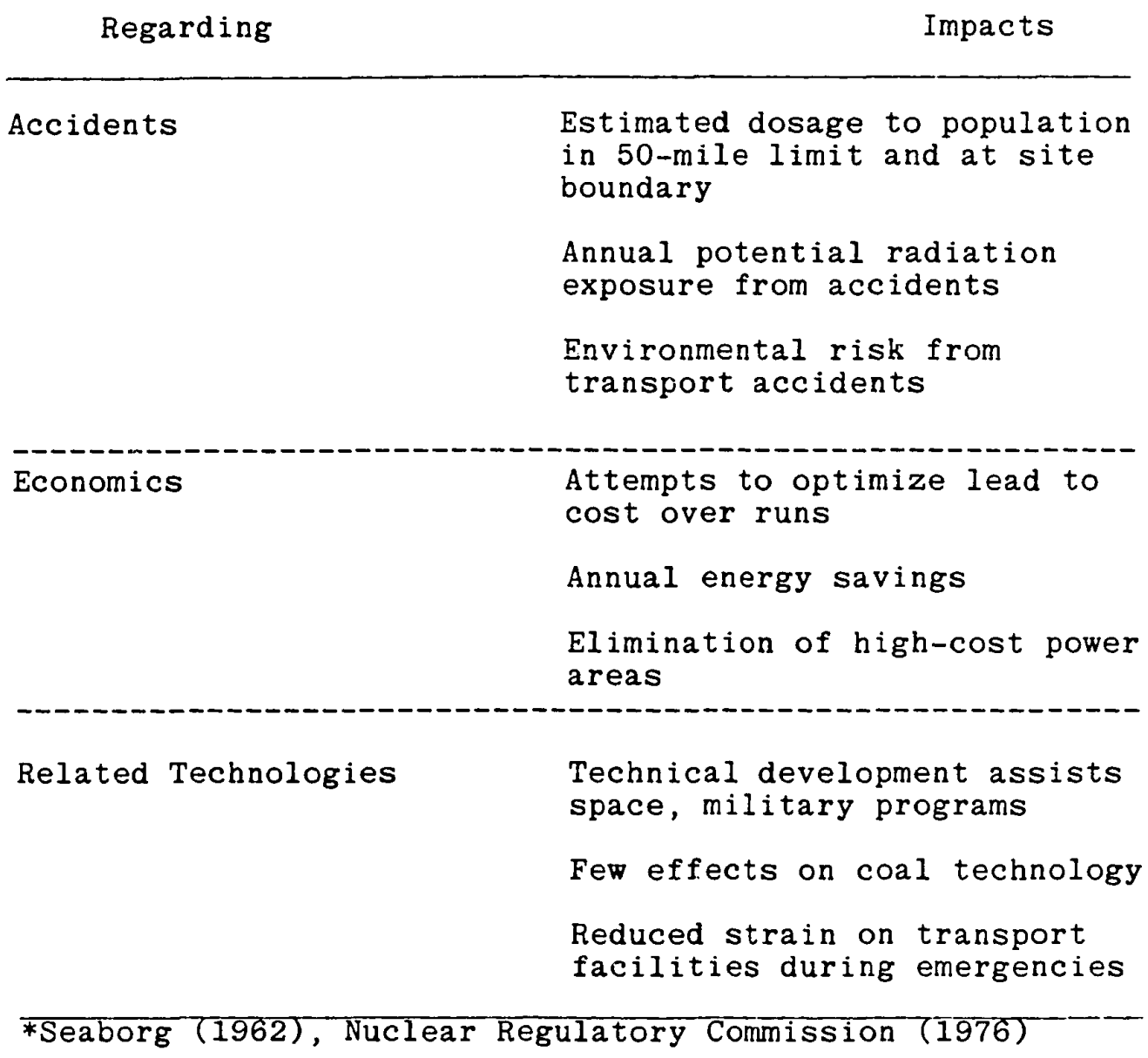


Impacts in Extrapolative Fiction. Through the 1940s and 1950s, most science fiction writers made use of nuclear technologies in their stories. A few of these writers became fascinated with the technology itself and wrote extrapolative stories exploring the consequences of its largescale implementation. Because they were fiction, these stories had to have two important ingredients: (1) a focus on individual human beings and their responses and (2) a crisis. As a result, the writers who produced the stories were compelled to examine the technology for potential human problems. When they found one (or more) that appealed to their own imaginations and their models of social change processes, they developed stories to present the problem(s). (See Chapter III for further discussion of this production process.)

Three stories, in particular, written in the years 1940-1955, focus on the impacts of nuclear power plant construction and operation and are relevant to any discussion of the consequences of implementing nuclear powergeneration technologies.* "Blowups Happen" is the earliest, written by Robert A. Heinlein in 1940 and updated in 1946. The technological description is limited by what was known at the time, but his presentation of the human problems-affecting operator efficiency and policymaking capabilities

*These stories are summarized in Chapter III, and are analyzed in terms of the issues they raise in the preceding section ( $p$ p 120-148). 
--associated with operating nuclear power plants has been shown (by the experiences at Turee Mile Island and of the Washington Public Power Supply System, among others) to be relatively accurate. Its focus is on the individual and organizational consequences of building and operating largescale nuclear power plants as Heinlein saw them in 1940 and 1946. "The Day of the Moron" was written by H. Beam Piper in 1953, when the United States government was installing some of the first nuclear power plants and the "atoms for peace" novement was emerging. His story, like Heinlein's, deals with the personnel problems in building and operating such a plant and, again, presents the technology as it was understood at the time of his writing, although with an insider's awareness of the potential dangers. "Moron" describes a set of problems stemming from a situation that has since been shown (at Three Mile Island) to be a major source of concern: inadequate training and testing of those whose job it is to work with a highly dangerous and poorly understood technology. Finally, "Counterspy," by K. Edwards (1951), is the third story to be examined here. The focus is a weapons research plant that is only incidentally a power plant, but the story graphically portrays the ways and means terrorists might use to cause a breakdown in the operation of a nuclear reactor.

These three stories explain nuclear power plant technology and raise a number of important issues regarding its implementation. As Table XXIII shows, they portray a set 
TABLE XXIII

CONCERNS ABOUT NUCLEAR POWER PLANT TECHNOLOGIES AS DESCRIBED IN EF STORIES*

-The relative danger of nuclear power plant accidents (compare to other technologies)

-The special training and character requirements for nuclear reactor operators

-The role of nuclear power plants in meeting the growing demand for electricity in this country

-The effects on decisionmaking of the heavy capital investments required

- The need for decisions concerning the plants that cannot be made by a Chief Executive Officer in a bureaucracy

-The personal danger for those who work in nuclear power plants

-The strain on management, operators, and security people responsible for preventing accidents

-The vulnerability of large, centralized power systems based on nuclear power plants

-The necessity for heavy security around nuclear reactors

-The potential problems of dealing with unions in critical work areas

* Heinlein, 1946; Piper, 1953; Edwards, 1951 
of problems and consequences associated with implementing nuclear power-generation technologies that have emerged as important to decision-makers concerned with the impacts of such plants on our society and its environment. However, as was made clear in the discussion of impacts described in assessments, these concerns were not included in some of the critical IA reports on nuclear power that were produced in the period following the publication of these stories.* Comparison of Impacts. Clearly, there are sibstantial differences between the types of impacts described in the EF stories and those described in the IA reports. Table XXIV presents those differences. Both the AEC (Seaborg) and the NRC reports have followed the pattern identified in the statistical content analysis (pp. 101-112). They have emphasized quantitative ecological, economic, and demographic impacts, while ignoring the personal and institutional impacts resulting from the implementation of the innovation. The EF stories have similarly followed the pattern of the stories analyzed in that section, identifying a broader range of possible impacts and emphasizing social and quality-of-life factors such as emotional well-being and personnel management problems.

* It is worth noting here that an IA report prepared by the Office of Technology Asscssment (1983), did describe the effects of detonating a nuclear weapon $i \bar{n}$ a U.S. city. Although this report provided the impetus for the highly controversial television film "The Day After" (American Broadcasting Corporation, 1983), it still does not deal with the human concerns associated with nuclear power plants. 
TABLE XXIV

\section{COMPARISON OF IMPACTS DESCRIBED IN IA REPORTS}

\section{AND EF STORIES: NUCLEAR POWER PLANTS}

\begin{tabular}{|c|c|c|}
\hline Regarding & Fiction & Assessments \\
\hline \multicolumn{3}{|l|}{ INDIVIDUALS AND GROUPS } \\
\hline - Accidents & $\begin{array}{l}\text { No electrical power for } \\
\text { large segments of the } \\
\text { country } \\
\text { Many people injured or } \\
\text { kilied }\end{array}$ & $\begin{array}{l}\text { Estimated fraction of } \\
\text { 10 CFR Part } 20 \text { limit } \\
\text { at site Doundary of } \\
.001 \text { to } 1.2 \\
\text { Estimated dose to } \\
\text { Population in } 50- \\
\text { mile radius/man-rem } \\
.25 \text { to } 1100 \\
\text { Annual potential radia- } \\
\text { tion exposure from } \\
\text { accidents is well } \\
\text { within normal varia- } \\
\text { tions of background } \\
\text { Environmental risk from } \\
\text { transport accidents: } \\
\text { l fatal injury in } 10 ; \\
\text { s475 property damage/yr }\end{array}$ \\
\hline \multirow[t]{3}{*}{-Personnel } & $\begin{array}{l}\text { High stress for operators } \\
\text { managers and technical } \\
\text { personnel }\end{array}$ & \\
\hline & $\begin{array}{l}\text { Heavy burden from need } \\
\text { for security }\end{array}$ & \\
\hline & $\begin{array}{l}\text { Need for special } \\
\text { training and } \\
\text { character in plant } \\
\text { workers }\end{array}$ & \\
\hline \multirow[t]{3}{*}{ ECONOMICS } & \multirow[t]{3}{*}{$\begin{array}{l}\text { Substantial capital } \\
\text { investment in plants } \\
\text { Local economy grows } \\
\text { around plant workers }\end{array}$} & $\begin{array}{l}\text { Attempts to optimize } \\
\text { by working at the } \\
\text { technology's edge } \\
\text { leads to cost overruns }\end{array}$ \\
\hline & & $\begin{array}{l}\text { Annual savings of } \\
\text { s4-5 billion }\end{array}$ \\
\hline & & $\begin{array}{l}\text { High cost power areas } \\
\text { no longer exist }\end{array}$ \\
\hline \multirow[t]{3}{*}{ RELATED TECHNOLOG:ES } & $\begin{array}{l}\text { New cybernetic controls } \\
\text { development }\end{array}$ & \multirow{3}{*}{$\begin{array}{l}\text { Technical development } \\
\text { will assist space and } \\
\text { military programs } \\
\text { No significant effect } \\
\text { on coal technologies } \\
\text { Reduced strain on } \\
\text { transportation system } \\
\text { during national } \\
\text { emergencies }\end{array}$} \\
\hline & $\begin{array}{l}\text { Reduced use of coal-fire } \\
\text { technologies }\end{array}$ & \\
\hline & $\begin{array}{l}\text { Use of radio-isotopes } \\
\text { in medicine, military, } \\
\text { transportation }\end{array}$ & \\
\hline \multirow[t]{3}{*}{$\begin{array}{l}\text { CORPORATE/ } \\
\text { GOVERNMENT STRUCTURES }\end{array}$} & $\begin{array}{l}\text { Increased need for } \\
\text { security means increased } \\
\text { power for security } \\
\text { personnel }\end{array}$ & \\
\hline & $\begin{array}{l}\text { Heavy government involve- } \\
\text { ment ard regulation of } \\
\text { nuclear power industry }\end{array}$ & \\
\hline & $\begin{array}{l}\text { Need for decisions that } \\
\text { can't be made by a Chief } \\
\text { Executive Officer because } \\
\text { of redtape and policy } \\
\text { overrides }\end{array}$ & \\
\hline
\end{tabular}


The results of these comparisons between EF stories and IA reports--especially in light of the results of the analyses described above--demonstrate the complementarity of the two approaches to considering the consequences of innovation and suggest a strong need for some integration of extrapolative fiction into the IA process if all the relevent impacts for a given innovation are to be described by a given impact assessment. 


\section{CHAPTER V}

\section{USING EXTRAPOLATIVE FICTION IN IMPACT ASSESSMENT}

The previous chapters described analyses of both EF stories and IA reports in terms of their differences and similarities in content. The results of those chapters suggest that the use of extrapolative fiction has some potential utility for assisting decisionmakers considering the consequences of current actions. This chapter explores ways that EF stories and IA reports can be combined to provide a more effective tool for that purpose. The first sections of this chapter provide a framework for doing so, building on the results of previous chapters and outlining an expanded approach to impact assessment that makes such a synthesis possible. Later sections describe alternative formats within that approach and provide illustrative examples of two of the alternatives suggested.

\section{A SYNTHESIZED APPROACH}

An approach that combines extrapolative fiction and impact assessment would include an iterative sequence of activities based on the steps in Table III (p.32). It would start with a description of the innovation--technology, dam, federal land management program, etc.--being studied in the context of the human--social, techno-economic, and physical 
--environment in which it will be placed. That description may include alternative actions being considered, and would definitely include an analysis of the implementation process. In short, this description would provide the information regarding the innovation on the basis of which the impact analysis may be developed. It would be followed by a forecast of the relevant aspects of the innovation. In an EIS, that might be a description of new construction techniques as they affect a building project under study. In a TA, forecasts of related technologies or of expected changes in the technology being assessed would be described here--as, for example, the development of graphic terminals would be an important determinant of the rate and level of impact of graphics-based production control systems. In a social impact assessment, both the new techniques for implementing the innovation and expected changes in related areas would be included, along with any other expected changes in the implementation of the innovation for the period of study.

This process views impact assessment as based on a new definition of purpose--a driving question that differs from that driving the current IA process. The history and criticisms of impact assessment described in Chapter II, combined with the absence of certain impact areas found in the statistical content analysis, provide the bases for an enlarged definition. Rather than asking: 
What are the likely short-and long-term impacts of such-and-such an innovation on a society or community and its environment?

the new process asks a new kind of question, tentatively stated as:

What are the agencies, actors, and systems which will most strongly affect or be affected by this innovation and how can the key actors be led to understand--ultimately to be able to act on the understanding of--the effects?

This question focuses on the individuals and organizations likely to be involved in the implementation of the innovation as well as the social, physical, and other systems and environments.

As a new kind of problem statement this question requires new kinds of information for its answer--much of it nonquantifiable. Moreover, the new information would be gathered and synthesized within a framework designed for a specific assessment, and new techniques would permit the synthesis of a gestalt as well as the analysis of the parts. The resultant product would, in turn, fulfill the objectives for which impact assessment was originally conceived (as described in Chapter II).

Collecting Information

An enhanced IA process, asking for new kinds of information, requires new techniques for collecting that information. In the traditional IA process, both primary and secondary sources are used to develop a data base. The use of questionnaires, hearings, and literature reviews is 
traditional, along with numerical indicators from a variety of secondary sources, which are then analysed as data points using quantitative methods. An expanded process uses these, and adds the investigative reporters' sources--interviews, internal documents, and informal communication media-for information that may be useful in conjunction with the results of traditional data manipulation. Moreover, such an approach emphasizes the need for personal, anecdotal information as potential sources for useful insights and intuitively comprehendable images.

It emphasizes as well, the iterative nature of the research and analysis process. The use of a "first-cut," or "scoping," phase is encouraged,* along with the use of EF stories as a way to develop that gestalt. Second and third cycles through the process, again using the models and devices of extrapolative fiction--along with the more traditional analytical techniques--increase the likelihood that the necessary information is included.

Developing Models

In an enhanced IA process, assessors recognize the importance of mental and verbal models as well as dynamic and structural models in assessment methodologies (see

* In such a phase, the team works through the whole project once quickly to generate a "gestalt"--an intuitive sense of the nature of the system-under-study--before proceeding with the analysis in a more rigourous fashion. Typically, key actors are identified and major issues are defined in the scoping or first-cut analysis. (see Porter et al., 1980; Armstrong and Harman, 1978) 
Figure 9). They recognize that clarifying their mental models provides them with (and depends on) an intuitive understanding of the system. This may be generated by a verbal model, and is followed by a verbal model that provides the initial parameters of the study and the system. A structural model at this point may illustrate the elements of the system and their relaiionships in a simple graphic form. The resulting diagram may be (though not necessarily, depending on the study) translated into a set of equations which may then become one or more dynamic models, describing the relationships between the elements over time. This dynamic model, then, is used along with other kinds of information to form a new set of mental models. Using the new mental model, the assessors then produce new verbal models to communicate their understanding to others.

With this process assessors can address the new objectives. Moving from one modelform to another through the analysis and research, emphasizing the important mental and verbal models, they can begin to deemphasize structural and dynamic models.* Shifting their focus from the tools of assessment to the innovation and its effects, these assessors can identify the strongly affected parties and systems, as well as the key actors and agencies likely to affect the innovation. Then, having done so, they can

*Armstrong and Harman (1978) and Linstone et al. (1978) recommend that structural and dynamic models should play an ancillary roie in the assessment process, rather than the central role which they currently play in most assessments. 


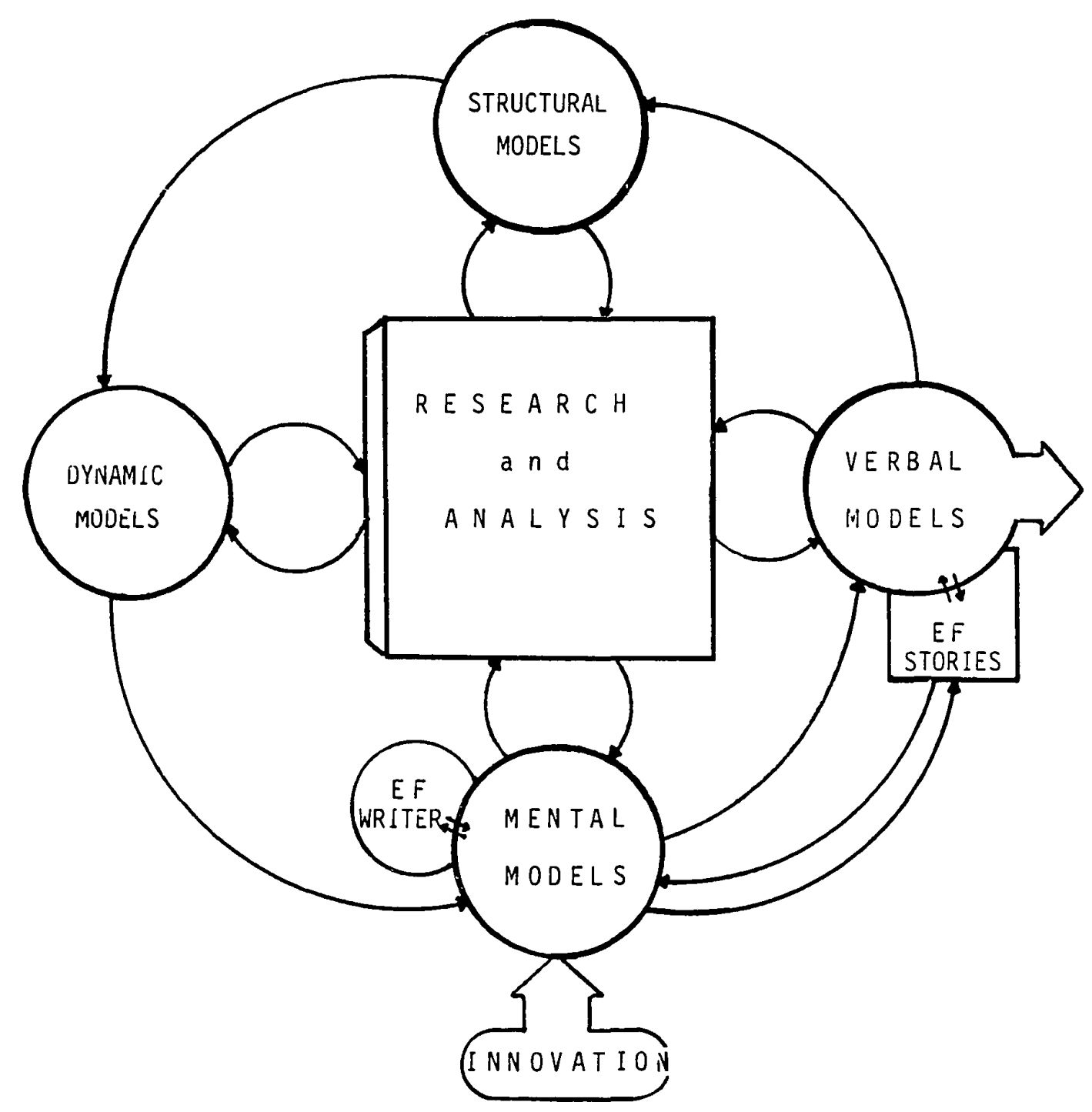

Figure 9. The pattern of modelforms in a synthesized approach, with its emphasis on mental and verbal models. 
address the results of their efforts to the appropriate audience.

Modeling the system-under-study becomes much more complex in this enhanced IA process than was apparent in the traditional process. By consciously including nonquantifiable impacts on the society as a whole, the community, and other programs within the problem definition, assessors may no longer rely on structural of dynamic computer models as the primary method for testing their alternatives. Porter and his colleagues recognize this when they state that "common sense, insight, and intuition are still the assessor's best guides" to developing and describing possible futures (Porter et al., 1980: 157). The contribution of extrapolative fiction may be most strongly felt in this activity.

Communicating the Results

This enhanced IA process shifts the focus of assessment activities toward sharing information about the innovation with the appropriate actors and away from gathering data and applying quantitative analytical techniques. Reports of results are therefore seen as providing decisionmakers with information that is about the impacts of an innovation on a community or society and the responses available to them within the framework of their organizations' policies and procedures. The report is also seen as communicating a gestalt of the system--shifting the decisionmaker's image of 
the nature of the innovation and its impacts toward a wider, more inclusive view.

The concerns described in Chapter II indicate that this perception of the IA report has not been the norm in the past. Impact assessment traditionally has been seen as a primarily analytical process, assuming that the rigor and scientific objectivity necessary to meet its objectives were possible only by emphasizing the techniques of quantitative analysis. To a large extent this assumption reflects the assumptions of the field's immediate precursors--operations research and systems engineering--and the "technical" perspective (Linstone, 1983) from which practitioners in those fields operate. According to Linstone and his colleagues, this perspective tends to treat all kinds of situations and systems as problems amenable to data-oriented modeling techniques and their inherent reductionism. The characteristics of the technical perspective contribute to an impact assessment methodology in which analysis is emphasized and synthesis is misunderstood or avoided, in which generalizations are sought and idiosyncrasies eliminated, and in which the need for objectivity requires that the human subjectivity of the investigator be (at best) downplayed or (at worst) rationalized away (Linstone, 1983). However, the users of these assessments must make an intuitively acceptable decision about implementing an innovation. The assessors who wish to have their results used, therefore, "should not only know who the readers are, 
but also should estimate what sort of interest and attitudes and how much understanding they will bring" to the presentation (Haemer, 1965: 16). Their report should reflect the fact that their audience--the decisionmakers-must make judgements, create new alternatives, or at the least understand the nature of the system-under-study based on the material presented. Moreover, the report should assist decisionmakers to make effective use of their intuitive sense--or mental models--in the decisionmaking process, helping them overcome the notion of subject-vs.object long enough to perceive the system with which they are concerned as part of themselves.

The form in which information about the system is communicated has a substantial effect on decisionmakers' ability to achieve this realization and to change their mental model or image of that system. Kenneth Boulding addresses this problem in his study of communication and mental images (1977). He states, "changes in the image as a result of symbolic intercourse (language) would depend, of course, on the skill of the communicators" as well as the capacity of the medium used (Boulding, 1977:55).

The effective communicator, according to Boulding, is one who chooses to send a message using the particular combination of elements from a common symbol set that the recipient can absorb and respond to with a minimum of filtering and translating. This means that the effective conmunicator of an innovation's effects must choose from 
several types of verbal models, ranging from highly imagistic poetry, novels, and short stories, through journalistic reports, to the technical articles and reports that Root had in mind when he presented the model-forms described above (p. 196). Each of these verbal models has its own set of language (i.e., artistic or technical), guidelines (e.g., structured, verifiable, aesthetically pleasing), and audiences. Each draws on a rich history and tradition that tends to dictate the style and perspective of the author. In general, it may be said that choice of type "requires identification of the potential assessment users and of the sorts of information and forms of presentation they require" (Porter, et al., 1980:400]. If the goal is to change the image of the decisionmaker so that it includes the range of effects and options associated with an innovation, then the model chosen must reflect that goal.

In this synthesized approach, with such goals, the use of such alternative verbal models such as EF stories and well-written scenarios becomes increasingly important. These new verbal models can include both specific individual and broadscale societal or organizational information about innovations and their impacts. They provide alternative images and encouraging an intuitive understanding, thereby facilitating the decisionmaking process as they report assessors' results. 
Including Extrapolative Fiction

By now it should be clear that meeting the objectives of impact assessment becomes more likely with an approach that includes the kinds of models and techniques that make up extrapolative fiction. The discussion so far does not explain, however, precisely how such EF models and techniques can be merged effectively with the more formal and quantitative IA approaches. That question is the focus of this section. The following pages explore ways and means of including such models and techniques in the IA process as currently practiced.

Two basic alternatives for incorporating extrapolative fiction into an impact assessment methodology are considered here. In the first alternative, the fiction is appended to a completed process as a means for illustrating the results. In the second, the fiction contributes to the research and analysis process: the assessment team uses already published stories that deal with the technology or policy in question in their research process, or includes one or more members who can write one or more new stories in conjunction with an ongoing study.

\section{APPENDING EF STORIES TO IA REPORTS:}

\section{ALTERNATIVE FORMATS}

At least four interesting possibilities exist for the use of previously published EF stories in or alongside an IA report. (1) The report could actually include one or more 
short stories as scenarios of possible futures (along the lines suggested by Porter et al., 1980). Or, an anthology could be put together--either (2) in place of the report, but with extensive editorial comments and technical appendices, or (3) along with the report, to exemplify some of the impacts and issues raised in the report. Finally, (4) passages from relevant stories could be included in the report to clarify or demonstrate the extent of specific issues and impacts.

Stories as Scenarios in the Report

One possible outline for including stories as alternative scenarios in an IA report is presented in Table $\mathrm{XXV}$. This outline presents the assessment findings in a brief summary, places the stories early in the report as imagistic models of the results of alternative actions on the part of decisionmakers, and includes the analytical, methodological, and technical support descriptions at the end of the report. In such an outline, the stories serve to provide the reader with clear images of the possible effects of the innovation and of the potential results from the decision options that are available. The more technical material, describing the basis for the stories, are placed after these imagistic summaries in increasingly detailed sections, where they can be used but need not be waded through to discover the meaning of the report. 


TABLE XXV
POSSIBLE OUTLINE FOR AN IA REPORT
THAT INCLUDES EF STORIES

Summary of Conclusions, Recommendations

Alternative Scenario \#I ("story title")

Alternative scenario \#2 ("story title")

$\cdot$

$\cdot$

Issues and Policy Options

Summary of Analysis and Results

Methodology

Data Base

Background Paper \#l (detailed report of analysis)

Background Paper \#2

References

Index 
A good index is essential to a report organized in this way, so that information about points raised in the stories and summary material at the beginning can easily be located elsewhere in the text as questions come up or the reader's interest is piqued.

\section{Anthologies}

A collection of stories, or anthology, could be organized around themes such as important policy issues, institutional changes, and communities or groups affected, or could be organized by their sequence in time. Such an anthology would include commentary and technical information supporting the issues and policy options, again in a journalistic style to facilitate the reader's understanding of the content. Table XXV provided an example of the table of contents for an anthology of this type, describing life-extending technologies, and Chapter VI includes a detailed description of that anthology.

One tool for structuring a time-based anthology is the Divergence Map, developed by Miller, Schwartz, and their colleagues at the Pacific House (Pacific House, 1972). Figure 10 illustrates this framework, showing the ranks of cells into which stories (or scenarios) may be placed according to whether they are likely to occur "sooner" or "later" or somewhere in between. Table XXVI provides a sample table of contents for an anthology in which short stories and excerpts from novels describing life-extending technologies are clustered into near future, middle-range 


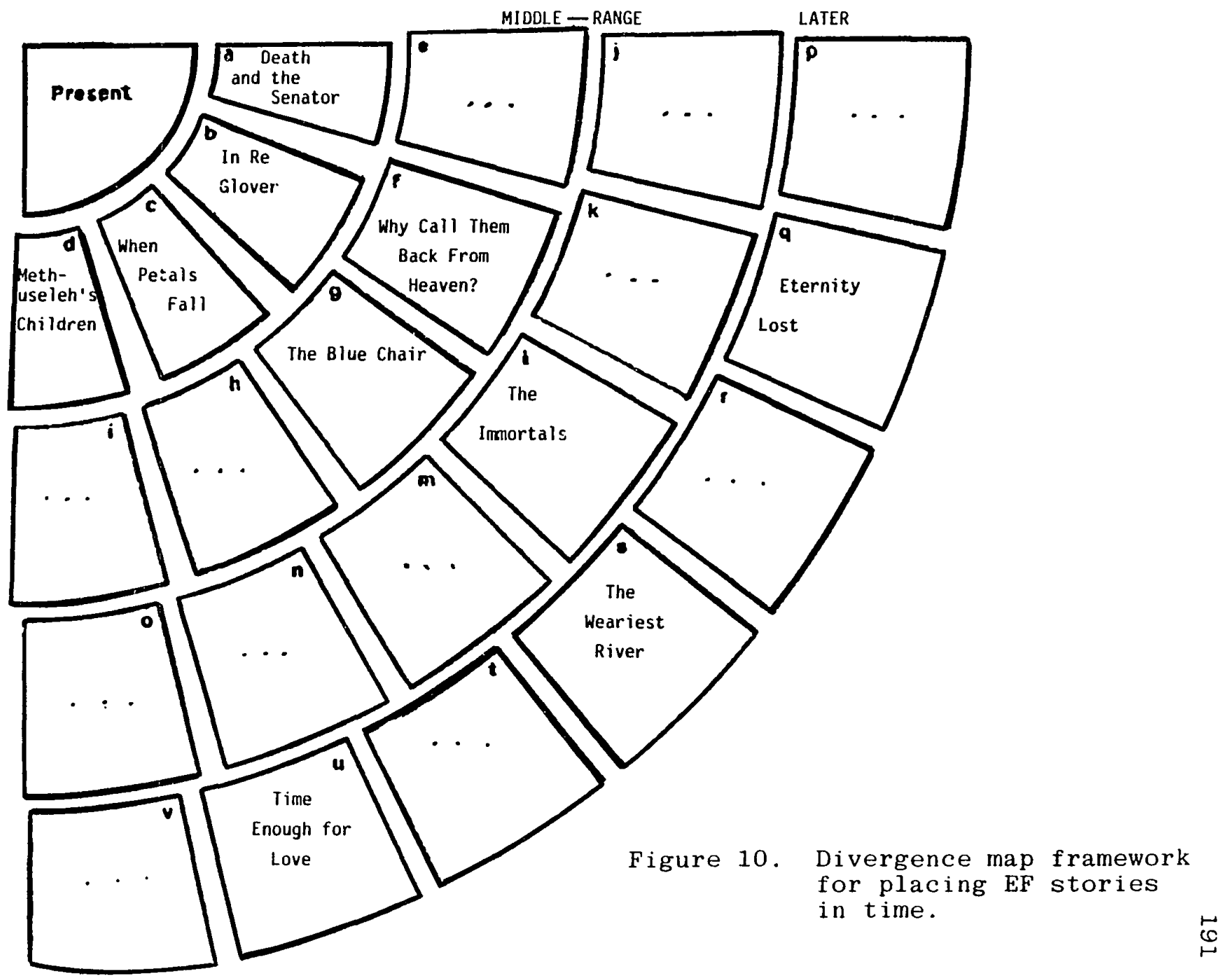


TABLE XXVI

TIME-BASED TABLE OF CONTENTS FOR AN ANTHOLOGY

ON LIFE-EXTENDING TECHNOLOGIES

INTRODUCTION TO LETS

THE NEXT DECADE

Introducing the Technologies

"Death and the Senator" Arthur C. Clarke

"In Re Glover", Leonard Tushnet

"When Petals Fall", Sydney J. van Scyoc

"Methuseleh's Children", Robert Heinlein

Suminary of Near-Future Possibilities

THE NEXT CENTURY

Extrapolating the Effects

Why Câll Them Back from Heaven?. Clifford Simak

"The Immortals" James Gunn

The Blue Chair, joyce Thompson

Summary of Mid-future Possibilities

THE FAR FUTURE

"Eternity Lost" Clifford Simak

"The Weariest River" Thomas N. Scortia

Time Enough for Love, Robert Heinlein

Considering LETs and their Implications

AFTERWORD 
future and distant-future sections, according to their position on the "map." Each of these sections would include appropriate editorial comments, using a journalistic style, to describe the technologies being considered in each story and to suggest questions to be kept in mind while reading them.* The comments would also mark divisions between time periods and provide transitions. Then, in conformance with the original design for Divergence Maps, the reader could be asked in an afterword to consider some alternative pathways through the futures described by the stories--choosing an ideal, an expected, and perhaps a to-be-avoided pathway for the society. Readers might also be asked to consider other alternatives suggested but not described by the material in the collection.

\section{Quotes and References}

The fourth technique for using pre-published stories is to include passages from such stories in an otherwise technical report. This technique is most appropriate where relevant stories are easily available and the report requirements prohibit the inclusion of whole stories or the relevant stories are either too long to be included or may not be reprinted because copyright releases are unavailable. In such cases, a brief summary, possibly including a passage

\footnotetext{
*Greenberg and Warrick's Political Science Fiction (1974) provides a useful example of this style of commentary.
} 
or two, can stand in place of the story, with a footnote referring the reader to the story itself as a useful adjunct to the report. The summaries used for the Thematic Analysis section of Chapter IV may be useful examples for this approach.

\section{EXTRAPOLATIVE FICTION IN THE RESEARCH PROCESS}

A second alternative for introducing extrapolative fiction into impact assessment is to include the techniques and products of extrapolative fiction in the IA research process. This alternative has the potential for leading to a coherent final product in which the insights to be gained from the fiction are clearly incorporated into the analysis.

There are two main approaches to including extrapolative fiction in the IA process. Team members may read EF stories early on in the research process to provide a gestalt of the system and to raise individual and qualityof-life issues, or they may include a fiction-oriented team member in the IA research activities to introduce EF techniques and ask the questions necessary for fiction's human orientation during the research process. Limitations of this alternative vary with the approach used.

Having team members read selected stories early in the research process can potentially increase communication within the team, across discipline lines. The images in the stories can provide a common basis for discussion outside of the usual disciplinary concerns. More, such a 
process can, as does the scoping process (or "first cut" analysis) provide an initial set of options, issues, and impacts to be explored and expanded upon in the IA process.

The results of the comparison of nuclear power stories and IA reports described in the previous chapter are indicative of the effect the use of EF stories as part of the scoping process might have on the assessment of the impacts of those technologies. Both of the reports analyzed in that chapter could be expected to have included a wider range of impacts if the assessment teams had used these stories early in the research process as part of the basis on which they identified significant issues or impact areas to be studied. The teams might have discussed possible personnel problems as well as potential outcomes of highly unlikely but serious accidents that might result from such problems. They might also have considered the issues of control of operation under hazardous conditions, and the effect of the profit motive on the safe design, construction, and operation of such plants.

The systematic use in the IA process of published EF stories that include such issues and impacts could lead to IA reports that reflect consideration of the potential emotion-charged issues that may emerge concerning the technology, as well as the rational expectations of the assessors. Further, such an approach to combining extrapolative fiction and impact assessment would provide an alternative "outsider" perspective on the innovation. 
One of the limitations of using stories in the research process is the present lack of topical bibliographies. Most bibliographies of science fiction are listed by author rather than by topic or story-type. Consequently, locating appropriate works may be a tedious process at first.

There are, however, numerous fans and collectors of science fiction who can be approached for references, as well as a fair number of librarians, bookstore keepers, and information specialists who are familiar with such works and would be delighted to search for out-of-print or archival material on topics that interest them. In addition, many "closet" fans are currently associated with futures-oriented research institutions and engineering firms that might be undertaking IA studies. Any of these people would be able to locate works that relate to a given study. In the meantime, Appendix A includes a list of works, by topic, that deal with the time frame and setting required of the IA process and may be a useful starting point.

Including a Fiction-Oriented Team Member

The inclusion of a fiction-oriented team member on the IA team is limited by the skill of the writer, the team's openness to alternative approaches, and the capacity of the subject to capture the writer's imagination and lead to a story which is more than anecdotal material. While a roadway lined with motels may provide the basis for a story, an individual building might not. Robots do; toilets (even 
composting ones) generally do not. Destruction and disruption of communities do; a building on the corner does not (except when it symbolizes a greater issue, as in Disch's 334, which describes the lives of three generations in a public housing building). In general, it may be said that the subject matter has to be something a writer can envision people experiencing and must hold the potential for conflict.

Including a fiction-oriented person on the team is also limited by the acceptance by the team of the fictionwriter's humanistic--as opposed to analytic--orientation. Because writers of fiction are concerned with human actions and human responses to those actions, they will ask new questions at the level of particulars, rather than at the general level of statistical analysis which is the norm in impact assessment. Because fiction writers depend on their own intuitive understanding and on images of the whole for their material, they will seem to leap to conclusions before the rest of the IA team has completed the analysis--which may cause some friction among team members.

In spite of these potential difficulties, Lipinsky and his colleagues at the Institute for the Future found including fiction in their report a useful attention-getter (Lipinsky, 1978; 1980). They were completing a study of the potential effects of electronic funds transfer systems for a large banking corporation. There was some difficulty communicating, so members of the team finally wrote a report 
that was a novel, circulated the manuscript informally, then held the formal briefing as planned. This method was declared effective when the bank executives arrived at the briefing with specific questions--for the first time in the history of the project (Lipinsky, 1980).

In another study, researchers at SRI International's Center for the Study of Social Policy included anecdotal material alongside more formal scenarios in their final report (SRI, 1977). These anecdotal sidebars were developed by the forecasting team (and written by those of its members with aspirations to become authors of fiction) to present aspects of a series of alternative societal contexts in which to embed potential transportation innovations over the next fifty years. The sidebars presenting each alternative societal future described "a day in the life" of characters in each alternative as they moved from place to place using the transportation systems available to them there and then. Figure 11 illustrates the format of that report.

Other possible ways a person with fictive skills could enhance the IA process include the methods described in the previous section for incorporating previously published EF into the assessment. A story could be written (or gleaned from the literature) and used as part of the scoping, or "first-cut," assessment process. A collection of alternative stories could be put together, like those described earlier, by appealing to professional authors (through the science fiction authors' networks and 


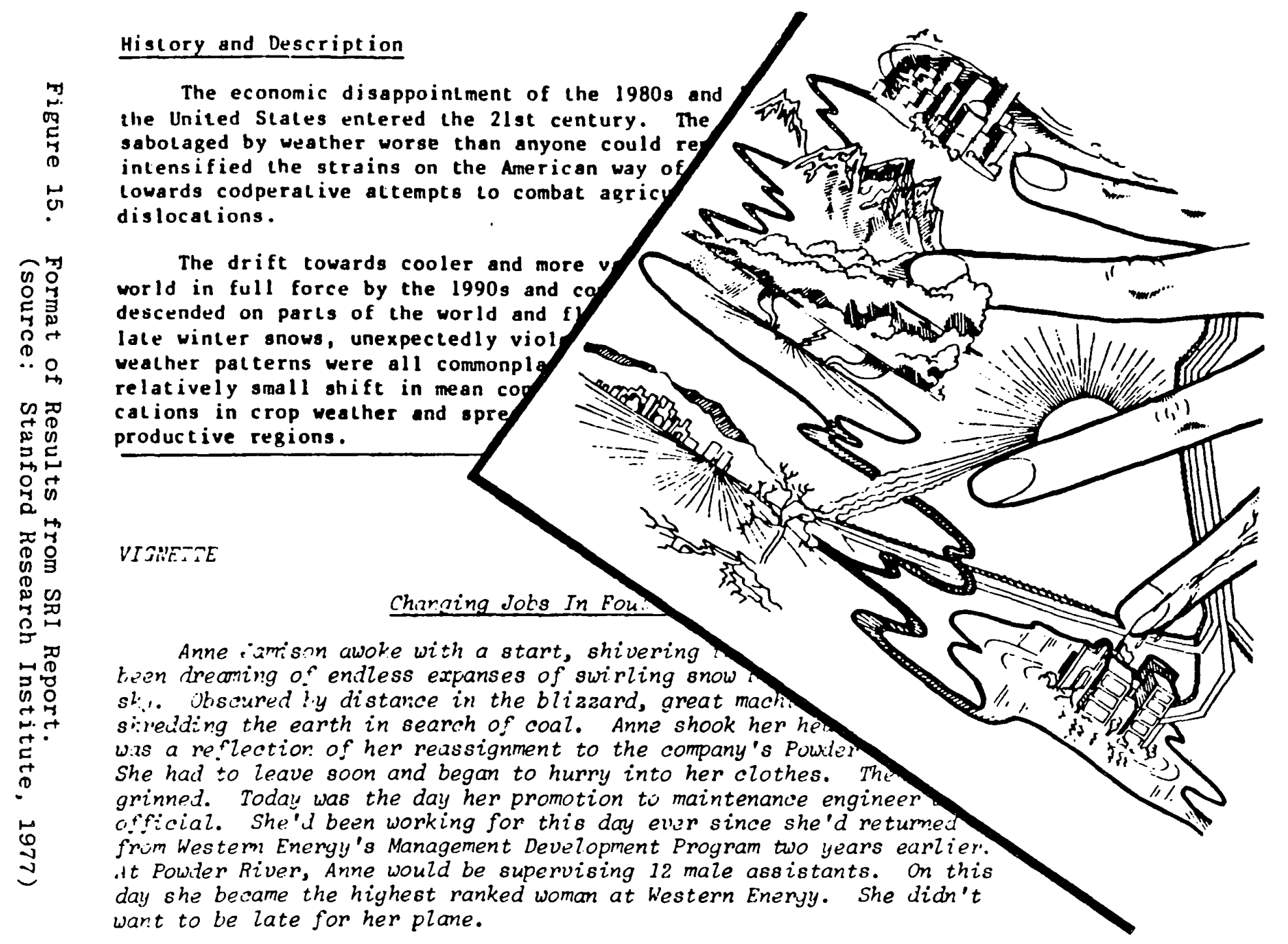


publications) to participate in a writers' workshop based on a draft IA report, by asking the team's writer to develop a few sketches, or by having team members cooperatively pull something together (as is typically the case for scenario development and occurred in the Institute for the Future and SRI examples, cited above). Or, as is described in Chapter VI and exemplified in Appendix B, a story could be written to synthesize and illustrate some of the major problems and potentials for the problem under study.

The inclusion of extrapolative fiction in the IA process is clearly a possibility. Further, each of these alternatives has the potential for enhancing the IA process, that is, meeting the objectives of that process more effectively. The task remains, however, to attempt the synthesis. 
CHAPTER VI

\section{ILLUSTRATIVE CASE STUDIES}

In the preceding chapter a number of alternative formats were proposed for incorporating extrapolative fiction into the IA process. The results of the analyses presented in Chapter IV suggest that each of these has the potential for improving the process and results of impact assessment by expanding the types and variety of jmpacts described in the final report, but that potential has not yet been tested. This chapter develops two of the suggested alternatives into case illustrations of the integration of the two forms to explore the potential of those alternatives and provide substantive support for the proposal which this dissertation presents.

\section{AN ANTHOLOGY DESCRIBING LIFE-EXTENDING TECHNOLOGIES}

This section of this chapter explores one of the alternative formats described in Chapter $V$ : the development of an anthology of EF stories to go along with an IA report. The anthology developed here is made up of stories selected from a number of science fiction journals and anthologies and of excerpts from various novels. The report that it is designed to complement was prepared by The Futures Group for the National Science Foundation (Gordon et al., 1979). 
The topic of both the report and the anthology is lifeextending technologies. It is a particularly appropriate topic for an example including EF stories in an IA report, since the possibility of immortality has long fascinated artists in our culture and has been an innovation assumed to be part of the ever-closer technological future by a number of authors. The number of EF stories to choose from is relatively large, therefore, and the potential for complementing the report is enhanced.

The Futures Group Assessment

Theodore Gordon and his colleagues at The Futures Group (Glastonbury, Connecticut) received a grant in 1975 from the National Science Foundation to perform a technology assessment of life-extending technologies (LETS). The stated purpose of the study was to

identify prospects for life extension, a spectrum of impacts which may follow these technologies, and policy options open to public and private decision makers to amend these impacts. (Gordon et al., 1979: xvii)

Specific objectives of the research were

1. To identify the potential for and forecast the emergence of life-extending technologies in the next 25 years

2. To form plausible scenarios from these forecasts that depict not only the sequence of technologies that might be expected but also demographic, economic, political, social, and ethical considerations

3. . . to identify the various groups at interest; 
4. . . to identify a spectrum of impacts, both favorable and unfavorable, which flow logically from the scenarios

5. To contribute to the methodology of impact assessment. . . (Gordon et al., 1979: xvii-xviii).

These objectives are similar to those described in Chapter II for impact assessment (pp.42), except for the lack of a discussion of the impacts on the physical and natural environment.

Gordon and his colleagues began their study with a Delphi questionnaire designed to establish the experts' opinions and forecasts for the development of a range of LETs.* The individual technologies identified from the questionnaires were then clustered into two groups: Iifespan-extending and curve-squaring technologies. The first group, the span-extending techniques, are those which increase the number of years a person might hope to live, while curve-squaring** techniques increase the likelihood for an individual to reach the expected age at death for the population as a whole.

Dynamic computer simulation models used population data collected for 1900-1975 and projected the survival curve of the population to the year 2100 based on scenarios

\footnotetext{
*The Delphi Method involves a series of questionnaires sent to a group of experts, analysed, then sent again until some consensus is reached. M. Turoff and $H$. Linstone describe its appplication in The Delphi Method, 1975.

** These techniques are called "curve-squaring" because they squared-off the peak of the graph showing age at death for the population.
} 
portraying the estimated effects of different combinations of LETs and of expected work- and consumption-oriented behaviors on the part of the population (Gordon et al., 1979). These scenarios assume a range of possibilities, from no change in life span or use of life-extending technologies, to a doubled expectancy with square-curving due to the use of disease control, artificial organs, organ anti-aging techniques, genetic and cellular anti-aging techniques, and the "cure" of senile dementia.

The demographic scenarios which resulted from the models were then used to compute impacts on the labor force and the economy. These impacts were used in turn, along with interview results, as the basis for computing impacts on social security, pension funds, insurance, and healthcare costs. The initial impacts were also used to identify social impacts and as the basis for a discussion of values and LETs.

Results of the Futures Group study were documented in a seven-volume report of which six volumes are divided into topical areas--e.g., Social Aspects, Demographic and Economic Aspects, and so on--and one is a summary of the others. The following paragraphs summarize the impacts described in those volumes according to the structure of that report. 
Economic and Demographic Impacts

Most of the impacts described in this study were developed, in part, on the basis of the economic and demographic impacts projected by computer models developed at The Futures Group. In the summary volume of their report, Gordon et al. describe the demographic impacts in considerable detail (in twenty-six pages of graphs, tables, and text). Economic impacts are described in similar detail (twenty-one pages of text and supporting graphics). Of the seven volumes in the full report, the fourth volume describes the demographic and economic impacts and the models used to generate them.

These impacts consist primarily of projections of population and labor force structures, based on the seven technology combinations and possible shifts in retirement age. They indicate that the size of the population in A.D. 2000 would range from 267 million to 275 million, with a labor force ranging from 123 million to $135 \mathrm{million}$ and an average age of from 34.5 years to 36.5 years, depending on the combination implemented. Similar results are shown for the year A.D. 2025--though the population is larger and its members older--and both sets are summarized in Table XXVII. In addition, Gordon and his colleagues considered the effects of LETs on the insurance industry, listing the expected impacts of LETs on pensions and social security, life insurance, and health insurance, respectively. These Iists reflect not only the high level of uncertainty 
TABLE XXVII

SUMMARY OF ECONOMIC AND DEMOGRAPHIC IMPACTS OF LETS

AS DESCRIBED IN THE FUTURES GROUP STUDY

\begin{tabular}{|c|c|c|c|c|c|c|c|c|c|c|}
\hline Scenario & $\begin{array}{r}\text { Labor } \\
2000\end{array}$ & $\begin{array}{l}\text { Force }^{\mathrm{a}} \\
2025\end{array}$ & $\begin{array}{l}\text { Consur } \\
2000\end{array}$ & $\begin{array}{l}r^{a} \\
2025\end{array}$ & $\begin{array}{l}\text { Popul } \\
2000\end{array}$ & $\begin{array}{l}\text { ation }^{a} \\
2025\end{array}$ & $\begin{array}{l}\text { Average } \\
2000\end{array}$ & $\begin{array}{r}\text { Age } \\
2025\end{array}$ & $\begin{array}{l}\text { Over } \\
2000\end{array}$ & $\begin{array}{c}65 \\
2025\end{array}$ \\
\hline Normal Aging & 123 & $138-150$ & 225 & 275 & 275 & 328 & 34.5 & 36.3 & $12 \%$ & $14 \%$ \\
\hline $\begin{array}{l}\text { Curve-Squaring } \\
\text { same retirement }\end{array}$ & $"$ & $"$ & 220 & 265 & $\begin{array}{l}267 \\
267\end{array}$ & $\begin{array}{l}325 \\
325\end{array}$ & $\begin{array}{l}36.5 \\
36.5\end{array}$ & $\begin{array}{l}42 \\
42\end{array}$ & $\begin{array}{l}14 \\
14\end{array}$ & $\begin{array}{l}22 \\
22\end{array}$ \\
\hline delayed ret. & 135 & 185 & & & & & & & & \\
\hline $\begin{array}{l}\text { Squared \& extended } \\
\text { same retirement }\end{array}$ & 123 & $138-150$ & 225 & 275 & 267 & 325 & 36.5 & 42 & 14 & 22 \\
\hline delayed & 135 & 185 & & & & & & & & \\
\hline $\begin{array}{l}\text { Doubled (no Curve- } \\
\text { squaring) }\end{array}$ & 123 & $138-150$ & 220 & 265 & 275 & 328 & 34.5 & 36.3 & 12 & 14 \\
\hline delayed retirement & 135 & 185 & & & & & & & & \\
\hline
\end{tabular}

a. expressed in millions. 
associated with LETs at the time of reporting, but also the effects of such technologies on the earning capacity, healthcare needs, and support requirements of a population with a substantially increased number of senior citizens.

\section{Social Impacts}

Social impacts were identified in a symposium held by the American Council of Life Insurance and in interviews with sociologists and social gerontologists (referred to in the study as "interest group panelists"). Both groups were asked to review a prepared taxonomy of possible social impacts, to add other impacts to that taxonomy, and to assess "which of these they felt were most significant in terms of the degree of change they would bring to society" (Gordon et al., 1980: 159). The resulting social impacts are described in four pages of text in the summary volume, the bulk of which deals with the social security system and pension plans. In the full study, Volume Three includes both the description of the current state-of-society with regard to the elderly and the forecasted social impacts.

The primary impacts are summarized as follows:

1. The aged will have more political clout, but will probably remain divided along traditional political lines and hold a variety of points of view

2. The nuclear family will continue to decline in importance, with institutions taking over more childraising functions--but surrogate families for "orphaned" elderly may increase

3. Intergenerational marriages will increase, as will intergenerational tensions 
4. New communications technologies will make mass entertainment, education, and information available to the homebound or bedridden

5. The extended, multigenerational family will be reinvigorated. (Gordon et al., 1979: 20)

In addition, the research team identified the following potential impacts:

1. LETs will cause shifts in definition of retirement age from a specific age to capacity for work.

2. LETs will mean more consumers with fewer incentives for saving for old age and more need for social services such as housing support, healthcare, and entertainment

3. Lifelong learning may or may not become the norm with LETs, depending on the types of LETs and the capacity for educational institutions to change

4. LETs may lead to a decline in emphasis on the childparent dependency relationship

5. Mass-entertainment media and special entertainment packages may play an important role in helping the elderly wile away the time

6. Crimes that target the elderly may increase as more people become vulnerable (through increasing life span or expectancy) or may decrease if LETs enhance the vigor and alertness of older people

7. LETs may become the scapegoat, blamed for a variety of changes that may have occurred regardless of their use.

The apparent contradictions between the first (the aged have political clout) and last (LETs become the scapegoat) of the primary social impacts and the uncertainty expressed in some of the impacts listed in this latter group are indicative of the lack of knowledge and high degree of uncertainty associated with the development pattern of lifeextending technologies at this time. 
Values Impacts

A series of essays, presented in Chapter Seven of the summary volume and Volume Six of the full report, deal with the values questions associated with LETs. The essays, prepared by the Institute of Society, Ethics, and the Life Sciences, point out some of the differences between the two main forms of LETs: curve-squaring having generally less effect on values than span-extending technologies. The potential impacts on values resulting from the use of LETs, which analysis of the essays suggest that the authors have assumed, are summarized below.

1. Lifespan extension would delay the debilitating effects of aging without eliminating them and so would encourage the current attitude that aging is not a disease

2. The development of specific ways of life to minimize the physical debilitation associated with aging would encourage an attitude that those who age involuntarily are diseased while those who choose not to live in those ways are deemed irrational

3. New understandings of the aging process may radically change current attitudes regarding privileges, rights, benefits, and status accorded those who exhibit symptoms of aging

4. Advances in understandings and technologies would continue to challenge conceptions of the nature of humanness

5. Increases in life expectancy would have little effect on the family, but increases in lifespan would hasten the deterioration of the extended family, incurring resistance to LETs by certain cultural and religious groups

6. Increased expectancy means increased likelihood that one will live into the retirement years, and could increase the attention devote ndertaken beyond the "productive" years; extended lifespans may lead to an increased value on 
schooling, skill development, second careers, and sabbaticals

7. Use of prosthetic devices may change concepts of the body and of wholeness or integrity

8. If LETs are scarce or are distributed unevenly, there is the possibility of social upheaval

9. If LETs must be purchased by coercive controls on fertility, lifestyle choices, or pollution levels, concepts of personal freedom may be radically altered

10. If LETs depend on actions taken during childhood years, then current attitudes regarding the freedom of parents or doctors to "decide what's best" will shift

11. LETs will have an effect on assumptions about knowledge, with curve-squaring technologies decreasing uncertainty about one's personal future (as one is more certain about the likely time of death), and span-extending technologies increasing uncertainty about appropriate allocation of resources

12. Some LETs will have impacts on assumptions of rights and responsibilities regarding suicide, euthanasia, the right to refuse treatment, and decisions about required vs. expendable care.

These potential values impacts, gleaned from the set of essays in the Futures Group study, raise some fascinating policy questions.

\section{Policy Issues}

The policy issues identified in the Futures Group IA report are summarized in the following list:

1. whether programs designed to implement life extension should encompass attitudes and perceptions about old people as well as biomedical components

2 . whether alternative policies concerning resource allocations for such programs should be seen as strictly competitive or whether policies should be 
favored which contribute to the achievement of the goals of other policies as well

3. the level of support for basic research, for facilities, and for training good, young, biomedical researchers;

4. the division of responsibility among agencies with programs related to Iife extension;

5. the need to confront emotional reactions to aging control and rejuvenation technologies;

6. the presence in our society of values regarding death which may undermine interest in life extension;

7. whether LETs will increase or decrease the quality of Iife or whether they will simply lengthen existence

8. the rights, privileges, benefits, and status of the aged

9. the relative importance of our obligations to future generations, especially in terms of resources

10. how to distribute LETs, especially if they are scarce or if people feel entitled to them.

These issues are presented in the Summary volume of the report (Gordon et al., 1979: 22-33). Although they are not discussed at length in this impact assessment, these issues do provide the basis for a set of recommendations which are also listed in the Summary volume. These recommendations include suggestions for government-sponsored studies on: retirement age (with regard to the nature of work and the ratio of dependents to producers in our economy), international impacts, and the secondary costs involved with producing and distributing LETs.

Clearly, many of the issues raised in the report are not dealt with in the analysis of impacts or in the recom- 
mendations. Some of the issues neglected by Gordon and his colleagues have, however, been considered in the EF stories published on the subject of life extension. A set that focus on the same timespan are summarized below.

An EF Anthology

The EF literature contains a number of short stories and novels that explore the possibilities of extended life spans. Some of these focus on cryogenics and the possibilities and problems associated with suspending the life processes by keeping the body at very low temperatures. Others consider rejuvenation techniques. Still others examine the possibility of genetic selection combined with transplantation. Table XXVIII provides a list of stories dealing with LETs by type of technology.

Many of these stories deal with issues that are raised in the Futures Group assessment described above. The following pages describe a set of stories that might be included in an anthology complementing that assessment. Set within the next several decades, these stories offer glimpses of what it might be like to live with and cope with some of the issues and impacts that Gordon and his colleagues have described.

"Death and the Senator", by Arthur C. Clarke, (in Greenberg and Warrick, 1974) describes an early stage in the process of the development of Iife extension when a critical operation at a critical point in life can renew vigor and 
TABLE XXVIII

EF STORIES DESCRIBING LETS

$\begin{array}{ll}\text { Technology } & \text { EF Story } \\ \begin{array}{ll}\text { Cryogenic maintenance } \\ \text { of a suspended body }\end{array} & \text { The Door Into Summer, } \\ & \begin{array}{l}\text { Robert Heinlein } \\ \text { Why Call Them Back From }\end{array} \\ & \text { Heaven? ' Clifford D. Simak } \\ \text { "In Re Glover", Leonard } & \text { Tushnet } \\ \text { Non-cryogenic maintenance } & \text { "When Petals Fall", Sydney } \\ \text { of aged bodies } & \text { J. Van Scyoc } \\ \text { Pills or Treatments at } & \text { "The Immortals", James Gunn } \\ \text { Maturity } & \text { "Eternity Lost", Clifford } \\ & \text { Simak } \\ & \text { "The Weariest River", } \\ & \text { Thomas N. Scortia } \\ & \text { The Blue Chair, Joyce } \\ \text { Thompson } & \text { "Methuselah's Children" } \\ \text { Robert Heinlein }\end{array}$


restore lost capacities, extending one's productive years considerably--if one has access to it.

The story opens as the Senator comes to terms with the fact that he has a terminal condition, one that may not permit him to live more than another year. His hopes for the Presidency crushed, he realizes how "much he had missed - . in his relentless pursuit of power" (Clarke, in Greenberg and Warrick, 1974: 160), that even though his wife and children are lost to him, his grandchildren love him. He resolves to see them while they still do, canceling other appointments to make the time.

The conflict is established when the head of NASA shows him that a technique, developed by Soviet scientists in their space station, could possibly restore his heart and save his life. The Senator considers this opportunity--and the irony that it should only be available from the Soviets, since he was the one who had--in spite of NASA's attempts to point out the medical advantages--shut down the U.S. program. Now only the Soviets had a zero-gravity laboratory in which to develop the techniques that might prolong his life and make it possible for him to become the next U.S. President. Moreover, through the very agency the Senator had cut, the Soviet Space Program Director was offering those techniques to him.

However, it becomes obvious that only a select few can be treated in this facility, and that treating him would mean refusing others. The Senator considers the old problem 
of too little good for too many needy. He also considers his own role in creating the current situation, as the one who had made an American space hospital impossible, denying others the help he was now being offered. "Could he accept the help he had denied to others? Once he might have done so--but not now" (Clarke, in Greenberg and Warrick, 1974: 166).

Having accepted the reality of his own death, the Senator has found a new set of values. He refuses for himself the life-extending technology which he has denied to other Americans through his actions. He chooses not the sure nomination for the Presidency, but a few months of love and peace with his family as the next--and last--phase in his life, and so illustrates Clarke's point that values and behaviors are affected by the certainty of death and that limited availability of technologies will have even greater effects.

"When Petals Fall," by S. J. Van Scyoc (1973; in Carr, 1980) goes beyond Clarke's focus and addresses the issue of life-extension versus 1 ife-enhancement in the context of the issue of one generation's responsibility to future generations.

The protagonist, Kelta West, is a Federal Inspector responsible for ensuring that the nursing homes in her district obey regulations and take adequate care of the "hundreds of thousands" of elderly who 
lay in their cradles swaddled in senility, entubed at every orifice, gaping eyes deserted, lax mouths wordless, . . doggedly fighting out the last moments of personal existence; blood circulated by machinery, minds erased by age, they waited for the miracle that could restore them to function, however minimal.

(Van Scyoc, in Carr, 1980: 117)

Kelta's work is complicated by an organization called the Messengers who periodically work their way into the homes, disentube whole wards (holding as many as one hundred patients) and let them die. Besides being illegal, these "messengers" raise public awareness of the homes and the role they play in the society, requiring that the federal agencies responsible for them deal with the media as well as the homes' managers.

Her work is also complicated by researchers who need to experiment on the patients (but can't do so legally) to test the potential "immortality" drugs which the patients are waiting for. Discovering that a number of patients have survived a Messenger's visit because of such research, she questions the researcher responsible for their survival. He indicates that he has developed a serum, but that "all it does is enable the body to survive as a body, not as a viable personality. . . They are helpless. Hopeless. But alive." (Van Scyoc, in Carr, 1980: 126). He requests her assistance in getting the drug to market. Her response is unequivocal

\footnotetext{
- . You're not asking just for moral support. You're asking for our drinking water, our oxygen, our children playing. I say no. You've had your roses,
} 
Doctor. I hope you enjoyed them. You've had your time on Earth too. Now it's our turn. (Van Scyoc, in Carr, 1980: 127)

Having inade this statement, she delivers an ultimatum: the researcher and his sponsors can be prosecuted or they can shut down the project.

In response, they argue that their results will put public sentiment on their side. Contending that they are wrong, that the public resents maintaining corpses, the inspector restates her ultimatum and leaves, to secure the tape of the conversation, and to use the last of her water tokens for a shower, hoping that the flowing water can cleanse her of the whole affair--and the knowledge that she herself can never have a child in this world of limited resources, pollution, and a too-rapidly growing population. As she goes, the inspector reflects on the fact that changing public sentiment is leading to changed attitudes about death and, particularly, about euthanasia. So--after providing glimpses into the nature and scope of the issues of responsibility to future generations, and of life-extension without life-enhancement--the story closes on the consideration of the definition of rights and responsibilities regarding euthanasia, and of expendable care.

"In Re Glover," by Leonard Tushnet (1968, in Sargent, 1977: 39-48) deals with the legal implications of maintaining the body of a person whose mind is inactive, but who is not yet dead, to be revivec at some future point in time. The technology in this story is not one considered in the 
Futures Group study, but is one being considered today for some terminally-ill patients who have the finances to arrange Iife extension and the determination to be cured. Based on the principles of cryogenics, this technology involves suspending the body's processes by lowering its temperature and keeping it in cold storage until such time as a breakthrough will permit curing the disease. The process is still experimental, but has been used successfully on a number of mammals, and has captured the imaginations of a number of journalists. It also is a recurrent theme in science fiction.

"In Re Glover" describes the court case surrounding the suspension of 1 ife for a very well known and well-to-do entrepreneur with a number of heirs.

Ralph Glover, the brilliant and dynamic founder of the many-sided business empire bearing his name had died--or had he? If he were dead, his four sons by his first wife and his two daughters by his second (both wives having predeceased him--if that term could be used without prejudice) were due to inherit the entire estate, share and share alike, after a number of relatively minor bequests had been paid; the great Glover Foundation, the internationally known medical research institution, was to get nothing, having been the recipient of munificent gifts during the founder's lifetime; the federal government and the states of residence of the heirs were eagerly anticipating the considerable inheritance taxes. If he were not dead, the trustees of the tax-free Glover Foundation would continue to receive, as they had for five years now, all revenues from the many corporations constituting the Glover enterprizes; the children were to fend for themselves, meaning that the sons and sons-in-law would have to find jobs, and the federal and state governments would have to wait until Glover's actual demise to collect. (Tushnet, 1968, in Sargent, 1977: 43-44) 
Court was prepared to take it on, recognizing that the case would set landmarks in law, in a new field of law as well as in the laws of wills, mortmain, trusts, and homicide, with overtones. . . on euthanasia and medical and legal malpractice. (Tushnet, 1968, in Sargent, 1977: 43)

As the story unfolds, the case is even more complex than it seems at first glance. It involves more than the question of what constitutes death. Numerous twists and turns in the plot and in the relationships between the people involved carry the reader through the case while the legal issues involved in this particular form of life extension are made dramatically clear, along with the issues associated with current attitudes about death in our society and the effect of extended lifespans on the family and on retirement.

Why Call Them Back From Heaven?, a novel by Clfford Simak (1967), focuses on the nature of a life lived in the expectation that one will get a second chance--that, having died, one will wake up having had one's body preserved and treated so that it is now immortal. Simak describes a number of interesting personal, social, and economic impacts as resulting from this state of affairs.

For one, people become extremely careful not to be hurt before they reach the second life:

A man had to live, this first life, as long as he was able. It was the only opportunity he had to lay away a competence for his second life. . . . [I]t would never do to let a piece of carelessness. . . rob him of the years needed to tuck away the capital he would need in the Iife to come. (Simak, 1967: 1213) 
As well, many inconveniences are accepted to "tuck away" the necessary capital. Simak's protagonist, a public relations specialist for the organization responsible for maintaining the bodies--the Forever Center--enters his room after turning down a large bribe to undermine the Forever Center . . for the first time in his life, the poverty and squalor of it struck him across the face.

The bed stood in one corner and in another corner a time stove and a keeper for his stock of food. A mangy carpet, with holes worn here and there made an ignoble effort to cover the bareness of the floor. . . This is the way we live, he thought. Not myself alone, but many billion others. Not because we want to, not because we like it. But because it is a wretched way of life we've imposed upon ourselves, a meanness and a poverty, a down payment on a second life. . (Simak, 1967: 45)

This effort to minimize current expenditures in order to maximize later spending capacity is encouraged by the society and by the Forever Center, who will hold the saved funds in trust. Yet once the savings are built up, new problems emerge: people who are not earning money in this life are spending the capital put away for the next.

James worked so hard all his 1 ife and we scrimped and saved. Now that he can't work any more, we have time to just sit and take it easy and do a little talking and go visiting and such. But we're getting behind, financially, every blessed day. We are using up the little that we've saved . . . (Simak, 1967: 28)

Not surprisingly, a new counter-culture emerges. Based on the fundamentalist Christian tradition, these outcasts are called the Holies. Non-conformists in an age of selfimposed conformity, they insist on the right to believe in something beyond physical existence. They preach on street corners and ask "Why should people. . believe in anything 
at all if they have the legal--not the spiritual mind you, but the legal--promise of immortality?" (Simak, 1967: 90). These people, living on the fringes of the culture, maintain their right to die, and insist on witnessing the Bible and God's law as expressed therein to everybody in spite of the police's determined efforts to eliminate them.

Another major impact of this LET is demonstrated when the protagonist is declared outcast on charges trumped up by the security chief and leaves the heavily populated coastal area. He finds vast stretches of land unpopulated and unfarmed, with houses and barns left empty by people who have gone to the cities to get jobs to build the capital necessary for happiness in the second life. With the majority of people living as close as possible to the Forever Centers so that their bodies may be immediately preserved and living on virtually nothing that is not produced in the cities, farming becomes an antiquated and useless art.

Finally, Simak raises some interesting issues concerning the state of the economy. He points out how the once small, charitable foundation

. . had become the biggest thing the world had ever known.

Big in many ways. Big in the hold it had on the public imagination. . . Big in the participation in the program, . . And, perhaps most important of all, big in its assets and investments.

For all those millions. . had left their funds in trust with Forever Center. And one day the world woke to find that Forever Center was the largest 
stockholder of the world and that in many instances it had gained control of vast industrial complexes. (Simak, 1967: 47)

Through such characterizations, Simak takes the possibilities and extrapolates them to the point where the absurd extremes no longer seem quite so absurd.

Issues and Impacts in the EF LET Stories

A number of issues raised in the Futures Group's assessment are dealt with in these stories. These include:

1. the problems associated with uneven distribution of LETS

2. the importance of the multigenerational extended family for aging seniors

3. those who choose not to use LETs may be deemed irrational by their neighbors

4. the effect of LETs on assumptions about knowledge-and the effect of certainty regarding one's time of death on one's way of 1 ife and values

5. the effect of LETs on assumptions about the right to refuse treatment

6. the increased political clout of the aged

7. increased intergenerational tensions

8. the relationship between expectations about old age and consumer behaviors

9. the role of entertainment in helping the elderly while away the time

10. the blame placed on LETs for negative social or environmental changes

11. changes in status and benefits for the aged

12. changes in lifestyles that reduce personal freedoms resulting from the desire to purchase LETs

13. the possibility of changes in assumptions regarding euthanasia 
14. the potential effects of resource allocation patterns for developing LETs

15. whether LETs will increase or decrease the quality of life or whether they will simply lengthen existence.

Through the experiences of people living, working, and dying in a world which includes the possibility of greatly extended lifespans, these four authors present half of the issues and impacts that the Futures Group study have included in their report, in a way that illustrates and clarifies the nature and scope of those effects. They have also presented a number of impacts and issues that were not dealt with in that report. The following list summarizes this latter group:

1. the desire of people who expect to live lengthy lives (or eternal ones) to avoid accidental injury or death

2. the need to avoid spending money while earning if one expects to live a long time with no new source of income

3. the potential for a successful producer or distributor of LETs to become a significant economic--hence political--power, especially if people's life savings are held in trust by that distributor

4. the possibility of significant shifts in population toward medical-technj.cal centers--especially if there is a time factor involved in making LETs work

5. the use of forfeiture of access to LETs as a punishment for offenses against the distributor or the state.

These issues, as well as the impacts leading to and flowing from them, bring the possibility of LETs to a new level of concern and point out possible areas of study for future, more specific impact assessments on the subject. 
Excerpts from the stories described in this section, then, could be combined with others to form a topical anthology that provides vicarious experiences and clear images of the consequences associated with the issues and impacts raised in the Futures Group report. Moreover, such an anthology would extend the results of that assessment, offering new insights and possible areas of study for follow-on assessments. Prepared as a companion volume to the Futures Group Summary volume, an anthology including these stories could have introductions and afterwords that related the stories to the material in that volume--might perhaps even be cross-indexed with that volume to ensure maximum utility for decisionmakers.

THE GUAYULE RUBBER STUDIES

This section describes an alternative approach to integrating extrapolative fiction and impact assessment-that of including a fiction-oriented member on the IA team. In this section the original assessment process is described along with that of a sample synthesis of extrapolative fiction and impact assessment techniques. The synthesis is presented as a summary, a story, and an outline for a full report (these are included as Appendix $B$ to this dissertation). The IA reports described here are concerned with the commercialization of guayule, a desert shrub with a latexlike substance in its cells. 
Guayule first became a subject of interest in the United States during World War II when the source of rubber, hevea trees in Southeast Asia, became inaccessible. In 1948, concern about the future of guayule diminished when oil discoveries in the Middle East, combined with U.S. farmers' demands for resumption of their rights to plant other crops on their lands, caused the Department of Agriculture to halt the guayule program. Interest in guayule surfaced again when the OPEC oil embargo of 1973-74 created an awareness of how dependent on outside sources this country had become for many of its basic needs--including oil for synthetic rubber production--and how undependable those sources were. Responding to that interest, the National Academy of Sciences issued a statement that research into the development of guayule as a domestic source of rubber should be supported (National Academy of Sciences, 1977), and Congress passed the Native Latex Act of 1978, establishing the Joint Commission on Guayule Research and Commercialization, cochaired by the Deputy Secretaries of Agriculture and Commerce.

As one part of the research effort resulting from the commission's work, a technology assessment was funded by the National Science Foundation to identify the impacts of and suggest policy options for the commercialization of guayule. The University of Arizona proposed jointly with the Midwest Research Institute to extend the agronomics research effort already underway at the University into the policy and 
business implications of the potential new crop (Foster et al., 1980a; 1908b).

Shortly after that project was funded, Portland State University was asked by the National Science Foundation and agreed to include the Arizona assessment as one which they would study and expand on as part of a project developing the multiple perspectives concept (Linstone et al., 1980). I was part of Dr. Linstone's team and used the results of both projects to develop the synthesis described in this chapter.

The University of Arizona Assessment

The first assessment of guayule commercialization was undertaken by a group of scientists whose primary interest was in finding a "solution" to the "problem" of how the best policy alternatives could be isolated and implemented. The University of Arizona's Office of Arid Lands Studies (U of A) research team included agronomists, social scientists, and desert ecologists who were to work with researchers experienced in policy analysis from the Midwest Research Institute (MRI) of Kansas City, Missouri, to complete the study. The two groups divided up the work and proceeded separately and then together to complete the assessment. An interim report was published in April, 1980 (Foster et al., 1980 a), with final results released in the summer of that year (Foster et al., 1980b). 
Methodology. The $U$ of A team spent considerable effort analyzing the state-of-the-art for guayule, including developments in agronomic research, the economics of guayule production, and environmental constraints. In the process, they interviewed people from many interest groups in the rubber community and in the southwestern (United States) farming community. Using dynamic and econometric models, they projected rubber demand and supply into the year A.D. 2000, and developed two scenarios--one based on "laissezfaire" policies and the other on "strong federal involvement"--for guayule's development.

These two scenarios were compared in terms of the rubber demand and supply, economics, and environmental constraints which the team had identified. Econometric models were used to provide statistics on needed acreage, seed production, and processing facilities for each scenario. Simple extrapolation techniques were used to scale impacts over time based on these statistics.

Based on their comparison of the two scenarios and the impacts identified for each, the $U$ of $A$ team defined the main goals for commercializing guayule and, with the help of people from MRI, listed what they considered to be the relevant impacts and policy issues. The policy issues identified were classified as "strategic" or "non-strategic" "social," "economic," or "other." Out of this list of policy issues, and based on the team's interviews and experience, the team then identified and listed a set of 
policy conflicts, institutional failures, and resolution mechanisms likely to be encountered in or needed for the full commercialization of guayule.

Results. The $U$ of $A$ assessment predicted a shortfall of natural rubber in the United States of from 2.4 to 4.9 million metric tons by A.D. 2000. The team assumed a doubling of the rubber content of guayule (to twenty per cent) in five to ten years, a base yield of five hundred pounds per acre per year, and an available acreage of from 1.5 to 2.0 million acres by the year A.D. 2000. They pointed out continued $r$ ises in the costs of both natural and synthetic rubbers over recent decades and the current, depressed state of the rubber industry as factors to be considered.

Given this context, the $U$ of $A$ team went on to develop the two scenarios for the development of guayule. According to Scenario A ("laissez-faire"): $1.5 \mathrm{million}$ acres would be planted in A.D. 2000 (42\% in California, $32 \%$ in Texas, $19 \%$ in Arizona, and 6\% in New Mexico); and the cost of guayule would range from $\$ .60$ to $\$ 1.50$ per pound of rubber produced. In this scenario, then, the United States would meet one hundred percent of its predicted shortfall of natural rubber by 1991 (Foster et al., 1980a; 1980b).

In Scenario B, heavy government involvement would result from a reduction in rubber imports to one-half of current levels. This crisis situation would increase federal funding and support for guayule development and lead 
to: heavy research and development emphasis, increasing yield per acre by 73 percent over Scenario A; 2.0 million acres in production in A.D. 2000, requiring sixteen processing plants and close to twenty-five million pounds of seeds; a quasi-governmental corporation coordinating and managing the program; and half of the natural rubber demand being met by 1990 .

Impacts on the human environment were identified and evaluated by the team for both scenarios and were seen as relatively minor. This evaluation was based on the assumptions that guayule would replace other crops in water-short areas rather than be extensively grown on previously uncultivated lands, and that processing plants would be placed in urban areas. Substantial social impacts--described as increased employment--were identified for the alternative assumption of a processing plant located in a more rural, less populated region.

Policy issues for the "laissez faire' scenario (A) were found to center around: the scale of production and the benefits received by interest. groups (e.g., rubber companies, farmers); the different risks and investment tradeoffs experienced by private developers compared to government agencies; and the tradeoffs between allocation and development of various resources (e.g., water for crops or industry; land for food, fiber, or housing). For the "heavy federal involvement" scenario (B), conflicts over international relations, antitrust regulations, and 
strategic materials stockpiling policies were expected, in addition to those issues identified in Scenario A (Foster et al., 1980a; 1980b).

presentation. The $U$ of A study follows the traditional IA report format. The nature of guayule and the state-ofthe-art for its development introduce and dominate the body of the written report. The development of the two scenarios--their requirements and the limited potential . impacts--follows that section. Discussion of policy issues and options make up a few pages at the end of the report. Tables and graphs are used frequently to supplement the text, often without any explanation tying them into the written report.

In addition to the formal draft and final written reports, the $U$ of $A$ team presented their results at the Third International Guayule Conference and to the annual meetings of the Guayule Rubber Society over the period the study was being conducted. These were formal presentations, making substantial use of tables and graphs reproduced from the written report. The reports were well presented, clearly stating the methods used in the study and the results achieved.

Comments and Concerns. The $U$ of A study has been criticized for its lack of scope and the relative weight placed on the technology compared to the impacts and policy issues in the presentation (Linstone, 1981). When the results were presented at the Third International Guayule 
Conference (Taylor, 1980a), a number of questions were raised during the discussions concerning the reliability of the numbers and the utility of the conclusions.

An evaluation of the $U$ of $A$ report in terms of the objectives set for impact assessment (described in Chapter II) gives the following results. The report's emphasis is on the technology rather than on the desired focus, the technology's effects. Those impacts discussed relate primarily to the interest groups involved and only secondarily to the natural or physical environment. For example, there was no analysis of impacts resulting from extensive planting on previously uncultivated lands. The effects of guayule commercialization on related technologies and on the national economy are included as assumptions rather than identified and evaluated as impacts, and impacts on local economies are discussed minimally. When impacts are discussed, their extent is described only as either "Iimited" or "significant." The alternatives--"laissezfaire" and "strong federal involvement"--are based on single anticipated changes in the political environment and assume no change in the physical or social environment. Long-term or indirect effects are not discussed, even though there is some attempt at a cost-benefit analysis. Moreover, there is little relationship between the forecasts and the identified impacts, except as implied in a table describing "policy conflicts" and their resolution. Overall, there was little improvement in methodology over previous studies, in large 
part because of a lack of experience in impact assessment on the part of the majority of $U$ of $A$ team members and their resultant dependence on policy-oriented MRI analysts for guidance.

However, while many members of the guayule research community are not convinced that the study results are credible, they are using those results (e.g., Flynn, 1981; Perry and Hanson, 1981). As indicated in interviews with members of that community, there are a number of reasons for their use of these questionable results. The forecasts are broad enough to ensure some degree of congruence with what may actually occur. The report is clearly written and was released at a time when decisions were just beginning to be made by the Guayule Commission concerning implementation. Moreover, the community was involved in the process (through interviews and comments on draft versions of the reports) and feels some ownership in the results--although their involvement is not very visible in the final report.

These comments on the $U$ of $A$ assessment reflect, to a large extent, the fact that the report was prepared by an inexperienced team to meet the expectations of the funder, the National Science Foundation and the co-contractor, the Midwest Research Institute rather than the needs of the users--rubber company executives, government officials, other researchers, and citizen groups. 
Developing an Alternative Model

In April, 1980, Dr. Harold A. Linstone asked this author to join a research team at the Third International Guayule Conference to assist in interviewing key actors in the guayule programs as part of his research on the use of multiple perspectives in technology assessment. From this experience came the idea of developing a report on guayule as an illustrative example of this dissertation's thesis. The topic was an interesting one, in part because it included elements of environmental, social, and national policy concerns. Moreover, there was an opportunity for the kinds of research necessary to implement the approach to impact assessment suggested by this dissertation.

Methodology. The research began with a review of the $U$ of A interim report (Foster et al., 1980a) and the National Academy of Sciences statement (1977). The team then attended the Third International Guayule Conference--a fourday event that permitted a participant-observer approach to the research. Since most of the sessions were made up of technical paper presentations that could be monitored by others, I emphasized meeting and interviewing those actors not met by the other members of the team and following up on details or new information. Those interviewed ( 1 isted in Table XXIX) include rubber company executives, members of the $U$ of A team, farmers and local bankers, and government officials associated with guayule's development. 
TABLE XXIX

KEY ACTORS INTERVIEWED FOR THE GUAYULE RUBBER STUDY NAME POSITION

Don Weihe, Joe Neivert

Jack Reidl

Earl Gregg

Pasquale (Pat) Gallioto

Alex Mercuri

Francis Wolleck

Isi Siddiqui

H. T. Huang

Ed Flynn

Dan Bragg

Jonathon Taylor

David Rubis

Wayne Whitworth

Jimmy Tipton

Robert Heckler
Firestone International Division (includes guayule)

Goodyear International Division

B.F. Goodrich; also chairman of Rubber Division American Chemical Society

Anderson Mfg., Guayule Processing

Chairman Guayule Commission, also Dep. Sec. Dept of Agriculture

Co-chairman Guayule Commission, Dep Sec., Dept. of Commerce

Director of Guayule Program State of California Dept of Agric.

National Science Foundation, polymer research program monitor

"Mr. Guayule Rubber News",

"Mr. Guayule of Texas" directed feasibility study at Texas A\&M

Member Technology Assessment team, Office of Arid Lands Stud. UofA

Agronomist, $U$ of $A$, also convenor of joint meeting between the rubber companies and Commission

Agronomist, New Mexico State U

Agronomist, Texas A\&M University

President, Farmers and Merchants Bank Las Cruces, New Mexico 
The questions listed in Table XXX were used as interview guidelines, although such questions as "How do you feel about guayule and its development?" and "What do you get out of its success?" were usually added. Additional insights were gained by participating in informal group discussions and events, and in the more formal Guayule Commission Hearings held in conjunction with the Conference.

I maintained the participant-observer role through the rest of the Linstone team's efforts, attending several meetings at which their results were discussed and working papers were exchanged, and contributing to their report (Linstone et al., 1981). Finally, at the end of the study period, I made a series of site visits--tn Southwest Texas, New Mexico, and the rubber companies' offices in Akron, Ohio. Information gained from these visits was shared with other team members on their request and provided the final pieces of information needed to complete this illustration.

A synthesized report was drafted based on all of these experiences and some additional analysis of the organizations, institutions, and communities involved. Several attempts were made to draft a report that would demonstrate the major issues and impacts of guayule commercialization while being interesting and entertaining reading. These attempts were based on the premise that different forms of verbal models were appropriate for different kinds of insights needed by different groups of readers. A technical discussion of data bases and analysis was extracted from the 
TABLE XXX

QUESTIONS USED FOR INTERVIEWING THE GUAYULE ACTORS

1. Why haven't the rubber companies moved further? USDA? other agencies?

2. How will entrpreneurs proceed?

3. What key people are not at this meeting? ${ }^{a}$

4. How did you get involved with guayule?

5. Are new organizational arrangements needed?

6. What is the impact of a rubber cutoff for the rubber co's?

7. Who are the key people for action?

8. What is the connection between guayule and jojoba?

9. Who would stand to make the most money?

10. Who would suffer most?

11. Who is the biggest help? hindrance?

12. What has been the dumbest decision?

13. What questions do you have? puzzles about guayule development?

14. What role could NSF play? BIA? Texas?

15. What existing agency would you give temporary responsibility for guayule's development to?

16. (What is wrong with the U.S. program? what is your country doing?) ${ }^{b}$

17. What are some other uses for guayule besides latex?

a. The Third International Guayule Conference, Pasadena, California, April, 1980

b. directed to representatives from other countries (researchers attended from Mexico, French West Africa, Australia, and Southeast Asia) 
$U$ of A material and developed to provide supplementary material for the synthesized report. A report on organizations and processes used a journalistic style to summarize the $U$ of $A$ and Linstone teams' results in those areas. A story presented the relevant images and permits an intuitive understanding of the nature of the technology and its effects on the people who will live with it.

The writing of such a story required that I be sufficiently immersed in the material to "see" clearly what guayule's cultivation would look like, to "feel" what the people working with it might feel, and to "take part in" their activities with regard to its development. The story line and characters must make it possible for the reader to share those "experiences" and to identify with the people who might be involved. Most of all, the story must be sufficiently engrossing to hold the readers' attention and ensure sharing of the "experience," so they might become familiar with the problems and possibilities likely to emerge from the development of guayule in the United States.

A number of outlines were drafted to meet these requirements. Table XXXI illustrates one outline considered. It plots a story that focuses--as did the studies on which it was based--on how guayule could be developed. A key character or prime mover dominates this approach, with a single hero focusing on a key decision point--in this case, the environmental problems associated with guayule's processing--and working out a technical 
TABLE XXXI

\section{ONE OUTLINE CONSIDERED FOR THE GUAYULE EF STORY}

\section{SETTING}

The President's pro-military stance creates the need for more equipment

-leads to an increased need for natural rubber

Unrest in Africa, combined with a swing to the left in southeast Asia (preference sales to China) virtually cut off U.S. access to hevea

Rubber companies ar panicked

- they've contracted to sell but have no raw materials

-they've dawdied and been bogged down in the EIS process for guayule

STORYLINE

Hero designs a processing plant that mitigates most environmental impacts.

(SKETCH: Heinlein-style hero-type, raised on SW farm, chemical engineering degree, just out of Air Force, refuses to work for big companies)

He forms a company, working with independent guayule activists to contract with Mexican ejidos, for 3-yrs worth of wild guayule.

(SKETCH: Langley-type trying to convince ejidos that they can benefit by giving her the crop as well as seed)

He contracts with American farmers to supply seedlings and buy all production in 4 years

(SKETCH: visit to hometown, parents, neighbors, schoolchums)

In the process of getting licenses, etc., his intentions become clear to the rubber companies. At first it gets rough, as they think they have to bully him out of his plans. Then, with the help of a particularly persuasive lawyer (female), he convinces them its to their advantage to sell him their military contracts for the interim, in return for his processing design (SKETCH: dealing with rubber company exec's)

(SKETCH: rubber company and military meeting where the need--and potential longterm market is spelled out)

(SKETCH: hero coming to admire his lawyer's professional --later personal--qualities)

(SKETCH: celebration of victory over companies)

\section{CRISIS AND DENOUEMENT}

Each permit/contract process is a minor crisis, building up to the final one--there is not 50,000 acres (minimum needed) worth of seed! Comic relief as everybody involved gets into the act looking for guayule seed stashes. They come in one-by-one until the last moment, when it looks as if the thing just can't be dcre after all--and the last needed stash is found (by accident) in a Rubis-type character's file drawer.

(SKETCHES: each character's experience trying to find seed)

\section{CLOSING SCENE}

Hero and lawyer-friend cement a longterm personal--as well as professional--partnership in the office of the built and operating plant. 
solution. This plot parallels that of Heinlein's "Let There Be Light." In true romantic fiction style, and with the help of a female ally, the hero overcomes the bureaucratic problems that threaten his technical solution. The advantage of such a storyline is that it tends to be fastpaced and can point out many of the problems and potentials of the innovation. The disadvantage in this situation became evident when the story was partly drafted and clearly would have to be novel-length to encompass so much action and background detail.

Another outline was selected, focusing on one piece of the earlier story, and a story, along with a summary of the full report were drafted. Presented in Appendix $C$, the summary and story (entitled "Synthesis") are placed in the framework of a full report, with placeholders for the more detailed technical information (much of which is included in Linstone et al., 1980).

Results. The nature of the methodology employed for this illustration led to some different conclusions about the nature of the effects of guayule's development from those were reached in the other studies (Foster et al., 1980; Linstone et al., 1981). Yet, to a large extent, the results (presented in Appendix B) are dependent on the other studies' findings--combining the interviewees' comments, the papers presented at the guayule conference, and the Guayule Rubber Society Newsletters with the $U$ of $A$ and Linstone teams' reports. 
Briefly, their reports present either-or situations. That is, the $U$ of $A$ and Linstone teams identified distinct courses of action in which each actor/agency is expected to do just one thing, without taking into consideration the effects of cross-fertilization among them. Alternative scenarios in those reports present extremes resulting from single policy stances on the part of individual decisionmakers. Impacts derived from those scenarios, therefore, are (as described above for the $U$ of $A$ report) fairly limited in scope and extent. Resulting from a single action (or set of actions), the impacts are described in terms of that action set rather than the whole context.

The results presented in Appendix B, using the tools of fiction* suggest a different range of possibilities. They lead to the expectation that a multi-pronged approach to guayule's development is more likely, given the actors involved. At least one rubber company can be expected to forge ahead with a vertically controlled production system (including their own processing plant and company-owned or leased plantations), possibly by 1985. In the meantime, talks are likely to continue among federal agencies to establish a mechanism for federal access to domestic rubber, possibly leading to an agreement (by the end of 1984) to

*As was indicated in Chapter III, some of the tools of fiction are those of the historian or investigative reporter, as well. Therefore a number of the results presented here could well have emerged from the efforts of such researchers. 
stockpile guayule. The National Science Foundation can be expected to switch their funding interest from agronomics and polymer research to engineering (i.e., processing) research, while other agencies--in the Departments of Commerce, Energy, and Agriculture--may be persuaded to fund some guayule-related projects over the next few years. As a result of these actions on the part of decisionmakers, the synthesized report also suggests that beyond 1985, the first environmental impacts of large-scale cultivation and smallscale processing should be felt--mostly around Fort Stockton, Arizona, where Firestone has a test plant and is likely to build a fullscale facility. The diversion of cotton-growing and sorghum-producing lands to guayule would decrease water use and shift agricultural market patterns for the area, while the possible use of previously uncultivated marginal lands--encouraged by the four-year wait for a return on investment--may increase erosion problems. In addition, haze problems from intensive planting of the resinous shrub would begin to be apparent, as would any air and water quality problems resulting from a small- to medium-scale commercial processing plant.

It is clear that these impacts--and the measures necessary to mitigate them--will play a significant role in determining the scale of development in the years to follow. In terms of the scenarios developed by the $U$ of $A$ team, should the federal government decide that guayule is a strategic resource that should be stockpiled, then these 
effects may play a lesser deciding role than if development continues on a laissez-faire basis with local governments making regulatory decisions. In either case, however, the results of this synthesized approach indicate that conflicts over water use (already a major problem in the Southwest), land use (agricultural vs. residential or industrial), agricultural emphasis (food or fiber), and regulatory authority (e.g., environmental protection) would emerge and need to be dealt with as guayule became an increasingly important crop in that region.

Results from interviews indicate that the mechanisms called for in the Linstone team report (1980) for resolving these conflicts seem to be emerging in the forum for information exchange that is the Guayule Rubber Society. As more people outside of the research community become involved in that society and its meetings, some of these conflicts can be dealt with before they become emotional and political issues. Useful exchanges occur during Society meetings, where different interest groups can share concerns and ideas on an informal basis, prior to more formal statements or negotiations.* The society's newsletter, "El Guayulero," also has made it possible for researchers and government officials to express concerns and to keep each other

*For example, at the International Guayule Conference in Pasadena, one informal group consisted of the Chairman and co-Chairman of the Guayule Commission, the major political activist, two agronomists, and the executive in charge of guayule for one of the large rubber companies. 
informed on progress in dealing with them (cf Flynn, 1981; Hanson, 1981; Siddiqui, 1981). At present, however, observations from the synthesized approach indicate that only a few interest groups are involved in the Guayule Rubber Society. This means that farmers, local officials, Indian tribes, and local labor are left out of the exchange, increasing the likelihood that their concerns will become significant issues, as these groups become aware of potential problems, but have no informal mechanism for dealing with them.

Presentation. As discussed earlier in this dissertation, dynamic models such as those used by the $U$ of A are appropriate in only limited situations and the technical report is a useful form for sharing some, but not all, kinds of information. Structural models such as those used by Linstone's team are appropriate in clarifying problems and relationships, and the verbal models of journalists are useful for sharing the kinds of information that result from interpreting those models or summarizing other reports. But, as the analyses of EF stories (Chapter IV) have demonstrated, fiction most often describes the social and quality-of-life impacts that reflect the hopes and fears of the people involved with the innovation to the reader outside of the community.

Clearly, all three modes are necessary to effectively communicate the results of this research: the technical report for data and analysis, the journal article for 
summarizing results and organizational concerns, and the fiction for bringing forth human issues from the generalized analysis. In the synthesis presented in Appendix B a story points out some of the most important processes, issues, and impacts associated with the implementation of the policies currently being considered. It is followed by a journalistic summary that provides an overview of the information available in the $U$ of $A$ and Linstone assessments. In a complete version (too lengthy to be attached to this dissertation) a more detailed technical report, including results and descriptions of the methodologies used to obtain the results would follow these, with data and analytical discussions evaluating potential impacts and policy issues or considerations placed in appendices.

In their final form, the summary and the story are combined in a report that emphasizes the effects of the commercialization process. The focus of the results is shifted away from the technology per se (as in the $U$ of $A$ report) and from the organizational processes necessary to the technology's implementation (as in the Linstone report) to the technology's effects on the people dealing with it.

A sense of what the issues, options, and needs will be in developing the technology is provided early on in the synthesis. The reader is given a feel for the elements of the problem through the story, then an overview of the important policy concerns in the summary. This suggests 
that the more technical analyses which follow them can be more readily understood and utilized by the report's users. To that end, the story is written as an allegory (see Suvin's and Campbell's comments on science fiction as allegorical, in Chapter III). Its characters are symbolic: an attompt to typify the various groups--the Mexicans, the Americans, the researchers, the engineers, the administrators, and the farmers--involved in guayule's development. Less attention was paid to the government and its role than in the IA reports, and more to the people doing the work. Since the emphasis in all of the reports was on cooperation and the forming of coalitions, the working marriages of research with development, Mexican with American, and agronomy with process-engineering are the focus of the story. The main characters' move from the Southwest U.S. to Akron, Ohio represents the needed shift in focus when the time comes to make a final commitment to fullscale development. At the same time, the story is written to present some of the issues and conflicts emerging from the development process.

The opening scene illustrates the possible environmental and economic effects of largescale cultivation.

The air rose, hot and odorous, above the rows of cactus-like bushes. The haze made it difficult to see, as in the distance, a tractor turned and headed back down between the rows. Behind the tractor, cultivator hooks turned the sandy soil around the bushes to ensure that no other plants would consume the precious water allotted to the crop. The man 
driving the tractor adjusted the scarf over his face to better keep out the dust and the fumes...

(Appendix B)

The memories of Mexico point up the need for continued cooperation with that country.

Then the scene shifted, and she was... a girl on her uncle's ejido across the border, going out with the rest of the family to gather the wild guayule. . . Each day, during harvest time, they would fill up the truck's bed with the prickly plants--roots and all on some--and haul their harvest to the cooperativa where it would be chopped and baled and set to the processing plant in Saltillo. (Appendix B)

The possible racial issues (Mexican and Caucasian) and the conflicts over land and water use (food or fiber, the cultivation of marginal lands, the ejidos) are touched on, as well.

The need for rubber and its decreasing availability are in the story, as they are in the rubber community, driving forces in guayule's development.

"Gentlemen," he said, "We have come to the point of decision. Either we accept that guayule is and must be our major source of natural rubber in the future, committing ourselves to its full development as a resource, or we continue to rely on an increasingly unstable and decreasingly productive supply of hevea. We believe that the best interest of the company lies in the sure, steady, local supply. (Appendix B)

And, as in the story, decisions will be made far away from the fields and processing plants, in another world of board rooms and briefings, based on logical arguments and forecasts combined with descriptions of procedures and personal benefits.

"If this corporation chooses to develop guayule according to its present policies, you can see that, in either scenario, we will have a significant short 
fall in our supply. . . If, however, the corporation makes a full commitment to the development of this resource, we can expect to meet both the shortfall of natural rubber and any deficit in synthetics resulting from the unavailability or high cost of petroleum." . . He described in glowing terms the position the company would occupy in a world short of rubber but depending on it for everything from tires to surgical tubing. He played on each Board member's personal concerns. . . Patiently and steadily he worked to convince them..

Gradually Consuela could see each one buy into the idea. Guayule was becoming important to them. A major source of income. A steady source of supply. One by one they accepted it. (Appendix B).

In this way the need to include the full range of incentives and effects is illustrated and the potential mechanisms for cooperation are described.

This synthesized report is designed to enhance the existing IA reports by going beyond them to include information and conclusions that are not included in those reports, and by using more effective verbal models for communicating the results. The hope was that the objectives for impact assessment would be more effectively met by including several different modelforms. The fear is that lack of skill or presence of unrecognized biases may limit the utility of the synthesized report unnecessarily. To minimize the basis for that fear, great care was taken to ensure that the story was well-founded in the data and information gleaned by other researchers as well as myself and portions of the manuscript have been reviewed by members of the assessment teams in early draft stages. 
Limitations. The story and summary report presented in Appendix $B$ are designed to provide insights into and facilitate the communication of the process and initial effects of guayule's commercialization. They do not deal with a number of the isses which have been raised concerning long-term impacts. Another report, including a story dealing with local Indian tribes' access to land, water, and processing facilities in a water-starved Southwest, might be used to deal with these long-term effects, as guayule commercialization gets underway and a new, updated IA report is needed.

These examples illustrate ways to integrate extrapolative fiction with impact assessment, thereby including a broader range of insights, impacts, and issues in the IA report than has otherwise been included. They are intended to illustrate the possibilities, but they lend substantive support to the proposal presented in this dissertation, as well. Insofar as they clarify and illustrate impacts and issues, and insofar as they introduce new insights and impacts, they contribute to the evidence that extrapolative fiction can enhance impact assessment by introducing new techniques and models into the IA process. 
CHAPTER VII

\section{CONCLUSIONS AND IMPLICATIONS}

The preceding chapters have examined the proposal that extrapolative fiction can provide insights otherwise missing from impact assessments and communicate a more complete understanding of the results of those assessments. This chapter summarizes the results of the preceding chapters, discusses possible reasons for those results, and suggests some potential implications. It also delineates the limitations of the research and recommends some possible follow-on activities.

\section{SUMMARY OF RESULTS}

A review of the literature concerning impact assessment results and methods disclosed that reviewers and practitioners have a number of concerns about the effectiveness of that field in fulfilling its function as an aid to decisionmakers. A number of criticisms have been leveled against IA reports regarding their lack of clarity, lack of discussions of social and quality-of-life impacts, and their heavy reliance on quantitative methods and presentations. Practitioners viewing the IA process have expressed concerns about the lack of interdisciplinary cohesion, the ineffectiveness of impact analysis and evaluation techniques, and the need 
for methodological enhancement. These criticisms and concerns suggest that some radically new approaches to impact assessment are in order.

A review of the literature concerning futuristic fiction suggested that such fiction may be useful to those teaching or practicing the policy sciences. Further review provided a set of parameters for a subset of futuristic fiction that meets the special needs and requirements of impact assessment as a field within those sciences. Called here extrapolative fiction, this subset deals with timeframes, locations, and scopes of concern regarding the impacts of innovations that are equivalent to those of impact assessment.

A comparative statistical content analysis demonstrated that EF stories discuss an innovation's impacts in emotional well-being and other quality-of-life and social areas with significantly greater frequency than IA reports. This analysis also demonstrated that, compared to the descriptions of impacts in the IA reports studied, EF stories consistently discuss a wider range of impact categories and provide specific, rather than general descriptions of those impacts.

A thematic analysis of early (1940 - 1960) EF stories showed that many of the themes and concerns expressed in the stories studied have emerged as issues of national concern in the decades following those stories' publication. That analysis also showed that natural or physical environmental 
impacts are described in the setting in which the story takes place, while impacts on individuals and groups are communicated through the experiences of the characters acting in the story. Impacts on the economy, related technologies, social institutions and politics were shown to be described as they contribute to the development of the plot and conflict in the story. That these impacts are tied to required story elements means that all EF stories can be expected to contain some description of most of these impact areas.

A comparison of individual EF stories with IA reports dealing with the same topics--nuclear power plants, automated "slidewalks" or roads, and smallscale submarines-showed that the EF stories address potentially critical issues regarding human responses to and operation of innovations that are not included in IA reports. In the most compelling case, the stories' focus on human response, combined with the fictional requirement for crises led to a clear illustration of the effects of operating nuclear power plants on inadequately prepared personnel and the effects of large capital investment on policymakers. In contrast, the IA reports studied--critical reports in the decisions to implement this technology--focused on impacts at the level of measurable radiation exposure and expected construction costs. The events at Three Mile Island and Washington Public Power Supply, anticipated by the fiction but not by the assessments, underscore the point. 
These results provide substantive support for the proposal that one way to remedy some of the weaknesses in the IA process described in the literature is through the inclusion of EF stories. There are, however, some significant methodological considerations. The perspectives and methods associated with the two fields differ almost to the point of complementing each other. Necessarily, these differences must be taken into account in any attempt to synthesize the two approaches.

Two alternative configurations were illustrated in this dissertation for incorporating extrapolative fiction in the IA process. The first appended EF stories to a completed IA report as a means for illustrating the IA results. This approach is effective insofar as two sets of conditions are met: (1) stories can be found that deal with the innovation assessed in the report, and (2) the available stories deal with the impacts or policy options described by the report. In the assessment of life-extending technologies, an anthology of stories focusing on the same time period was shown to illustrate and extend the report results.

The second illustration in this dissertation was the use of extrapolative fiction in the IA process. Two approaches were suggested for this configuration, and one was developed as a case study. The first approach was the use of EF stories by IA practitioners early in the research and analysis process as a means for establishing a holistic perception of the system and innovation under study, 
including the hopes and fears of those who may be living with that innovation. Again, this approach is effective only to the extent that relevant stories can be found in the literature. Avoiding this potential limitation, the second approach includes a person on the IA team with skills in writing, researching for, and drawing on related works of, extrapolative fiction. This latter approach has a further advantage since it ensures that the questions asked in the IA research process include those asked for fiction-oriented processes. It is limited, however, by the skill of the new team member and by the other team members' acceptance of that member's research style--which may be apparently quite different, since it is based in different models and perspectives. The inclusion of this author on a team investigating guayule's commercialization led to substantially different results and an alternative format for presenting those results.

\section{DISCUSSION OF RESULTS}

In this dissertation, one subset of futuristic fiction has been proposed as a tool to enhance a subset of the policy sciences: the futures-oriented systems practice of impact assessment. The results of the literature reviews and the analyses summarized in the preceding section support that proposal and suggest some possible explanations for its effectiveness. 
One potential reason for these results may be found in the plotting, setting, and character development requirements for fiction itself. In order to be a work of fiction, a story must have a character, conflict (either internal or with the environment, or in the best works, both), action, a crisis, and a resolution (see, e.g., Elkins, 1979; Bova, 1982). In order to be a work of speculative fiction, these ingredients must be placed in a setting that is logically developed from the current here-and-now of the author and his or her readers (see Heinlein, 1969). In order to fit within the realm of futuristic fiction, that setting must be clearly located in a time some years after here-and-now (Clarke, 1979). Finally, in order to fit the definition suggested here for extrapolative fiction, that setting must be a logical extrapolation of current trends placed within the next ifty years--the timeframe for most impact assessments--and located on this planet. Each of these restrictions on the elements of which the story is composed increases the likelihood that there will be some overlap in concern between a story and an assessment. At the same time they require that the focus of the story be at a level of personal experience which has typically been well outside of the realm of impact assessment, and so lead the story to provide very different, though related, descriptions of possible impacts.

Another way to understand these results is to look at the process by which the assessments and the stories are 
developed. Many of the stated and implied criticisms of IA reports that are discussed in Chapter III derive from an assessment process that is oriented to the academic disciplines of the assessors and which depends on traditional, reductionistic, and quantitative methods to solve clearly defined problems. That process is very effective for dealing with isolated events in a controlled environment or with very large numbers of elements in a well-understood environment (see, e.g., Waddington, 1977). Such a process, however, is ill-suited to dealing with what Checkland (1981) has called human activity systems-organizations, institutions, and societies made up of human beings that use technologies to interact with the physical environment. Extrapolative fiction, on the other hand, depends on a process that involves the research techniques of investigative reporting (see Heinlein, 1969; Bova, 1982) and the modeling techniques of the arts (see LeGuin, 1979; Elkins, 1979), both of which have evolved over the years to understand and portray the activities and responses of individual and collected human beings. Cutting across the disciplines, this process emphasizes synthetic, qualitative methods to clarify not-very-well-understood relationships.

Clearly, for impact assessment to achieve the objectives with which it has been institutionalized, both kinds of processes are needed. The analyses and illustrative syntheses presented in this dissertation demonstrate the degree to which there is both overlap and complementarity in 
the two kinds of results. Where the IA reports described quantitatively measurable impacts, the EF stories described qualitative impacts. Where the EF stories focused on the users and operators of the innovation, the IA reports focused on the society or region in which the innovation would be placed. Where the two were combined, a much broader range of impacts were described, at much more meaningful levels of detail.

\section{IMPLICATIONS OF A SYNTHESIS}

The implications of implementing these results and incorporating extrapolative fiction in impact assessment may be considered at three levels. The first is the process whereby IA reports are completed. As the Discussion section above suggested, the two processes complement each other and including the fiction process may lead to some interesting developments in the IA process. The second level is the content of those IA reports. To the extent that the fiction is included in IA reports, those reports will include some very different kinds of descriptions of impacts. Finally, the context of systems research, in which impact assessment methodology is developed, is the focus at the third level of implication.

\section{Process}

At the level of process, integrating these two fields suggests severl implications. The results described here 
validate what many IA practitioners have begun to express-that social forecasting is as much art as science, and that creativity and intuition are as important to the process as good trend extrapolation and cross-impact techniques. The experience of a decade has led these practitioners to recognize where their tools are lacking, and the results of this research provide the grounds for those practitioners to look at a new set of tools--those of extrapolative fiction-to use when known tools fail or need an assist. The tools of fiction, combined with the known techniques of impact assessment, permit the inclusion of intuitive, creative activities in the IA process and bring that process into the context of the new systems thinking.

The scope of the effects of such a synthesis is related to the method chosen for the synthesis. If the IA team chooses to use previously published EF stories, they may be limited by the lack of topical bibliographies in that area, by the time, resources, and staff available to perform the assessment, and by the difference in focus between many early EF stories and the majority of IA reports. The first of these difficulties may be ameliorated by adding new steps in the literature review phase: polling known fans of the genre or relying on information specialists or librarians. The second, however, must be addressed on a project-byproject basis: the project manager must weigh the availability of resources against the availability of appropriate story material. Should the manager decide that enough 
stories appropriate to the project-at-hand are readily available, then the initial literature review phase can include the half-hour to three hours that it may take to read a story or novel. Should the team decide to develop an anthology, then letters to previous publishers and perhaps the authors will be necessary to gain permission to do so.* Alternativeiy, the limitations imposed by the nature of stories that have already been published can be circumvented by including writers with fictive skills on the team. The experience described in this dissertation of including a fiction-oriented member on an IA team demonstrates that the synthesis of extrapolative fiction with impact assessment leads to the inclusion of new kinds of research and new ways of thinking in completing assessments. The inclusion of a fiction-oriented team member means the inclusion of a humanist in a techno-scientific environment. The writer of fiction, concerned first and foremost with human characters and their human problems, will ask new questions and analyze data in new ways, affecting the assessment team's forecasting and analysis processes. While this addition to the process may add to the assessment team's early meeting time, the reduction of frustration, wasted time, and other problems associated with lack of integration should compensate for that delay as the project approaches completion.

* Although these contacts may sound difficult, in fact, re-publication of works is considered by most authors to be indicative of the author's standing in the field, so gaining permission is generally straightforward. 
While including a technical writer on the team has been recommended elsewhere (Porter et al., 1980; Arnstein and Christakis, 1975) to ensure coherence and clarity in the technical report (see chapter II), including a writer of fiction may be somewhat more difficult. However, it is fairly easy to find good technical writers who are also interested in writing fiction, and who may be trained (through reading and through writers' workshops) in the techniques of extrapolative fiction. If finding such a writer is not possible, then holding a writers' workshop as part of the assessment process may be possible, reaching writers through professional associations and newsletters and providing facilities for them to work together for a few days (usually five to nine). The writers could use a draft report as a source of ideas, and would, through the workshop process, develop a set of mutually acceptable stories based on the assessment results.

In either case, the assessment team has been changed. Reading the fiction provides the members with an alternative (albeit vicarious) experience of the possibilities, and including a fiction-oriented team member changes the balance and orientation of the team as a whole. In the long run, the effects of that change may be compounded and may, in time, lead to significant changes in the formal IA methodology . 
Content

At the level of content, the inclusion of fiction as part of the IA report not only enhances the presentation of quality-of-life and other qualitative impacts, but may contribute to a new conceptualization of the function and nature of such reports-and of social analysis in general. By setting a precedent for the inclusion of emotional and aesthetic aspects of human life in policy documents, the synthesized approach described in Chapter $V$ of this dissertation could contribute to the emerging recognition that a wider range of factors are significant in the policymaking process than has traditionally been assumed. Making a decision may begin to be seen as more than making a rational choice between clearly defined alternatives.

In the short term, the synthesized approach may lead to one or more "best-selling" reports. Reports that catch the attention and interest of the citizens involved in a project or program should encourage those citizens' participation in the decisionmaking process, thus contributing to the accomplishment of another, process-oriented, objective for impact assessment: active citizen involvement. A particularly effective document could also be used to extend and enhance the role of impact assessment in the bureaucratic decisionmaking process. 
Context

In the context of an evolving systems science, the synthesis suggested here represents an initial step toward a new extension of the practice of that science by going beyond the inclusion of social scientists in policy studies to include humanists. Including students and creators of the literature of the future opens the door for other writers and literary critics to contribute to the field and may be seen as another small step in the move to integrate the new systems thinking with systems practice. Incorporating extrapolative fiction into the impact assessment process may contribute to an understanding of the role that intuitive and imaginative capacities play in the analysissynthesis processes of systems science, and encourage the inclusion of other humanistic writings (e.g., historical theories, formal essays, and philosophical studies) in that discipline. Rather than continuing the separation of the humanities from systems and futures research, the inclusion of extrapolative fiction in the impact assessment process encourages the participation of intuitive, imagistic, and humanistic scholars in social systems analysis and design.

At another contextual level, these results--of the literature reviews, the analyses, and the illustrative syntheses--may be seen as reflecting a new approach to systems research. Recent shifts in systems thinking, characterized by the work of Churchman (1968, 1977), Checkland (1981), Linstone $(1977,1983)$, Jantsch $(1976,1981)$, and 
others, have moved the field away from the quantitative, objective, analytical approaches of operations research and dynamic modeling which have been traditional. The new systems practice addresses human (or sociotechnical) systems as "fuzzy" systems, whose purpose and boundaries are observer-dependent, whose evolution requires coping with unsolvable "problems," and whose elements are recognized as individual human beings with feelings and fears that lead to apparently "irrational" actions and decisions when observed by those outside the system. Models are seen, in this new systems approach, as assisting understanding rather than predicting behavior. Analysis is seen as the first step in design--inseparable from the creative, intuitive design process. Research is seen as the process of discovering what is known rather than of proving an hypothesis. Within this framework, the inclusion of the verbal models of fiction in a systems process is entirely appropriate. The fiction provides another way to discover what is known, offering models that complement quantitative dynamic models. The fiction also emphasizes the subjective nature of the observer and the participants in the system being studied, illustrating their feeling-based behaviors as well as the rational decisions. Moreover, since the fiction is clearly as much about the author as about the subject being described, the epistemological problem of social systems research (i.e., the impossibility of separating the observer from the system) is at the minimum underscored, and 
may, in some cases, be made clear to the citizenry and decisionmakers who are likely to use the report.*

At the same time, including the intuitive and imaginative process of extrapolative fiction in the analytical impact assessment process may bring together again the several streams of futuristic writing--utopias, futures essays, social change theory, etc.--described by I.F. Clarke (1979; discussed in Chapter II). Rather than maintaining the disciplinary boundaries that have grown between these forms of writing, this synthesis could strengthen the links still present between them and, possibly, contribute to the deveiopment of the emerging discipline of futures research. Finally, the synthesis of extrapolative fiction with impact assessment can be considered an initial attempt to apply a theory of imagery to the policy sciences. The consideration of fiction as a form of communication that through its encouragement of the formation of mental images has significant potential for communicating decision-support information suggests a wide range of applications in the policy sciences. It may even eventually contribute to new developments in cybernetic theory, as the concept of sharing images becomes a part of the definition of communication and

*Heinz vonfoerster clarifies this problem in his discussions of "observing systems", summarized in Linstone and Simmonds (1977), and detailed in his Observing Systems (1981). He points out that, as cognitive beings, what we perceive are descriptions of reality that we create for ourselves, rather than anything outside of ourselves. 
extends the traditional notion of communication as an incessant stream of bits flowing from transmitter to receiver.

\section{LIMITATIONS OF THE RESEARCH}

This dissertation represents the culmination of a degree program in applied systems science with an emphasis in futures research. As such it is intended as a methodological contribution, offering the possibility of enhancing --rather than supplanting--existing models and approaches. It demonstrates that the field of extrapolative fiction can be used to enhance the practice of impact assessment without attempting to prove that EF stories, alone, can replace or supplant IA reports.

When this research was initiated (in 1979), it was seen as a necessary step into what was then uncharted territory: the integration of various forms of impact assessment and the collection and analysis of works of science fiction as possible contributors to that field. Since then, others-most of whom have been referred to in these pages--have published work along those lines, and the research has evolved to take into account their efforts.

Partly because of those others' efforts, a number of interesting problems and related study questions have emerged over the years. These questions, relating to how the decisionmaking process works, what the role of citizen participation should be in the impact assessment process, and what the potential role of estranged science fiction may 
be in clarifying perceptions of current cultural issues for decisionmakers, were unfortunately beyond the scope of this present work. Such questions, along with any stories or authors that may have been missed, will have to wait to be dealt with until the next project. 


\section{REFERENCES}

Adelson, M., "Issues of Scale and Trajectory," Working Paper in Linstone, 1980, op cit., pp 86-87.

Alexander, C., Notes on the Synthesis of Form, Cambridge,

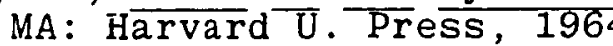

Allison, G., Essence of Decision: The Cuban Missile Crisis, Boston, MA: Lit tle-Brown, $197 \overline{1}$

Andersen, D. F., "Mathematical Models and Decision Making in Bureaucracies: A Case Story Told from Three Points of View," doctoral dissertation, Massachusetts Institute of Technology, Cambridge, Massachusetts, August, 1977.

Anderson, P., "How to Build a Planet" in The Science Fiction Writer's Association Bulletin, November, 1966, p.3.

Armstrong, J., and W. W. Harman, Methodology for Technology Assessment, Boulder Colorado: Westview Press, 1980 .

Arnstein, S. and Christakis, N., Perspectives on Technology Assessment, Academy for Contemporary Problems, Ann Arbor, Michigan: Ann Arbor Press, 1975.

Ascher, W., Forecasting: An Appraisal for Policymakers and Planners, Baltimore: Johns Hopkins Press, $197 \overline{8 .}$

Ashby, W. R., An Introduction to Cybernetics, London: Methuen \& Co. , 1964 .

Asimov, I., I, Robot, New York: Pocket Books, 1948.

- Foundation, Foundation and Empire, The Second Foundation, New York: Avon, $1951,195 \overline{2}, 1953$.

, "Introduction", Soviet Science Fiction, New York: Avon, 1962, p. 9. , interview in The Futurist, October, 1967, p.2. , "Asimov on Asimov", in Olander and Greenberg, 1972, op. cit. 
Asimov on Science Fiction, New York: Ballantine, 1983

Assagioli, R., Psychosynthesis, New York, Penguin, 1977.

Automotive News, "New Car Buying Up", February, 1982.

Bainbridge, W. S., and M. Dalziel, "The Structure of Science Fiction as Perceived by the Fans", Science Fiction Studies, No. 16, March, 1980, pp 165-169.

Ballou, P. K., Women: A Bibliography of Bibliographies, Boston: G. K. Hall, 1980 .

Bendix, S. "Preparing a Socially Useful EIS" presented to the Institute of Man and Science/ National Science Foundation Symposium on Improving the Utility and Relevance of Scientific and Technical Information in Environmental Impact Statments, Rensselaerville, New York, May, 1980.

Block, L., Writing the Novel, From Plot to Print, New York: Writer's Digest Books, 1979.

Bodley, B. H. Anthropology in Contemporary Human Problems, Reading, Ma: Addison-Wesley, 1976.

Boulding, K., The Image (11th edition), Ann Arbor, MI: Ann Arbor Press, 1977.

Bova, B., Notes to a Science Fiction Writer, New York: Avon, 1983 .

Bradley, M. Z., "My Trip Through Science Fiction" in Algol, Winter, 1977-78, pp 11-20.

Brunner, J., The Sheep Look Up, New York: Ballantine, 1970. , Stand on Zanzibar, New York: Bantam, 1968.

Bureau of Land Management, U. S. Department of the Interior, "Final Environmental Impact Statement of Proposed Increase in Acreage to be Offered for Oil and Gas Leasing on the Outer Continental Shelf", DES 74190, Washington, D. C., 1974.

Campbell, J., Prologue to Analog, New York, Doubleday, 1960.

Campbell, W. G., and Ballou, S. V., Form and Style; Theses, Reports, Term Papers (fourth edition), Boston, Houghton-Mifflin, 1974 . 
Carden, M. L., Feminism in the Mid-Seventies: The Nonestablishment, the Establishment, and the Future, report to the Ford Foundation, New York, 1977.

Carpenter, R. "The Scope and Limits of Technology Assessment," paper presented to the Seminar on Technology Assessment, OECD, Paris, January, 1972.

Carr, T., Dream's Edge, New York: The Sierra Club, 1980.

Cartmill, C., "Deadline", Astounding Science Fiction, March, 1944.

Checkland, P., Systems Thinking, Systems Practice, New York: Wiley, 1981 .

Churchman, C. W., Challenge to Reason, New York: McGrawHill, 1968, , "Managing Complexity" in Linstone and Simmonds, 1977, op.cit.

Ciriacy-Wantrup, S. V., "The Economics of Environmental Planning" in Land Economics, Vol.42, February, 1971.

Clarke, A. C., The Deep Range, New York: Signet, 1957.

Clarke, I.F., Interpretations of the Future, London: Oxford Press, 1979 .

Clifton, M. and Apostolides, A., "What Thin Partitions", Astounding Science Fiction, Vol LII, No.1, September, 1953, p. 8ff.

Code of Federal Regulations, Volume 10, Washington D. C.: U. S. Government Printing Office, 1974.

Council of State Governments, "Environmental Impact Assessment: Policy Considerations for the States", Lexington Kentucky: The Council, 1977.

Davenport, B., The Science Fiction Novel, Chicago: Advent, 1969 .

DeGreene, K. B., Sociotechnical Systems, New York: Pergamon, 1972 .

DeSouza, G. R. Systems Methods for Socioeconomic and Environmental Impact Assessment, Lexing $\overline{\text { Aon, }}$ MA: Lexington Books, 1979 . 
Dickert, T. G., and Domeny, K. R. Environmental Impact Assessment, Guidelines and Commentary, Berkeley, $\overline{\mathrm{CA}}$, University Extension Press, 1974

Dickert, T. G., and Jorgensen, J. "Guidelines for the Content of Environmental Impact Statements" in Dickert and Domeny (1974), op cit., pp.33ff

Disch, T., "A Modern Romance", in Sargent, 1978, op.cit. , 334, New York: Avon, 1978.

Duncan, H. D., Symbols in Society, London: Oxford University Press, 1968 .

Duncan and Jones, Methodology and Guidelines for Assessing Social Impacts of Development, Berkeley, CA: Berkeley Planning Association, 1978.

Edwards, K. "Counterspy," Astounding Science Fact and Fiction, February, 1953 .

Elgin, D., et al., "Alternative Futures for Environmental Planning" report to the Environmental Protection Agency, SRI International, Menlo Park CA, 1975.

Elkins, C., "Science Fiction vs. Futurology", Science Fiction Studies, Vol.6, 1979

Ellison, H. "A Boy and His Dog," Dangerous Visions, H. Ellison (ed.), New York: Doubleday, 1975. , "Repent, Harlequin! Said the Ticktockman," in Greenberg and Warrick, 1974, op.cit.

Elrick, G. S., Science Fiction Handbook for Readers and Writers, Chicago Review Press, $197 \overline{8 .}$

Embler, W. Metaphor and Meaning, Deland, Fla.: Everett/Edwards, 1966.

Ernst, D., et al., "An Assessment of Electronic Funds Transfer Systems," report to the National Science Foundation, Arthur D. Little, Co., Washington, D.C., 1975 .

Federal Highway Administration and State of Minnesota Department of Highways, "Final Environmental Statement for U. S. 59 in Stevens County, Minnesota, EIS-MN-74-0180-F, St. Paul, Minnesota, January, 1974. 
Fensterbusch, K., and Wolf, C. P., Methodology for Social Impact Assessment, Strousburg, PA: Dowden, Hutchinson and Ross, 1977.

Flynn, E., "Guayule: Where is it Headed?" El Guayulero, Vol. 3, No. 1, Spring, 1981, P. 6-11.

Foster, K. et al., "A Sociotechnical Survey of Guayule Commercialization," Interim report to the National Science Foundation, University of Arizona Office of Arid Lands Studies, Tucson, Arizona, April, 1980 .

Giele, J. Z., Women and the Future: Changing Sex Roles in Modern America, New York: The Free Press, $197 \overline{8}$.

Gordon, T., "Technology Assessment of Life Extending Technologies," report to the National Science Foundation by The Futures Group, December, 1979.

, Life Extending Technologies, A Technology Assessment, New York: Pergamon, 1980 .

Greenberg, M. H. and Warrick, P., Political Science Fiction,

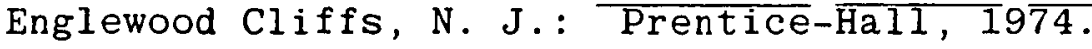

Haemer, K. W., "Writing for the Reader," American Telephone and Telegraph monograph, 1965.

Hall, A. D., and Fagen, W., "The Definition of a System," in Buckley, ed., Systems Research for the Behavioral Scientist, New York: Brazillier, 1973

Heckler, E. L., "Science Fiction and Trends for an Educational Policy," Research Memorandum, Educational Policy Research Center, SRI International, Menlo Park, California, December, 1968 .

, personal communication, April, 1981.

Heinlein, R. A., Worlds of Robert A. Heinlein, New York: Avon, 1965 .

, essay, in Davenport, 1969.

, "Blow-ups Happen", in Expanding Universe, 1980 , op. cit. . 
, "Let There Be Light!" in Expanding Universe, 1980 , op.cit.

, "The Roads Must Roll", in Expanding

Universe, 1980 , op. cit.

Heppenheimer, T. A., Colonies in Space, New York: Warner Books, 1977 .

Herbert, F. Under Pressure, New York: Del Rey, 1956.

Hesse, M. B., Models and Analogies in Science, Univ. of Notre Dame Press, 1966

Hetman, F. Society and the Assessment of Technology, Paris: $\mathrm{OECD}, 1974$.

Holsti, J., Content Analysis for the Social Sciences, Reading, MA: Addison-Wesley, 1973.

Hornick, R. and Enk, G., Institute on Man and Science, "Interim Report on Improving the Utility and Relevance of Scientific and Technical Information in Environmental Impact Statements," report to the National Science Foundation, Renssalaerville, N.Y., June, 1980.

Jantsch, E., ed., The Evolutionary Vision, Washington, D.C.: American Association for the Advancement of Science, 1981.

, and Waddington, C. H., Evolution and Consciousness, New York: Pergamon, 1976.

Jay, A. Management and Machiavelli, New York: Delta Books, 1976 .

Kawamura, K., and Christakis, N. "The Role of Structural Modeling in Technology Assessment", presented at the Congress of the International Society for Technology Assessment, Ann Arbor Michigan, October 24-28, 1976.

Keefe, W. F., Open Minds: The Forgotten Side of Communication, New York: AMACOM, 1975.

Krippendorff, K., Content Analysis: An Introduction to its Methodology, New York, Sage, 1980 .

LeGuin, U. K., Left Hand of Darkness, New York: Doubleday, 1967 .

, The Dispossessed, New York: Ballantine, 1969. 
The Language of the Night (collected essays, edited and with an introduction by $S$. Wood), New York: Ballantine, 1979.

" "The Function of Narrative", Nina Mae Kellogg Lecture, Portland State University, April, 1980

Lehnhoff, N., personal communication, Portland, Or: fall, 1981

Leinster, M., "Historical Note," Astounding Science Fiction, February, 1951, pp. $45 \mathrm{f}$ f.

Lem, S., "The Structure of Science Fiction" in Rose, 1976, op. cit.

Linstone, H. A., et al., "The Role of Structural Modeling in Technology Assessment" report to the National Science Foundation, Portland State University, 1978.

, "The Use of Alternative Decision Models for Technology Assessment," Progress Report No. 2 to the National Science Foundation, Grant No. PRA79-10020, Portland State University, June, 1980 .

, "Alternative Decision Models for Technology Assessment and other Decision Areas," final report to the National Science Foundation, Grant No. PRA79-10020, Portland State University, 1981 .

The Multiple Perspective Concept, New York: North Holland, 1983.

Linstone, H. A., and Simmonds, W. H. C., Futures Research: New Directions, Reading Ma: Addison-Wesley, 1977.

Lipinsky, G., "Communicating the Future," Futures, February, 1978 , pp. $29 \mathrm{ff}$.

, personal communication, October, 1980 .

Markley, O. W., "Imaging the Future" presented to the annual meeting of the Society for General Systems Research, Houston, Texas, 1980.

, Changing Images of Man, New York: Pergamon Press, 1982 . 
Martino, J. P., Technological Forecasting for Decisionmaking, New York: North Holland, 1972.

Martinson, T. L. "The Most Perfect Example of an Alien Ecology Ever Constructed", The Professional Geographer, 32(4), $1980, \mathrm{p} . \overline{471}$ ff.

Masters, R. and Houston, J. Mind Games, New York, Delta, 1972 .

Mead, M., "Models and Systems Analyses as Metacommunication" in Laszlo, The World System, New York, Brazillier, 1973.

Meltzner, A. "Organizational Views on the Commercialization of Guayule" Working Paper, in Linstone, 1980, op cit.

Michaelis, A., "Science Fiction and Technology Assessment: A Possible Interdisciplinary Correlation?", paper presented to the annual meeting of the International Association for Impact Assessment, May, 1983, Detroit, Michigan.

Miller, D. C. and P. Schwartz, "Divergence Mapping" prepared with the staff of Pacific House, San Francisco, 1972 .

Miller, R. "The EIS and the Decisionmaker: Closing the Gap", presented to the Institute on Man and Science, National Science Foundation Symposium on Improving the Utility and Relevance of Scientific and Technical Information in Environmental Impact Statements, Rensselaerville, New York, May, 1980.

, "Enhancing Systems Design Through the Use of Intuitive Methods" Proceedings of the Society for General Systems Research, Toronto, Ontario, 1981.

, "Models and Their Appropriate Roles", Proceedings of the Society for General Systems Research, Washington, D.C., 1982.

, "Forecasts from the Individual Perspective: Speculative Fiction" paper presented to the International Forecasting Symposium, Philadelphia, Pennsylvania, June, 1983.

Mitchell, A., et al., "Handbook of Forecasting Techniques", prepared for the Army Corps of Engineers Institute on Water Resources, SRI International, Menlo Park, CA, 1975. 
MITRE Corporation, "A Technology Assessment: Mariculture," report to the Office of Science and Technology, 1971.

Molitor, G. T. T., "Schema for Forecasting Public Policy Change," Policy Analysis, 1972, pp. 204-210.

Munn, R.E., ed., Environmental Impact Assessment: Principles and Processes, New York: Wiley, 1979.

Myers, G. E., The Dynamics of Human Communication, New York: McGraw-Hill, 1973.

National Academy of Sciences, "Guayule: An Alternative Source of Rubber", Washington, D. C.: U. S. Government Printing Office, 1977.

National Institutes of Health, U. S. Department of Health, Education, and Welfare, "Final Environmental Impact Statsment on NIH Guidelines for Research Involving Recombinant DNA Molecules," DHEW (NIH) 1489 and 1490, Washington, D. C., 1977.

National Organization for Women Newsletter, February, 1970.

Norman, C. The God That Limps: Science and Technology in the $1 \overline{980}$, New York: W. W. Norton, 1981 .

Nuclear Regulatory Commission, "Three Mile Island Environmental Impact Statement", Oakridge, Tennessee, 1976.

\section{8, 1979, Three Mile Island accident," by the} Office of Inspection and Enforcement, NUREG 0600, August, 1979.

O'Connor, F., "The Nature and Aim of fiction" in The Writer's Craft, J. Hersey, ed., Boston: Knopf, 1974

Ogilvie, J., "The Death of the Presidency", Coevolution Quarterly, Winter, 1980-81, pp. 5ff.

O'Neill, G. K., "Space Colonization and Energy Supply to the Earth", testimony before the Subcommittee on Space Science and Applications, U. S. Congress, July 23, 1975 .

Oregon Siting Council, "The Pebble Springs Decision", summary of council proceedings, Salem, 1979. 
Pacific House, "Divergence Mapping" unpublished guidelines, San Francisco, 1972.

Parade Magazine, "Strip Searches, The New Humiliation", February 1981.

Peele, E. "Social Considerations Relative to Impacts of Decentralized Solar Technologies," presentation to the Institute on Man and Science/ National Science Foundation Symposium on Improving the Utility and Relevance of Scientific and Technical Information in Environmental Impact Assessment, Rensselaerville, New York, May, 1980.

Perry, D. A. and G. Hanson, "Estimation and Improvement of Rubber Yield in some USDA Guayule Selections," El Guayulero, Vol.3, No. 1, Spring, 1981, p.14.

Petrie, H. D., "Do You See What I See? The Epistemology of Interdisciplinary Inquiry", Journal of Aesthetic Education, Vol 10, 1976, Pp. 9-15.

Pierce, J. R., Symbols, Signals, and Noise, New York: Harper and Row, 1961 .

Piper, H. B., "The Mercenaries" in Astounding Science Fact and Fiction, 1950, pp. 35ff.

"The Day of the Moron" in Astounding Science Fact and Fiction, September, 1951, pp. 13 ff.

Platt, C., Dream Makers; The Uncommon People Who Write Science Fiction, New York: Berkley Press, 1980.

Pohl, F., and Kornbluth, C. M., Gladiator-at-Law, New York: Bantam, 1955.

York: Bantam, 1957.

, The Space Merchants, New

Porter, A. L., et al., A Guidebook for Technology Assessment and Impact Anālysis, New York: North Holland, 1980

Rabiega, W. A., "Environmental Fiction for Pedagogical Purposes," Council of Planning Librarians Exchange Bibliography No. 590, June, 1974.

"A Classroom Delphi," The Professional Geographer, February, 1982.

, personal communications, fall, 1979 . 
Reynolds, M., Commune: 2000 A. D., New York: Bantam Books, 1974. 1979

Equality in the Year 2000, New York: Bantam Books,

Rogers, S., Miller, J. and Miller, R., "Enhancing the Design of an Industrial System Through the Use of

Intuitive Methods," Proceedings of the American

Institute of Industrial Engineers, May, 1980.

Root, G., "Models as Aids to Thinking," Proceedings of the Society on Systems, Man, and Cybernetics, San Francisco, 1976, pp $272 \mathrm{ff}$.

Rose, M., ed., Science Fiction, Englewood Cliffs, New Jersey: Prentice-Hall, 1976.

Rubinstein, M., Patterns of Problem-Solving, New York: Brace, Harcourt, 1975 .

Rulon, C., "Biology and Society" workbook, Long Beach City College, Long Beach, CA, 1973.

Sargent, P. Bio-Futures, New York: Ballantine, 1978.

Shapley, W. H., Phillips, D.I., R\&D, Industry, and the Economy, Washington D.C.: American Association for the Advancement of Science, 1978.

Shaw, B., "Escape to Infinity", Foundation, No. 10, June, 1976.

Siddiqui, I. "California State Guayule Development Program," El Guayulero, Vol. 3, No. 1, Spring, 1981, p.12.

Solid Waste Division, Metropolitan Service District, "Environmental Assessment, Rossman Processing Station", Portland Oregon, June, 1976.

SRI International, "Transportation in America's Future; Potentials for the Next Half Century", report prepared for the U. S. Department of Transportation, SRI International, Menlo Park, CA, 1978.

Strain, D., "Flexible Work Options at ESI", presentation to the Spring Seminar, Flexible Ways to Work, Portland Oregon, May 7, 1983 Suvin, D. , $\frac{\text { Metamorphoses of }}{\text { Yale Press, 1979. }}$ Sce Fiction, Cambridge, MA,

Taylor, J. G., personal communication, April 29, 1980. 
, "Technology Assessment of the Commercialization of Guayule," paper presented to the Third International Guayule Conference, April 28, 1980.

Tiptree, J., "The Women Men Never See", Analog, September, 1968, pp43ff.

Trask, G., and Burkhardt, C., ed., Storytellers and Their Art, New York, Doubleday, 1963.

U. S. Congress (94th), The Technology Assessment Act of 1972 .

U. S. Congress (92nd), The National Environmental Protection Act of 1970 .

U. S. Council on Environmental Quality, "Regulations for Implementing the Procedural Provisions of the National Environmental Protection Act," Washington, D. C., May, 1980.

U. S. Department of Commerce, Bureau of Statistics, 1982.

U. S. Department of Transportation, "Report on Automobile Usage and Trends," 1982 .

U. S. House of Representatives Subcommittee on Space and Astronautics, Hearings on "Solar Powered Satellite Stations", 1975 .

U. S. House of Representatives Select Committee on Aging, "Applications of Space Technology for the Elderly and Handicapped", Washington,D.C.: U.S. Government Printing Office, 1972.

U. S. Office of Management and Budget "Special Analysis K, Budget of the United States Government, F.Y. 1981", Washington, D. C., 1980

U. S. President's Commission on the Accident at Three Mile Island, Volume Four "Technical Assessment," Washington, D.C.: October, 1979.

Varley, J., The Ophiuchi Hotline, New York: Bantam, 1978.

Vaughn, F., Awakening Intuition, New York: Anchor, 1979.

von Bertalanffy, L., General Systems Theory, New York: Brazillier, 1968 . , Toward A Systems Perspective of Man, New York: Brazillier, 1981. 
Waddington, C. H., Tools for Thought, New York: Basic Books, 1977 .

Warfield, J., The Structure of Complexity, Battelle Monograph, Columbus, Ohio, 1973.

Warrick, P., The Cybernetic Imagination in Science Fiction, Cambridge, MA: MIT Press, 1980.

Watzlawick, P., et al., Pragmatics of Human Communication, Boston: W. W. Norton, 1967 .

Weiner, N:, The Human Use of Human Beings, New York: Anchor Press, $\overline{1954}$.

Wilson, M., Survival Skills for Managers, Boulder, CO: Johnson Publishing, I981.

Wolf, C.P., "Getting Social Impact Analysis into the Policy Arena," Environmental Impact Assessment Review,

Vol. I No. 1, March, 1980. pp. $32 \mathrm{ff.}$ 
APPENDIX A

TOPICAL BIBLIOGRAPHY OF

EXTRAPOLATIVE FICTION

(selected works) 


\section{TCPICAL BIBLIOGRAPHY OF EXTRAPOLATIVE FICTION}

\section{Space Colonies}

Bova, B., Millenium, Colony

two books describing the colonization of near space by corporate conglomerates. Deals with earth-colony relationships, starting with Milennium.

Clarke, A. Fountains of Paradise

A space elevator is built in Sri Lanka

Heinlein, R., The Man Who Sold the Moon collection of short stories describing how an entrepreneur collects the capital and creates a moon colony , The Menace From Earth collection of short stories describing life in nearspace colonies, including the Moon

Pohl, F. Man Plus

Colonizing some places may take reshaping human beings for the first wave.

Pournelle, J. High Justice

Corporate control of power sources leads to corporate development of space stations

Reynolds, M., LaGrange Five

Part of a series of books on A. D. 2000, describing formation and development of a colony at a LaGrange point

Sheffield, C., "The Man Who Stole the Moon"

a young engineer, frustrated by redtape in his attempts to test his rocket fuel, joins the mafia to build the resources to get to the moon

Submarine development

Clarke, A. The Deep Range, Dolphin Island mariculture leads to new tools and new ways of reaching the ocean's resources

Herbert, F. Under Pressure

the need for oil drives the U.S. to drill undersea wells

McLaughlin, D. Dome World undersea mining leads to undersea cities and wars 
Pohl, F. and J. Williamson, Undersea Quest cities develop around mines and wells

Pournelle, J., "The Enforcer" story in High Justice describing ocean thermal-electric plant and related production/housing facilities

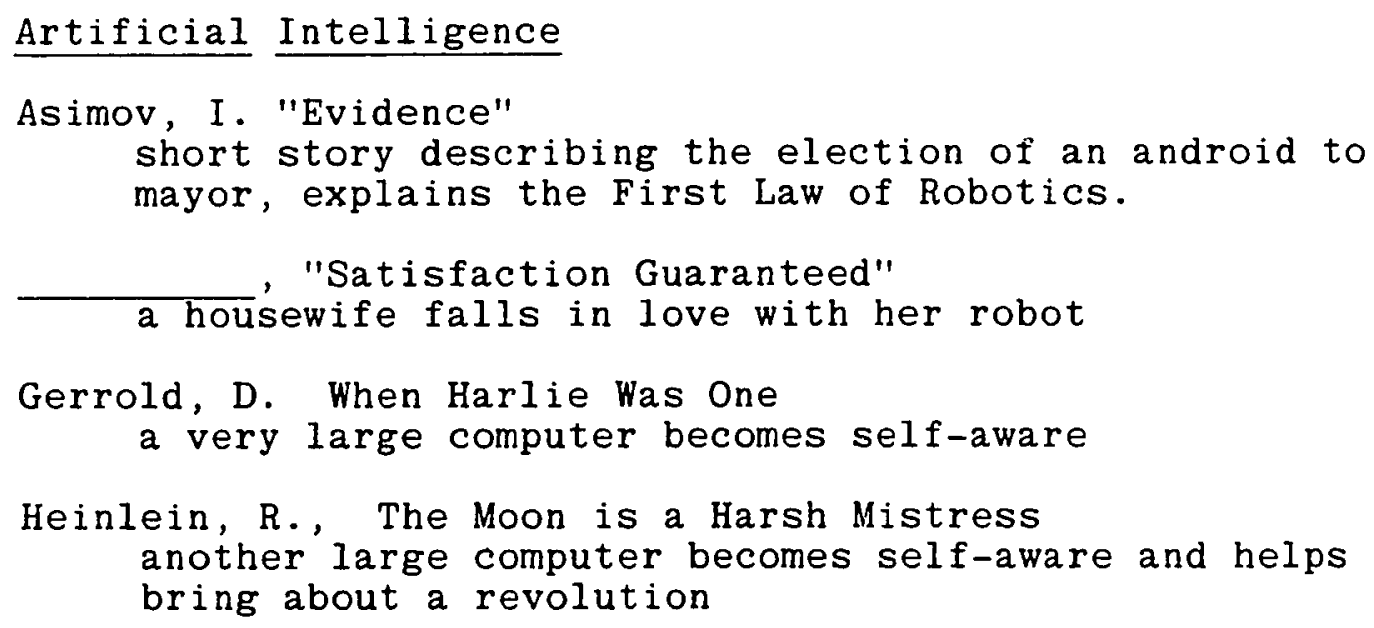

Gerrold, D. When Harlie Was One

a very large computer becomes self-aware

Heinlein, R., The Moon is a Harsh Mistress another large computer becomes self-aware and helps bring about a revolution

Keller, D. H., "The Psychophonic Nurse" a baby is tended by a robot nurse

\section{Production/Distribution Systems and Economics}

Bova, B. The Weathermakers one segment of the population controls the weather control systems

Clarke, A., The Deep Range whales are herded to provide protein for a hungry world

Coulsen, J., Tomorrow's Heritage the multinational corporations divide up the world to maximize profits, set up satellite stations and operate weather control facilities

Miller, W.M., "The Darfstellar" specialistic society in which creativity is harnessed to create new specialities

Pournelle, J. High Justice corporations develop massive integrated agro-industrial complexes based on nuclear power

Reynolds, M., Commune: 2000 A.D., Equality in the Year 2000 Guaranteed Annual Income leads to new social units as production systems require fewer and fewer workers 
in a planned economy is personal freedom a disease or a
cure?

Scheckley, R. "Cost of Living"

Keeping up with the latest gadgets puts children in debt for parents' purchases

\section{Changing Social Roles}

Disch, T. 334

interwoven stories of three women living in public

housing in New York--one a middle-aged mother, one a lesbian, and one whose husband nurses their child.

Heinlein, R. Friday

in a north america made up of many sovereign nations,

an "artifically enhanced" woman makes her way as a

courier for a revolutionary organization

Felice, C. "No One Said Forever"

a career woman comes to terms with the fact that this transfer will separate her from her child for at least two years

Rimmer, R. Proposition 31,

two couples decide to pool their resources in a

"corporate marriage" and pass a referendum in

California to make it legal

Psychological Enhancements

Anderson, P. Brain Wave

intelligence is suddenly doubled

Anvil, C. "The Great Intellect Boom"

a pill to improve the intellect backfires, leads to the need for an antidote

Heard, H. F. Doppelgangers

The fourth, psychological, revolution leads to a world state

McCaffery, A. To Ride Pegasus

A group of people with psi potential are brought

together in an institute

McDonald, J. D. "Trojan Horse Laugh"

a drug puts peoples emotions in synch--and a positive feedback loop goes into effect 
Phillips, P. "P-Plus" a personality enhancer used by a few creates a new elite; used by all, resumes business as usual

Reynolds, M. Ability Quotient scores on a super "I.Q." test determine one's life pattern

Sturgeon, T. More Than Human the next evolutionary step begins when a group of people come together to form a synergistic personality

Life-Extending Technologies

(see tables in Chapter VI)

Biomedical Technologies

Banks, R. E. , "The Happiness Effect" brain surgery provides "social adjustment" by removing "bad" synapses

Harrison, H. "The Ghoul Squad" transplants become the norm, and people have to state that they don't want their bodies used for parts

Heinlein, R. I Will Fear No Evil corporate chief arranges to have his brain transplanted into another person's body

McIntyre, V. "Spectra"

a girl is made into a cyborg 
APPENDIX B

Proposed Report Format for Including a Story in an Assessment of the Impacts of Guayule's Commercialization 


\section{CONTENTS}

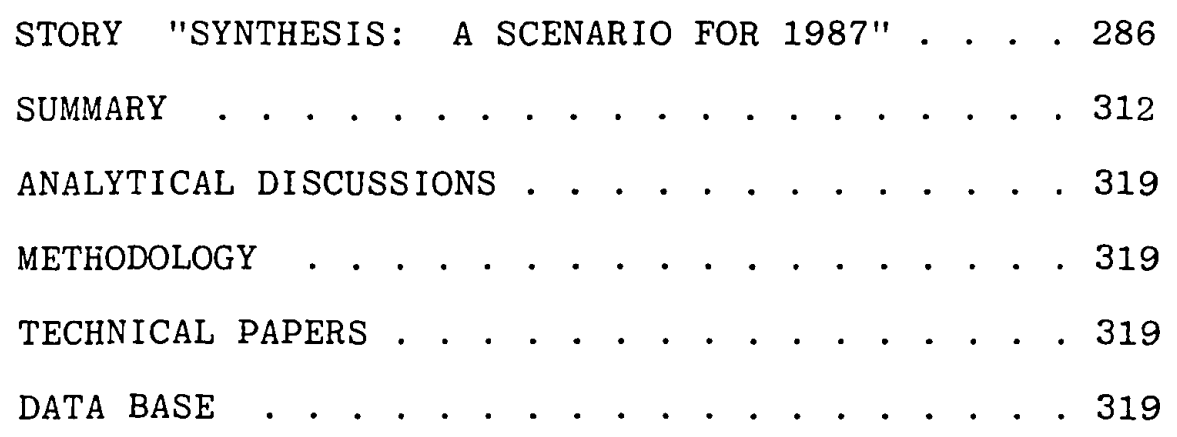




\section{"SYNTHESIS: A SCENARIO FOR 1987"}

The air rose, hot and odorous, above the rows of cactus-like bushes. The haze made it difficult to see, as in the distance, a tractor turned and made its way back between the rows. Behind the tractor, cultivator hooks turned the sandy soil around the bushes to ensure that no other plants would consume the precious water allotted to the crop. The man driving the tractor adjusted the scarf over his face to better keep out the dust and the fumes. He looked up and saw a pick-up truck parked at the end of the row. Waving, he acknowledged its presence, then proceeded to finish cultivating the row.

When he came to the end, he switched off the engine and jumped down.

"fio, David! What brings you out here?"

"Just checking on your crop, Al. Tryin' to get a sense of how much to plan for, when, at the plant."

"Well, this field's been in three years and's ready for topping. That one," he pointed across the road, "was topped last year, and I'm planning to pull it up next month."

"Sounds good. Looks good, too. Should be a pretty good harvest."

"Yeh, I think so. It should be a good year. Better be, the bank'11 be looking for their money." The farmer 
wiped his forehead with the scarf and started to put it back on. "It's a good thing the Ag people backed up my loan, otherwise I don't think I'd have been able to try this stuff. Of course, we're all counting on you guys at the plant to pay us enough to make it worth our while."

The man called David smiled, his blue eyes crinkling around the edges as he did so. "Well, right now it looks okay. The price of oil is pretty high and we've got a process that does a pretty good job of extracting the latex from these things. The company's even backing the building of a fullscale plant in town, so we ought to be able to give you a worthwhile price." He turned toward his truck. "Better let you get back to it, then. Have a good day!" David Archer swung up into the cab of the truck, his sandy hair falling into his eyes with the movement. As he started the engine, he thought about $\mathrm{Al}$, and the other farmers like him. They were all taking a chance on an experimental crop, based on his promises and on the Department of Agriculture's backing. Good farmers all, they had set aside a portion of their marginal lands to try a crop that was supposed to use less of that scarcest of resources--water--than any other marketable crop, and come back with a return at least as good.

His brow furrowed for a moment as he once more considered the risk they were taking. What if the company backed out now? Then he remembered this morning's phone call and relaxed. He smiled, and his ruddy cheeks glowed. 
If that call was any indicator, then, well, it looked as it they were going to win--at least in the short run. He swung the truck back onto the roadway and headed up into the hills.

At a break in the fence David turned the truck of $f$ the road onto a dirt track. He wound his way bst corn and cotton fields and, following an arroyo, headed toward a metal shack at the base of a shrub-covered hill. There he stopped and hopped out.

"Consuela!"

"Ola, David! Over here!"

Following the sound of the voice, David looked up the hill. There, halfway up the slope, was a bright patch of color he identified as his wife. He waved and started up through the cactus-like shrubs.

As he climbed, he found himself comparing the plants with those he had just seen in the field. Where those had been planted in neat rows, these seemed scattered all over the hilside. Where those were all the same stage of growth, these varied--some were ready to harvest. Most obviously, though, where the other field had been laced with irrigation lines, here there were none. To the casual observer, he was sure, this hillside would not look at all like the same sort of crop. Yet, to him, not only was it the same, but it was evident that the harvesters would be through here shortly, pulling out the mature plants and leaving the young ones behind to hold the soil. Moreover, he thought, this crop 
was likely to yield very nearly as much as the farmer's field below--with considerably less energy expended and soil damaged to produce it.

By now he had almost reached the spot where his wife was working. He paused a moment, ostensibly to catch his breath, but really to enjoy the sight of her. Her always lovely skin and shining black hair were even more attractive to him, clad as they were in a scarlet shirt and scarf.

She looked at him and smiled, "What brings you here, today, amigo?"

"Well, besides a chance to spend a few minutes with my favorite wife, some business and some news." As he talked, he closed the gap between them.

"The business is a crop check I'm making to see what kind of schedule we'll be running at the plant. I just came by Al's place and talked with him a bit. He's out cultivating that field, nearly suffocating from the dust and fumes."

Consuela nodded. "Yes, when they're planted that densely and all at the same growth stage, it does get pretty bad. The resins are pretty volatile.. But what's the news?"

Once more, David's eyes began to sparkle. "Frank called today." He paused.

"Yes?"

"He says he needs to beef up his staff a bit." Another pause. 
"Yes, so?"

"Well," he drawled, "he wants both of use to move to headquarters in Akron--you to take over the guayule development program and me to manage the production."

"Really? . . Why, David! That's wonderful!" Both of us--together!"

"Yes, both of us. Together." He reached out and took her hand. Pulling her towards him, he felt the excitement in her body, and loved the shining in her eyes. He kissed her soundly, then pulled back a little.

"There's a slight hitch, though."

"Yes?"

"He wants us there next month. Something about a program review."

Now Consuela drew back a little. "That's not much time."

"No, it isn't. But I think we can do it. You're pretty much done, here, and Joe can manage the plant well enough by now. Once this crop is harvested, we'll be in a good position to move on."

"I guess so . . . perhaps you are right." She looked thoughtful for a moment. "Yes, we are ready for a new challenge, aren't we?"

They hugged each other once more, then David turned back down the hill. "See you at home. Let's go out tonight and celebrate. Okay?"

"Okay, amigo. Hasta luego!" 
The two waved, then turned to their separate tasks--she gathering samples of her crop to test for yields, and he driving back to his office at the plant where, if all went as planned, it would be processed in a few weeks.

\section{I}

The sunset had transformed the desert sky. The deep blue was edged with gold, and the few high clouds turned lavendar as the sun sank toward the horizon. But Consuela Archer was hardly aware of the evening's beauty. Lost in thought, she prowled through the house, going from room to room, checking the movingmen's progress. As she did so, a sleek black cat followed, seeming to imitate his mistress' movements, certainly reflecting her mood.

The last night. Tomorrow a new home. New people, perhaps not so tolerant of a "chicana"--no matter that she was an agronomist married to an engineer. What if they were racist? What if the new house wasn't right after all? what if . . . ?

"Oh, please don't put that in there--it's very precious. Perhaps with the dishes?"

"Sorry, ma'am, but they're already in the van. The best I could do is a separate carton. Maybe a book box." "That would do, I think. If you don't mind." "No problem. I'll just get one out of the front room." The man left, and Connie picked up the object in question. It was a sculpture--metal--a globe nestled in a 
flowering plant. On the base were the words:

INTERNATIONAL SOCIETY FOR AGRONOMIC RESEARCH

Outstanding Achievement Award

Consuela M. F. Garcia

She studied it for a moment, then put it down. Wearily, she sank into the one remaining chair, leaned back, and closed her eyes, absently stroking the cat who had joined her.

Was it all possible? Could she, Consuela Maria Fernando Garcia, really be here, in this place, with all of this? How could it be? How could it possibly last? They were the questions she continually asked.

She took a deep breath and let it out. With the next breath, she seemed to move back in time. She was in school again, finishing her Master's at the University. Her advisor was a well-established researcher with a flare for picking fundable projects. He had just received a grant from a rubber company when she joined him, and was trying to develop an improved strain of guayule (Parthenium Argentatum gray) for rubber production. He also had an interest in attractive girls, which had made him doubly glad to have her join him in his research. It was uncomfortable sometimes, keeping his hands off, but it had been worth it. His support was invaluable getting her through the program-not only did it ensure her degree, but he had helped her publish her results. That publication had led to this award, and to everything else that had come her way. 
Settling in the chair, Consuela remembered the long hours in the greenhouse, tending the seedlings, nursing them along until they were ready to transplant into the field. Then the scene shifted, and she was no longer a student at the University, but a girl on her uncle's ejido across the border, going out with the rest of the family to gather the wild guayule. They were in the pickup truck, each armed with a machete, heavy leggings, gloves, and a sombrero or scarf to shade them from the desert sun. Each day, during harvest time, they would fill up the truck's bed with the prickly plants--roots and all on some--and haul their harvest to the cooperativa where it would be chopped and baled and sent to the processing plant in Saltillo. Her hands itched with the memory: it was hot work, and hard, gathering the resinous stuff, but it was an important part of her uncle's income, and he, with the other guayuleros, was proud to be able to earn cash by working on the land. More, he was proud of the consistently high yield his crop had, and carefully chose his gathering site to ensure it. Once more the scene shifted, and Consuela was in her apartment in Tempe. There was a young man sitting across from her on the couch, earnestly explaining the mysteries of butyl rubber. "It's not just that it can be used for everything from aircraft tires to surgical tubing, it's that we've become dependent on it as a nation. Our whole economy would suffer, if we were to lose our supplies." She had heard his words, and was sure he was right, but though his 
sandy hair and ruddy cheeks labeled him a gringo, she was realizing, then, that nothing seemed to matter, except that he existed and was there, with her.

A rustling sound brought Consuela back to the present, and she opened her eyes with a sigh. The mover was coming back into the room with a box full of crumpled paper. She go up from the chair, dumping the cat, as he looked at her questioningly.

"Think this'll do the trick?"

Consuela nodded. "It looks fine. Thanks for taking the trouble."

The man shrugged, smiling, and Consuela--with the cat behind her--resumed her prowl. The kitchen was empty except for a box of cleaning supplies. The dining room was full of boxes, empty and full. She gave the packer some additional instructions then went on to check the garage, her mind still awhirl with memories.

It was strange how those three memories were linked together. They were what had defined her life, had brought her here to this place and time. The annual guayule harvests, the need for a research project to complete her degree, and the earnest young expert on rubber--the three had come together in her development of a new strain of guayule. And that strain--using less water and yielding more rubber under "wild" conditions--had won the award which had led to her job, and it was developing it that had led to her marriage. 
A car door slammed outside, and, as it had years

before, Consuela's heart began to beat a little faster. She turned to the doorway, her face lighting up at the sight of her husband silhouetted in the rectangle of light.

"Oh, David, it's good you are here. There are so many things left to pack and I haven't even thought about dinner, and your mother called and wants to meet us, and the . . "

"Hey! Slow down! Mas poco, por favor!" He kissed her soundly and led her out to the back porch. There, the last rays of sunlight could be seen touching the mountains to the east, turning them red then deep purple, as the night's shadow moved across the desert.

"Now tell me, what's the problem here?"

"Well, mostly, the movers are nowhere near done, and they promised to be out hours ago. I'm afraid we're going to miss our flight if they don't finish tonight."

"That's typical. They never seem to believe us when we tell them how much stuff we have. How many rooms are left to pack?"

"Only the study, but it has all the books and papers, and the paintings. . ."

"Im-m-m. That shouldn't take more than two hours for them to finish--I'll see if I can't persuade them to stay and finish tonight. When they're gone, we can go grab a bite to eat on our way over to your brother's house. That way we'll get there too late to talk politics. How's that sound?" 
"Good enough, as long as you call your mother in the meantime. I don't think she should drive all the way to the airport to meet us, but she'll only listen to you."

"Okay, it's a deal. Anything else?"

Consuela shook her head "No . . yes. . . No, I guess not. You go call her and keep an eye on the packers for a while. It's so nice here, I think I'Il take a break and enjoy the evening's coolness."

Sure, Boss, you do that. I'll bring us a drink on my way back out."

"Thanks, amore!"

"You bet, chica!"

Consuela laughed and turned back to the view. She tried to memorize every detail: the valley filled with sparkling lights, the band of darkness twisting through them where the river ran, the sillhouette of the cactus against the darkening sky. It was hard to believe they were leaving all of this. It seemed such a part of her after all the years. First school, then later, the work with the agricultural extension agency, trying to get the farmers to plant her strain and save the seed. That had been a difficult time, a Mexican woman working with the gringo farmers. Thank heaven she'd had David's support; his recommendation that she come work for his company had given her a new level of respect from the farmers--and herself. How glad she was he had convinced her to marry him. 
Her mind focused for a moment on their wedding day. Poor David, inundated by her family, as brothers and sisters, cousins, aunts and uncles all swarmed in to celebrate the youngest granddaughter's marriage. Never mind her husband was a gringo, he got the same treatment they all did--including the endless discussions of politics and sports. Fortunately, he spoke a fair amount of Spanish. And when he got tired, he could always pretend not to understand. It was a transparent trick, but tolerated because he was, above all, courteous, and more, he was now Consuelo's esposo: a member of the family.

Connie chuckled at the recollection, shifting her seat on the porch steps. Micny of them had already met him, sometime earlier, when she had been visiting her uncle between terms. David had been part of a group touring northern Mexico. When the group had arrived in her uncle's village, Connie had been brought out to act as interpreter. David had insisted on seeing guayule "in the rough" and was willing to pay for samples. So they'd all piled into her uncle's truck to take the crazy tourista and introduce him into the profession. Since it wasn't time for harvesting, they only took along sacks for seeds to sell to the seed companies in the U.S., and a machete to show him how it was done.

David had been fascinated. She could still hear the wonder in his voice. "This is latex! It's the real stuff, in a cactus!" of course, he had known all along that it 
was, but she supposed it was one thing to know about something and quite another to experience it.

Whatever, he was very excited and insisted on keeping samples--both of the bush and of the seed. He'd also asked for Connie's address in the States and promised to pay a visit.

And a good thing, too, Connie thought. For it had been those very seeds that had made her strain the wonder that it was, using so much less water and fertilizer, hardier in a wider range of temperatures, and yielding as much and more than other varieties. That had been a very opportune visit, even not counting the fact that they'd fallen in love.

The sun was fully set now, and the breeze was turning chill. Connie went back inside, where David was just finishing his drink preparations.

"Sorry, no salt for the rims."

"Oh, well. I guess we'll have to rough it."

They smiled and touched glasses, toasting each other with the margaritas in a little ritual that had marked every important occasion since their first date some five years before.

"Did you work things out with your mother?"

"I think so, she's planning to meet us at the new house, with a picnic supper and some 'moving in' things, rather than at the airport. That way we'll get a chance to get oriented a bit, and she can feel like she's helping. Okay?" 
"Fine, of course." She took a long, slow swallow from her drink.

One of the movers came in and announced that they were through packing. "We'll just load the rest of this in the van and get out of here," he said.

David looked up at him. "Sounds good. Thanks."

"Sure." He picked up a box marked 'files' and proceeded out the door.

"Must be time for us to get out of his way," said David. He escorted Connie into the empty kitchen, where they perched on one of the counters. "Let me tell you what happened at the office today."

He took a sip of his drink while Connie waited expectantly.

"Frank called from Akron, wanting to know when we were arriving. I told him late tomorrow, and he sounded terribly relieved." David paused to look at his drink, then went on. "It seems that the program review for guayule has been moved up for a special Board meeting on Monday. And, if it goes well, he wants to call for a reorganization, to set up a new Division, separating guayule out from the International Division.

"Why David, that's wonderful! That means they've realized guayule has the potential to meet the shortfall and they're going to go for it!"

David held out a hand, as if to steady her. "Well, almost. So far only Frank has. He still has to convince 
the Board that there's even going to be a shortfall in rubber, then that guayule can meet it and finally that the company should increase it's investment and open the second plant." He slid off the counter and began to pace. "And that's where we come in. He needs our input for the presentation on Monday."

"That means we'll need to work on it there, this weekend."

"Yep. I told him we'd come in Saturday afternoon. That'll give us the morning to get ourselves together, and leaves Sunday to work out the details."

"Sounds good." The two looked at each other for a moment, and smiled. Without knowing, they were sharing the same thought--"Where would I be without you?" Then, at the same time they both began,

"But, you know. . ."

"Still, I think. . ."

They laughed, and David pointed to his wife to go first.

"I was just thinking that it made so much sense to push guayule to fullscale development, especially with the work we've done overcoming the environmental problems. With my strain and your process, they really can't lose!"

David nodded. "My thought precisely, but we still have to convince the Board."

"I suppose you're right. . I just hope they have the sense to see how important it is." She looked thoughtful for a moment, took another sip, then downed the last of her 
drink. "Well, we've a busy weekend ahead of us. Let's see how those movers are doing."

Connie strolled out of the room, while David watched her admiringly. Then he gulped down his drink and followed her.

\section{I I}

"Well, so much for that hope," Connie thought as she watched her brother come out to meet them--from the look of him they were in for a good talking session tonight, aftera11. But she put the thought a side, and by the time he had the car door open for her, she had a smile for him. Not only was it expected of her, but she was genuinely fond of this older brother who, like her, had made his way across the border to learn the skills he could take back and work with. They both were chicanos here--successful, but still Nexican. And they had come to depend on each other for support over the years.

"Ola, Miguel! Como esta?--How're things going?"

"Bien! and you, little sister?"

"Well, your 'little sister' is feeling pretty ancient right now: it's been a long day. But generally, things are going pretty smoothly--aren't they, David?" She turned to her husband as he emerged from the other side of the car. David reached across the roof of the car to take Miguel's hand. "Yeh, things are in pretty good shape--at least at this end. It looks as if we'll make tomorrow's 
flight after all." He grinned at his brother-in-law.

Miguel's return grin was genuine as they clasped hands. They too were good friends. He offered to help with the luggage. "You'll get the room on the patio tonight. Tio Juan went home for a few weeks to meet with the ejido--he's worried about the guayuleros--but he left explicit intructions that you were to have that room."

Connie was delighted. "How thoughtful of him! Our uncle knows how I love the sound of the fountain at night." Miguel smiled gently at his sister. "Yes, he is a thoughtful man. And right now a worried one. He left a letter for you. Maybe after you're settled we can talk about it."

"This doesn't look good at all." It was David who broke the silence after they'd all read the letter.

They were sitting on the low benches around the fountain in the patio, drinking Miguel's specialty--strong hot coffee with tequila and a sugar cube. Miguel was leaning back, his eyes closed, all traces of smile gone from his face. Across from him, David was still going over the pieces of a paper in his hand, as if reading the words one more time would change their meaning. Consuela sat between them, her chin in her cupped hand, staring into the flowing water of the fountain.

"That's an understatement," she said, and took another sip from her cup. "If I were Tio Juan, I'd be worried 
sick--the ejido can't afford to miss the guayule harvest.

Not this year, or any year for that matter."

Miguel sat forward. "The question is, what can we do about it? Or, more rightly, what can you two do about it? You're the experts."

"I don't see that we can do anything about it," David said. "It's oil money that's drawing workers off the ejido, not guayule."

"I think I understand what Miguel's getting at, amore." Connie's voice was tense with fatigue. "He's saying that oil money $\in$ lsewhere wouldn't be half so attractive if there were steady guayule money at home."

"Yes, that's it exactly," Miguel put in excitedly. "Only if the land can produce a living will the ejidos survive." He was warming to his subject. "And the ejidos must survive if the Revolution is to have any meaning. Only if they succeed will the government continue the land reforms our fathers won for us."

"You mean that if they leave the land they lose it?" David sounded incredulous.

"Well, it's not that direct. But that's what it amounts to." Miguel stood up and began pacing the area in front of the fountain. "You see, the ejidos developed out of the Land Reforms that were the promise of the Revolution back in the thirties. Land for the people, not just the rulers. The process still isn't complete--only about half the land has been redistributed, and most of that is 
marginal desert. But the promise is still there, and it's still a big issue throughout Mexico."

Miguel stopped for a moment and looked at his companions. "You know, I've never looked at it that way before, but in a way, the banks and the big corporations, they're just like the old patrons--controlling most of the land and money and paying paysans to do the work." He looked thoughtful and resumed his pacing.

"In any case," he went on, "the redistributed land must be worked and occupied, or the politicians and big companies say, 'Look, it doesn't work! These people don't really want to own their own land!' And stop the program altogether."

"So, in the long run, the land reverts back to the state or gets sold to the corporations, is that it?" asked David.

"Close enough, anyway," Miguel sighed.

"And in the meantime," Consuela put in, "Tia Carmela and old Carlos and all the others who have lived their lives for the land are left without it." She turned to her husband, "Oh, David, we must go to help!"

But David was looking at the letter again. "No, I don't think that's what your Uncle Juan had in mind." $\mathrm{He}$ stood up too, and with Miguel, looked down at his wife. "I think what he wants us to do is create a market for guayule that's big enough to keep the guayuleros at home. He wants that second processing plant nearby--it would have to be on 
the border--and he wants good prices for the harvest, to boot."

Connie sat there, looking at the two men. All of a sudden it was too much. She was too tired. On top of everything, now she was to create a processing plant. The idea was staggering. Looking at the two men, she started to laugh, a long low chuckle that soon turned into giggles and then guffaws. She leaned back and held her sides, shrugging her shoulders in apology. "And (titter, titter) I suppose (gasp) he wants (giggle) it next (whoop) week!" With that she collapsed in a gigglingly helpless heap.

Watching her, David couldn't help but smile, himself. "No, but I imagine next month," and he chuckled, "might be soon enough." Then he, too, started to laugh.

Miguel, watching these two, shrugged his shoulders, muttering something about "loco gringo" and started to leave. Then, turning back, he gave them both a hug, said goodnight and left them to their hysterics, knowing that once they had considered it, these two, they would find a solution. If there was one to be found.

\section{IV}

The Board room was quietly luxurious. The deep plush carpet, the upholstered chairs, and the intricate pattern of inlay in the table top all spoke of a long tradition of affluence. As Connie looked around the room, she was once more impressed that she should be here, now, in such a place 
--and frightened now lest it be taken from her all too quickly. She studied the men around her, looking for signs that they might be open to the reasonable and logical arguments she and the others had worked so hard to put together this weekend.

There was the Chairman, a grandson of the original founder who thought of the company as part of his family. There were two lawyers, an accountant, and three other members who had worked with the company for years. Two of these, she knew, had been part of the International Division--responsible for natural rubber from Libya and Southeast Asia, and now responsible for guayule. They were used to being at the top and would be disinclined to see any limitations placed on their division, its role within the corporation. These were the ones to worry about. Then the Chairman started to speak, and she turned her attention to him.

"Since this is a special meeting," he began, "we will dispense with minutes and move right along to the matter at hand." He cleared his throat. "We are here to listen to Mr. Frank Wyman, director of the Guayule Project, and to review its progress to date. Mr. Wyman, you have the floor."

Frank stood up and paused, waiting for everyone's full attention. "Thank you, Mr. Chairman, Gentlemen of the Board. It's a pleasure to be here this morning." Then he began the presentation. 
He ran quickly over the main points of the argument for maintaining a strong supply of natural rubber, including the rising costs of oil. He discussed the currently unstable international situation, and particularly the social, political, and economic changes being experineced in the rubber-producing countries. He then described the advantages of a domenstic supply, briefly reviewing the successes and difficulties the company had in developing such a supply.

He reminded them of the development of a new high-yield strain, making guayule commercially viable, even a potential major profit-maker. Then he introduced Consuela.

"And today, gentlemen," he announced, "we are fortunate to have with us the developer of that strain. Ms. Garcia has recently accepted our offer and will be heading the guayule stock-development program in our Research Department." He paused to let the approving response die down.

Then Frank introduced David. "We also are fortunate to have Dr. David Archer with us today. He has been directing our operations in Arizona, and has developed a processing system which not only ensures maximum recovery of latex from the plant, but does so with a minimum effect on the natural environment, and with a net gain in energy used. Dr. Archer has agreed to manage our production operations."

Once again, Frank paused while sound of approval filled the room. 
Then he let them have it. Using the charts, he demonstrated how the new strain and new production techniques had moved guayule from a small experimental operation to an increasingly significant source of natural latex. He moved quickly through the graphs and tables, showing with each a steady increase in production for guayule and a highly unstable and defintely decreasing supply of the hevea latex from other countries.

Finally, he turned back to the Boardmembers. "Gentlemen," he said, "we have come to the point of decision. Either we accept that guayule is and must be our major source of natural rubber in the future, committing ourselves to its full development as a resource, or we continue to rely on an increasingly unstable and decreasingly productive supply of hevea. We believe that the best interest of the company lies in the sure, steady, local supply.

"Moreover," he went on purposefully, "we believe that the only effective way to develop it is to create a separate Continental Rubber Division within the company, which would be headed by a Vice President and would parallel the other Divisions in terms of organizational structure."

New sound--coughing, throat clearing, chair scraping, and voices talking--suddenly filled the room. Consuela stifled a groan as she thought of her uncle, the ejido, and all of the work leading up to this point. The Chairman had to pound for order. 
"Mr. Wyman," he said, "you are suggesting a major reorganization of this company--more, a major change in corporate policy. While it is true that your figures are very persuasive, and the presence of these two eminent scientists deserves consideration, do they really provide a sufficient basis for such a shift?"

"Mr. Chairman, I believe they do." Frank brought out a new set of charts. "And I think you will, too."

"Up to now," he went on, "we've been looking at historical developments. Here are some projections for the future."

With the Board looking on warily, Frank proceeded to outline three alternative production levels, based on three levels of support within the corporation. Then, against these, he compared two potential futures for the country. In the first, the cost of petroleum continued to rise at its current rate, the national trade deficit continued to increase, oil-dependent countries became more and more unstable, and shipping costs finally exceeded production costs for hevea. In the second, oil prices rose, then leveled off as new energy sources came on line, leveling the trade deficit as well, but increasing instability in the rubber-producing countries, as new energy sources disrupted traditional economic and political structures. Exports of hevea, along with other goods, were severely disrupted. 
"As you can see," he said, "the chances of maintaining an adequate supply of hevea look very slim. At the same time, the price of synthetic rubber, based on the price of petroleum, is likely to increase, making the natural rubber more desirable for many uses." He pulled out another chart.

"If this corporation chooses to develop guayule according to its present policies, you can see that, in either scenario, we will have a significant shortfall in our supply. If you choose to expand development but within the current structure, we will be in a good position to make up a significant portion of the natural rubber deficit. If, however, the corporation makes a full commitment to the development of this resource, we can expect to meet both the shortfall of natural rubber and any deficit in synthetics resulting from the unavaiability or high cost of petroleum.

Frank discussed it. He dwelt on the benefits resulting from being prepared. He described in glowing terms the position the company would occupy in a world short of rubber but dependent upon it for everything from tires to surgical tubing. He played on each Board member's personal concerns. For the lawyers, he dwelt on the increased stability of the corporation. For the accountant, he set out high profit margins and relatively low production costs. For the oldtimers, he played up the excitement of a new venture, likening it to exploring a new country. And for the Chairman, he mentioned the prestige the company would be accorded for having met and averted a potential crisis. 
Patiently and steadily he worked to convince them, answering their questions straightforwardly, point up time and time again how they all would benefit from the change.

Gradually Consuela could see each one buy into the idea. Guayule was becoming important to them. A major source of income. A steady source of supply. One by one they accepted it. Out of that acceptance, Consuela was beginning to believe, would come the development funds needed to establish this crop to which she had devoted so much of her life. And out of it would come to processing plarts so necessary to her family's way of life.

She looked across the table at her husband. He caught her glance and smiled. Together, they had come to this point. Working in their own areas, agronomy and engineering, with others and individually, they had made it possible for desert farmers to raise a crop with low water needs and high yields, for the company to have a steady source of profits, and for the country to have a sure supply of the rubber on which it depended so much. As one by one the doubts were laid aside, and the mood of the board reversed, success was in sight. There would be much work to do, planning and building the plants, improving the strain, educting farmers and laboraers. But looking across this table, they knew: the work and the effort were worth it; the project was established, and they had done it--would continue to do it--together. 


\section{SUMMARY}

Guayule is a desert shrub which grows naturally in the arid regions of northern Mexico and the southwestern United States. It produces a latex very similar to that produced by rubber trees (hevea) grown in Southeast Asia and Africa. This latex is a necessary ingredient in aircraft tires, radial tires, and surgical equipment. Therefore, threats to supplies can be critical to the economy. Such a threat existed during World War II when hevea was unavailable, and the Emergency Rubber Project was instituted to provide guayule rubber. The project was disbanded, however, when the war was over, oil was discovered in the Middle East, and the land was needed for food crops.

In recent years, prices and availability of hevea have fluctuated radically while consumption has increased. With nearly 4 million tons of natural rubber used in this country this year, shortfalls are increasingly likely, expected by the year 2000 to range between $1 / 2$ and 5 million metric tons. They may be met by several alternatives:
a) reduced demand for natural rubber
b) new processing methods, including -recycling, reclamation -development of a cast tire
c) new supplies, including -increased hevea stands in Brazil, Liberia, Ghana 
-increased synthetic rubber production (from oil wood, or coal)

-production of guayule

Each of these alternatives is under investigation by the federal government and the rubber companies.

Guayule Production

A desert plant, guayule needs 18-24" of water per year--less than alfalfa, cotton, corn, or sorghum--and therefore could be effectively in southwest Texas, New Mexico, Arizona, or California. Current yields range from $15001 b s$ per acre of rubber in 3 years at Arizona test sites to 2880 lbs per acre (in 5 years) at Bakersfield, with an expected doubling through breeding programs to $20 \%$ by weight by 1990. Potential planted acreage by 2000 is 1.5 to 2 million acres, suggesting a possible yield of 1 to 3 million metric tons of guayule over a 3-5 year period around the year 2000 .

There are a number of potential constraints to development at the level, including:

- capital formation--a depressed tire industry and a lack of investment capital reduce the likelihood of new developments by rubber companies;

- potential air pollution--turpines from plant resins may create a haze over the fields;

- production costs--processing and cultivation costs currently exceed those of hevea;

- availability of government "seed" money--front end funds for research and development are needed. 
The major interest in guayule's development is on the part of the researchers, who lack economic and political clout. Rubber companies and government agencies are maintaining a defensive "wait and see" position, while they-especially the government--are in a position to convince the private sector there is a market for the rubber produced. Such mechanisms as the development of a strategic stockpile could encourage state and other agencies to facilitate experimentation and processing facilities. As yet, however, there is only talk about such plans, and the available funds are inadequate for a full-scale push for commercialization.

\section{Impacts of Development}

Table One summarizes the technical and institutional impacts of the commercialization of guayule. They are listed according to two alternative strategies: Scenario $A$, in which the rubber companies and the growers operate under a laissez-faire policy; and Scenario B, in which the government plays a major role in developing the resource, following a major cutback in imports of hevea. They represent four levels of interest, the local, the regional, the national and the international. Over all, it may be said that the impact of guayule's development is limited across most sectors, except when seen as the only source of natural rubber, when it has significant effect on those industries which are dependent on natural rubber for their products or services. 
Guayule can bring back into use those lands abandoned due to lack of water or to poor soil quality. This could increase agricultural employment as much as 268 in Pecos County, Texas, and somewhat less in other areas of the depressed southwest. In addition, by replacing cotton and other water-consuming crops, it could ease water availability--especially in California and Texas.

Air quality may be affected by the volatile resins, both in the ground and during processing. These and the acetone used in processing may engender respiratory or dermatological problems for workers. In addition, fire hazards are increased, compared to other crops and products in the region.

Another area of impacts is U.S.- Mexico relations. With Mexico a traditional supplier of guayule and currently developing its own controlled productioncapability, there are many opportunities for both cooperation and competition between the two countries.

\section{Policy Issues}

A number of policy issues surround the development of guayule. These may be roughly divided into those concerning how it should be developed, what the results of its development might be, and strategic concerns for the nation with regard to the importation of rubber. Issues relating to the stimulation of guayule's development include conflicts over 
federal or private investment, and federal or private risktaking. The extent of this issue's importance depends on the relative strategic importance placed on a domestic supply of natural rubber by the U.S. government.

A second major issue arel with regard to guayule is its regulation. Whether federal, state or local agencies will regulate cultivation and processing of guayule is, to a large extent determined by the nature of its impacts, and again, its strategic importance. To the extent that the federal government perceives guayule's development as essential to national security, it will maintain regulatory control. To the extent that it is a smallscale private venture, the local governments will be responsible for regulating the industry's development in their areas.

Mitigation of any adverse impacts resulting from guayule's development will also depend largely on the perceived need for the product. If, for example, it is found that significant reductions in air quality result from large plantings of guayule, and guayule is not seen as strategically important, then stringent measures--including possible limitations on crop size--may be put in place to mitigate that impact. At the same time, even if the federal government places great inpo-tance on guayule's development, the Environmental Review process may slow development considerably--particularly if someone chooses litigation as a means to set policy. Another potential problem resulting from the fullscale 
development of guayule is the promotion of corporate farms in an area which has been traditionally family-farmed. The high front-end costs of guayule planting and the long ( 3 to 5 years) wait for returns through harvesting the shrubs, makes it difficult for the small family farm to finance it. Larger farms with acreage to spare, or corporations with greater risk-taking capabilities will have greater incentives to cultivate the crop.

Finally, there is the whole set of issues surrounding the relative importance of strategic policy compared to existing water, land, and agricultural policies throughout the region, and national antitrust policies as they affect the rubber companies' control of the resource. These may be resolvable only as the question of leadership is resolved: insofar as the federal government takes the lead in the development of guayule, it can override or preclude conflicts with other policies. This leadership, however, is somewhat in conflict with the current administration's efforts to maximize private sector development of resources.

Table II summarizes these policy issues with their potential problems and resolution. 
TABLE ONE

\begin{tabular}{|c|c|c|}
\hline \multirow{3}{*}{$\begin{array}{c}\text { SECTORS AND } \\
\text { GUAYULE } \\
\text { Econowyc secrors } \\
\text { Parties-et-Intereat }\end{array}$} & \multicolumn{2}{|c|}{ PARTIES AFFECTED BY } \\
\hline & \multicolumn{2}{|c|}{ COMMERCIALIZATION } \\
\hline & $\underset{\text { Scenarato } A}{\operatorname{InPACTS} \text { OR CONS }}$ & $\begin{array}{l}\text { Eogence } \\
\text { Bcenar 10 B }\end{array}$ \\
\hline \multicolumn{3}{|l|}{ Local rocus } \\
\hline 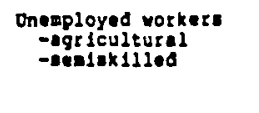 & $\begin{array}{l}\text { Locallzed benofits } \\
\text { frow new jobe } \\
\text { very linted benefite } \\
\text { foon newly cruated } \\
\text { procensing jobe }\end{array}$ & \\
\hline $\begin{array}{l}\text { Environgental, } \\
\text { beslth, affety }\end{array}$ & Elalted affecte & $\begin{array}{l}\text { Potentiel adverse } \\
\text { alfecte in the } \\
\text { ehort tors }\end{array}$ \\
\hline $\begin{array}{l}\text { General busines: } \\
\text { conmundty }\end{array}$ & 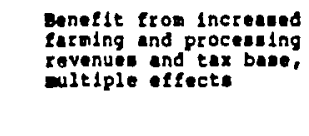 & $\begin{array}{l}\text { Potentlal conatruc- } \\
\text { tion of tize or } \\
\text { other rubber } \\
\text { tabrication plant } \\
\text { In Southwert, } \\
\text { nultiple effect. }\end{array}$ \\
\hline
\end{tabular}

Reglonel pocus

aserlean Indian

and other minorteles

Llalted ponltive effecta probuble economlc geine for Indiane thru land, vater

mondoevented fars vorkers

Linited effect: Probable Increased agration

Marginal farm operetlons and pluced farmers

Banking and

Elnaneial

inatutions

Comounit les at

jarge

Benefle by ohlfeing to

to Benefit tron SBA leas vater-demanding alsetance and
crop

Oncertalney rolated to Modecate Inpacte finaneing four-year in rlak buorbcrop tion, lonne,

Increased neede for Game

ocilal gooda, Including bousing, hesith, roade, pollce, lise protection

Environwent at
large

minimal Inpects over near
and niddie tere

Possible new pettero of insect infestation, other perte, aoderate pollution pote ex prilities, moderat

mational poeus

gelance of trade for 0.s. rubber
importe, rubber

mexlean-0.s. relations.

Maxican Governeant

ninimal effects over near and bidde tere

Probab1 atsalne If bleck meitet appers

Benefite Ifolted to land base developont and employment in rurei, depreseed comunitiles

Noderate effect: over mlddie, Jong term

Isprovement thro cooperation in

senefite by and $R$ technology

International pocus

beves grower:

wo lose of 0.8. Erkets wask of 0.8. arkete, gain in other vorlo mi

Relat lonshlp between

Mexican land ovnership

sane O.S. Rubber Co.: and

lave prohlbit largeecale plantation ounerohip 


\section{ANALYTICAL DISCUSSIONS}

In this section would be included the discussion of scenarios and impacts from the University of Arizona study and the discussions of organizational structures and processes from the Portland State University study. Some additional discussion--describing the forecasts implicit in the other reports--would te included as well.

\section{METHODOLOGY}

This section would include the models and their results as used by the University of Arizona team and the "analysis" and introduction from the Portland State University report.

\section{TECHNICAL PAPERS}

This section would be made up of the working papers, data base descriptions, and in-progress resports which support and substantiate the earlier sections. It would be organized in a structure that parallels those sections and is indexed along with them. For example, the material supporting the sections on guayule's development would precede that on the scenarios.

\section{DATA BASE}

In this last section would be any tables, charts, graphs, or listings which provided the basic data for the models and the discussions presented earlier. In many cases they 
would be simply referenced. In many others, however, a single page will be adequate to provide the specific numbers or relationships used as the basis for analysis and synthesis in the assessment. 